
Agricultures tropicales en poche Directeur de la collection

Philippe Lhoste

\section{Le fonio, une céréale africaine}

Jean-François Cruz, Famoï Béavogui

Avec la collaboration de Djibril Dramé

Éditions Quæ, CTA, Presses agronomiques de Gembloux 
Le Centre technique de coopération agricole et rurale (CTA) a été créé en 1983 dans le cadre de la Convention de Lomé entre les États du groupe ACP (Afrique, Caraïbes, Pacifique) et les pays membres de l'Union européenne. Depuis 2000, le CTA opère dans le cadre de l'Accord de Cotonou ACP-CE. Le CTA a pour mission de développer et de fournir des produits et des services qui améliorent l'accès des pays ACP à l'information pour le développement agricole et rural. Le CTA a également pour mission de renforcer les capacités des pays ACP à acquérir, traiter, produire et diffuser de l'information pour le développement agricole et rural. Le CTA est financé par l'Union européenne.

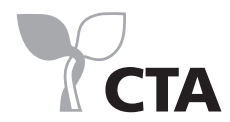

partageons les connaissances au profit des communautés rurales sharing knowledge, improving rural livelihoods

CTA, Postbus 380, 6700 AJ Wageningen, Pays-Bas www.cta.int

Éditions Quæ, RD 10, 78026 Versailles Cedex, France www.quae.com

Presses agronomiques de Gembloux, Passage des Déportés, 2, B-5030 Gembloux, Belgique www.pressesagro.be

(C) Quæ, CTA, Presses agronomiques de Gembloux 2011

ISBN (Quæ) : 978-2-7592-1040-4

ISBN (CTA) : 978-92-9081-475-7

ISBN (PAG) : 978-2-87016-114-2

ISSN : $1778-6568$

(C) Le code de la propriété intellectuelle du $1^{\text {er }}$ juillet 1992 interdit la photocopie à usage collectif sans autorisation des ayants droit. Le non-respect de cette disposition met en danger l'édition, notamment scientifique. Toute reproduction, partielle ou totale, du présent ouvrage est interdite sans autorisation des éditeurs ou du Centre français d'exploitation du droit de copie (CFC), 20, rue des Grands-Augustins, 75006 Paris. 


\section{Sommaire}

Avant-propos..........................................

Remerciements .....................................

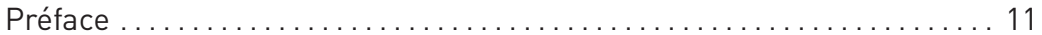

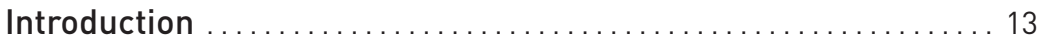

1. Origine et distribution géographique .................. 15

2. La plante et le grain ............................ 17

Plante herbacée.................................... 17

Grains minuscules et vêtus ............................. 20

3. Les systèmes de culture et de production ............... 23

Caractéristiques de quelques zones de culture du fonio............. 23

Importance de la production ........................... 46

Pratiques agricoles de production $\ldots \ldots \ldots \ldots \ldots \ldots \ldots \ldots \ldots \ldots \ldots \ldots$

4. La récolte et l'après-récolte ........................61

Récolte manuelle ...................................6 61

Stockage et séchage des gerbes.......................... 66

Battage et vannage .................................. 69

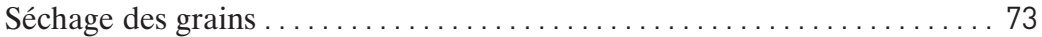

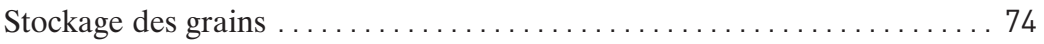

5. La transformation et la qualité des grains .............. 77

Structure physique et composition du grain de fonio .............. 77

Décorticage et blanchiment............................. 87

Lavage et dessablage avant cuisson $\ldots \ldots \ldots \ldots \ldots \ldots \ldots \ldots \ldots \ldots . \ldots 2$

6. L'amélioration des technologies post-récolte ............. 95

Battage .......................................... 96

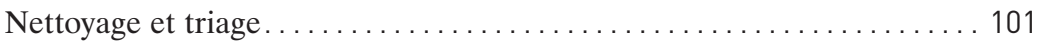

Mécanisation du décorticage ............................ 106

7. L'élaboration de produits nouveaux ................... 115

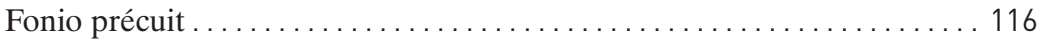

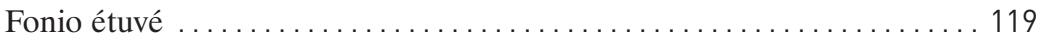




\section{L'amélioration des techniques de séchage} du fonio transformé ................................. 123

Quelques initiatives pour améliorer le séchage ................ 123

Séchoirs mis au point dans le cadre du projet Fonio............... 126

9. La commercialisation.............................. 131

Commercialisation du fonio en Guinée ...................... 131

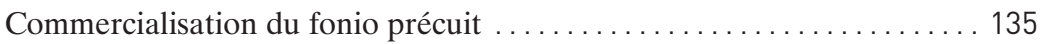

10. La consommation ................................. 141

Pratiques de consommation .............................. 141

Mode de préparation et recettes .......................... 146

Fonio et diététique .................................. 151

Conclusion......................................... 155

Glossaire........................................157

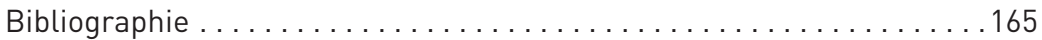

Sites internet ................................. 171

Sigles et acronymes ............................ 172

Index ............................................. 173 


\section{Avant-propos}

La collection «Agricultures tropicales en poche » a été créée récemment par un consortium comprenant le CTA de Wageningen (Pays-Bas), les Presses agronomiques de Gembloux (Belgique) et les éditions Quæ (France). Cette nouvelle collection, comme l'était celle qui l'a précédée («Le technicien d'agriculture tropicale» chez Maisonneuve et Larose), est liée à la collection anglaise, "The Tropical Agriculturist », chez Macmillan (Royaume-Uni). Elle comprend trois séries d'ouvrages pratiques consacrés aux productions animales, aux productions végétales et aux questions transversales.

Ces guides pratiques sont destinés avant tout aux producteurs, aux techniciens et aux conseillers agricoles. Ils se révèlent également d'utiles sources de références pour les chercheurs, les cadres des services techniques, pour les étudiants de l'enseignement supérieur et pour les agents des programmes de développement rural.

Nous saluons cet ouvrage original sur le fonio, il inaugure avec bonheur la série consacrée aux productions végétales. Cette céréale africaine est en effet qualifiée de «mineure» par rapport aux productions «majeures» des céréales mondialisées telles que le riz, le blé, le maïs, l'orge ou le sorgho dont les productions sont très supérieures. La production de fonio est localisée en Afrique de l'Ouest et elle est quantitativement modeste, mais elle tient une place intéressante dans cette région pour plusieurs raisons. Sa culture s'adapte aux aléas climatiques et se contente de sols pauvres et de terrains difficiles qui seraient mal valorisés par d'autres cultures. Dans ses zones de production de Guinée et des pays voisins, cette petite céréale participe par sa précocité à la soudure alimentaire et elle est très appréciée pour ses qualités gustatives et nutritionnelles; son intérêt est donc très reconnu localement mais aussi en dehors de la zone de production. Cela justifie le regain d'intérêt de la recherche et développement pour cette plante comme en témoignent les récents projets qui lui ont été consacrés. Les auteurs Jean-François Cruz et Famoï Béavogui, promoteurs et acteurs de ces projets, ont contribué aux améliorations technologiques de sa culture et de sa transformation qui en facilitent la commercialisation et l'exportation, ce qui tend aussi à en relancer la production.

Cet ouvrage est donc le fruit d'une coopération exemplaire et le résultat d'un travail collectif impressionnant comme en témoignent 
les remerciements ci-après. Il présente une synthèse agréable, complète et bien illustrée des connaissances anciennes et récentes sur cette céréale africaine trop méconnue dont il va permettre une meilleure valorisation.

Philippe Lhoste Directeur de la collection Agricultures tropicales en poche 


\section{Remerciements}

Les auteurs remercient toutes les personnes qui ont collaboré, de près ou de loin, aux deux grands projets «Fonio» réalisés depuis le début des années 2000 et permis, d'une certaine manière, la réalisation de cet ouvrage, et particulièrement :

Francis Troude et François Mazaud, aujourd'hui en retraite, et qui, de leur poste à la $\mathrm{FAO}$, ont respectivement promu, puis supervisé le premier projet d'amélioration des technologies post-récolte du fonio.

Nicolas Bricas, qui a été l'initiateur des recherches engagées par le Cirad sur cette céréale. Les chercheurs et techniciens du Cirad de Montpellier qui ont participé aux différents projets Fonio : Mme Geneviève Fliedel, Mme Sandrine Dury, Mme Mila Lebrun, Michel Rivier, Joël Grabulos, Jean-Michel Méot, Patrice Thaunay, Olivier Gibert, Jacques Chantereau, Francis Forest, Didier Richard, Patrick Dugué, Frédéric Lançon, Bernard Bridier, Jean-Luc Ndiaye et, pour le suivi administratif et la valorisation, Benoît Cervello, Mme Pascale Lantier et Mme Cindy Van Hyfte.

Les partenaires du secteur privé : Philippe Gauthier (société Racines), Christophe Eberhart et Mme Pauline Huet (Éthiquable), Mme Rachel Revesz (société Gaïa), Jacques Alvernhe (ONG Le Damier).

En Guinée, les chercheurs et techniciens de l'Institut de recherche agronomique de Guinée (Irag) : Thierno Alimou Diallo, Youness Chaloub, Mamadou MinthéCamara, Ansoumane Sané, Moussa Doumbouya, Martin Tioutiouré Camara, Saïdou Diallo, Souleymane Sakho du centre Irag de Bareng/Timbi Madina et Mme Madina Ndiaye du centre Irag de Foulaya/ Kindia en Moyenne Guinée. Jacques Gigou (Cirad/Irag), N'Famara Cissé, Gansilé Nieba, Mme M'Mah Aïcha Kollet Soumah, N'konou Doumbouya du centre Irag de Bordo/Kankan en Haute Guinée.

Les partenaires du secteur privé : Mme Habiba Diallo, Mme Hadja Aminata Diop, Mme Barry et les nombreuses autres transformatrices de fonio à Kindia. Adboulaye Diallo, transformateur à Labé, Francis Loua, artisan mécanicien à Labé, El Hadj Tamsis Sow du village de Seghen, El Hadj Madamou Seydou Gallé Diallo de la Fédération des paysans du Fouta-Djalon.

Mme Zenab Diallo, gouverneur du Common Fund for Commodities (CFC) en Guinée. 
Au Mali, Djibril Dramé et les équipes de technologues, agronomes et socioéconomistes de l'Institut d'économie rurale (IER) du Mali et notamment Mme Cissé Oumou Traoré, Mme Coulibaly Salimata Sidibé, Mme Berthé Aïssata Bengaly, Mme Martine Samaké, Mme Yara Koreissi, Mme Bore Fanta Guindo, Mme Tangara Adiaratou Sidibé, Mohamed Diarra, Kola Tangara, Moussa Daouda Sanogo, Michel Vaksmann (Cirad/IER), Diakalia Sogodogo, Lamissa Diakité, Moctar Traoré, Alpha Oumar Kergna et le machiniste de Koutiala, El Hadj Moussa Traoré.

Oumar Niangado (ancien directeur de l'IER et aujourd'hui délégué de la Fondation Syngenta), qui fut l'un des premiers chercheurs maliens à s'intéresser au fonio.

Les partenaires du secteur privé : Mme Mariko Fadima Siby de la société Ucodal, Mme Deme Aïssata Thiam de la société Danaya, Mme Soumaré Modia Sangaré, Mme Coulibaly Aïda Diop, Mme Batoma Sacko «femme du fleuve» à Bamako, Mme Tangara de Ségou et les nombreuses autres transformatrices de fonio, ainsi que Singalé Soumaré du Grenier du paysan de Kayes, mais aussi les constructeurs d'équipements Imaf (et notamment Arboncana Touré), SIpS (Abdou Diop), Mod Engineering (Moussa Diarra), BCN (Baba Coulibaly Neto) et Stéphane Besançon de l'ONG internationale Santé diabète.

Au Burkina Faso, Éric Vall, Augustin Kanwé, Mme Nadine Andrieu, chercheurs au Cirdes, et Sansan Da de l'Inera de Bobo Dioulasso, ainsi que Brehima Diawara, Alhadi Wereme, Gouyahali Son et les équipes des départements Technologie alimentaire et Mécanisation agricole de l'Institut de recherche en sciences appliquées et technologiques (Irsat) de Ouagadougou, notamment Mme Charlotte Konkobo Yaméogo, Mme Laurencia Ouattara, Rachidi Karimou, Mathieu Kambou, Theodore Hiem, Stéphane Zangré. Mais aussi le constructeur d'équipement SGGI, le représentant des producteurs Zakaria Kienou et les transformatrices de fonio, dont Mme Asséto Traoré ( $\mathrm{E}^{\text {ts }}$ Tout Super) de Ouagadougou et Mme Traoré Korotoumou de Bobo Dioulasso.

Au Sénégal, Babacar Touré, Mme Khanata Sokona, Ousmane Gueye, Mme Fatou Ndoye, Pape Seck et leurs collègues de l'ONG Enda Graf, et les transformatrices de fonio, Mme Ndiaye Aïssatou de la société Koba Club à Kédougou, Mme Aïssatou Diagne Deme de Free Work services à Dakar, les transformatrices de fonio de Kolda et Sanoussi Diakité. 
Au Bénin, Romain Dossa et Mme Nadia Fanou Fogny, de l'université Abomey Calavi à Cotonou.

Aux Pays-Bas, Mme Inge Brouwer, de l'université de Wageningen. Andrey Kuleshov, Project Manager au Common Fund for Commodities (CFC) d'Amsterdam.

En Belgique, Didier Stilmant, Brice Dupuis et leurs collègues du Centre wallon de recherches agronomiques (CRA-W) de Libramont.

Nous voulons particulièrement saluer la mémoire de nos collègues disparus tragiquement : Bakary Daho, thésard du Cirdes de Bobo Dioulasso, qui travaillait sur la filière fonio au Burkina Faso; Doré Guindo, directeur du centre IER de Sotuba à Bamako, qui a coordonné les activités des équipes maliennes dans le cadre du projet Fonio financé par l'Union européenne; Souraghata Kouyaté, agromécanicien, qui a participé à la mise au point et à la diffusion des équipements post-récolte du fonio en Guinée; Claude Marouzé et Jacques Brouat, du Cirad à Montpellier, qui ont longtemps travaillé à la conception et à la mise au point des équipements post-récolte du fonio. Nous gardons en souvenir leurs qualités de générosité et de dévouement.

Nous remercions également toutes les personnes, producteurs, transformatrices, employées, stagiaires, commerçants, vendeuses, consommateurs, décideurs, qui ont consacré du temps à répondre aux diverses enquêtes ou qui ont participé aux différentes expérimentations.

À tous ceux qui ont été cités et à ceux qui ont peut-être été oubliés, nous sommes vraiment reconnaissants.

Enfin, nous remercions les personnes qui ont contribué à la publication de cet ouvrage et particulièrement Tristan Meudic pour ses dessins, notre confrère Mamadou Billo Barry pour la rédaction de la préface; nos collègues, Mme Geneviève Fliedel, Jean-Pascal Pichot et Michel Havard qui ont eu la gentillesse de relire le document; et pour l'édition, Mme Corinne Thonnat, correctrice; Mme Joëlle Delbrayère, infographiste; Mme Martine Séguier-Guis pour les éditions Quæ et Philippe Lhoste, directeur de la collection Agricultures tropicales en poche. 



\section{Préface}

C'est avec beaucoup de bonheur que j'ai accepté de préfacer cet ouvrage consacré au fonio qui est pour moi une céréale légendaire. Dans mon jeune âge, je le cultivais tous les ans, avec mes parents, au Fouta-Djalon. Visiter le champ familial au stade de l'épiaison pour voir les minces panicules balancer harmonieusement au rythme du vent et sentir son arôme est un de mes plus beaux souvenirs. Le fonio reste encore aujourd'hui mon plat préféré.

Comme le signalent les auteurs, le fonio (Digitaria exilis Stapf) est une céréale peu connue, à petits grains vêtus, produite essentiellement en Afrique de l'Ouest. Mais, c'est surtout en Guinée, au Fouta-Djalon, que le fonio est le plus cultivé (environ $60 \%$ de la production mondiale) car il y constitue l'aliment de base de la population. Aujourd'hui exporté vers l'Europe et les États-Unis, le fonio est maintenant consommé au-delà de sa zone de production.

Lintérêt des scientifiques pour cette plante dite «mineure» est très récent. Ce n'est que dans les années 2000 qu'une équipe pluridisciplinaire de chercheurs africains et européens a pour la première fois pris l'initiative d'étudier, de manière large, la filière fonio en Afrique de l'Ouest. Cette équipe a mis en œuvre, successivement, deux projets de recherche avec la participation de différents acteurs de la filière fonio (agriculteurs, transformatrices, constructeurs d'équipement, commerçants, transporteurs, décideurs politiques, etc.). Ces deux projets «Fonio», financés par le Common Fund for Commodities, puis par l'Union européenne, ont été réalisés en Guinée, au Mali, au Burkina Faso, au Sénégal et au Bénin, avec la participation de chercheurs français, belges et hollandais. Certains d'entre eux ayant pris part à ces deux projets de recherche ont eu l'idée de valoriser leurs travaux en rédigeant cet ouvrage, qui est le premier consacré exclusivement au fonio. Ils ont aussi exploité d'autres travaux et articles anciens pour donner aux lecteurs une image plus précise et plus complète du fonio, dans tous les aspects de la filière : la plante et son grain, les systèmes de culture, les techniques culturales, la production, la transformation, la commercialisation y compris l'export et la consommation.

Cet ouvrage nous montre que le fonio est une culture traditionnelle des zones tropicales de savanes. Il est cultivé dans une large diversité de conditions de milieu, partout sauf dans l'eau. Sa particularité est sa capacité à se développer sur des sols pauvres où d'autres céréales comme le riz ou le maïs 
auraient du mal à pousser. Cette capacité à supporter les sols pauvres fait de lui une plante qui ne vient très souvent qu'en fin de rotation culturale, après plusieurs années de culture de plantes plus exigeantes comme l'igname, le riz ou l'arachide. Il peut être en tête de rotation sur des sols qui ne supportent pas les cultures exigeantes et se succède alors à lui-même pendant plusieurs années (de trois à six ans et plus). Il est aussi résistant à la sécheresse grâce à son système racinaire très développé. Cet ensemble de caractéristiques confère au fonio une rusticité qui permet de valoriser les terres marginales et de maintenir l'environnement. Mais le décorticage manuel du fonio, activité essentiellement féminine, est difficile à réaliser.

Bien que son rendement soit relativement faible — de 500 à $1000 \mathrm{~kg} / \mathrm{ha}$ 一, il présente des caractéristiques nutritionnelles appréciées des consommateurs. C'est une plante savoureuse consommée sous diverses formes : couscous préparé à la vapeur ou à l'eau bouillante, bouillie, tô, etc. Il est considéré dans les familles paysannes comme un aliment qui donne la santé car il est «léger» dans le ventre, ne fait pas grossir et est facile à digérer. C'est pour ces mêmes raisons qu'il est souvent recommandé aux malades ou aux convalescents. Le fonio présente aussi des qualités sur les plans économique et social. Il est ainsi vendu plus cher que les autres céréales. De plus, un plat de fonio peut être considéré comme un plat d'honneur car il n'est servi qu'aux personnes de marque (sages, autorités, dignitaires religieux, beaux-parents, invités d'honneur, etc.) lors des grandes cérémonies (baptêmes d'enfant, mariages, funérailles, etc.).

Enfin, tout le mérite de M.M. Jean-François Cruz et Famoï Béavogui est d'avoir réalisé un travail de synthèse analytique d'envergure, aboutissant à ce document qui dévoile au public l'importance économique et sociale du fonio. Leur ouvrage expose également les défis à relever en termes d'amélioration de la production, de la transformation et de la commercialisation du fonio. Il se termine par des propositions concrètes de recherche et d'intervention qui découlent des connaissances acquises et des réflexions personnelles de ces deux auteurs, éclairant ainsi les décideurs et tous les acteurs de la filière. Mon souhait est que la publication de cet ouvrage ouvre la voie à l'émergence d'une filière fonio forte au bénéfice des paysans et des autres acteurs impliqués. D'autres espèces mineures attendent aussi d'être connues du public.

À Conakry, le 23 mai 2011

Mamadou Billo Barry Directeur scientifique et directeur général adjoint de l'Institut de recherche agronomique de Guinée (Irag) 


\section{Introduction}

Depuis dix mille ans et la naissance de l'agriculture, de très nombreuses plantes ont été domestiquées pour l'alimentation humaine ou animale, mais aujourd'hui seules quelques dizaines d'espèces sont cultivées à grande échelle sur la planète. Parmi les céréales, les espèces les plus courantes comme le riz, le blé et le maïs composent la base de l'alimentation d'une grande partie de l'humanité. Quelques espèces, souvent qualifiées de céréales mineures, ont été oubliées par les révolutions «vertes» alors qu'elles jouent un rôle important dans la sécurité alimentaire de populations parmi les plus pauvres. Bien adaptées aux conditions édaphiques et climatiques locales, elles résistent assez bien à la sécheresse et participent au maintien de l'environnement en assurant une couverture végétale sur des terres écologiquement fragiles et peu valorisées.

Parmi ces céréales traditionnelles, le fonio est une céréale à graines minuscules qui a longtemps constitué l'aliment de base de nombreuses familles des zones rurales d'Afrique de l'Ouest et qui est aujourd'hui redécouverte par les consommateurs urbains.

Ce document est le premier ouvrage consacré exclusivement au fonio. Il a pour but de regrouper dans un langage simple, parfois non technique, les informations disponibles sur cette céréale. La plupart des données proviennent des projets ou des programmes de recherche que les auteurs ont coordonnés ou auxquels ils ont participé depuis la fin des années 1990 et particulièrement les projets «Amélioration des technologies post-récolte du fonio» (1999-2004) financé par le CFC (Common Fund for Commodities) et «Amélioration de la qualité et de la compétitivité de la filière fonio en Afrique de l'Ouest» (20062008) financé par l'Union européenne. Des articles plus anciens, publiés par des chercheurs ou des voyageurs qui ont sillonné l'Afrique de l'Ouest, ont également été utilisés. Louvrage donne une description de la plante et des grains, et fournit des renseignements sur divers systèmes de culture et de production dans différents environnements. Il décrit les principales techniques traditionnelles de production et de transformation du fonio et il suggère des voies d'amélioration possibles. Il s'intéresse, enfin, à une meilleure valorisation du fonio en abordant des aspects touchant à l'élaboration de nouveaux produits, à la commercialisation et à la consommation. Le texte est organisé 
en chapitres qui couvrent ces principaux domaines. Que nos lectrices et nos lecteurs nous pardonnent s'ils considèrent que tel point a été laissé dans l'ombre ou que tel autre est trop développé, mais nos spécialités respectives de technologue et d'agronome y sont sans doute pour quelque chose. Les auteurs espèrent avant tout que cette publication aidera les différents acteurs de la filière, les techniciens ou les chercheurs comme les nouveaux consommateurs ou les simples curieux, à mieux connaître cette petite céréale africaine. 


\section{$\sqrt{1 .}$ Origine et distribution géographique}

Le fonio (Digitaria exilis Stapf) est considéré comme la plus ancienne céréale indigène d'Afrique occidentale. Les premières références au fonio comme aliment sont rapportées dès le milieu du XIV ${ }^{\mathrm{e}}$ siècle par l'explorateur berbère Ibn Battûta dans son Voyage au Soudan (actuel Mali). Il précise que, dans ces contrées, le coscoçoû (couscous) est préparé avec du foûni (fonio) «qui ressemble aux graines de moutarde» et il ajoute étrangement que «le riz est nuisible aux Blancs qui en font usage; le fonio est meilleur». Au XIX siècle, dans son Voyage à Tombouctou, l'explorateur français René Caillé évoque le fonio, qu'il qualifie de «foigné» (petite espèce de graminée), dès lors qu'il aborde, en avril 1827, les contreforts du Fouta-Djalon dans la région de Télimélé en Guinée. Puis, à mesure qu'il progresse vers l'intérieur de l'Afrique en traversant les régions de Kankan, du Ouassoulou, d'Odienné et de Tingrela, il rappelle fréquemment que le fonio constitue une des principales nourritures des habitants, qui le préparent en bouillie ou sous la forme de tau (aujourd'hui «tô»).

En 1905, L. Renoux et P. Dumas précisent que le fonio forme, avec le riz, le fond de la nourriture des populations et que «la précocité de certaines variétés remédie à la disette».

Plus près de nous, dans les années 1950, le célèbre agronome français Roland Portères lui consacre une monographie et note, en rappelant les travaux de Germaine Dieterlen, ethnologue française africaniste, l'importance que revêt le fonio dans la cosmogonie du peuple dogon au Mali, où il est considéré comme la première et la plus ancienne des graines cultivées. "Il est l'image de l'atome initial d'où est sorti l'univers». Cette céréale joue également un rôle très important chez d'autres sociétés africaines traditionnelles comme les Bassari du Sénégal, les Coniagui de Guinée ou les Bêtamaribê (peuple otamari) du nord du Bénin.

En 1894, le médecin André Rançon s'étonne que l'on puisse considérer le fonio comme une variété de sorgho et le désigne comme étant le Penicellaria spicata Wild. Puis, au début du $\mathrm{xx}^{\mathrm{e}}$ siècle, le fonio est appelé Paspalum longiflorum et c'est d'ailleurs ainsi qu'il est nommé 
par L. Renoux et P. Dumas en 1905. En 1912, Henri Jumelle, dans son article sur les cultures coloniales, précise que le fonio serait exactement le Digitaria exilis Stapf d'après Auguste Chevalier, botaniste français. En 1915, Otto Stapf pense que Digitaria exilis, auquel il a associé son nom, dérive de la forme sauvage Digitaria longiflora. Il révèle aussi que c'est Auguste Chevalier qui, le premier, a donné le nom de fonio (nom bambara) à cette plante dans son rapport «Une mission au Sénégal » en 1900 (Stapf, 1915). La primo-domestication du fonio daterait de 5000 ans av. J.-C. (Purseglove, 1985) et le principal centre de domestication du fonio serait le delta central du fleuve Niger (Portères, 1976).

Laire de culture du fonio s'étend entre les $8^{\mathrm{e}}$ et $14^{\mathrm{e}}$ parallèles nord, du Sénégal au lac Tchad. Plus à l'est, la céréale secondaire cultivée est l'éleusine (Eleusine coracana). C'est surtout en Guinée, dans les régions montagneuses du Fouta-Djalon, que le fonio représente l'une des bases de l'alimentation des populations. Comme l'illustre la figure 1.1., on le cultive également au Mali, au Burkina Faso, en Côte d’Ivoire, au Nigeria, au Bénin, au Sénégal, etc.

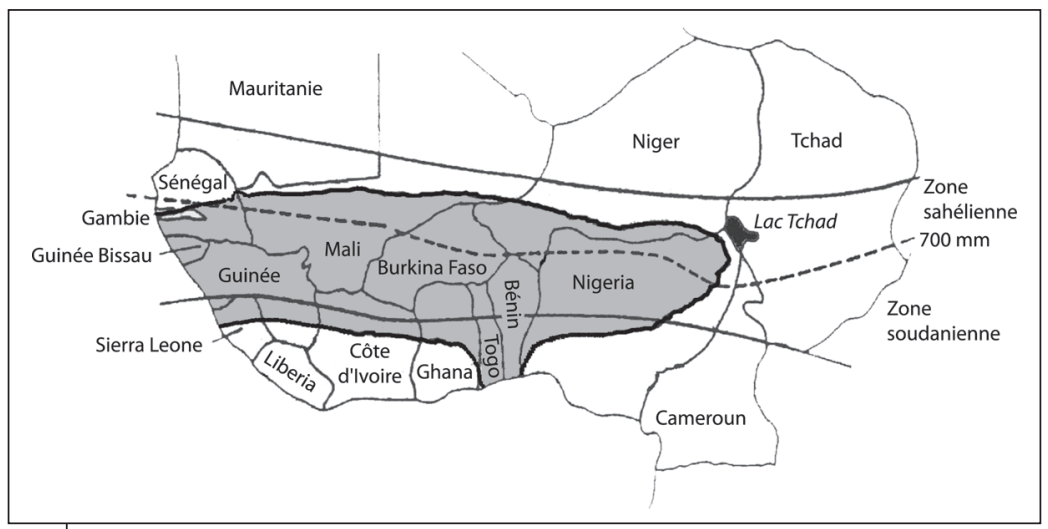

Figure 1.1.

Zones de culture du fonio (Digitaria exilis) (Cruz, 2001 d'après R. Portères).

Hors d'Afrique, le fonio est cultivé en République dominicaine où il aurait été introduit au $\mathrm{XV}^{\mathrm{e}}$ siècle. Connu sous le nom de funde, il a été conservé par les agriculteurs en raison de sa bonne résistance à la sécheresse. Il semble qu'il soit redécouvert aujourd'hui comme un produit de gourmet ayant même de supposées propriétés aphrodisiaques (Morales-Payán et al., 2002). 


\section{La plante et le grain}

Du point de vue de la botanique, le fonio est une monocotylédone glumacée de la famille des graminées (ou poacées) et du genre Digitaria. Les Digitaires qui regroupent plusieurs centaines d'espèces sont parfois cultivées comme plantes fourragères et seulement trois ou quatre espèces sont exploitées pour leurs grains.

On distingue ainsi le fonio blanc (Digitaria exilis) et le fonio noir (Digitaria iburua) en Afrique occidentale, le millet sanguin (Digitaria sanguinalis) en Europe orientale et le raishan (Digitaria cruciata) dans les montagnes Khasi du nord-est de l'Inde. Aujourd'hui, seul le fonio blanc revêt une certaine importance en Afrique de l'Ouest. Son nom botanique est Digitaria exilis (Kippist) Stapf et il est souvent considéré comme une des neuf espèces de mil (House, 1995) et qualifié parfois de «millet digitaire». Les anglophones d'Afrique de l'Ouest le nomment «hungry rice» ou «acha» et, localement, il reçoit de très nombreuses appellations selon les régions ou les ethnies: fundi, fini, foundé, foinye, ipoaga, ova, pon, etc. En 1955, l'agronome Roland Portères, qui étudie les appellations génériques vernaculaires, conclut en disant que les termes désignant le fonio ont tous le sens de «nourriture, aliment», c'est-à-dire de «chose à manger».

\section{Plante herbacée}

Le fonio est une petite plante herbacée annuelle de 30 à $80 \mathrm{~cm}$ de hauteur qui présente une inflorescence composée le plus souvent de deux ou trois racèmes ou épis (figure 2.1). Les racèmes portent les épillets groupés par deux (variétés hâtives), trois ou quatre (variétés tardives) sur des pédicelles (figures 2.2. et 2.3.). Lépillet comprend une fleur stérile et une fleur fertile qui donne le grain de fonio. Le chaume, cylindrique et creux, est très fin (diamètre inférieur à $1 \mathrm{~mm}$ ) et, à maturité, les tiges sont couchées sur le sol. Le fonio est une céréale qui talle bien (2 à 6 talles ou plus pour les variétés tardives).

Le système racinaire du fonio est très développé avec de nombreuses racines fines et d'abondantes radicelles. Limportance particulière de ce système racinaire, qui peut descendre jusqu'à plus d'un mètre 
de profondeur, permet d'expliquer le bon comportement de la plante durant les périodes de sécheresse et son adaptation aux sols pauvres qu'elle exploite efficacement.

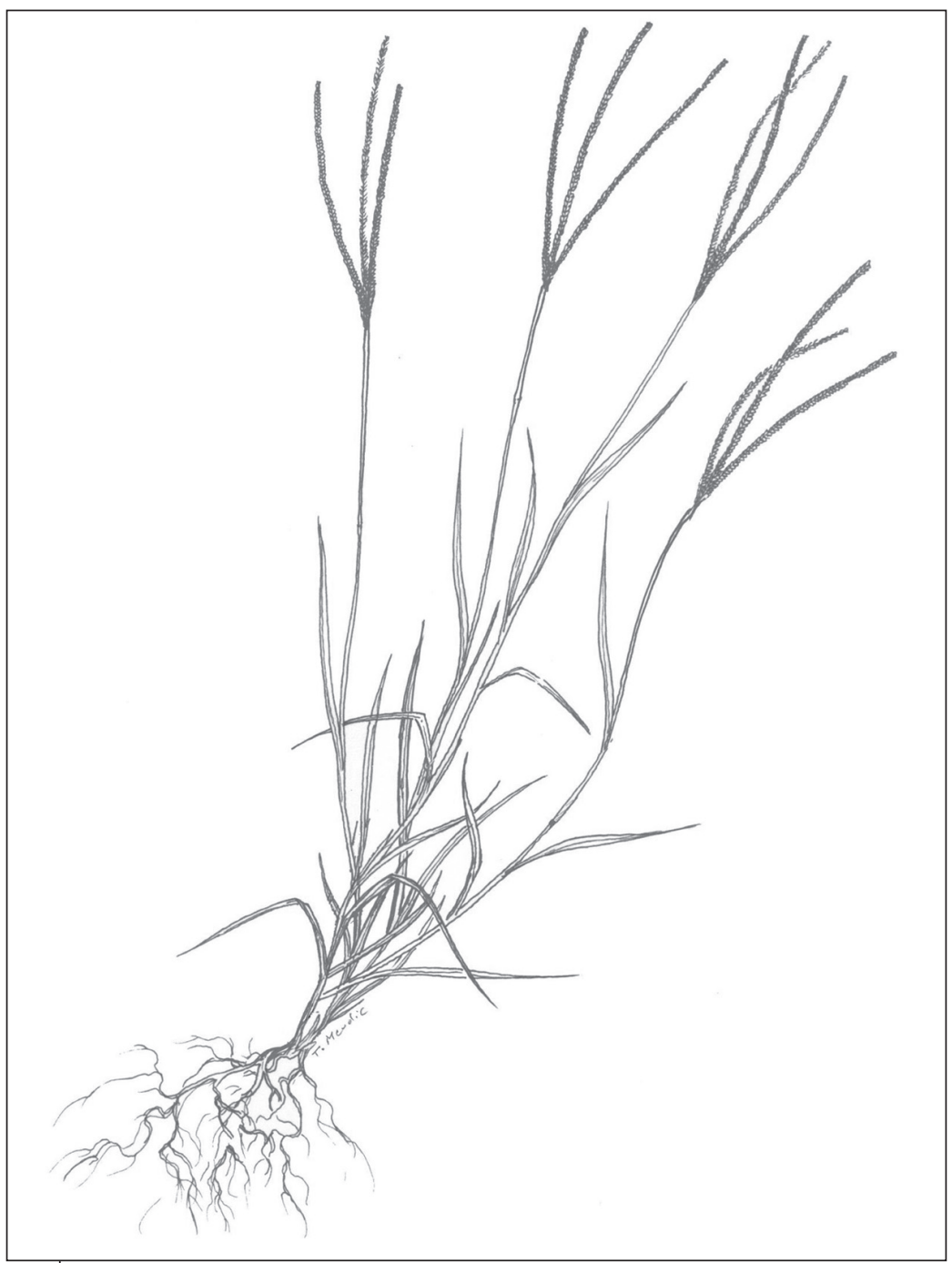

Figure 2.1.

Plant de fonio (T. Meudic). 


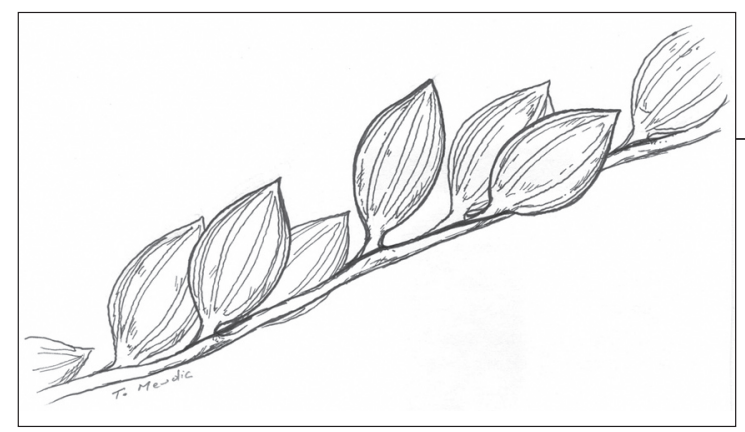

Figure 2.2.

Portion de racème

(T. Meudic).

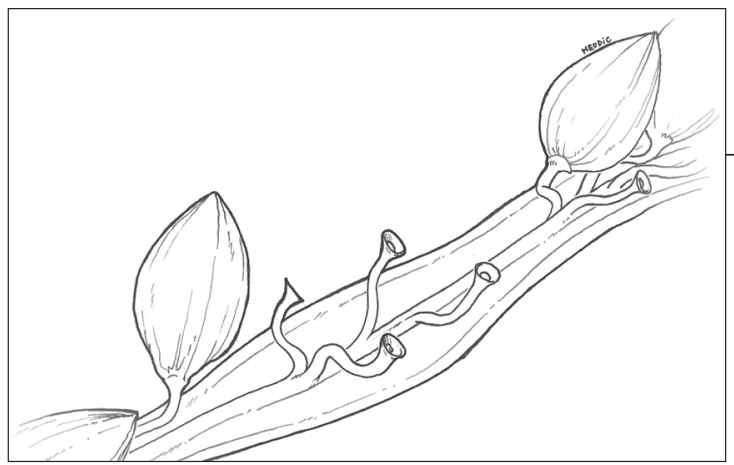

Figure 2.3.

Pédicelles groupés par 4 (T. Meudic).

La biodiversité des fonios est grande et les nombreuses variétés locales, ou écotypes, diffèrent par la couleur et le port de la plante, la couleur ou la taille des grains, et plus fréquemment par la longueur du cycle végétatif (Diallo et al., 2008). On distingue communément les variétés extra-précoces de 70 à 90 jours, les variétés hâtives de 90 à 110 jours, les variétés semi-tardives (ou intermédiaires) de 110 à 130 jours et les variétés tardives à plus de 130 jours de végétation. Des collections sont conservées par pays; l'une d'elles comprenant plus de 400 entrées se trouve en France, à l'Institut de recherche pour le développement (IRD) de Montpellier.

En 1955, l'agronome Roland Portères avait proposé une distinction en cinq groupes raciaux selon des caractéristiques morphologiques :

- variétés densa : plantes élevées portant 3 ou 4 racèmes très longs $(15-18 \mathrm{~cm})$ et où les pédicelles sont groupés par 4 (120-140 épillets par $10 \mathrm{~cm}$ ). Les grains sont petits et globuleux (2 100 grains par gramme) et la plante est très pigmentée. Variétés tardives localisées au Togo sous l'appellation Semre ou Sebre. 
- variétés rustica : il s'agit là de "grands fonios» (foniba) portant 2 ou 3 racèmes de 9 à $12 \mathrm{~cm}$ de longueur où les pédicelles sont groupés par 4 (90-120 épillets par $10 \mathrm{~cm})$. Grains elliptiques $(1750$ à 1800 grains par gramme). Variétés tardives localisées en Guinée, au Mali, au Sénégal sous les appellations Foniba, Konso, Rané, Siragué, Kassambara, Tama.

- variétés mixta : plantes de $60 \mathrm{~cm}$ à paille fine portant 2 ou 3 racèmes de 8 à $12 \mathrm{~cm}$ de longueur où les pédicelles sont groupés par 4 (90120 épillets par $10 \mathrm{~cm}$ ). Grains ventrus à ellipsoïdes (1 900 grains par gramme) à péricarpe blanc jaunâtre à rosâtre. Variétés demihâtives, généralement colorées localisées en Guinée sous les appellations Saara, Moussogbé, Keleaningbé.

- variétés stricta : petites plantes de 40 à $65 \mathrm{~cm}$ à paille très fine portant souvent 2 racèmes de 8 à $12 \mathrm{~cm}$ de longueur où les pédicelles sont groupés par 3 (60-110 épillets par $10 \mathrm{~cm})$. Grains ovoïdes allongés généralement blancs (1 800 grains par gramme) principalement sur 1 rang sauf au milieu du racème. Variétés précoces localisées en Guinée, au Mali et au Sénégal sous les appellations Momo, Kouroukeleni, Peazo, etc. ou encore fonio blanc hâtif.

- variétés gracilis : plantes de 50 à $60 \mathrm{~cm}$ à paille fine portant souvent 2 racèmes de 8 à $14 \mathrm{~cm}$ de longueur où les pédicelles sont généralement groupés par 3 (80-90 épillets par $10 \mathrm{~cm})$. Grains ovoïdes (1 700 grains par gramme) apparemment sur 2 rangs. Variétés précoces localisées en Guinée, au Mali et au Sénégal sous l'appellation Berele (ou Bèrèlen).

\section{Grains minuscules et vêtus}

Comme le riz, le fonio est une céréale dite «vêtue» car les grains, après battage, restent entourés de glumes et glumelles, et on parle alors de «fonio paddy» (voir cahier de photos couleur). Il s'agit là d'un abus de langage car le terme de paddy est normalement réservé au riz et désigne les grains de riz vêtu ou «riz en balle». C'est donc par similitude et par simple commodité que certains technologues ont pris l'habitude de qualifier les grains de fonio non décortiqués de «fonio paddy». Ces grains sont de très petite taille, de l'ordre du millimètre, et le poids de 1000 grains est en moyenne de $0,5 \mathrm{~g}$. Une description de la composition physique et biochimique des grains est donnée au chapitre 5. 
Comparés aux autres céréales connues, les grains de fonio sont minuscules (voir figure 2.4. et cahier de photos couleur); ce qui rend d'autant plus difficile leur transformation (décorticage) et leur nettoyage car ils ont une taille comparable à celle des grains de sable.

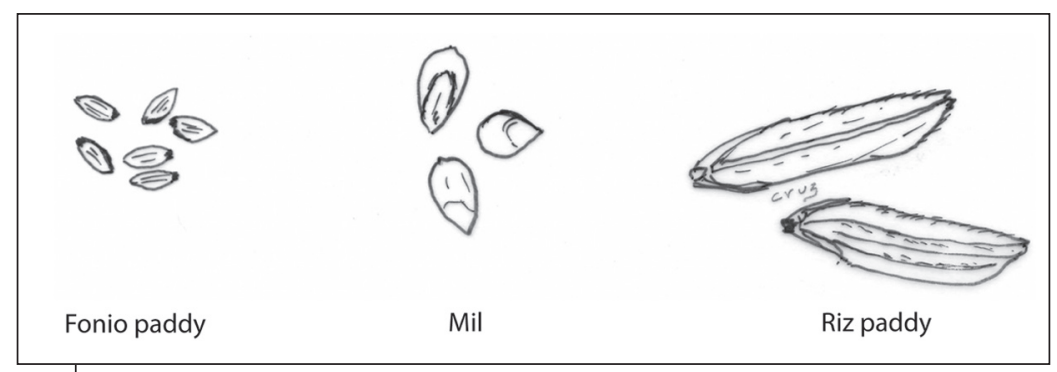

Figure 2.4.

Grains de «fonio paddy» comparé au mil et au riz paddy.

\section{Autres appellations «fonio»}

Le «fonio noir» est une culture observée dès 1911 par Dudgeon dans la zone de Zaria en pays haoussa dans le nord du Nigeria, où elle était appelée «iboru» par les populations locales (Stapf, 1915). Cette petite céréale a été décrite par Otto Stapf en 1915 et porte depuis lors le nom de Digitaria iburua Stapf. En 1946, Roland Portères écrit que l'aire culturale du fonio noir est localisée sur la zone nord-ouest des plateaux du Bauchi au Nigeria (figure 2.5.) et dans les contreforts méridionaux des montagnes de l'Atacora à cheval sur le Togo et le Dahomey (Bénin actuel). Il précise que c'est seulement au Togo que le fonio noir est cultivé à l'état pur dans les cantons de Kandé, Kpessedé et Ataloté. Cette espèce, peu appréciée, serait difficile à décortiquer et ne servirait qu'à la préparation de la bière locale dite «tchapalo». On le trouve aussi en mélange agraire avec quelques variétés de fonio blanc dans le canton de Birni, au sud de Natitingou (Bénin), où il serait utilisé comme aliment de soudure à l'instar du fonio blanc.

Le «fonio à gros grains» est parfois considéré comme une variété de fonio alors que Portères le définit comme une espèce différente relevant de Brachiaria deflexa. À l'état sauvage, cette petite céréale est présente dans les savanes côtières sableuses et dans les zones soudano-sahéliennes, où elle est connue comme un millet de ramassage. Il semble qu'une variété soit cultivée dans le nord du Fouta-Djalon, en Guinée, dans la région de Mali à plus de $1000 \mathrm{~m}$ d'altitude, où les cultivateurs la nomment «founi kouli» ou «fonio à grosses graines». Ses grains sont réputés plus farineux que ceux du fonio 
blanc et la farine est utilisée pour la préparation de galettes et de beignets (Portères, 1951). Brachiaria deflexa est parfois qualifié de «animal fonio» (de Wet, 1995).

Le «fonio sauvage» (Panicum laetum) vulgairement appelé «haze» est une graminée annuelle spontanée dont les graines sont utilisées comme aliment de cueillette par les populations nomades (Tamashek, Peuhl, etc.) des régions septentrionales du Mali, du Burkina Faso ou du Niger (voir plus loin).

Le terme «fonio» est quelquefois utilisé à tort pour désigner d'autres céréales. Ainsi au Tchad, l'éleusine (Eleusine coracana) est très souvent appelée «fonio» et, dans le nord du Cameroun, c'est le mil penicillaire (Pennisetum glaucum) qui est parfois nommé fonio tandis que le sorgho (Sorghum vulgare) est appelé mil. Cette grossière erreur est également faite par plusieurs auteurs comme Dalziel en 1937 ou Baudet en 1981, qui qualifient Digitaria exilis Stapf de «petit mil».

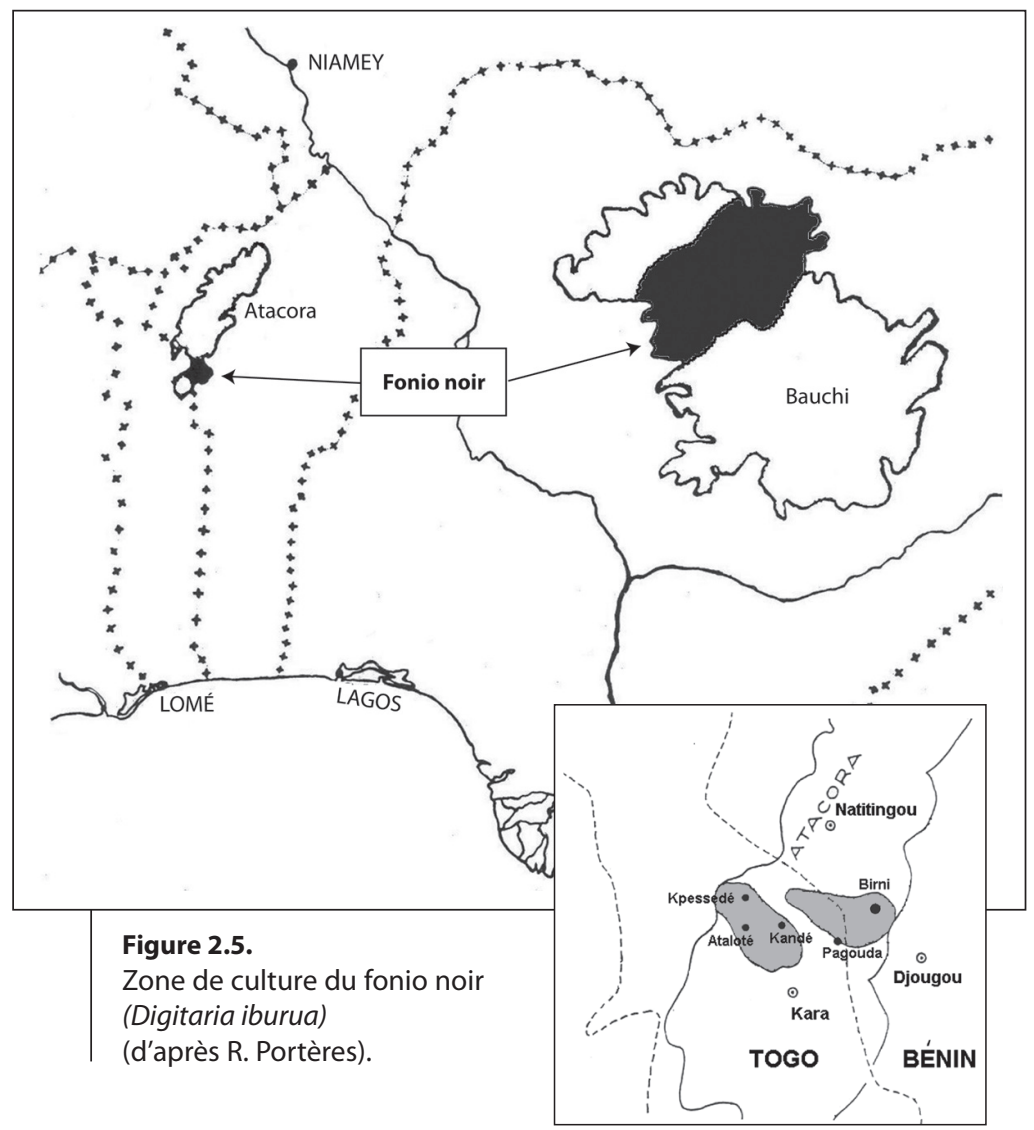

Figure 2.5.

Zone de culture du fonio noir (Digitaria iburua)

(d'après R. Portères). 


\section{$\sqrt{3 .}$ Les systèmes de culture et de production}

Le fonio est cultivé dans l'Ouest africain sous climat tropical, à saison sèche bien marquée, avec des températures moyennes de 25 à $30^{\circ} \mathrm{C}$ et une pluviométrie annuelle de 600 à $1200 \mathrm{~mm}$. Mais, en Guinée, le fonio est aussi présent dans les zones montagneuses où l'altitude dépasse $1000 \mathrm{~m}$ avec une plus forte pluviométrie (1 500 à $2000 \mathrm{~mm}$ ) et des températures nettement plus fraîches ( 15 à $25^{\circ} \mathrm{C}$ pendant la saison de culture).

\section{Caractéristiques de quelques zones de culture du fonio}

Les principaux exemples décrits sont ceux de pays francophones.

\section{II) Principales zones de production du fonio en Guinée}

\section{Le Fouta-Djalon en Moyenne Guinée, terre de prédilection pour la culture du fonio}

En Guinée, le fonio est produit dans les quatre régions naturelles, mais c'est surtout en Moyenne Guinée et en Haute Guinée qu'il est le plus cultivé, y occupant la deuxième place après le riz (Diallo, 2003). Il y représente à la fois un aliment de base et un aliment de soudure avant les récoltes des autres cultures.

En Moyenne Guinée, le fonio couvre en grande partie le FoutaDjalon (figure 3.1.). Ce massif gréseux est constitué de hauts plateaux tabulaires allongés du sud au nord, de Dalaba à Mali, à une altitude d'environ 1000 m, et jusqu'à 1425 m au mont Diaguissa vers Dalaba et $1538 \mathrm{~m}$ au mont Loura vers Mali. Ces plateaux sont creusés de nombreuses vallées plus ou moins encaissées. Les principales sont celles de Kokoulo, Kakrima et Téné qui séparent l'ensemble en trois grands massifs (Dalaba, Labé, Mali), comme le montre la figure 3.2. À l'est, le plateau est moins élevé (700 à $900 \mathrm{~m}$ ) et s'étend jusqu'aux confins de la Haute Guinée; à l'ouest, les montagnes deviennent de grandes zones herbeuses coupées de galeries forestières. 


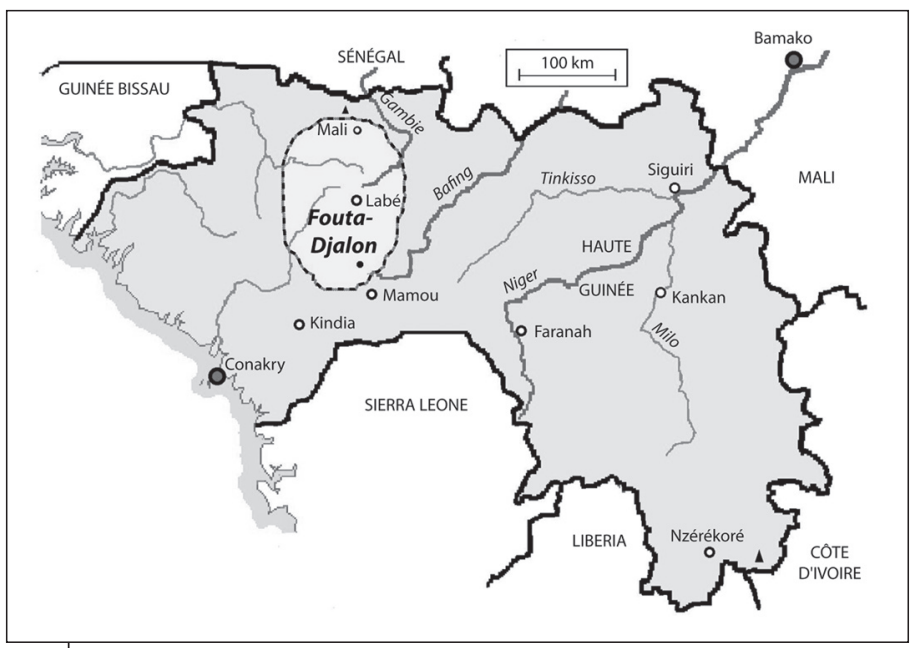

Figure 3.1.

Région du Fouta-Djalon, en Guinée.

Le climat est de type soudano-guinéen avec deux saisons bien distinctes. Mais, modifié par l'altitude, il est qualifié de climat montagnard guinéen foutanien. La saison pluvieuse ou «hivernage», qui dure cinq mois, de mai à octobre, apporte les pluies de mousson de l'océan. Le Fouta-Djalon, qui reçoit 1500 à $2000 \mathrm{~mm}$ de pluies par an, est souvent appelé le «château d'eau de l'Afrique de l'Ouest», car de nombreux fleuves comme la Gambie, le Bafing (devenant plus loin le fleuve Sénégal), le Tominé ou Corubal et le Tinkisso, affluent important du Niger, y ont leur source. La saison sèche, de novembre à avril, est soumise à l'influence de l'harmattan, vent sec et chaud qui vient du Sahara, mais l'altitude du Fouta permet d'atténuer l'aridité de cette saison grâce aux brouillards nocturnes et matinaux qui enveloppent les montagnes. Les températures moyennes mensuelles ne dépassent pas $25^{\circ} \mathrm{C}$ et le climat du Fouta-Djalon, tempéré et frais, est souvent considéré comme très agréable.

Les sols sont généralement pauvres en éléments minéraux. La longue altération des grès et des schistes a donné naissance à des sols ferrallitiques. Dans les zones de Timbi Madina à l'ouest de Labé, on distingue le dantari, sol de plaine sèche à végétation herbacée, ferrallitique argilo-sableux de couleur claire, pauvre en matière organique, souvent consacré à la culture du fonio et le hollandé, sol de piémont ou 

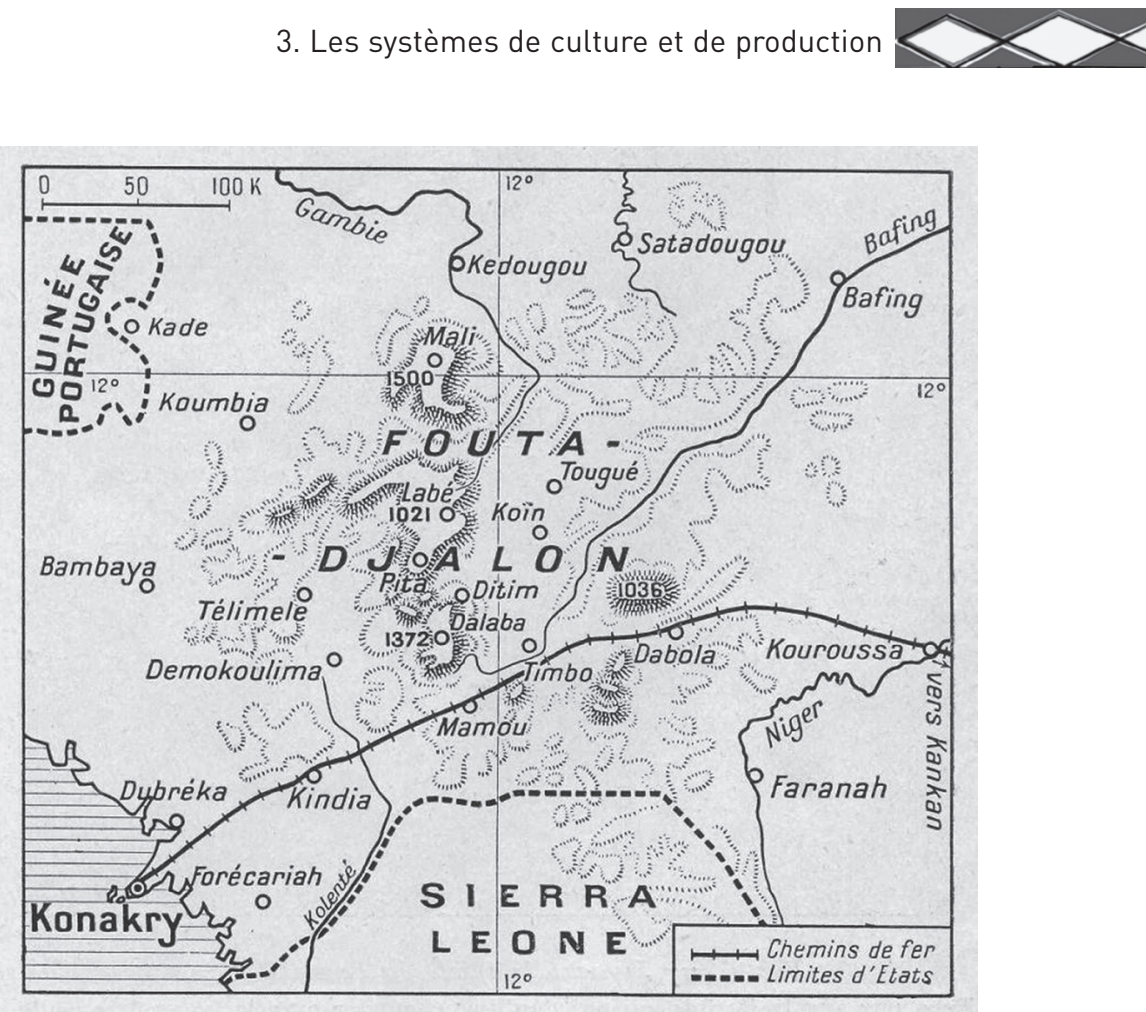

Figure 3.2.

Carte ancienne du Fouta-Djalon (Balachowsky, 1954).

de plaine, ferrallitique limoneux argileux de couleur sombre, sur lequel on cultive habituellement du riz.

Les sols de pente ou hansanghéré, sols rouges ferrallitiques caillouteux portant une végétation arbustive, sont issus du démantèlement des cuirasses latéritiques. Ces sols filtrants ont une structure qui facilite le développement des racines en profondeur. Réputés plus fertiles, ils sont recherchés pour la culture des céréales et notamment pour le fonio. En aval des pentes, on trouve des sols de bas-fonds, argilolimoneux à hydromorphie saisonnière, appelés dunkiré. On y cultive surtout la pomme de terre, le riz, le maïs ou l'arachide, qui assurent l'essentiel des revenus des ménages agricoles. Enfin, sur le plateau, lorsque le ruissellement a emporté tous les éléments fins du sol, il reste les bowé, constitués d'un sol squelettique sur cuirasse latéritique sur lequel poussent quelques arbres et, en hivernage, quelques graminées pouvant servir de pâturages. La succession des différents types de sols est illustrée par la figure 3.3. 


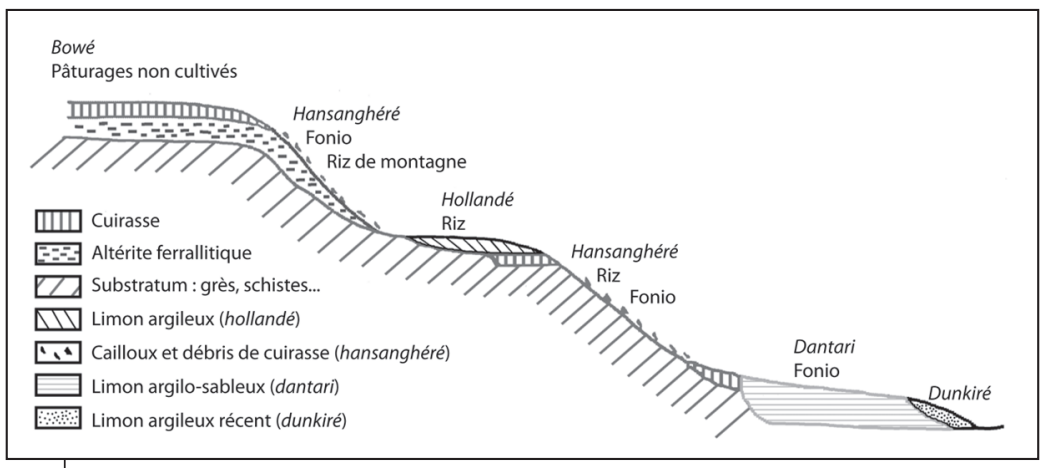

Figure 3.3.

Position relative des différents types de sols (d'après J.-M. Garreau, 1993).

Toute cette région, peuplée d'une majorité de Peuhl et de quelques populations mandingues (Dialonké, Soussou, Malinké, etc.), est consacrée à l'élevage et à l'agriculture vivrière. Le manque de ressource en sols de bonne qualité explique pourquoi le fonio, culture très peu exigeante et capable d'exploiter les derniers éléments du sol, est si prédominant. De nombreux agronomes ont longtemps affirmé que le fonio était responsable de l'épuisement des sols (Sudres, 1947), mais il est sans doute plus juste de penser que les populations locales cultivent le fonio parce que c'est souvent la seule culture possible sur des terres très pauvres.

$\mathrm{Au}$ Fouta-Djalon, la toposéquence structure les systèmes de culture, dont les principaux sont les «tapades», les champs extérieurs et les bas-fonds. La tapade est un espace enclos, lieu d'habitation d'un groupe familial, qui constitue le cœur de l'exploitation. Autrefois, le terme de tapade qualifiait seulement la clôture (haie vive ou mixte) protégeant de la dent des troupeaux cet espace clos qui, lui, était appelé "gallé». La tapade est divisée en parcelles (sountouré) cultivées, sans jachère, par les femmes qui disposent chacune d'une case d'habitation individuelle. La culture y est intensive (en travail et en transfert de fertilité) et combine diverses espèces comme le maïs, cultivé près des cases et parfois associé au niébé, la patate douce, l'arachide, le manioc, la pomme de terre, l'oignon, la tomate, l'aubergine et diverses plantes à sauce comme le gombo, l'oseille de Guinée et les piments. On y trouve également de nombreux arbres fruitiers comme les manguiers, les orangers, les bananiers et quelques avocatiers, ou encore 
certains arbres cultivés pour la fabrication de perches ou pour la teinture (indigotier). Le fonio peut parfois être cultivé en tapade, mais il concerne alors les zones périphériques les plus marginales et les moins amendées ou les surfaces récemment annexées à la tapade.

Le deuxième système traditionnel de culture concerne les champs dits «extérieurs», plus ou moins éloignés des tapades et généralement consacrés à la culture extensive du fonio en rotation avec le riz pluvial, l'arachide ou encore le manioc. Mais le plus souvent le fonio se succède à lui-même. Il s'agit d'une culture traditionnelle avec une gestion encore collective des travaux, en particulier sur les terres éloignées du village. Le rendement y est faible, souvent inférieur à $800 \mathrm{~kg} / \mathrm{ha}$, à cause de la pauvreté des sols et de l'absence de fertilisation. En effet, l'apport de matière organique (bouses, crottins, résidus de culture) ou minérale (cendres) est réservé aux parcelles des tapades et aux cultures de bas-fonds. Alors que la production des tapades reste du domaine des femmes, celle des champs extérieurs est du ressort des hommes, qui en ont assuré la préparation par défriche et brûlis. Les femmes, et les enfants, interviennent néanmoins dans la production en participant aux opérations de semis, de sarclage, et en prenant part activement aux récoltes. Sur les champs extérieurs, ouverts, on pratique la culture durant quelques années, puis on laisse reposer la terre pendant une période de jachère pâturée plus ou moins longue. En zone de plaine sur dantari ou hollandé, la culture du fonio se succède à elle-même, durant quatre à six ans, suivie d'une jachère d'égale durée. En zone de pentes ou hansanghéré, la période de culture est plus courte (deux à quatre ans) et la jachère est plus longue. On peut ainsi avoir une culture de riz pendant deux ans, suivie d'une culture de fonio pendant deux ans, et ensuite une jachère de sept à neuf ans. En 1949, on décrivait la rotation de la manière suivante : riz, riz, fonio et arachide (le champ est divisé en soles inégales), fonio et arachide ou fonio seul, manioc, jachère (Guillaume et al., 1949). Lorsque le besoin en terres cultivables augmente, la durée de la jachère peut parfois être réduite, mais elle peut s'accroître si, à l'échelle du village, la force de travail diminue en raison de l'émigration des jeunes hommes.

Enfin, le troisième système de culture concerne la culture des basfonds sur les sols de dunkiré, dont la mise en valeur date de l'époque coloniale. Ces zones alluvionnaires à hydromorphie saisonnière, de texture argilo-limoneuse, sont ainsi exploitées depuis de nombreuses années pour la culture de produits vivriers (riz, maïs, etc.). Mais l'espace en bas-fonds est limité et on cherche souvent à le valoriser 
au mieux en y pratiquant en saison sèche le maraîchage et particulièrement la pomme de terre, qui occupe une place importante et qui, dans certains endroits, procure l'essentiel des revenus des exploitations. Comme pour les tapades, l'amélioration de la fertilité des sols de bas-fonds est essentiellement due au travail des femmes. Lapport de cendres de bois accroît la richesse en macronutriments (calcium, potassium, magnésium) et réduit l'acidité du sol. Dans les tapades et dans les bas-fonds, le pH est relativement équilibré, alors qu'il est acide dans les sols dantari ou hollandé des champs extérieurs. Le fonio n'est jamais cultivé dans les bas-fonds.

Le Fouta-Djalon est la principale région productrice de fonio en Afrique de l'Ouest. La région de Labé produit à elle seule plus de $100000 \mathrm{t}$ de fonio soit près de la moitié de la production nationale en Guinée et près du tiers de la production totale en Afrique de l'Ouest (tableau 3.1.).

Tableau 3.1. Production de fonio selon les régions de Guinée en 2006 (données arrondies).

\begin{tabular}{lcccccccc}
\hline Région & Boké & Kindia & Labé & Mamou & Faranah & Kankan & Nzérékoré & Total \\
\hline Production (t) & 15000 & 12000 & 105000 & 34000 & 26000 & 20000 & 6000 & 218000 \\
\hline
\end{tabular}

Source : Service national des statistiques agricoles, ministère de l'Agriculture et de l'Élevage, Guinée.

\section{Le «fonio à grosses graines» (Brachiaria deflexa)}

Le Fouta-Djalon serait le seul endroit où l'on cultive le «fonio à grosses graines» comme céréale alimentaire. En 1951, Roland Portères rapporte que des cultures de ce fonio ont été identifiées dès 1938 par A. Sudres dans la région de Labé vers $1000 \mathrm{~m}$ d'altitude, puis dans la zone de Mali entre 1000 et $1200 \mathrm{~m}$ et qu'il a lui-même prélevé un échantillon dans un grenier d'un cultivateur de Mali. Ce fonio à grosses graines (ou founi-kouli en langue foulah) est à cycle court (70 à $75 \mathrm{j}$ ) et il n'est alors semé qu'en août, longtemps après le «vrai» fonio, sur des terrains situés à flanc de coteau, plus riches et mieux drainés. La plante, qui rappelle le riz pluvial, peut atteindre $1 \mathrm{~m}$ de hauteur et les rendements en grains seraient supérieurs à ceux du fonio cultivé dans les mêmes conditions. Ses grains, moins vitreux que ceux du fonio, donnent une farine utilisée pour la préparation de gâteaux ou de beignets. 


\section{La Haute Guinée, zone des savanes et des plaines inondables}

La Haute Guinée, qui couvre environ $41 \%$ du territoire guinéen, est située à l'est du Fouta-Djalon et s'étend jusqu'à la frontière du Mali. Divisée en deux régions administratives (Kankan et Faranah), elle correspond globalement au haut bassin du Niger. Des hauts plateaux accidentés du Fouta-Djalon, le relief descend brusquement sur un plateau inférieur qui s'incline faiblement vers le nord-est et dont les altitudes sont comprises entre 300 et $500 \mathrm{~m}$ (figure 3.4.). Le fleuve Niger et ses affluents comme le Tinkisso sur la rive gauche, le Milo et le Niandan sur la rive droite ont creusé dans ce haut bassin des plaines alluviales, sujettes à inondation et bordées d'un système de terrasses. Cette région est sous l'influence du climat tropical sud-soudanien caractérisé par l'alternance d'une saison des pluies de mai à octobre et d'une saison sèche de novembre à avril, avec la prédominance de vents d'est (harmattan). La pluviosité, de $1200 \mathrm{~mm}$ à $1700 \mathrm{~mm}$ annuels, est inférieure à celle du Fouta-Djalon et fait de la Haute Guinée une région de savanes herbeuses et arborées et de forêts éparses.

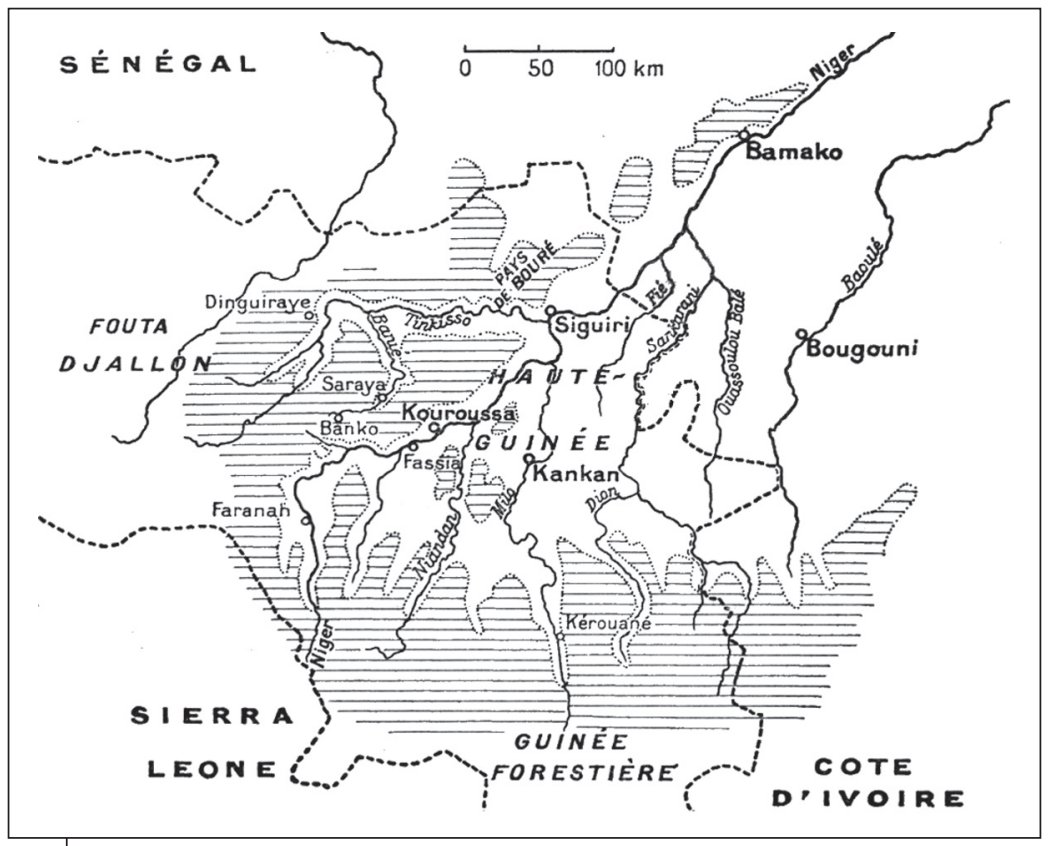

\section{Figure 3.4.}

Carte ancienne de la Haute Guinée (Gallais, 1959).

Le grisé horizontal correspond au cadre montagneux dépassant $500 \mathrm{~m}$. 
La population, principalement constituée de Malinké, est encore essentiellement rurale et sa densité, beaucoup plus faible qu'au Fouta-Djalon, ne dépasse pas 30 habitants au $\mathrm{km}^{2}$. Les principales activités sont agricoles et concernent l'agriculture vivrière et l'élevage, mais aussi l'arboriculture fruitière et le maraîchage. Des manguiers sont fréquemment plantés sur les hautes terrasses alluviales et les versants, alors que l'exploitation de l'anacardier, d'introduction récente sur les plateaux, est encore limitée. Les activités extra-agricoles concernent le commerce, l'artisanat, la pêche, la chasse, la cueillette et, par endroit, l'orpaillage traditionnel. Les fruits des grands arbres de la savane comme le néré (Parkia biglobosa) et le karité (Vitellaria paradoxa) sont traditionnellement transformés par les femmes, respectivement en soumbala et en beurre de karité, commercialisés sur les marchés locaux.

Les plaines humides des bassins du Niger et de ses affluents sont très favorables à la riziculture inondée, alors que les zones les plus hautes des plaines à proximité des villages sont parfois vouées au maraîchage réalisé par les femmes et destiné à la commercialisation.

Sur les plateaux et les versants, la culture itinérante sur brûlis est le mode de production le plus répandu en raison de la faible densité de population et du manque d'équipements dans les exploitations agricoles. En Haute Guinée, le fonio constitue encore une importante culture vivrière après le riz pluvial et le riz de plaine, mais avec le maïs, le sorgho, le mil, l'arachide ou le manioc. La figure 3.5., qui illustre la toposéquence type en Haute Guinée en 1959, reste toujours d'actualité dans ses grandes lignes, même si certaines des variétés indiquées ont pu changer. Aujourd'hui, les régions de Kankan et Faranah contribuent à plus de $20 \%$ à la production nationale de fonio (tableau 3.1.).

Le fonio est généralement cultivé après une ou deux années de riz pluvial, de maïs et parfois d'arachide, et laisse la place le plus souvent au manioc. Le fonio peut ainsi bénéficier des effets d'un précédent cultural de légumineuses (arachide) pour améliorer ses rendements. Puis les pailles de fonio peuvent être utilisées comme paillage pour les buttes du manioc. Les rotations de cultures sont ensuite suivies d'un temps de jachère relativement long, qui dépasse souvent dix ans (Bourdillat, 1995).

Les paysans assurent une rotation des cultures sur les parcelles jusqu'à un épuisement avancé du sol. Cet épuisement est souvent révélé par la présence d'une plante parasite comme le striga (Striga hermonthica). Son apparition est généralement associée à la pauvreté des sols, qui résulte d'une monoculture céréalière pratiquée pendant 


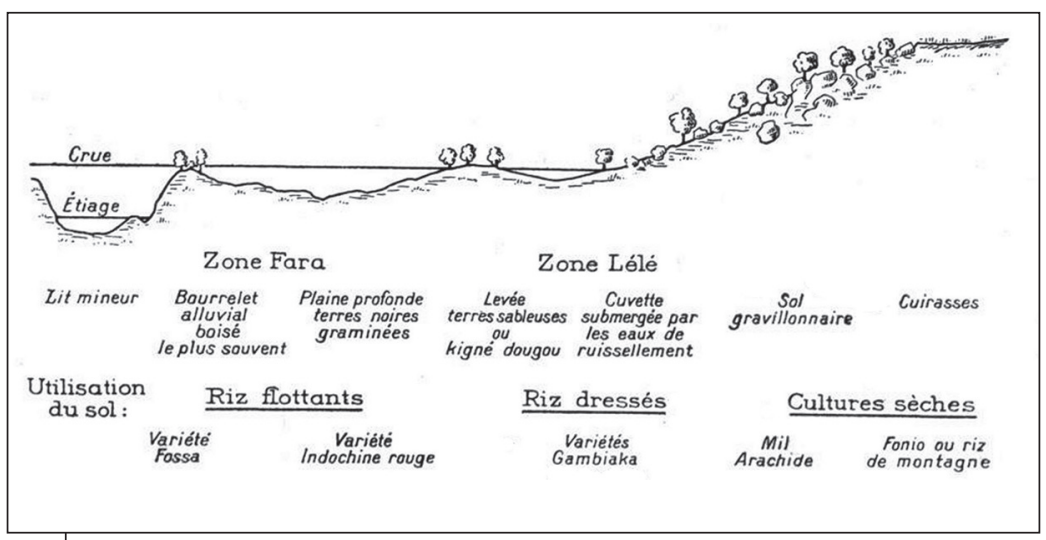

\section{Figure 3.5.}

Utilisation du sol dans la plaine d'inondation

du haut Niger en 1959 (Gallais, 1959).

trop longtemps et de l'absence d'apport d'intrants (fumier, compost ou engrais). La baisse de la fertilité du milieu est parfois due à des nématodes, mais le fonio ne serait pas sensible à ces vers parasites des racines et certains chercheurs ont même proposé d'utiliser le fonio en rotation avec les cultures maraîchères dans le but de contrôler les nématodes du genre Meloidogyne (Sarr et Prot, 1985).

Avec l'appauvrissement des sols, les cultures de l'igname et du riz pluvial sont parfois abandonnées au profit du manioc cultivé en rotation avec du fonio. Dans certains cas, cette rotation intègre des légumineuses comme l'arachide, le haricot niébé ou le haricot voandzou. Le fonio n'est cultivé en tête de rotation que lorsque les producteurs pratiquent une monoculture sur plusieurs années avec de très courtes jachères, mais le cas est assez rare (Bourdillat, 1995).

Le fonio est parfois cultivé en association avec une autre plante. En Haute Guinée, l'association la plus courante est réalisée avec une autre céréale comme le sorgho ou le mil, et de temps à autre avec l'oseille de Guinée (Hibiscus sabdariffa L.).

Certains producteurs sont capables d'effectuer deux campagnes de fonio la même année, sur une même parcelle ou plus fréquemment sur deux parcelles différentes (Béavogui et al., 1992). Pour la première campagne, ils sèment une variété "précoce», en mai ou juin, dès l'arrivée des premières pluies. Grâce à son cycle court de 75 jours, ce fonio hâtif est récolté en juillet ou en août. Si cette première récolte 
est généralement peu productive, elle permet néanmoins de nourrir les familles durant la période dite «de soudure», en attendant la récolte des autres céréales (riz, maïs, sorgho) qui débute rarement avant fin septembre. La deuxième campagne est semée avec des variétés à cycles plus ou moins longs, qui sont récoltées à partir d'octobre. Les grains de ces variétés plus tardives et plus productives sont alors stockés comme réserves et sont consommés au cours de l'année ou vendus, en partie, selon les besoins familiaux.

\section{IID Quelques terroirs de culture du fonio au Mali}

Dans l'ouest du Mali, une première zone de production est située vers Kéniéba au sud de la région de Kayes, aux confins du Sénégal et de la Guinée. Dans cette région du Bambouk, où la plaine de la rivière Falémé est brusquement marquée par la haute falaise de Tambaoura, les conditions agroclimatiques sont relativement favorables, mais l'agriculture y est souvent concurrencée par l'exploitation de l'or. Les activités agricoles restent centrées sur les productions vivrières et le fonio constitue pour les populations malinké une culture de tradition en rotation avec le sorgho, le mil, le riz pluvial ou l'arachide. Au nord-est de cette zone, dans le Kaarta, la limite septentrionale de la culture du fonio se trouve légèrement en deçà de celle des cultures de mils et sorghos, au niveau de l'isohyète $600 \mathrm{~mm}$. L'ethnie sarakolé, qui peuple cette région limitrophe de la Mauritanie, n'a pas pour tradition de cultiver le fonio et les rares cultures de fonio rencontrées sont situées dans des villages bambara pour lesquels le fonio reste un mets de choix.

$\mathrm{Au}$ Mali, l'aire principale de culture du fonio est située au sud du fleuve Niger dans un triangle Bamako-Sikasso-Mopti (figure 3.6.). La production de fonio est surtout concentrée dans la région de Ségou autour de la ville de San, avec un centre important comme Tominian, mais également au sud-ouest de la région de Sikasso vers Bougouni, et notamment dans les communes rurales de Garalo et Kolondiéba. Plus à l'est, dans la région de Mopti, on cultive aussi du fonio en pays dogon dans la plaine du Seno proche du Burkina Faso et particulièrement dans le cercle de Bankass. Ces régions, arrosées par le fleuve Niger et la rivière Bani, ont un climat à deux saisons de type soudanien à soudano-sahélien (isohyètes annuelles comprises entre 1300 et $600 \mathrm{~mm}$ ) et constituent une grande zone de productions vivrières. Les cultures de sorgho, maïs, riz, mil, arachide, suivies du niébé, du voandzou 
(pois de terre ou pois bambara) et du fonio, sont les plus connues. Ces plantes sont cultivées un peu partout dans la zone et sont consommées sous différentes formes. Les légumineuses sont réputées intéressantes pour leur capacité à améliorer la fertilité des sols et pour leur potentiel fourrager. Leur teneur élevée en protéines en fait des ressources très importantes au point de vue nutritionnel. Toutes ces zones de savanes allant de la haute vallée du Niger jusqu'au delta central sont considérées par certains agronomes comme des foyers de diversification de nombreuses céréales comme le fonio, le riz africain et certaines races de mil ou de sorgho (Havinden, 1970).

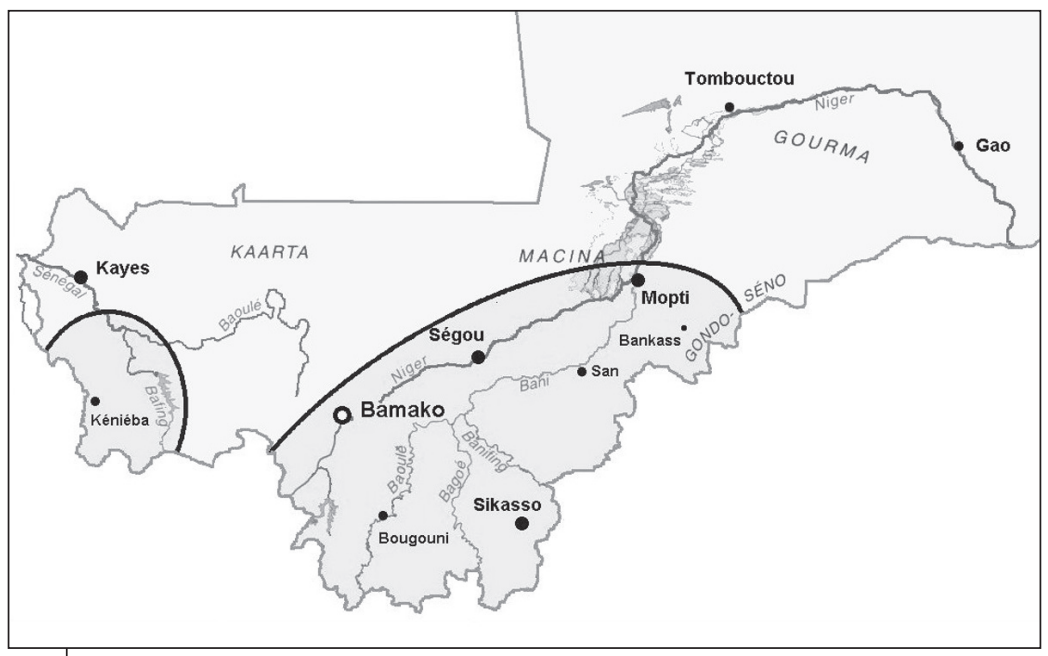

\section{Figure 3.6.}

Principales zones de production du fonio au Mali.

Dans la zone de San et de Tominian, les productions comme le mil et le fonio sont obtenues sur des sols sableux, alors que le sorgho est cultivé par endroit sur des terres plus argileuses. Avec des précipitations annuelles de 700 à $800 \mathrm{~mm}$, la région de San est peu favorable à la culture du maïs, qui a tendance à se développer dans les contrées méridionales. Cette zone de San, marginale de la zone cotonnière, est caractérisée par une majorité d'exploitations peu ou moyennement équipées en matériels et gérant de faibles effectifs de bovins. Depuis les années 1970, la durée de culture sur une même parcelle a augmenté. Les systèmes traditionnels, avec des périodes de culture de quatre à cinq ans alternant avec une jachère de quinze à vingt ans, ont évolué 
vers des systèmes itinérants de huit à dix ans de culture, ou même des systèmes de culture presque permanente (près de trente ans) qui rendent des jachères disponibles et permettent ainsi une augmentation des surfaces cultivées (Gigou et al., 2004). Les superficies ensemencées en fonio ne régressent pas et montrent l'intérêt que les paysans accordent à cette céréale. Mais les rendements sont souvent variables et évoluent selon les cas entre 500 et $1000 \mathrm{~kg} / \mathrm{ha}$. La production de fonio dans cinq régions du Mali est présentée dans le tableau 3.2.

Tableau 3.2. Production de fonio dans cinq régions du Mali en 2006.

\begin{tabular}{lcccccc}
\hline $\begin{array}{l}\text { Caractéristiques } \\
\text { de la culture du fonio }\end{array}$ & Kayes & $\begin{array}{l}\text { Koulikoro } \\
\text { (Bamako) }\end{array}$ & Sikasso & Ségou & Mopti & $\begin{array}{c}\text { Total } \\
\text { Mali }\end{array}$ \\
\hline Superficie (ha) & 6820 & 910 & 13120 & 12180 & 12740 & 45770 \\
\hline Production (t) & 4860 & 680 & 7770 & 9140 & 3800 & 26250 \\
\hline Rendement (t/ha) & 0,71 & 0,75 & 0,59 & 0,75 & 0,3 & 0,57 \\
\hline
\end{tabular}

Source : Cellule planification et statistiques, ministère de l'Agriculture, Mali.

Dans la région de Bougouni, moins peuplée, l'économie est à prédominance agricole. Les principales cultures de rente pratiquées sont le coton, l'arachide, les cultures maraîchères et les fruits, alors que les cultures vivrières sont le maiis, le mil, le sorgho, le fonio et le niébé. Les rendements des céréales locales sont relativement faibles, et les cultures de sorgho et de fonio sont marginalisées sur les sols les plus pauvres. Le fonio est généralement cultivé en fin de rotation et de préférence après une légumineuse comme l'arachide. Les paysans ont tendance à remplacer la culture du sorgho par celle du maïs, car ils considèrent que c'est la céréale qui valorise le mieux l'arrière-effet de la fertilisation apportée au cotonnier. Les femmes pratiquent souvent la culture du fonio pour couvrir les besoins financiers de la famille, mais elles ont parfois du mal à trouver des débouchés sur les marchés locaux. Elles sont également actives dans le commerce des produits de cueillette transformés comme le soumbala à partir de néré et le beurre de karité. En raison de la pénibilité des opérations au champ, la culture d'une parcelle de fonio par une femme est un signe de courage qui est souvent salué et respecté par la communauté villageoise (Vall et al., 2007).

Dans la plaine du Séno (qui signifie «sableux» en langue peuhl) au pied de la falaise de Bandiagara, le fonio est cultivé en rotation avec le mil, qui occupe l'essentiel des terres cultivées, alors que plus au sud vers la frontière avec le Burkina Faso, on cultive davantage le sorgho ou le riz dans la haute vallée du Sourou. Les systèmes agricoles 
combinent toujours agriculture et élevage. Les agriculteurs mettent en valeur des champs proches du village qui reçoivent des amendements organiques (fumiers et déchets ménagers) et des champs éloignés du village, ou champs dits «de brousse», qui sont mis en jachère après quelques années de culture. Les paysans laissent dans leurs champs certains grands arbres de la savane comme les karités, les nérés et les balanzas (Acacia albida). Quelques rendements moyens de culture obtenus dans le village de Lagassagou en 2000 sont rappelés dans le tableau 3.3.

Tableau 3.3. Rendements moyens obtenus dans le village de Lagassagou (région de Mopti).

\begin{tabular}{llr}
\hline Type de champ & Culture & $\begin{array}{c}\text { Rendement moyen } \\
\text { (kg/ha) }\end{array}$ \\
\hline Champ de brousse & Mil & 450 \\
& Arachide & 1100 \\
& Niébé (intercalé avec mil) & 80 \\
& Fonio & 800 \\
Champ proche du village & Mil & 1050 \\
\hline
\end{tabular}

Source : Samaké, 2003.

\section{La culture du fonio en pays dogon}

En 1940, l'anthropologue française Denise Paulme a décrit l'attention particulière que les Dogon (Mali) portent aux cultures et notamment au fonio : «Le fonio se sème à la volée et ne demande qu'un seul sarclage, un mois environ après la levée des graines [...]. Tandis que s'accomplit lentement le travail de la terre, que les semences germent, que les tiges croissent et que les épis se forment, les réserves des greniers, où l'on doit puiser le grain des repas, semblent diminuer chaque jour plus rapidement. La famine, toujours menaçante, pourra-t-elle être écartée ? [...] De nombreux dictons marquent avec quel soin les hommes suivent la croissance des plantes qui assurent leur subsistance. Les tiges de fonio (variétés à végétation rapide) commencent à sortir au dixième mois (août); leur minceur les fait alors comparer à des aiguilles : menene duba, dit-on, "on a fabriqué des aiguilles". Les épis grossissent rapidement, dès le début du onzième mois : "le fonio est enceint", pô bere. Enfin, les cultivateurs peuvent annoncer joyeusement la nouvelle au village : pô purai, "le fonio est sorti, est mûr". La famine est évitée cette année encore, car dès cette époque, on peut récolter le fonio.» 


\section{II) Les zones de fonio dans le sud-ouest et l'ouest} du Burkina Faso

Au Burkina Faso, le fonio arrive au cinquième rang des céréales cultivées, largement représentées par le sorgho et le mil, puis par le maïs et le riz. Comme il représente moins de $1 \%$ de la production céréalière totale, il est considéré comme une céréale secondaire mais il garde une image très positive d'aliment traditionnel, de bonne qualité, très apprécié par les populations qui le cultivent (Bobo, Senoufo, etc.).

Le fonio est surtout produit dans le sud-ouest du Burkina Faso dans les provinces du Kénédougou, du Houet ou de la Comoé et, dans l'ouest, dans les provinces plus septentrionales du Banwa et de la Kossi, le long de la frontière malienne (figure 3.7.). Selon les années, la production de fonio au Burkina Faso varie de 10000 à $20000 \mathrm{t}$ avec des rendements moyens de 600 à $800 \mathrm{~kg} / \mathrm{ha}$. Mais il existe de fortes disparités entre les zones subhumides et les zones plus arides.

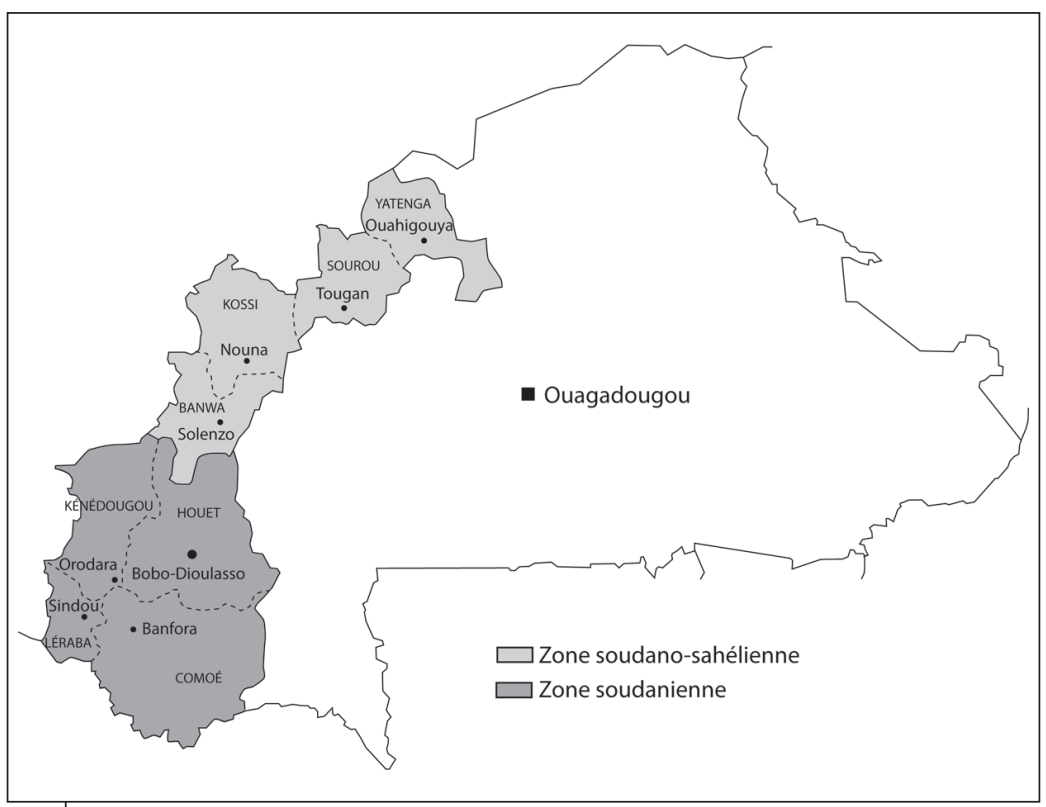

Figure 3.7.

Zones de production du fonio au Burkina Faso. 


\section{Le fonio des zones subhumides du Kénédougou-Houet}

Les régions du Kénédougou-Houet correspondent aux hauts bassins du fleuve Mouhoun (ex-Volta noire), qui descend du massif gréseux de la falaise de Banfora. Le relief est constitué de plateaux et de plaines subhumides où la pluviométrie supérieure à $900 \mathrm{~mm}$ par an ne constitue pas un facteur limitant, mais où les sols ferrugineux tropicaux sont relativement pauvres. La végétation de type soudanien est caractérisée par un développement important des espèces ligneuses formant des savanes boisées et des forêts-galeries le long des cours d'eau. Les conditions naturelles de ces régions permettent une agriculture très diversifiée, surtout dominée par l'arboriculture et notamment les agrumes et les manguiers (Vall et al., 2007). La province du Kénédougou est ainsi qualifiée parfois de verger du Burkina Faso. Les productions vivrières sont également importantes et particulièrement les céréales (maïs, sorgho, mil). Le fonio est présent un peu partout et notamment dans les zones de Peni et Toussiana au sud de Bobo Dioulasso, et dans la région d'Orodara où sa part dans l'assolement est voisine de $20 \%$. Le fonio ne vient jamais en tête de rotation car, sur un sol trop riche, le rapport grain/paille est en défaveur du grain et sa végétation est trop luxuriante (Stilmant et Dupuis, 2007). Ces régions du sud-ouest du Burkina Faso produisent également des légumineuses (niébé, arachide) et des racines et tubercules (ignames, manioc). Le coton reste une des principales cultures de rente et contribue aux revenus monétaires des ménages agricoles. Le maraîchage est par ailleurs une activité porteuse. Enfin, l'élevage connaît un développement remarquable et son importance est reconnue au plan social et économique.

Dans cette partie du Burkina Faso, on trouve des parcelles de fonio exclusivement gérées par des femmes. Lorsque, dans l'unité de production, les surfaces en fonio sont relativement importantes et parfois supérieures à 2 ha, les femmes, qui sont généralement sous-équipées en matériels agricoles et en animaux de trait, doivent louer les équipements de labour. Elles doivent aussi faire appel à la main-d'œuvre extérieure pour les opérations de récolte et de battage, ce qui entraîne des dépenses importantes (Vall et al., 2007). Les femmes se rémunèrent alors en vendant une partie de leur production de fonio, lorsque les prix sont les plus élevés, au cours de la période de soudure entre mai et juillet.

\section{Le fonio dans les zones semi-arides de la Kossi}

La région de la Kossi, frontalière du Mali, prolonge au sud la région malienne du Séno-Gondo jusqu'au nord du pays bobo. Cette zone est 
constituée d'une vaste plaine sableuse avec quelques collines ou replats à l'ouest. Elle est soumise à un climat soudano-sahélien semi-aride où la pluviométrie annuelle, qui varie entre 600 et $800 \mathrm{~mm}$, est aléatoire et ne permet pas une diversification importante des cultures. Lagriculture est ainsi dominée par les céréales traditionnelles comme le sorgho, le mil et le fonio, qui constituent les cultures alimentaires de base. D'autres cultures comme les légumineuses (niébé, arachide, voandzou) ou le maïs complètent l'alimentation des ménages. Les cultures de rente sont limitées au sésame et au coton, mais les excédents de certaines cultures alimentaires comme le fonio peuvent être commercialisés pour fournir des revenus complémentaires aux ménages (Vall et al., 2007).

Dans ces zones semi-arides qui s'étendent de Nouna, la capitale de province, jusqu'à Djibasso à l'ouest et aux rives du Sourou à l'est, les exploitations sont plus grandes (1,7 ha par actif) que dans les autres zones précédemment décrites (en moyenne 1 ha par actif). Cette évolution est permise par un meilleur niveau de mécanisation (culture attelée) et une nécessité de s'adapter au mieux au risque de déficit pluviométrique (Vall et al., 2007). Comme dans les régions maliennes voisines du Séno et de San, le fonio n'occupe pas plus de $20 \%$ de l'assolement et s'intercale souvent entre deux cultures de mil ou de sorgho. Les producteurs conservent en général trois sortes de variétés de fonio : une variété à cycle court, une variété à cycle intermédiaire et une variété à cycle long même si l'une d'elles est parfois dominante. En raison du caractère erratique des pluies, les producteurs des zones semi-arides sèment souvent la ou les variétés précoces à cycle court qui permettent d'assurer l'alimentation des familles dans l'attente des autres récoltes. Le fonio joue alors un rôle essentiel d'aliment de soudure suppléant quelque temps l'absence de mil et de sorgho dans les greniers. Mais aujourd'hui certains producteurs souhaitent aussi le valoriser en culture de rente, comme en témoigne la «foire du fonio» organisée chaque année en février dans le village de Bomborokuy à $40 \mathrm{~km}$ au nord de Nouna.

\section{ID Le fonio dans d'autres pays d'Afrique de l'Ouest}

\section{Le fonio, culture traditionnelle du Sénégal oriental et de Haute Casamance}

Au Sénégal, le fonio est cultivé dans le sud et le sud-est du pays dans les régions du Sénégal oriental (de Koungheul, Koussanar à Kédougou) et de Haute Casamance (de Sédhiou à Vélingara). C'est 
surtout dans le département de Kédougou qu'il est produit par les ethnies jalonké et bassari sur les contreforts du Fouta-Djalon. Les surfaces cultivées varient de 0,25 à 1 ha par exploitation familiale et les rendements sont voisins de 600 à $800 \mathrm{~kg} / \mathrm{ha}$ (Dramé et Cruz, 2002). Les plus petites surfaces sont cultivées par les femmes, qui cherchent de plus en plus à valoriser le fonio comme une culture de rente. Ailleurs, en raison du manque de moyens de transformation, le fonio a progressivement été abandonné pour être remplacé par d'autres productions comme le maïs ou les cultures maraîchères. Dans bien des villages, le fonio n'est plus qu'une culture destinée à l'autoconsommation et maintenue, bien souvent, pour les simples besoins de pratiques ou cérémonies traditionnelles (fêtes, culte, médecine traditionnelle). Cette céréale, autrefois abondante, est devenue aujourd'hui tellement marginale qu'elle n'apparaît que très peu dans les statistiques agricoles, qui évaluent néanmoins la production actuelle entre 1000 et 1500 tonnes.

Les rares variétés conservées sont souvent à cycle court (variété Momo ou Yaoko) ou à cycle intermédiaire (variété Dibong ou Mora), cultivées comme céréales de soudure pour les besoins d'autoconsommation des ménages en attendant la récolte des autres céréales. Les variétés semi-tardives (Rané ou Findiba) sont plus rares et les variétés tardives disparaissent progressivement (USAID, 2008). Ce produit est faiblement commercialisé car de nombreux producteurs considèrent que « le fonio est un produit pour les fêtes et n'est pas cultivé pour être vendu». Cependant, dans certaines zones du Sénégal comme à Koussanar, à Kolda, à Sédhiou ou à Kédougou, des associations féminines ou des groupements villageois, souvent soutenus par des ONG, souhaitent relancer la culture du fonio à des fins commerciales. Cela est aujourd'hui facilité par la diffusion de nouvelles machines performantes qui rendent plus aisée la réalisation des opérations post-récolte. Ils doivent alors chercher à retrouver certaines variétés tardives qui ont parfois disparu des villages et à écouler leur production sur des marchés réguliers.

\section{Le fonio, culture de piémont dans l'Atacora au Bénin}

Au Bénin, le fonio est produit dans la région de Natitingou, chef-lieu du département de l'Atacora, situé au nord-ouest du pays. C'est une zone de petites montagnes (la chaîne de l'Atacora culmine à 658 m) au climat soudano-guinéen, avec une saison humide de juin à octobre donnant une pluviométrie moyenne annuelle de 1000 à $1300 \mathrm{~mm}$. Cette région, au fort potentiel touristique en raison du patrimoine 
architectural somba, a une économie essentiellement agricole. Elle produit du mil, du sorgho, du niébé, de l'igname, du manioc, de l'arachide et plus récemment du maïs et du coton. Le riz est cultivé dans certains bas-fonds et le fonio est encore présent dans quelques zones de l'Atacora, où il semble néanmoins en régression constante depuis l'introduction de variétés hâtives de maïs. La pénibilité des tâches de transformation du fonio est l'une des principales raisons de son abandon progressif. Seule la sous-préfecture de Boukoumbé assure l'essentiel de la production de la région, soit environ 1500 t pour 2500 ha cultivés, avec des rendements moyens voisins de $600 \mathrm{~kg} / \mathrm{ha}$. Dans cette zone de piémont, proche de la frontière togolaise, le fonio représente encore plus de $20 \%$ des surfaces cultivées, car il conserve une importance socioculturelle forte pour certains groupes ethniques somba, comme le peuple otammari. Même si, à l'instar du mil, du sorgho et du riz, le fonio représente, pour eux, une graine à consommation «masculine», on observe une très forte implication des femmes dans les opérations culturales et plus encore dans les opérations post-récolte.

Comme dans la plupart des zones de production, les producteurs du village de Kouya, proche de la frontière togolaise, reconnaissent utiliser trois types de variétés selon la durée de leur cycle de culture : une variété précoce appelée Kouatnanfa; une variété intermédiaire, Ipordawan; une variété tardive, Ipo n'kouani ou «fonio lépreux», difficile à décortiquer, mais qui donne un fonio bien blanc. Une autre variété, Ikantoni, extra-précoce, est moins fréquente. Ces différentes variétés, récoltées à des périodes différentes entre août et septembre, sont toujours stockées séparément. Le fonio, appelé «ipoaga» en langue ditamari, est en grande partie destiné à l'autoconsommation et reste, encore aujourd'hui, considéré comme une céréale de soudure. Loffre est, de ce fait, dispersée et relativement faible sur le marché car il n'y a pas de réels circuits de commercialisation.

\section{Le fonio dans le nord-ouest de la Côte d'Ivoire}

En Côte d'Ivoire, le fonio est essentiellement cultivé au nord-ouest du pays dans les régions d'Odienné, de Touba et de Tengrela, et aux confins de la Guinée et du Mali. Ces zones de savanes à climat tropical soudanien connaissent une seule saison des pluies de juin à octobre et sont soumises, entre décembre et février, à l'harmattan, vent sec et poussiéreux venant du Sahara. Ces régions sont essentiellement agricoles avec une prépondérance des cultures vivrières céréalières comme le maïs, le riz, le sorgho et le mil. Ligname est 
moins présente que dans les zones plus méridionales. L'anacarde et le coton sont les principales cultures de rente. Le fonio est une culture secondaire qui, en raison de sa rusticité et sa bonne adaptation aux sols pauvres, s'est maintenue au cours du temps malgré des rendements relativement faibles de 600 à $800 \mathrm{~kg} / \mathrm{ha}$. Les données sont souvent manquantes, mais la production nationale est généralement estimée à environ 14000 t pour 20000 ha. Le fonio est consommé sous la forme de tô, mais aussi de couscous à la sauce arachide ou encore cuit comme le riz au gras pour préparer le plat traditionnel appelé «fesro» (Aboua et al., 1989).

Historiquement, la première référence au fonio dans la région d'Odienné est faite par le voyageur René Caillé. Lorsqu'il quitte le village de Manégnan (aujourd'hui Maninian) et arrive le 26 juillet 1827 au village de Tangourouman, les habitants lui donnèrent à souper «un plat de foigné avec une sauce aux herbes». Puis, alors qu'il est obligé de séjourner à Timé (Tiéme) durant cinq mois pour se soigner, il note que le fonio est une nourriture courante des populations locales : «Les Mandingues de cette partie de l'Afrique [...] ont tout ce qui est nécessaire à la vie : ignames, maïs, riz, mil, foigné, haricots, giraumons et pistaches croissent en abondance dans cet heureux pays [...].»

Il précise que «le foigné, qui se sème dans le courant de mai, est récolté en juillet» et qu'il est consommé sous la forme de tô en donnant une description de sa transformation : "Les femmes prennent beaucoup de peine pour le nettoyer; elles exposent ce grain au soleil, puis elles le mettent dans un pilon, en séparant la paille, ce qui demande beaucoup de temps et de travail; ensuite, pour en extraire le son, elles se servent, comme au Sénégal, d'un layot; elles le pilent une seconde fois; et quand le grain est bien nettoyé il devient blanc et gros comme des grains de poudre à canon; alors elles le lavent puis le mettent dans une corbeille pour le faire égoutter, et le laissent reposer pour qu'il gonfle un peu; enfin elles le remettent de nouveau dans un mortier, et quelques coups de pilon suffisent pour le réduire en farine : s'il n'est pas humecté, il faudrait beaucoup plus de temps pour la trituration. C'est avec cette farine qu'ils font une bouillie qu'ils nomment tau [...]. Quand cette bouillie est cuite, on la met par cuillerée dans une calebasse, et on l'assaisonne d'une sauce faite de feuilles de giraumon et quantité d'autres herbes, de piment et enfin d'un peu de gombo pour la rendre gluante : cette sauce est toujours sans sel et sans beurre» (Caillé, 1830). 


\section{ID Le cas particulier du «fonio sauvage»}

Le «fonio sauvage» (Panicum laetum Kunth) vulgairement appelé «haze» ou «aze» (figure 3.8.) croît naturellement dans toute la zone sahélienne sur les sols limono-argileux des plaines, des dépressions ou des oueds temporairement arrosés par les pluies et les eaux de ruissellement. Les grains de fonio sauvage sont de forme ovoïde, mais plus gros et plus globuleux que ceux du fonio. En moyenne, leur longueur est de 2,2 mm et leur largeur de $1,4 \mathrm{~mm}$; le poids de 1000 grains est d'environ $2 \mathrm{~g}$. Les «balles» sont brillantes et cireuses (voir cahier de photos couleur).

\section{Les plaines à fonio sauvage dans le Gourma malien}

$\mathrm{Au}$ Mali, cette petite plante annuelle de 30 à $60 \mathrm{~cm}$ de hauteur crô̂t en abondance dans le Gourma, où elle forme de vastes prairies qui malheureusement se dégradent peu à peu à cause de sécheresses répétées. Le fonio sauvage sert de plante fourragère aux troupeaux, mais ses grains sont également récoltés pour servir de nourriture aux populations nomades, qui le considèrent comme une des meilleures petites céréales sauvages.

En 1991, Jens B. Aune donne une description de la récolte : «La récolte du fonio s'effectue en deux étapes. Dans un premier temps, la récolte est effectuée en balançant à la hauteur des inflorescences un panier spécialement conçu pour recueillir les grains détachés par le mouvement. Ensuite, lorsque les grains restés sont mûrs et tombent à terre, le sol est balayé après la fauche de la paille pour les récolter. Les grains mêlés à la terre sont ensuite épurés par vannage. Une partie non négligeable reste à terre et sert alors de semence pour l'année suivante. Au Gourma, la récolte peut commencer en août et durer jusqu'en novembre. Les grains sont importants pour l'alimentation de la population du Gourma et le surplus obtenu est vendu sur les marchés locaux.»

\section{Le fonio sauvage dans le Brakna mauritanien}

Une description de la récolte (figures 3.9. et 3.10.) et de l'utilisation du fonio sauvage est faite par l'explorateur René Caillé alors qu'il séjourne chez les Maures brakna, dans la région du lac d'Aleg (dans le Sahel mauritanien actuel) pour préparer son voyage à Tombouctou. Il décrit ainsi sa soirée du 6 septembre 1824: «On soupa fort tard, notre repas consista en sanglé, arrosé de lait doux. Ayant remarqué que les grains qui composaient ce mets étaient entiers, j'en demandai 

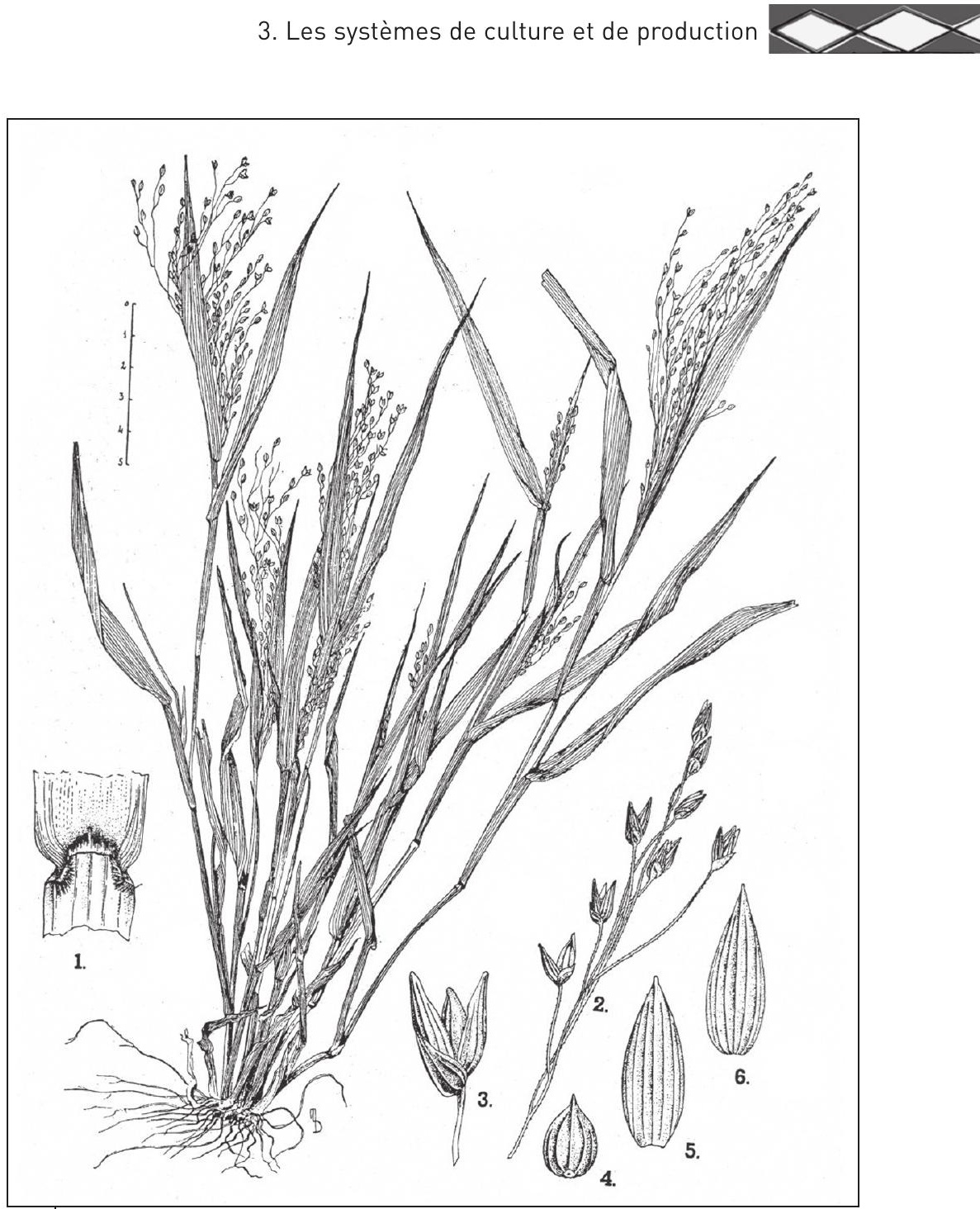

Figure 3.8.

Panicum laetum Kunth (Busson, 1965). 1. Ligule. - 2. Fragment de la panicule. 3. Épillet. - 4. Glume inférieure. - 5. Glume supérieure. - 6. Lemma.

le motif; on m'apprit que ce n'était pas du mil, mais du haze, et que dans cette saison les marabouts emploient leurs esclaves à le ramasser. Ce grain est très commun et croît naturellement, sans culture. On me montra des esclaves occupés à cette récolte : c'étaient des femmes, elles étaient munies d'un petit balai et de deux corbeilles; l'une de 
celles-ci, plus petite que l'autre, est de forme ovale, et surmontée d'une anse. Lorsque le haze est commun et qu'il n'a pas encore été foulé par les troupeaux, elles marchent en balançant cette corbeille à droite et à gauche, de manière à froisser sur les bords l'épi des graminées en le frappant; de cette manière les graines mûres cèdent et tombent au fond. Quand elles en ont une certaine quantité, elles la versent dans la grande, destinée à contenir la récolte. Cette méthode donne le grain beaucoup plus propre que la seconde, mais elle en donne moins abondamment, car on conçoit que tout le grain battu ne tombe pas dans la corbeille. Lorsque l'herbe a été foulée, ou qu'une première récolte a été faite comme je viens de le dire, elles coupent la plante avec un couteau dentelé qu'elles ont à cet effet, puis balaient le grain par terre, en font de petits tas qu'elles enlèvent ensuite. Et, comme par ce moyen il se trouve plus de terre que de grain, elles l'en séparent avec le layot, ce qui demande beaucoup de temps.» (Caillé, 1830)

René Caillé précise encore que la récolte d'une journée n'est que de «cinq livres» soit 2,5 kg.

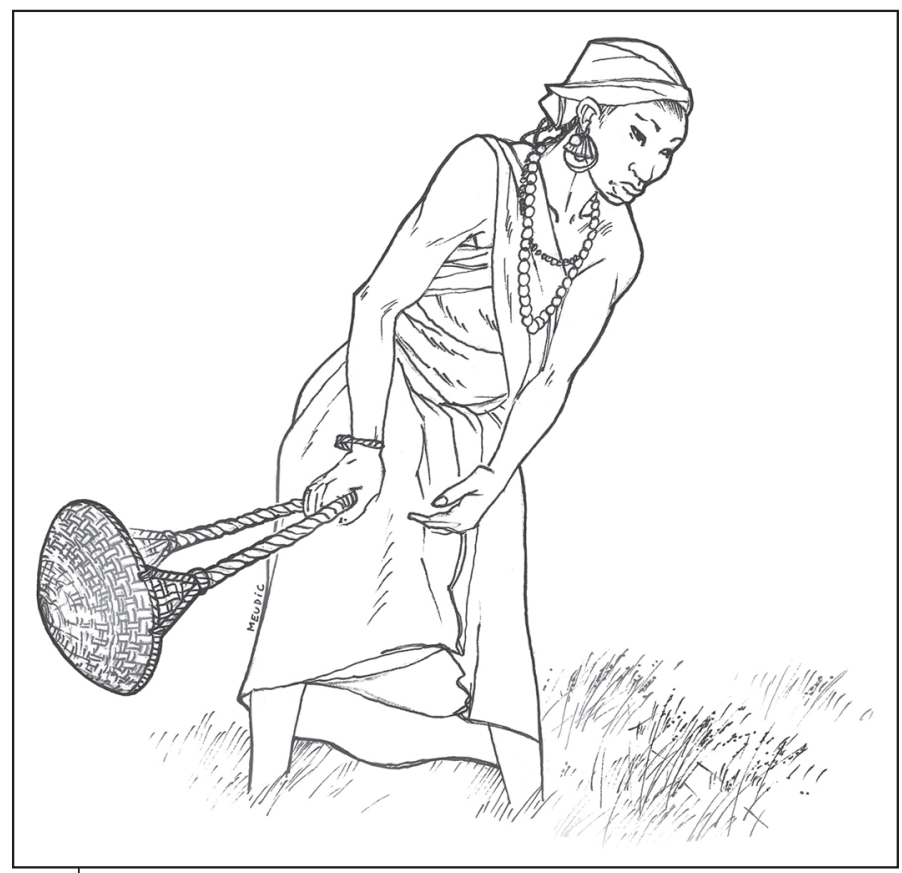

Figure 3.9.

Récolte du fonio sauvage (T. Meudic). 

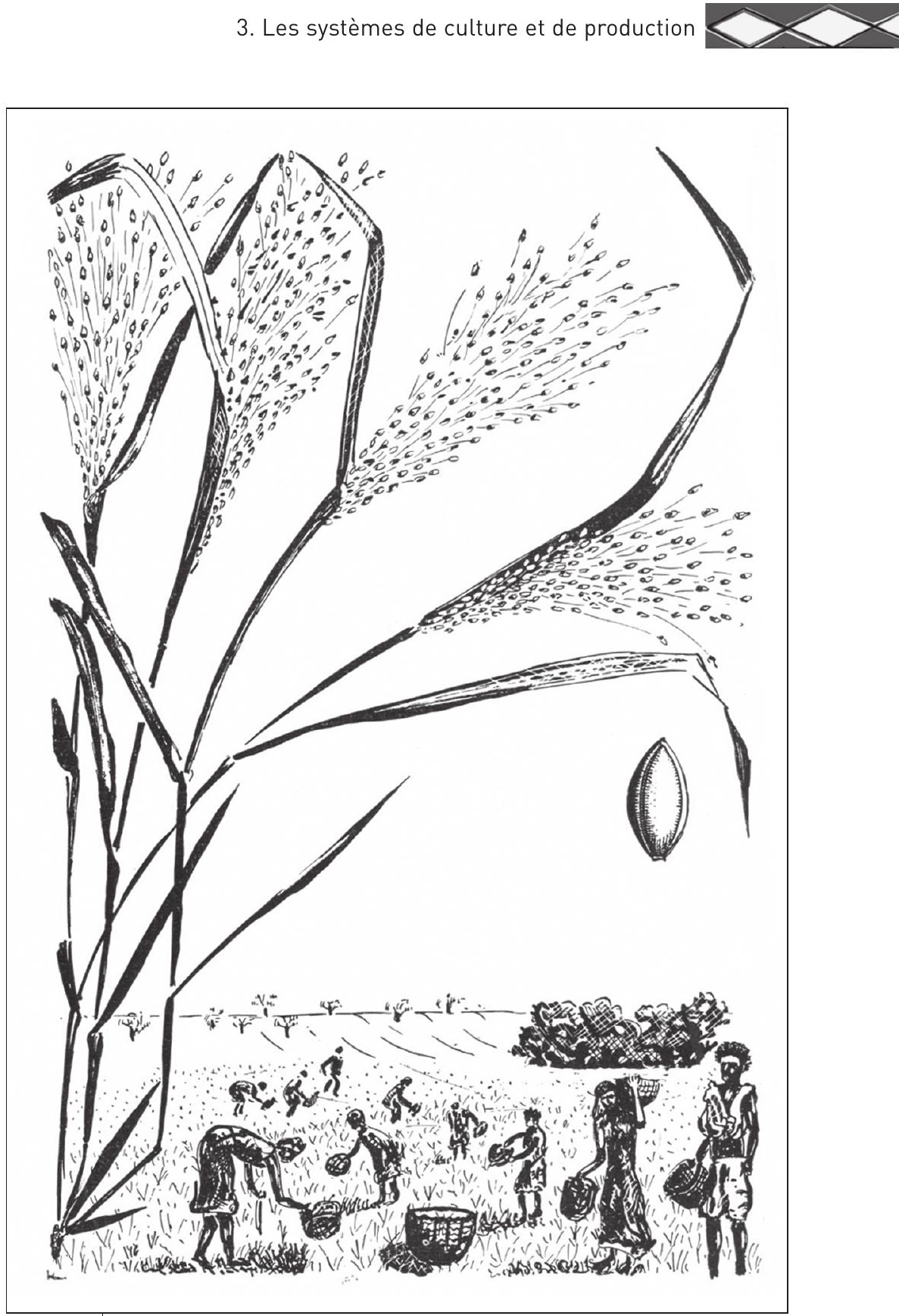

Figure 3.10.

Scène de récolte du aze et aspect de la plante

(Jacques-Félix, 1963 @ Publications scientifiques du MNHN, Paris).

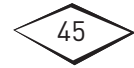




\section{Importance de la production}

D'après la FAO (Organisation des Nations unies pour l'alimentation et l'agriculture), la production de fonio en 2006 atteint $365000 \mathrm{t}$ pour une surface récoltée de 475000 ha. Le rendement moyen est voisin de $770 \mathrm{~kg} / \mathrm{ha}$, mais il peut parfois atteindre plus de $1 \mathrm{t} / \mathrm{ha}$ en Guinée, pays qui assure, à lui seul, plus de $60 \%$ de la production, et être inférieur à $500 \mathrm{~kg} / \mathrm{ha}$ dans certaines zones septentrionales du Burkina Faso ou du Mali. Les différentes productions par pays sont rappelées et complétées dans le tableau 3.4.

Tableau 3.4. Production de fonio par pays en 2006.

\begin{tabular}{lcc}
\hline Pays & Production (t) & Surface cultivée (ha) \\
\hline Guinée & 218000 & 190000 \\
\hline Nigeria & 95000 & 197000 \\
\hline Mali & 26500 & 50000 \\
\hline Côte d'Ivoire & 13500 & 19000 \\
\hline Burkina Faso & 7500 & 10000 \\
\hline Guinée Bissau & 2000 & 4500 \\
\hline Bénin & 1500 & 3000 \\
\hline Niger & 1000 & 1500 \\
\hline Total & 365000 & 475000
\end{tabular}

Source : Faostat (données arrondies).

Lévolution de la production au cours des quarante-cinq dernières années (figure 3.11.) montre une forte diminution des quantités produites (de 180000 à 130000 t) au cours des décennies 1960 et 1970, puis une reprise régulière à partir de 1980 . Les rendements restant relativement constants et proches de $700 \mathrm{~kg} / \mathrm{ha}$ sur toute la période, cette reprise de la production est due à l'extension des surfaces cultivées.

\section{Pratiques agricoles de production}

\section{ID Le fonio : produit de l'agriculture familiale}

Le fonio est cultivé par de nombreux petits producteurs pratiquant une agriculture familiale sur des surfaces de 0,5 à 1,5 ha. Dans certaines 

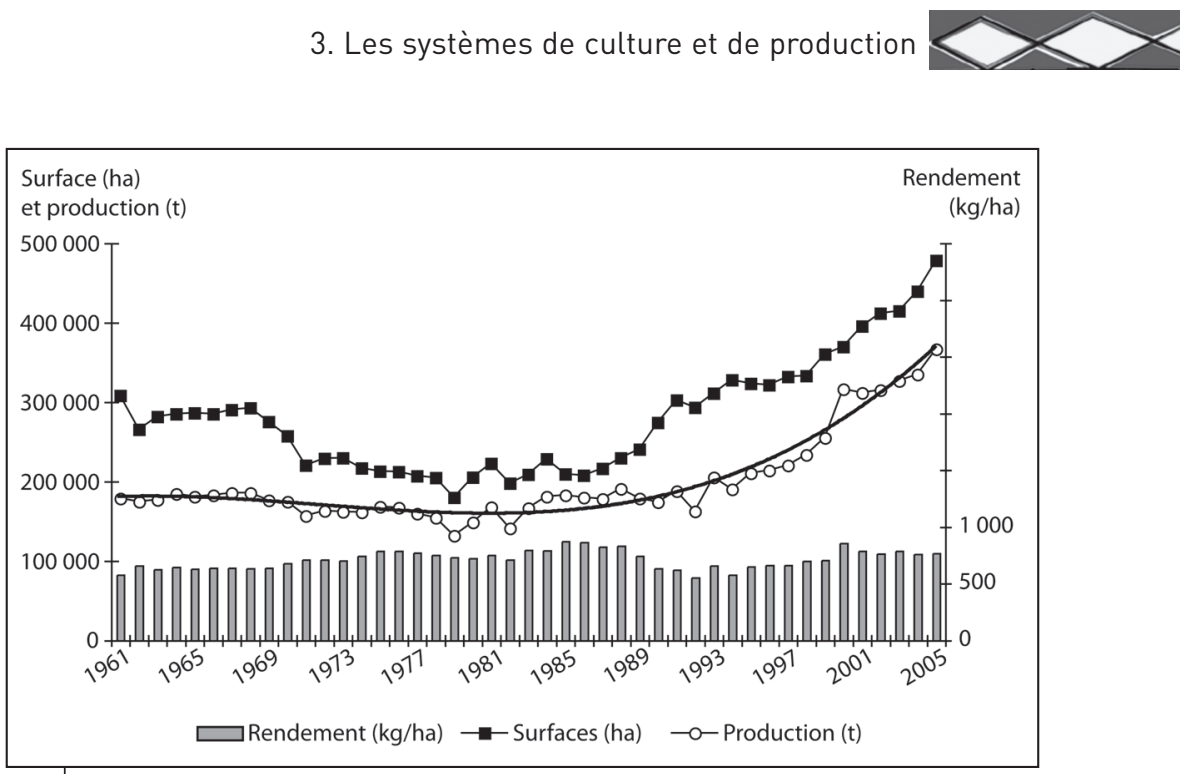

Figure 3.11.

Évolution de la production de fonio (d'après Cruz, 2011a).

régions, le fonio a été abandonné par les hommes pour devenir une culture typiquement féminine avec des surfaces réduites avoisinant 0,2 à 0,5 ha. Dans la plupart des zones de production, le fonio joue d'abord un rôle de céréale de soudure durant les mois les plus difficiles pour l'obtention de ressources alimentaires. Il a déjà été précisé qu'en utilisant des variétés ou écotypes à cycle court les producteurs peuvent subvenir aux besoins alimentaires de leur famille en attendant la récolte des autres céréales comme le mil, le sorgho, le maïs ou le riz. Les fonios plus tardifs sont conservés dans l'exploitation pour être consommés au cours de l'année, particulièrement à l'occasion de cérémonies ou de fêtes, ou pour être vendus selon les besoins monétaires des ménages (Cruz, 2009). Par leur longue pratique de la culture, les paysans ont abouti à l'obtention de nombreux cultivars locaux bien adaptés à leur environnement, contribuant ainsi au développement de la biodiversité (Niangado et Kebe, 2002).

La culture du fonio est encore aujourd'hui essentiellement manuelle avec un outillage simple (daba ou houe traditionnelle) pour la préparation du sol et une faucille pour la récolte. Nécessitant peu de technicité, la culture manuelle est bien maîtrisée par les paysans, mais elle est très souvent laborieuse et exigeante en temps. Dans certaines plaines et pour la préparation de parcelles de grande superficie, les paysans ont parfois recours à la culture attelée. 


\section{ID Le fonio dans la rotation des cultures}

La rotation des cultures est une méthode ancestrale qui permet de maintenir ou d'améliorer la fertilité des sols et de limiter la prolifération de certaines plantes adventices. Dans de nombreuses zones tropicales, la rotation culturale s'effectue sur plusieurs années, puis lorsque le sol est épuisé, il est alors laissé en friches. Selon les régions et la disponibilité en terres, les durées de jachère sont plus ou moins longues et peuvent varier de quelques années à plus de dix ou quinze ans. Aujourd'hui, dans certaines zones, la durée de la jachère tend à diminuer à cause de la pression démographique alors qu'elle peut s'accroître là où apparaît l'exode rural. Dans la région de Pita, en Guinée, certains «anciens» regrettent que la terre ne soit plus cultivée et sont unanimes pour reconnaître que les temps de repos de la terre augmentent : les champs sont défrichés tous les dix à quinze ans actuellement au lieu des sept à neuf ans dans le passé (André et Pestaña, 2002).

Le paysan choisit un assolement en fonction de ses besoins vivriers, de la qualité des terres dont il a la maîtrise et des revenus monétaires qu'il peut espérer de certaines cultures.

Dans la rotation des cultures, le fonio est le plus souvent semé après une légumineuse comme l'arachide et le niébé, ou encore une oléagineuse comme le sésame, en fin de rotation culturale.

Des exemples de rotation culturale ont déjà été donnés précédemment :

- Exemple 1 : riz pluvial, riz pluvial, arachide, fonio, jachère (zone de montagne en Guinée).

- Exemple 2 : riz pluvial, fonio, fonio, jachère (zone de plaine en Guinée).

- Exemple 3 : mil, fonio, mil, jachère (plaine du Séno au Mali).

Le fonio est rarement cultivé en tête, sauf parfois en zone de coteau en Guinée ou naturellement lorsqu'il s'agit d'une monoculture sur des sols pauvres, en plaine, hors des parcelles habituellement assolées.

En 1944, le géographe Jacques Richard-Molard donne quelques exemples de successions culturales sur différents types de sols en Moyenne Guinée : "À Tiri-Tara, près de Mali, 1400 m d'altitude, les bons dantaris boisés peuvent donner du fonio 7 ans consécutifs : le dantari herbeux, 3 ans seulement; les hansagnérés boisés 3 ou 4 ans; 
déboisés, un an seulement; puis jachère pour 7 ans sans qu'aucune autre culture soit possible. À Dandou, les meilleurs hansagnérés donnent 5 à 7 années de fonio, ce qui aboutit en fin de compte à des rendements lamentables. Sur le plateau de Labé où l'excès de population provoque une exploitation abusive, des dantaris sont ensemencés en fonio 10 ans de suite, pour arriver à ne plus fournir que $150 \mathrm{~kg} / \mathrm{ha}$, à peine deux fois la semence. À Timbi-Madina, l'on ne dépasse guère la $7^{\mathrm{e}}$ année. La moyenne s'établit entre 3 et 6 années quand le terrain n'est bon qu'au fonio. Puis jachère de 7 ans. Un hansagnéré riche porte un an du riz de montagne; l'année suivante, des arachides; on l'épuise par une ou deux récoltes de fonio; ensuite 7 ans de jachère. Un bon hollandé peut commencer par donner une, deux ou même trois récoltes de riz consécutives, ensuite une ou deux de fonio. Les hollandés pauvres sont laissés au fonio comme les dantaris. Larachide sur hansagnéré riche peut bénéficier de la $1^{\text {re }}$ année. Après quoi le fonio lui succède pour finir. Parfois l'arachide peut succéder au riz. On a alors une véritable suite de cultures : une année de riz de montagne; une d'arachides; une ou deux de fonio, puis 7 ans au moins de jachère. Il semble bien que l'arachide (comme le riz) ne succède jamais au fonio. Suivant la valeur du hansagnéré, on peut avoir par exemple 3 années d'arachides, puis une de fonio; ou 2 d'arachides, puis 2 de fonio; ou une d'arachides et 3 de fonio. Ainsi, c'est toujours le fonio qui termine, comme le manioc dans les contrées équatoriales, parce qu'il est le mieux adapté aux terres en voie d'épuisement, ce qui explique sa prédominance écrasante sur les hauts plateaux.»

Dans la plupart des situations, les paysans font tourner leurs cultures sur une parcelle jusqu'à ce qu'il y ait une forte apparition d'adventices comme le striga (Striga hermontica), qui représente un signe de fatigue du sol des parcelles cultivées. Les paysans installent alors une dernière année de fonio car il est réputé comme la seule culture qui peut encore pousser sur un sol épuisé. Mais, en général, les producteurs cherchent si possible à éviter les céréales comme précédent cultural pour minimiser la présence du striga dans les champs de fonio.

Le fonio est parfois cultivé en association avec d'autres plantes comme l'oseille de Guinée (Hibiscus sabdariffa L.) comme c'est le cas en Haute Guinée, au Mali et au Burkina Faso. Certains préconisent également le fonio comme un précédent à la culture du niébé, de l'arachide ou du sésame afin de limiter la prolifération de Macrophomina phaseolina, champignon responsable de la pourriture charbonneuse des racines de diverses cultures au Sahel mais 
qui n'attaque pas le fonio. Une étude récente a démontré que le développement de la pourriture charbonneuse peut être réduit significativement dans les parcelles infestées et les rendements de niébé améliorés en champ paysan par la rotation du niébé avec le fonio (Ndiaye et al., 2008).

\section{Les opérations préculturales : le nettoyage des parcelles et la préparation du sol}

Les principales opérations préculturales, généralement réalisées par les hommes et les enfants, sont le nettoyage des parcelles, puis le labour pratiqué surtout à la daba (houe locale illustrée en photo 3.1.) en grattage manuel sur les petites surfaces (figure 3.12.). Pour les parcelles de fonio plus importantes, le labour à la charrue tend à se développer car il est plus rapide et moins fatigant que la technique manuelle. Le labour est le plus souvent effectué en traction animale (bœufs, cheval), rarement avec un tracteur. Les unités de production qui ne disposent pas de matériel aratoire et d'animaux de trait, comme c'est souvent le cas des exploitations dirigées par les femmes, doivent alors faire appel à des prestataires de service, qui sont souvent d'autres producteurs (Vall et al., 2007). Cela entraîne parfois des retards dans la préparation des champs et représente dans tous les cas un poste de dépenses important qui peut atteindre $25 \%$ des dépenses totales par hectare.
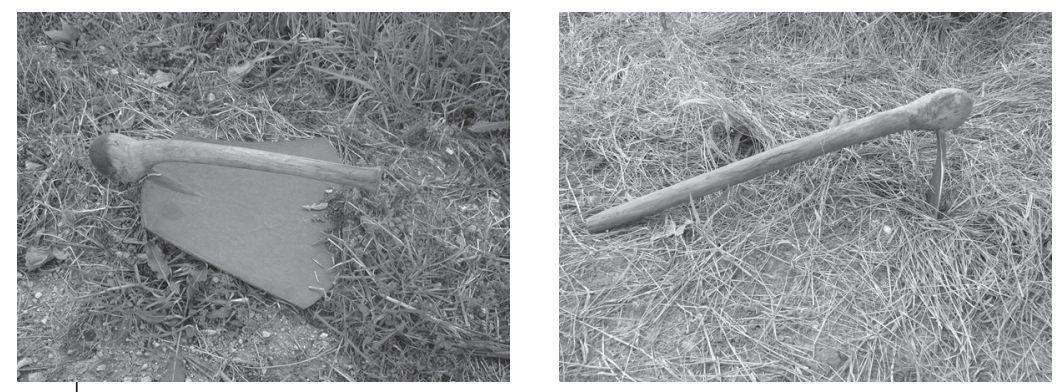

Photo 3.1.

Différentes daba du Mali et du Burkina Faso (๑ J.-F. Cruz).

En Guinée, les opérations préculturales varient selon les zones de culture. En zone de coteaux et en zone de montagne, on pratique, la première année, un défrichement puis un brûlis avant le semis alors qu'en sol de plaine, on procède à un labour suivi d'un hersage 
avec souvent l'utilisation de la culture attelée. Les défrichements sont effectués de février à mars en montagne et de mai à juin sur les coteaux. Dans la plaine de Timbi Madina au Fouta-Djalon, la culture attelée est quasiment entièrement réservée à la culture du fonio (figure 3.13.). Les cultures sur abattis-brûlis sont en général des cultures temporaires parfois qualifiées d'itinérantes (Mazoyer et Roudart, 1997) et sont souvent rendues responsables de la disparition de certaines forêts tropicales fragiles. Le fonio et le riz de montagne (ou riz pluvial) ont ainsi été accusés de dégrader le Fouta-Djalon (Sudres, 1947) et ont même été qualifiés de «lèpres qui rongent le pays» (Portères, 1955).
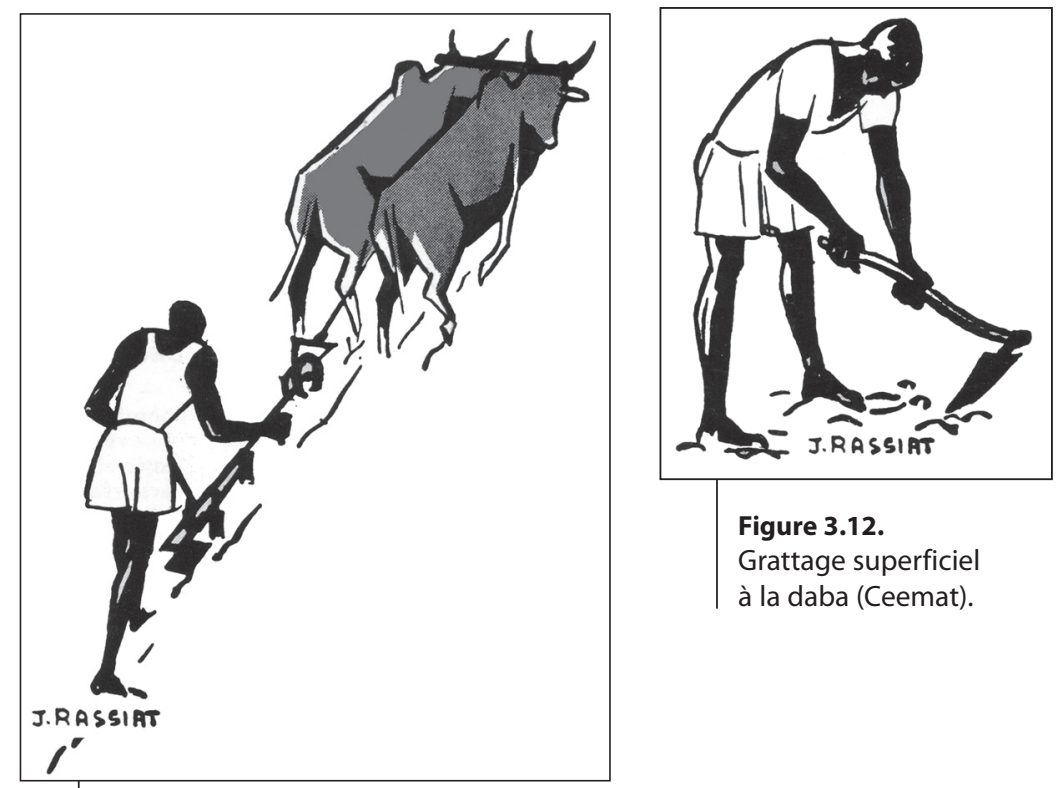

Figure 3.12.

Grattage superficiel à la daba (Ceemat).

Figure 3.13.

Labour à la charrue

(Ceemat).

\section{IID Les semis}

Aux premières pluies ou même avant, le semis est fait à la volée sur un sol superficiellement ameubli (figure 3.14.). Le champ est divisé en plusieurs bandes et le semis est souvent réalisé dans la même 
journée, immédiatement après le labour des champs ou reporté au lendemain matin lorsque le labour s'est achevé en fin de journée (Daho et al., 2007). Les semences utilisées sont des grains de fonio paddy de la récolte précédente prélevés parmi les meilleurs grains des meilleures parcelles. Elles sont conservées à part selon leur durée de cycle (variétés précoces, intermédiaires ou tardives) pour éviter les mélanges de variétés, qui conduiraient à des maturités décalées dans une même parcelle. Pour le semis à la volée, elles sont parfois mélangées à du sable ou à de la cendre pour favoriser une répartition plus homogène des semis.

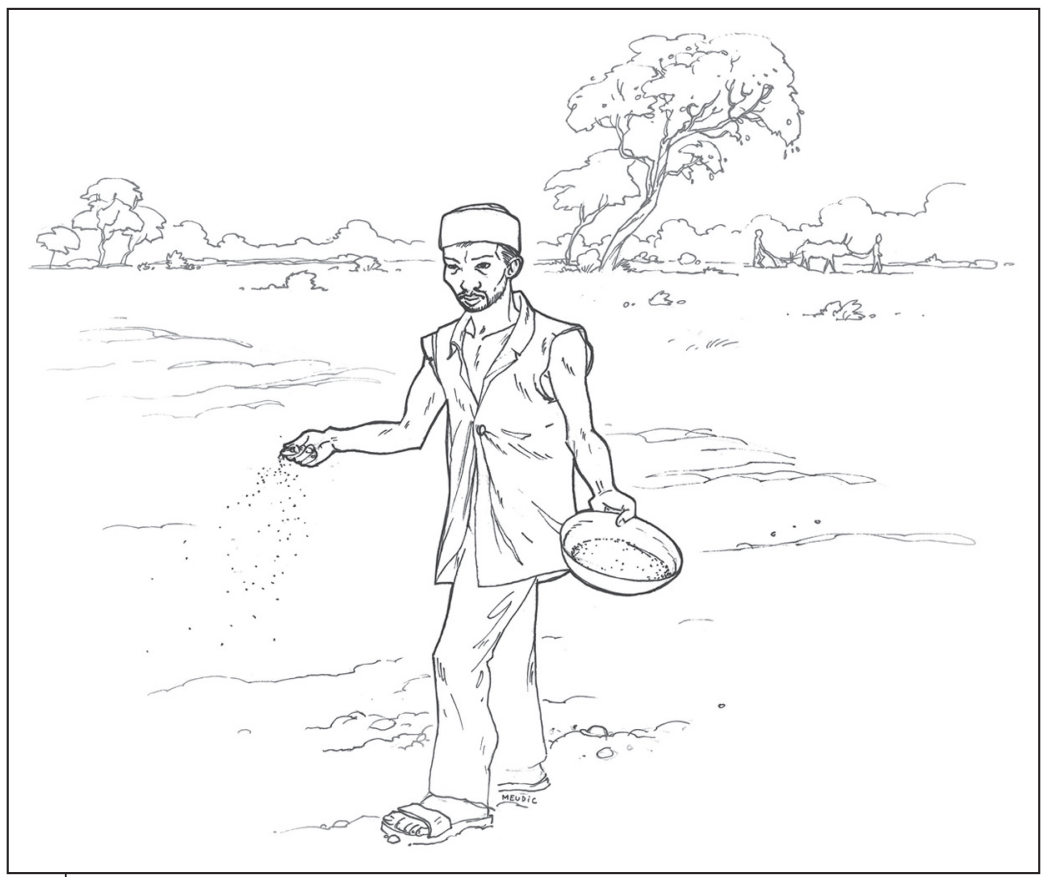

Figure 3.14.

Semis du fonio à la volée (T. Meudic).

Les dates de semis sont variables selon les zones agroécologiques et l'apparition des premières pluies ou selon les variétés semées. Elles peuvent être échelonnées de la mi-mai dans les zones méridionales à début juillet dans les zones semi-arides septentrionales. En zone humide montagneuse de Guinée, certains fonios sont parfois semés presque à la fin du mois de juillet. Selon les régions, les producteurs 
décident parfois de décaler les semis dans le temps afin de permettre un étalement des récoltes. L'époque des semis est même considérée par certains comme un critère de classement des variétés. Ils distinguent :

- les fonios à semis précoces réalisés sur terrains secs avant les premières pluies. Lorsque ces fonios sont également hâtifs, ils sont alors souvent considérés comme des fonios de soudure (ou «fonios de disette»);

- les fonios à semis mi-précoces réalisés au moment des premières pluies;

- les fonios à semis tardifs qui sont réalisés lorsque l'hivernage est bien installé entre fin juin et juillet.

En mai 1827, l'explorateur René Caillé, qui séjourne dans le village de Cambaya, proche de la rivière Tinkisso et de la ville actuelle de Dabola en Haute Guinée, donne une description de la culture du fonio : «Le sol de ces belles plaines se compose d'un sable gris très dur, et fertilisé par le débordement du Tankisso; les terres les plus élevées, privées de l'inondation, sont destinées aux cultures d'ignames, de cassaves, de maïs, de petit mil et du foigné, autre espèce de petite graminée que l'on cultive beaucoup. On sème le foigné dans le courant de mai, et on le récolte dans le mois de juillet, lorsque le riz n'est pas encore à quatre pouces au-dessus du sol : on peut en faire deux récoltes par année. Sans cette graminée qui croît avec beaucoup de rapidité, ce pays serait souvent exposé aux plus grandes disettes, car ces peuples ont l'habitude de ne semer que très juste ce qui leur est nécessaire : souvent même ils ne sèment point assez, alors ils ont recours au foigné. [...] Ils n'ont cependant qu'un seul instrument aratoire, c'est une pioche, fabriquée dans le pays; elle est longue de six pouces, et large de quatre; le manche, de dix huit à vingt pouces, est très incliné. Ils remuent la terre à un pied de profondeur pour les semences du riz, mais pour celles du foigné, ils ne prennent pas autant de précaution; ils ne font que couper les herbes et jettent le grain à la volée, avant que la terre soit préparée; puis en tirant les herbes, il se trouve couvert : ce sont les femmes qui sont chargées de cette opération assez simple. On ne prend même pas la peine, quand le foigné est levé, d'arracher les mauvaises herbes qui gênent sa croissance. Le riz est traité avec plus de précaution : on a soin de le sarcler, et de le dégager des mauvaises herbes, sans le transplanter.»

Les graines de fonio sont très petites. Pour cette raison, elles ne doivent être enfouies que très superficiellement. En 1955, Portères a 
montré qu'il existait une limite à la profondeur d'enfouissement avec un horizon létal se situant à $6 \mathrm{~cm}$ et un optimum théorique à $2 \mathrm{~cm}$ à une température de $30{ }^{\circ} \mathrm{C}$, qui apparaît comme la plus favorable pour la germination. Lorsque les champs ont été labourés à la main, le semis est naturellement superficiel et les graines sont ensuite légèrement enfouies par un rapide hersage à la main ou un léger binage à la daba ou en frottant des branchages sur le sol ensemencé. Un léger enfouissement est nécessaire également pour éviter que les graines ne soient consommées par les oiseaux ou pillées par les fourmis. Les quantités de semences utilisées sont de 30 à $40 \mathrm{~kg}$ par hectare. Sur les sols labourés à la charrue, la dose de semis utilisée peut être plus importante en considérant que certaines graines enfouies trop profondément ne vont pas germer correctement. Des doses de semis plus importantes (70 kg/ha ou plus) sont aussi utilisées par certains producteurs, qui souhaitent accroître la réussite de leur semis et limiter la prolifération des adventices.

Lidée d'un semis en ligne du fonio est régulièrement reprise par certains chercheurs. Mais elle n'est vraiment pas nouvelle car, dès 1905, L. Renoux et P. Dumas, deux agents de culture de l'AfriqueOccidentale française travaillant dans les vallées du Sénégal et du haut Niger, disent l'avoir pratiqué dans les stations agricoles en utilisant $18 \mathrm{~kg}$ de semences à l'hectare. Ils précisent que «l'usage du semoir a son intérêt quand il s'agit de grandes surfaces, quand les semences sont chères, ce qui a lieu à certaines époques de l'année. Les semences sont réparties plus uniformément. La végétation s'en fait mieux. Avec le semis à la volée, il se produit toujours des touffes qui se développent mal, restent jaunes et même périssent. Enfin, le semis en lignes distantes de 15 à $20 \mathrm{~cm}$ rend les sarclages faciles. On peut même les exécuter avec le cultivateur mécanique». Mais la mécanisation du semis demande de réfléchir, au préalable, aux différentes alternatives possibles en considérant leurs avantages et leurs inconvénients : semis à la volée mécanisé, semis en poquets avec un semoir monorang (figure 3.15.), semis en lignes continues, semis multirangs avec semoir de type maraîcher, etc.

\section{ID La germination et l'entretien de la culture}

$\mathrm{Au}$ moment des premières pluies, lorsque les graines rencontrent alors des conditions de température et d'humidité favorables, la germination a lieu rapidement en quelques jours. Les pluies ne doivent 

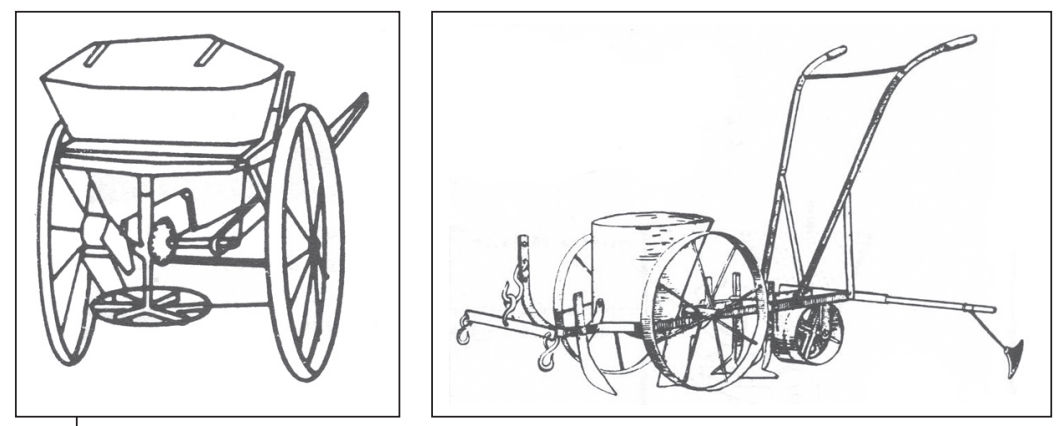

Figure 3.15.

Semoir «à la volée » et semoir monorang SuperÉco pour culture attelée (Ceemat, 1975).

cependant pas être trop violentes au risque de déplacer les graines ou de les enfouir trop profondément. En semis sur sol sec, les tornades sur sol poussiéreux en début d'hivernage peuvent entraîner les plus gros dégâts et obliger le producteur à semer à nouveau son champ. Pour la germination et la levée au champ, une température de $30^{\circ} \mathrm{C}$ semble un optimum. En 1905, L. Renoux et P. Dumas ont donné une première description de la germination du fonio : «En trois jours le cotylédon apparaitt; le champ revêt une teinte vert foncé. Très résistant à la sécheresse, le jeune plant ne périt pas, bien qu'une nouvelle pluie se fasse attendre huit et quinze jours. Les feuilles se recroquevillent, se dessèchent, mais dès que l'humidité reparaît, le plant repart à nouveau.» Cette capacité des jeunes plants de fonio à s'adapter aux sols pauvres et au caractère aléatoire des pluies en début d'hivernage, fait du fonio une des plantes les plus à même de résister aux changements climatiques et à la sécheresse.

En 1955, R. Portères a également décrit la germination et le développement des plantules (figure 3.16.) :

1. «La germination du fonio est très rapide et la faculté germinative se conserve facilement pendant 2 ans. La radicule émerge d'abord, puis vient le coléoptile mais l'écart des vitesses de croissance est tout de suite tel qu'on a souvent l'impression que le coléoptile est sorti le premier. La radicule prend assez tardivement des poils absorbants et ne présente pas à son extrémité une forme en massue, comme cela s'observe généralement chez les Panicées. »

2. «La préfeuille qui se développe perce l'extrémité du coléoptile avant ramification de la racine.» «La préfeuille, verte, à marges pourprées 
dans beaucoup de races, rarement bronzée, est toujours poilue dans le fonio (toujours glabre dans l'Iburu); d'abord roulée en cornet et encapuchonnée par le coléoptile, elle se déploie progressivement pour s'étaler ensuite longuement comme dans toutes les Panicées [...].»

3. «La première racine de collet (racine mésocotyle) naît généralement lors de la nutation de la première feuille vraie en même temps que la racine primaire se ramifie. [...] Contrairement à ce qui se passe dans Eleusine coracana, par exemple, la tigelle n'a pas un développement plus rapide par rapport au système radiculaire. Il s'établit ainsi un équilibre entre les organes, lequel favorise le départ de la végétation du fonio dans les sols pauvres et très légers.»

4. «Toutes les feuilles qui suivent la préfeuille s'étagent en position distique; la préfeuille est à $180^{\circ}$ de la première feuille [...].»

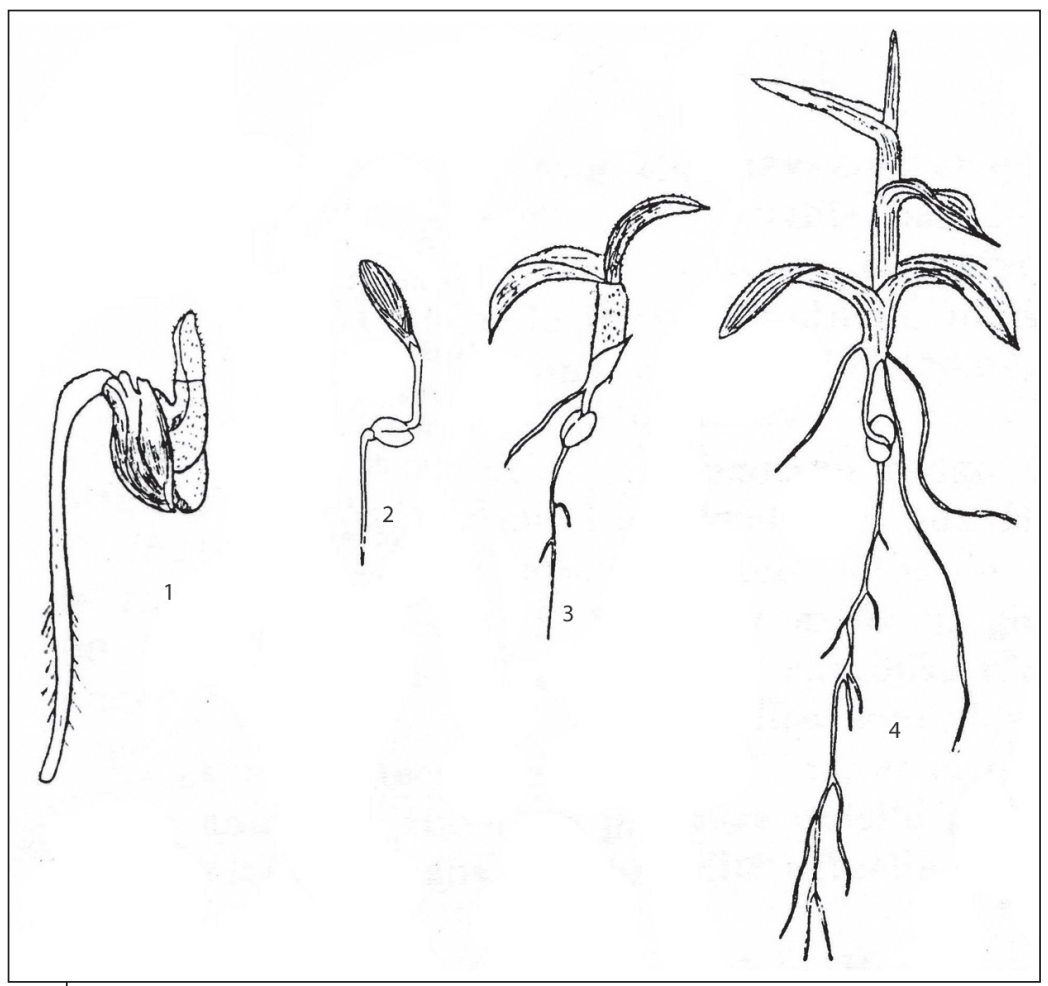

Figure 3.16.

Germination et développement de la plantule de fonio (d'après Portères, 1955). 
En début de germination, la jeune pousse puise une part importante de ses besoins dans la graine, puis la plante devient ensuite totalement autonome. À l'instar de nombreuses graminées d'origine tropicale et aride, le fonio réalise une photosynthèse dite «en $\mathrm{C} 4$ » lui permettant un taux de production de matière sèche élevé par rapport aux quantités d'eau absorbées. La photosynthèse est optimale même lorsque les plantes maintiennent un faible degré d'ouverture de leurs stomates, ce qui réduit les pertes d'eau par la transpiration.

Bien que le fonio soit très rustique et ne nécessite que peu d'interventions au cours de sa culture, il est bon d'éliminer les mauvaises herbes si l'on souhaite obtenir un rendement intéressant (Vall et al., 2008a). Un premier désherbage est souvent réalisé après quatre à sept semaines de végétation. S'il est réalisé précocement, soit une semaine à quinze jours après le semis, il peut avoir une répercussion très favorable sur les rendements à la récolte dans la mesure où il permet de limiter la concurrence entre les plants de fonio et les adventices. Ce sarclage, qui consiste à arracher les mauvaises herbes à la main, est une opération délicate qui nécessite un savoir-faire particulier pour distinguer correctement les jeunes pousses de fonio des adventices. Cette opération fastidieuse est généralement réalisée par les femmes, les enfants ou les personnes âgées, ou plus rarement par une main-d'œuvre extérieure. Le désherbage mobilise une quantité de main-d'œuvre relativement importante. Les temps de travaux de désherbage varient de 6 hommesjours par hectare en zone semi-aride à 16 hommes-jours par hectare en zone subhumide, où la pousse des mauvaises herbes est habituellement plus importante (Daho et al., 2007). Pour bien séparer le fonio d'autres graminées, il est souvent nécessaire d'attendre jusqu'à la floraison et un deuxième désherbage s'avère alors indispensable. $\mathrm{Si}$, par manque de temps ou de main-d'œuvre, les sarclages ne sont pas réalisés, les rendements s'en trouvent affectés et les semences récupérées à la récolte risquent d'être polluées par les graines de diverses adventices.

Il a déjà été rappelé que le striga (Striga hermonthica) constituait un des principaux ennemis du fonio poussant sur des sols épuisés. Cette plante parasite de nombreuses autres graminées comme le riz pluvial, le maïs, le mil ou le sorgho.

Les opérations de désherbage sont souvent les seules opérations d'entretien des cultures de fonio; ce qui fait dire à de nombreux producteurs que le fonio est une culture «facile». Au cours de la végétation les champs de fonio vont prendre différentes teintes : vert sombre puis vert tendre. Enfin, lorsque les grains arrivent à maturité, les teintes 
virent au jaune, au rouge ou au brun selon les variétés semées et en fonction de la pigmentation des tiges ou des épis. Renoux et Dumas (1905) parlent d'une variété Bérélé oulé à glumes très rouges qui, à maturité, donnent au champ un aspect rouillé.

\section{Le striga}

Dans leur ouvrage sur le sorgho, Chantereau et Nicou (1991) donnent une description de cette plante parasite :

«Le genre Striga renferme une trentaine d'espèces, dont 23 sont présentes en Afrique où elles occupent le terrain de façon très diversifiée [...].

La durée du cycle biologique du striga depuis la germination jusqu'à la production de graines est comprise entre 90 et 120 jours. On peut distinguer quatre stades phénologiques : la germination, la fixation sur l'hôte, la pénétration et la floraison-fructification. Les trois premiers ont lieu sous la surface du sol, le dernier est aérien.

Les graines de striga, très petites, sont produites en grande quantité (40 000 graines par plante) et leur longévité peut atteindre quinze à vingt ans. Leur dissémination dans le milieu se fait par l'eau et par le vent. La dormance est comprise entre deux et six mois, ce qui correspond à la saison sèche des pays à climat tropical semi-aride. Au début de la saison de culture, les grains s'imbibent d'eau (phase de préconditionnement), les grains ont alors besoin d'un stimulant de la germination produit par la plante-hôte [...]. Sous l'effet de cette stimulation, la graine émet une radicule qui se dirige vers la racine par chimiotropisme. Un renflement apparaît sur la radicule (création de l'haustorium) organe de pénétration du parasite dans l'hôte. Au niveau de la graine de striga se développe un tubercule à partir duquel des racines apparaissent $[\ldots]$.

Dans les zones sahéliennes où la période de semis se situe vers juin, le striga émerge courant août. La floraison et la fructification débutent à la mi-septembre et peuvent se poursuivre jusqu'à la fin octobre [...].

En matière de lutte curative, l'arrachage avant floraison des strigas et le brûlage sont des moyens efficaces.»

En culture, le fonio est sujet à peu de déprédations même si quelques paysans déplorent parfois l'attaque de certains insectes (espèce de cantharides), d'oiseaux ou de mammifères (phacochères). Le fonio peut ainsi faire l'objet d'une courte surveillance contre les oiseaux durant les premiers jours après le semis ou juste avant la récolte.

Les producteurs n'utilisent aucun produit de lutte chimique et aucun intrant. En Moyenne Guinée, certains paysans qui travaillent chaque année les mêmes parcelles pour la culture du fonio font parfois un 
apport d'engrais de type NPK mais cela est relativement rare. Au besoin, des recherches récentes ont montré qu'il était sans doute préférable de fournir des apports modérés d'engrais par un précédent cultural de type légumineuses ou par l'apport de fumier (Gigou et al., 2009). Par rapport à de nombreuses autres productions, le fonio, qui dans la plupart des régions ne reçoit ni engrais ni pesticides, a ainsi l'avantage d'être une culture «biologique» qui peut être valorisée comme telle.

\section{ID La floraison et la reproduction}

Une plante, et plus précisément une variété, est caractérisée par la durée de son cycle végétatif qui, décomposé en périodes de végétation, illustre les différents stades de développement. On peut ainsi distinguer plusieurs phases : installation, initiation paniculaire, floraison et maturation. En zone soudano-sahélienne, de nombreuses variétés de céréales dites «traditionnelles» comme le mil ou le sorgho expriment une photosensibilité vis-à-vis de la durée du jour et sont qualifiées de «photopériodiques». Selon le type de variétés, la date de floraison est relativement fixe quelle que soit la date de semis-levée. «Les plantes s'attendent pour fleurir ensemble.» Les recherches conduites au Mali par le Cirad et l'IER (Institut d'économie rurale) ont montré que le fonio était également une céréale photopériodique apte à réguler la durée des phases de végétation en fonction de la précocité de la date de semis. Comme la plupart des plantes tropicales, le fonio fleurit plutôt en «jours courts».

Linflorescence du fonio a été décrite par Portères (1955). Elle est composée le plus souvent de deux ou trois racèmes. Les racèmes portent les épillets très imbriqués et groupés par deux, trois ou quatre sur des pédicelles. Lépillet avec glumes comprend une fleur inférieure stérile et une fleur supérieure fertile avec glumelles. La fleur supérieure comprend trois étamines à filets blancs ou pourprés et des anthères jaunes ou jaunes pigmentées de pourpre. Lovaire supère possède deux stigmates plumeux de blanc à rose jusqu'à pourpre foncé suivant les variétés.

De nombreux auteurs ont longtemps affirmé que le fonio était allogame et que c'était grâce à cette pollinisation croisée (ou interfécondation) que le fonio conservait une diversité génétique relativement élevée (Vodouhè et Achigan Dako, 2006). Très récemment, une équipe 
de chercheurs du Bénin et d'Allemagne a indiqué que le fonio se reproduisait principalement par apomixie avec un peu d'autogamie (Adoukonou-Sagbadja et al., 2007). L'apomixie est une particularité génétique que possèdent certaines plantes sauvages, comme le pissenlit, de produire des graines sans véritable fécondation (donc sans méiose ou séparation des chromosomes ni fécondation ou mélange des chromosomes). Les graines qui en résultent sont en quelque sorte des clones de la plante mère. Ces premiers résultats, obtenus en 2010, méritent d'être confirmés.

\section{Génétique du fonio}

La ploïdie du fonio est longtemps restée confuse. Au xxe siècle, on considérait que Digitaria exilis comportait : $2 \mathrm{n}=54$ chromosomes (Purseglove, 1985; NRC, 1996).

En retenant un nombre de base des chromosomes de $\mathrm{x}=9$ comme pour d'autres Panicées, plusieurs auteurs ont conclu que le fonio était hexaploïde avec $2 n=6 x=54$ (Portères, 1955; Haq et Dania Ogbe, 1995). Mais certains ont suggéré que le fonio pouvait être diploïde $(2 \mathrm{n}=2 \mathrm{x}=18)$ ou tétraploïde $(2 \mathrm{n}=4 \mathrm{x}=36)$ (Baudet, 1981).

Des recherches récentes réalisées en 2006 sur 94 variétés d'Afrique de l'Ouest ont conclu que le fonio était tétraploïde, même si la diploïdie ou l'hexaploïdie pouvait exister, mais avec une occurrence relativement faible (Adoukonou-Sagbadja et al., 2007). 


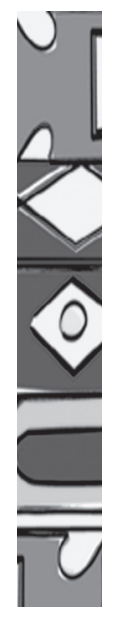

\section{La récolte et l'après-récolte}

\section{Récolte manuelle}

La récolte est réalisée dès que les grains arrivent à maturité et dès les mois de juillet et août pour certaines variétés précoces. La récolte des fonios hâtifs est un moment très attendu par les populations locales dont les réserves alimentaires sont épuisées à cette période de l'hivernage.

En 1905, L. Renoux et P. Dumas ont décrit cette période : «Le moment de la récolte des premiers fonios est le plus actif de l'hivernage. Les pluies sont torrentielles et à peu près journalières. Les cours d'eau envahissent progressivement les terres riveraines. Lindigène, qui a épuisé ses greniers, va tous les jours à son lougan voir s'il peut moissonner [...]. Il est enfin mûr. Entre deux averses, alors qu'un faible soleil a un peu ressuyé le champ et en permet l'accès aux moissonneurs, le propriétaire aidé de toute la famille procède à la récolte. Il coupe à la faucille; puis assemble les tiges en petites bottes de deux à trois kilos qu'il laisse sur le sol quelques heures, si le temps le permet. Enfin il rentre les abriter sous un hangar ou dans une case. Il faut manipuler le fonio avec précautions. Quand il est sec surtout, les grains tombent avec une extrême facilité. Le moissonneur doit toujours opérer sous une certaine humidité.»

Aujourd'hui encore, la moisson est restée exclusivement manuelle. Elle est faite à la faucille (figure 4.1.) par les hommes d'une même famille ou par des groupes d'entraide qui vont, tour à tour, sur les champs des différents membres du groupe. Les femmes qui dirigent les exploitations doivent souvent faire appel à du personnel en prestation de service. Lopération de fauchage est très exigeante en main-d'œuvre et nécessite, en général, de 20 à 30 hommes-jours par hectare. Les faucheurs se répartissent des bandes de travail sur chaque parcelle et ils progressent ainsi de front avec un léger décalage pour éviter tout oubli de fauche ou tout risque d'accident (figure 4.2.). Le fauchage nécessite un réel savoir-faire car, à maturité, les plants de fonio sont généralement très versés et la plupart des tiges sont couchées sur le sol. 
Le faucheur qui progresse dans le sens de la verse doit alors relever les tiges avant de les sectionner. Les tiges coupées sont ensuite assemblées par les femmes et les enfants en petites gerbes de 1 à $3 \mathrm{~kg}$ qui sont regroupées en bottes, puis transportées dans des corbeilles et mises à l'abri près des habitations pour les protéger des pluies. Durant cette période de l'hivernage où l'atmosphère est particulièrement humide, les bottes doivent alors être correctement aérées pour éviter tout risque d'échauffement et de développement des moisissures.

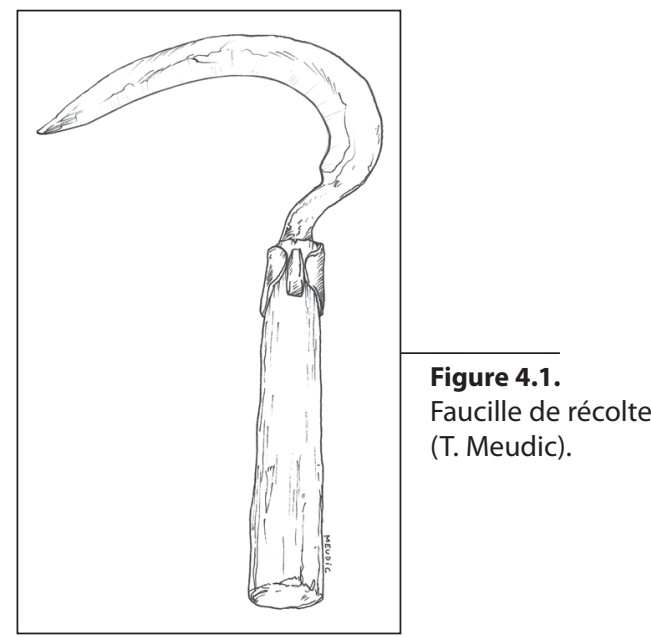

En 1940, D. Paulme a décrit la moisson du fonio chez les Dogon au Mali. C'est la seule période durant laquelle les hommes et les femmes, pour stimuler leur effort et atténuer leur fatigue, peuvent se permettre des moqueries et des chants osés, hors des règles habituelles de politesse et de bonne éducation. «La récolte du fonio, à la différence de celle du mil, se fait en commun : lorsqu'un de ses membres doit moissonner, tout le quartier, togu, vient l'aider. On respecte l'ordre d'âge des différents propriétaires, les champs du doyen sont moissonnés avant ceux de son cadet. L'homme chez qui on travaille nourrit les moissonneurs. Ceux-ci sont venus de bonne heure, mais le soleil est déjà haut lorsque les jeunes filles apportent le repas qu'elles ont préparé au village : bouillie de mil et poissons cuits au beurre de karité; le tout arrosé de larges rasades d'une eau où ont macéré des fruits de pegu. Le travail reprend après une courte sieste : les hommes coupent à la faucille les tiges, que les femmes, marchant sur leurs pas, ramassent et empilent. En dépit de l'effort qu'ils fournissent alors, les indigènes semblent tous considérer la moisson du fonio comme un des 


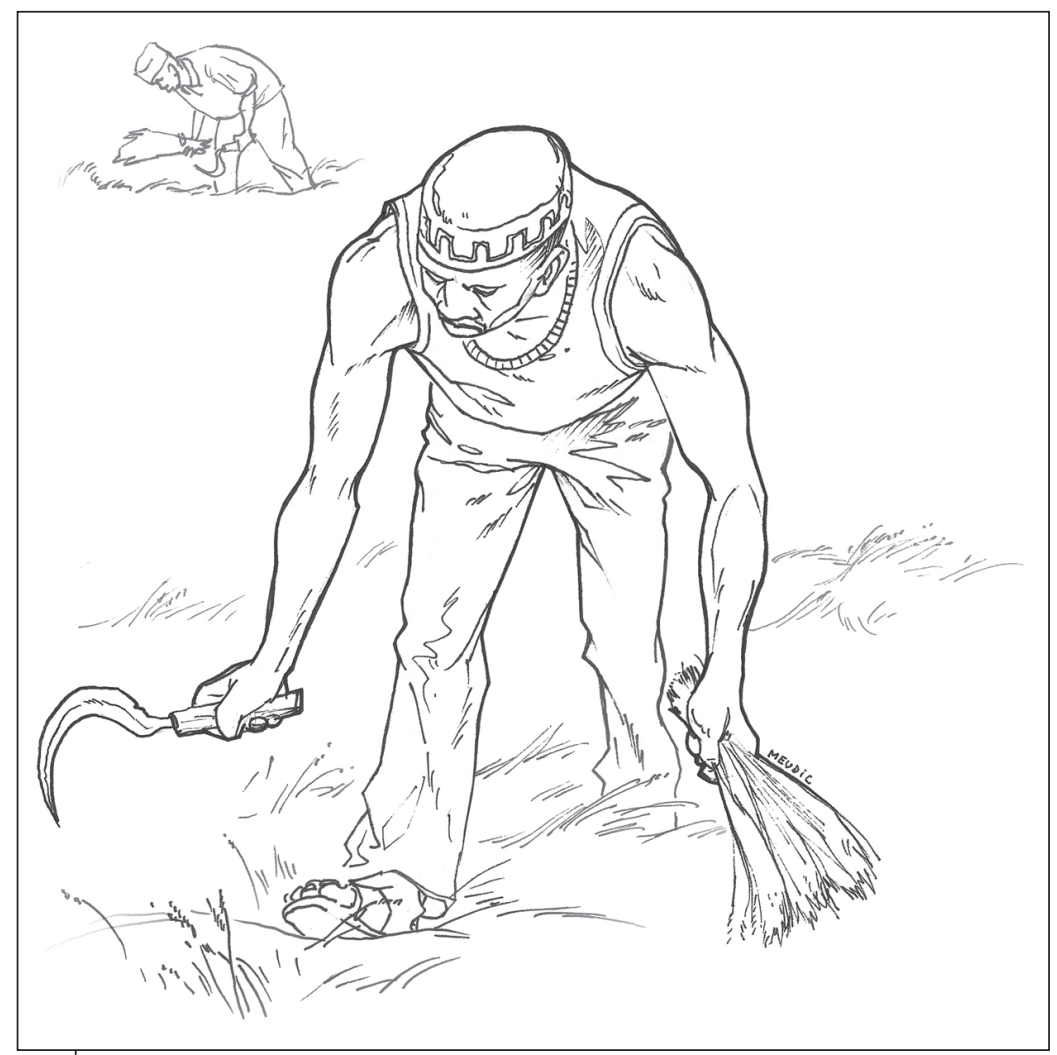

Figure 4.2.

Récolte manuelle du fonio (T. Meudic).

moments les plus attrayants de l'année; ils l'attendent avec une impatience bien compréhensible et en parlent encore longtemps après... Il existe même des chansons d'une franche obscénité, dites "pô ga ni", littéralement "chansons pour la moisson du fonio", que l'on ne peut chanter qu'en cette seule occasion.»

Dans les zones semi-arides et subhumides, la grande période de récolte du fonio correspond à la fin de l'hivernage entre mi-septembre et mioctobre, alors que, dans des zones plus humides du Fouta-Djalon, la récolte des fonios tardifs peut même durer jusqu'à fin novembre. À ces périodes de l'année, les pluies sont de plus en plus rares en rentrant progressivement dans la saison sèche; les gerbes récoltées demandent alors moins de précaution et peuvent être laissées au champ. 


\section{Hauteur de fauche}

Selon les zones, les hauteurs de fauche peuvent varier en fonction de l'utilisation ou non des pailles de fonio. Si l'on souhaite diminuer les charges de transport et réduire les efforts au battage, alors les tiges de fonio sont fauchées au tiers supérieur. Cela permet ainsi de laisser l'essentiel des pailles sur le champ qui pourront alors être broutées ou réintégrées au sol à l'occasion d'un prochain labour. À l'inverse, la fauche est effectuée au plus proche du sol lorsque l'on souhaite utiliser les pailles comme fourrage ou comme matériau, ou encore pour obtenir de la potasse après brûlage comme c'est le cas chez certaines productrices.

Des enquêtes réalisées au Mali et au Burkina Faso montrent que les opinions des paysans divergent sur la capacité du fonio à régénérer la fertilité des terres. Certains producteurs très croyants attribuent aux pouvoirs divins la capacité de fertilisation des sols par le fonio et d'autres considèrent que c'est le vent, les eaux de pluie, le piétinement des hommes et des animaux et la présence de termites sur les chaumes de fonio après la récolte qui améliorent la fertilité d'un champ de fonio (Daho et al., 2007).

Lefficience du fauchage pourrait être améliorée en utilisant des faux ou des motofaucheuses. Dès 1905, L. Renoux et P. Dumas, qui avaient envisagé la faux pour la récolte des fonios, précisent : «La faucille, avons-nous dit, est seule pratique avec les variétés qui se couchent complètement sur le sol. Mais la faux, que nous avons employée dans les stations agricoles, est bien plus avantageuse pour les fonios qui se maintiennent un peu dressés, à la condition de faucher sous la rosée pour ne pas perdre trop de grains.»

Plus tard, en 1929, à l'occasion d'une mission réalisée en Guinée, le professeur Émile Perrot, précise que quelques essais de faucheuses à riz ont été réalisés avec succès à Timbi-Touni au Fouta-Djalon, et qu'elles ont également pu être utilisées sur le fonio. Son rapport présente notamment une illustration du fauchage mécanique du fonio avec une lame de coupe à traction animale comparable à celle qui est montrée en figure 4.3.

Mais cette technique de fauche ne s'est apparemment pas développée. Le travail était sans doute épuisant pour les animaux et la verse du fonio ne facilite pas la fauche mécanique. Aujourd'hui, de nombreux spécialistes considèrent qu'en matière de récolte l'emploi de la traction animale se limite au soulevage des arachides et ne se prête pas à la moisson des céréales. La faucheuse à traction animale, à barre de coupe intermédiaire (largeur de 1,07 à 1,27 m) et entraînement du mécanisme par la roue, conçue pour la récolte des fourrages dans les 
La plante et le grain
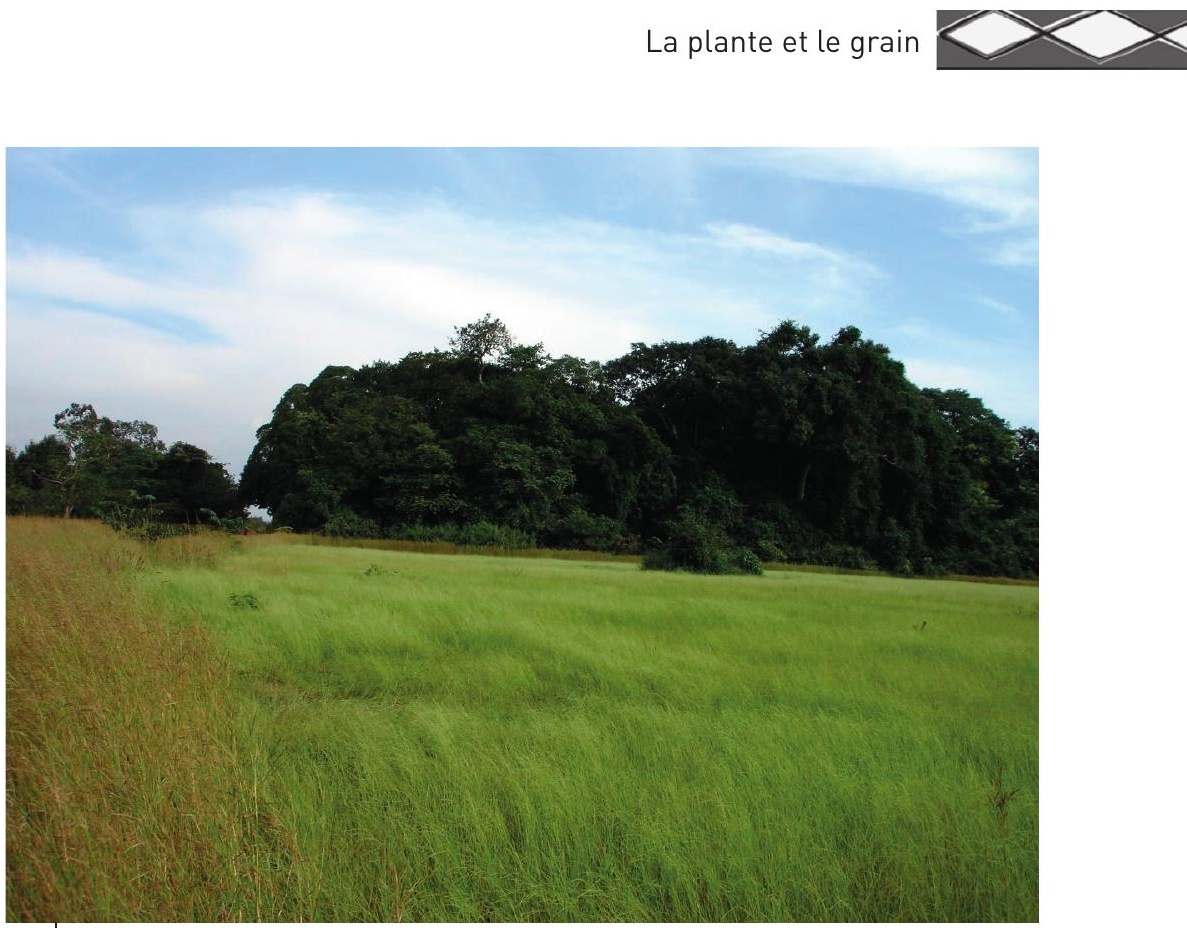

Champ de fonio au Fouta-Djalon en Guinée (๔ J.-F. Cruz).

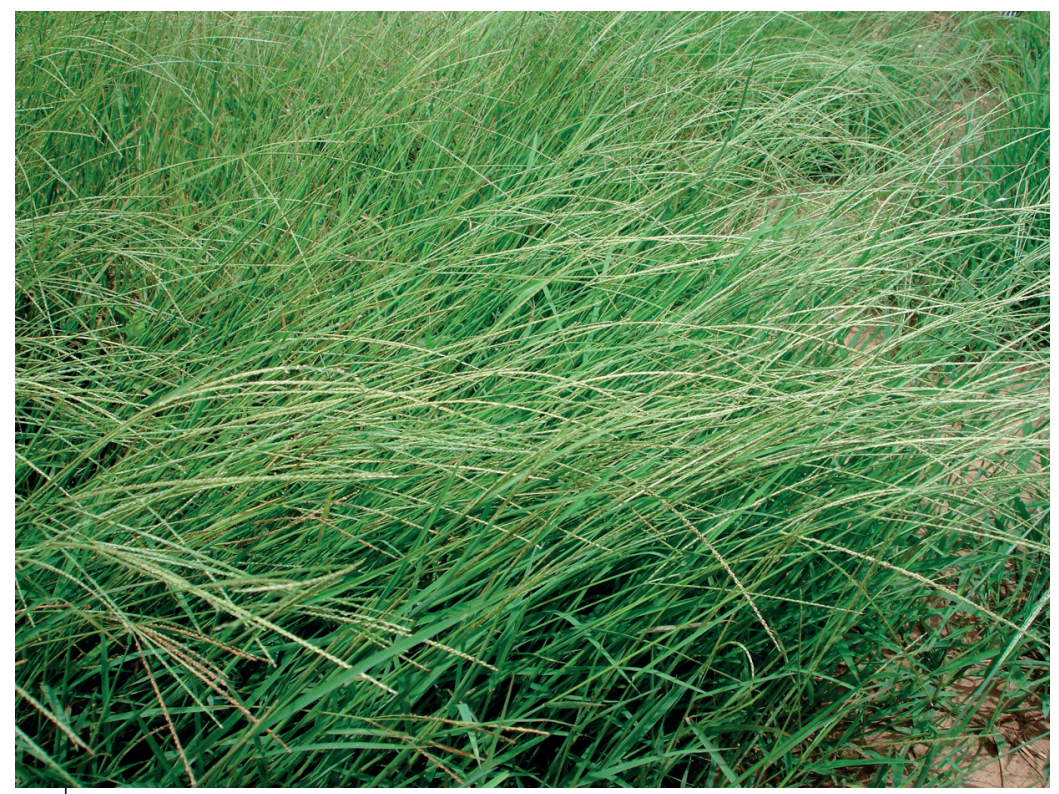

Plants de fonio (๑ J.-F. Cruz). 


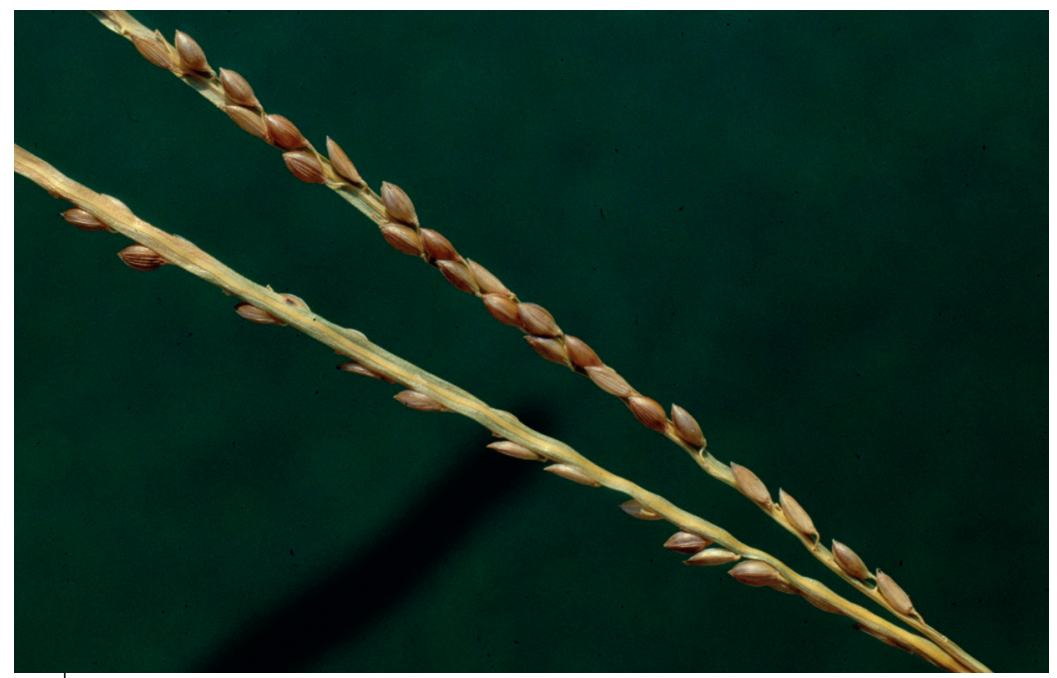

Racèmes de fonio (@ J.-F. Cruz).

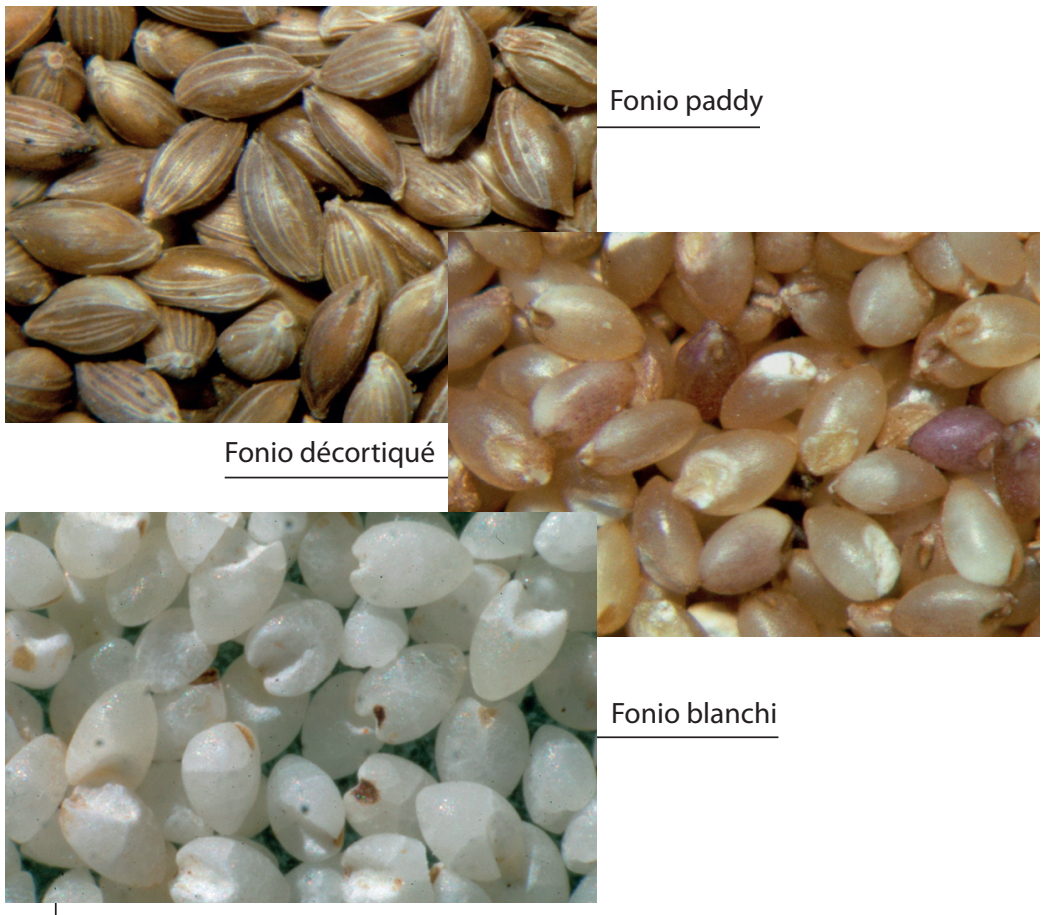

Grains de fonio (๑ J.-F. Cruz). 

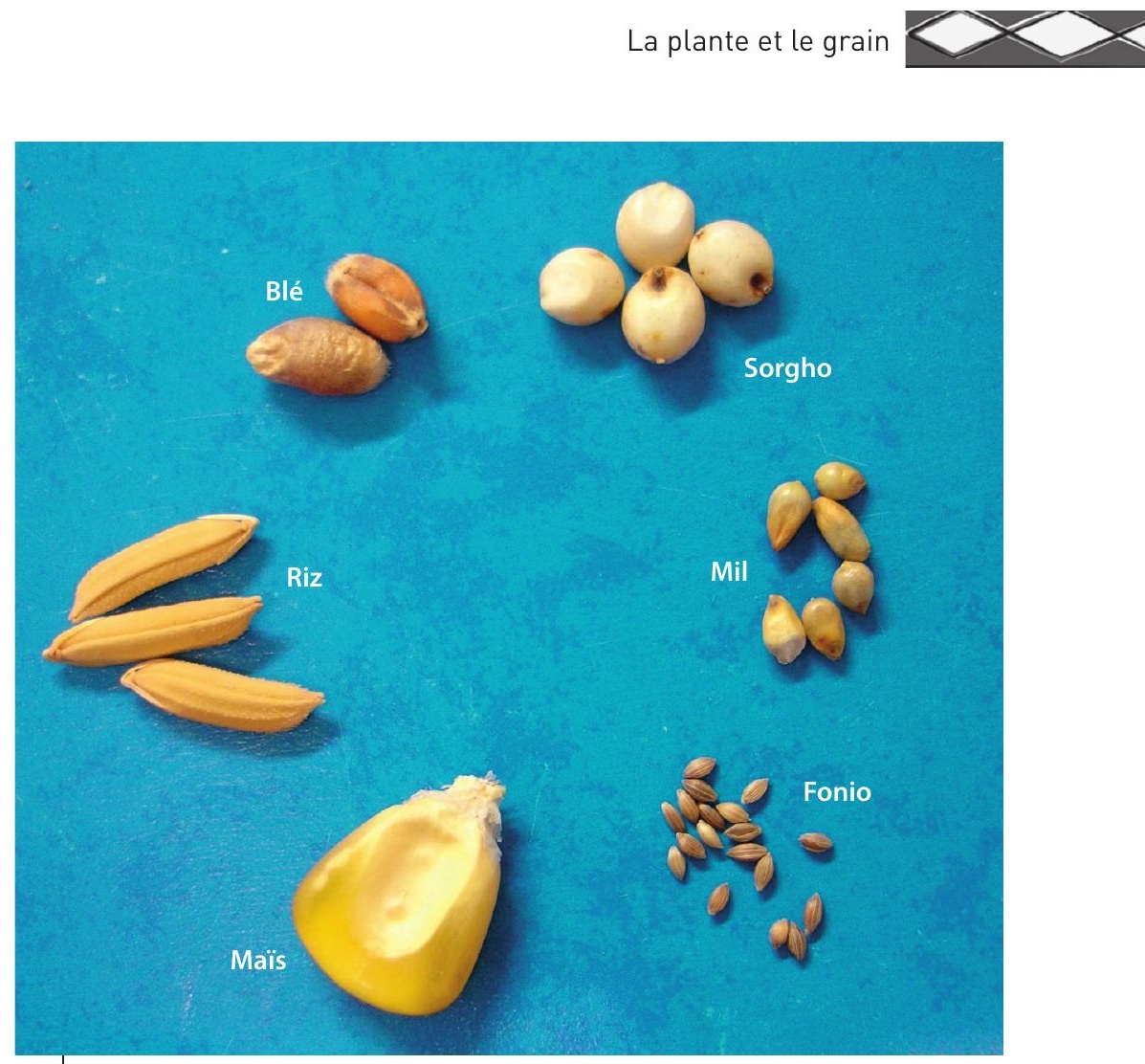

Comparaison de la taille de différents grains de céréales (๑ J.-F. Cruz).

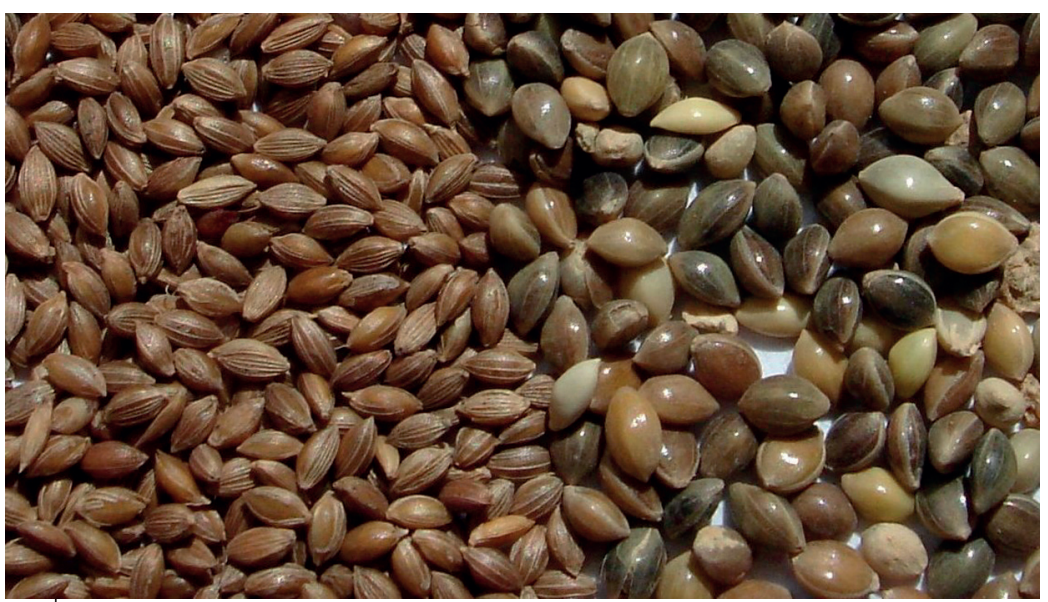

Grains de fonio (Digitaria exilis) et de fonio sauvage (Panicum laetum) (৫) J.-F. Cruz). 


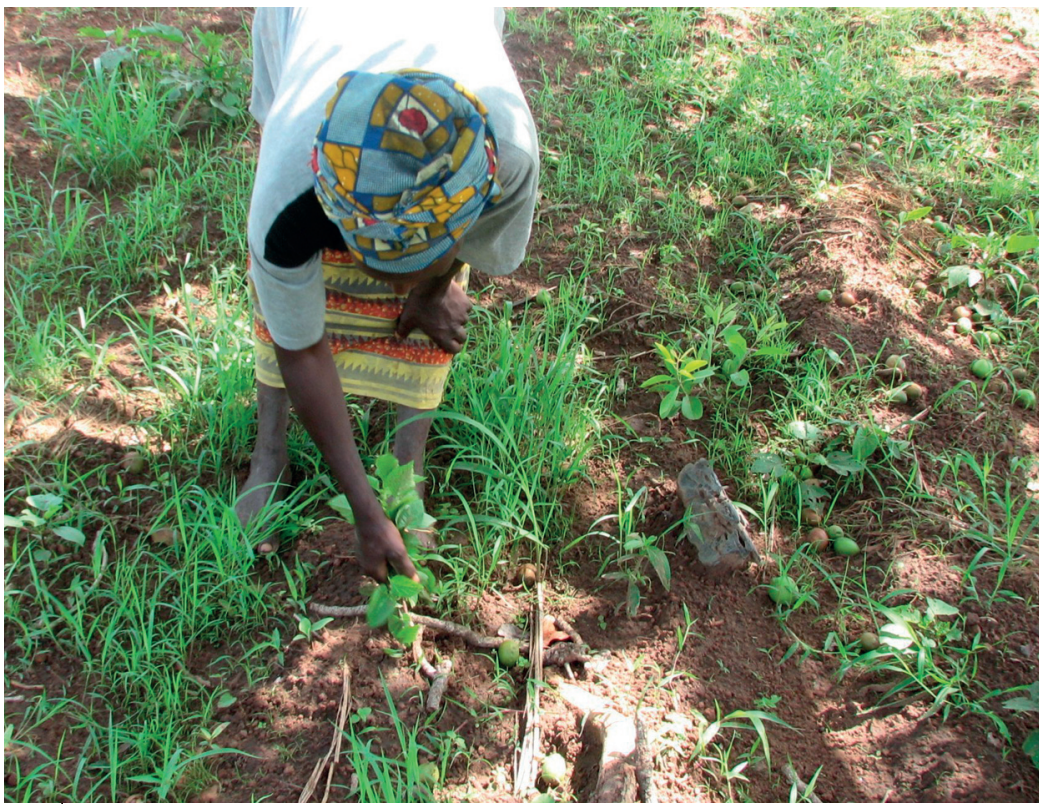

Désherbage du fonio au Burkina Faso (@ B. Daho).

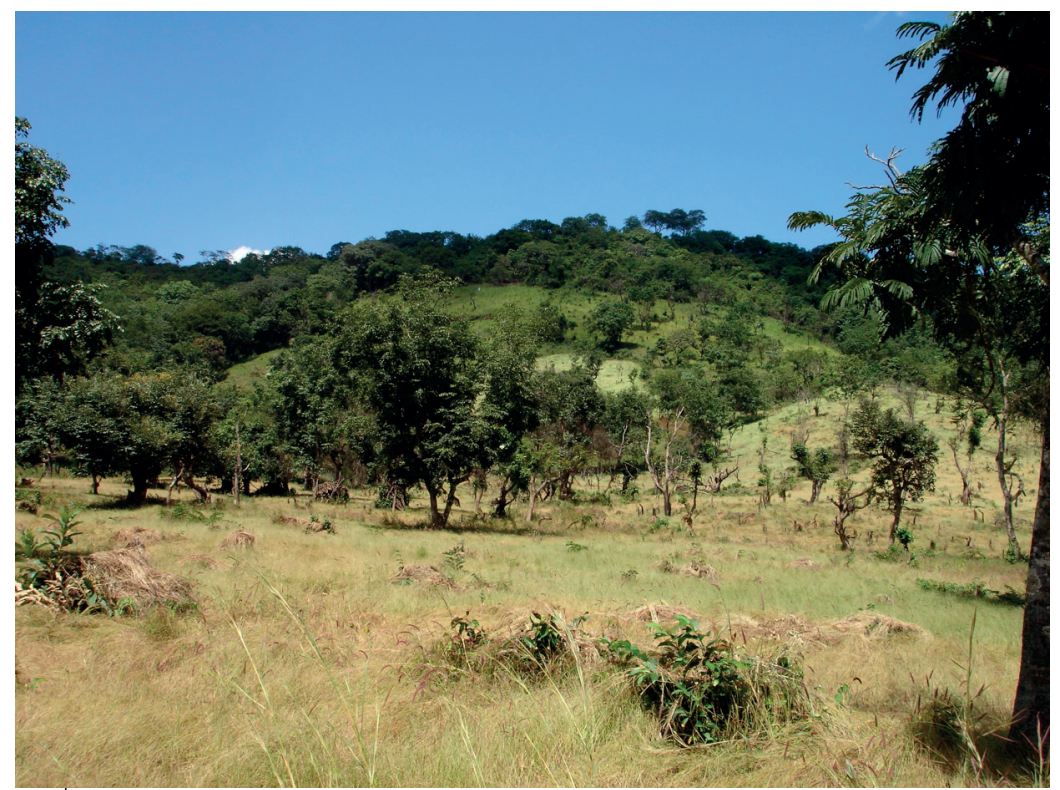

Fonio de plaine et de coteau au Fouta-Djalon (@ J.-F. Cruz). 

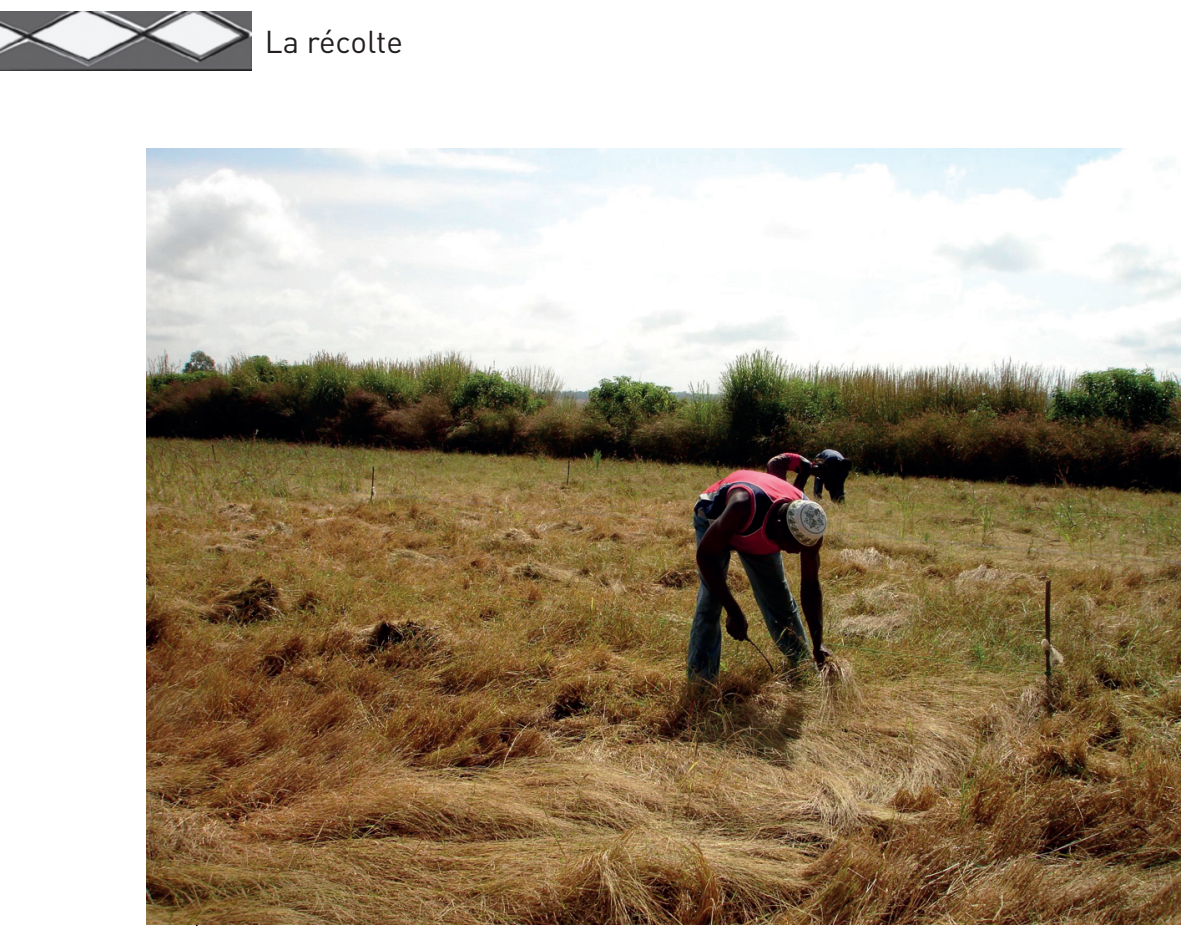

Récolte du fonio à la faucille (৫ J.-F. Cruz).

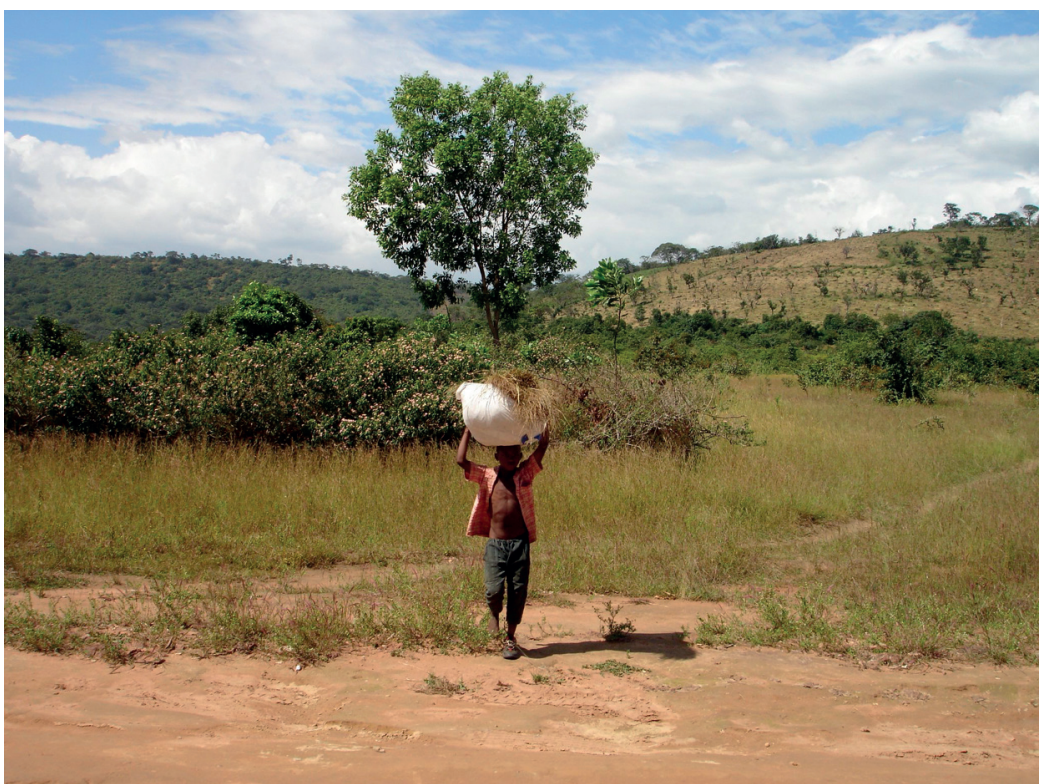

Transport des gerbes de fonio après la récolte (৫ J.-F. Cruz). 


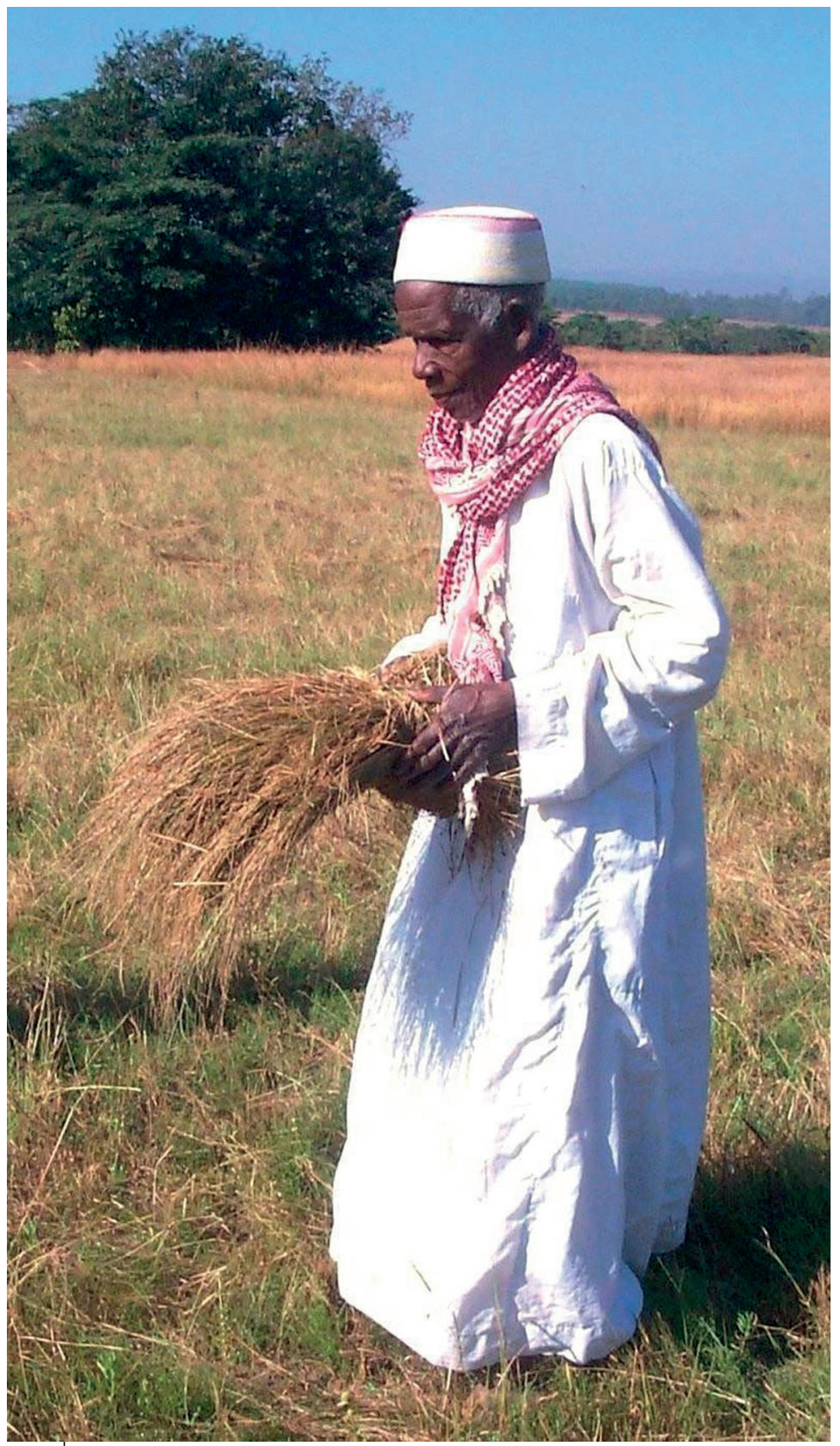

Producteur de fonio en Guinée (৫ J.-F. Cruz). 


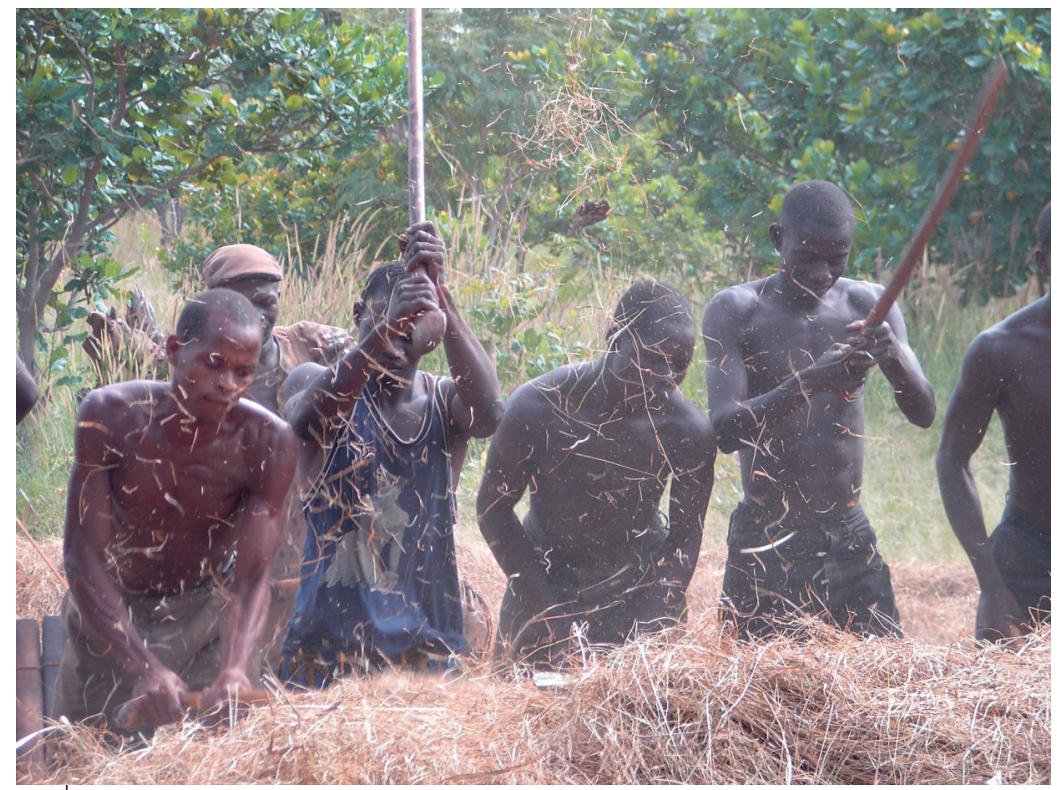

Battage au bâton par les hommes au Burkina Faso (৫ J.-F. Cruz).

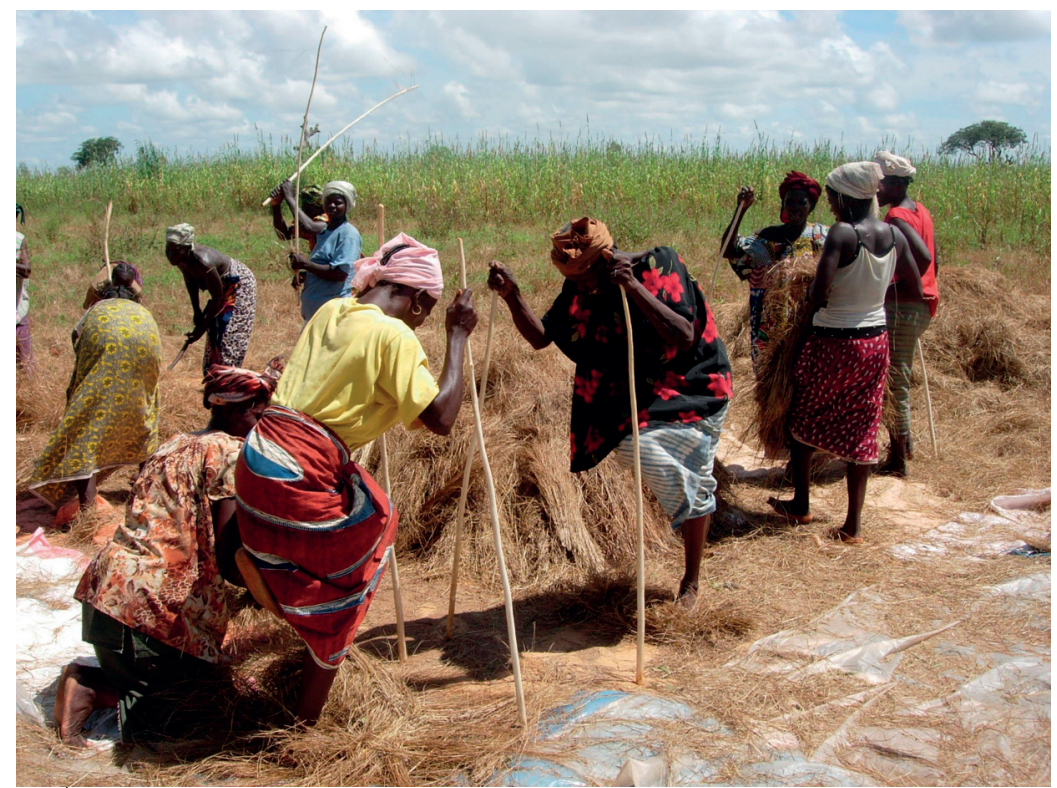

Battage par foulage au pied par les femmes au Burkina Faso (๔ É. Vall). 

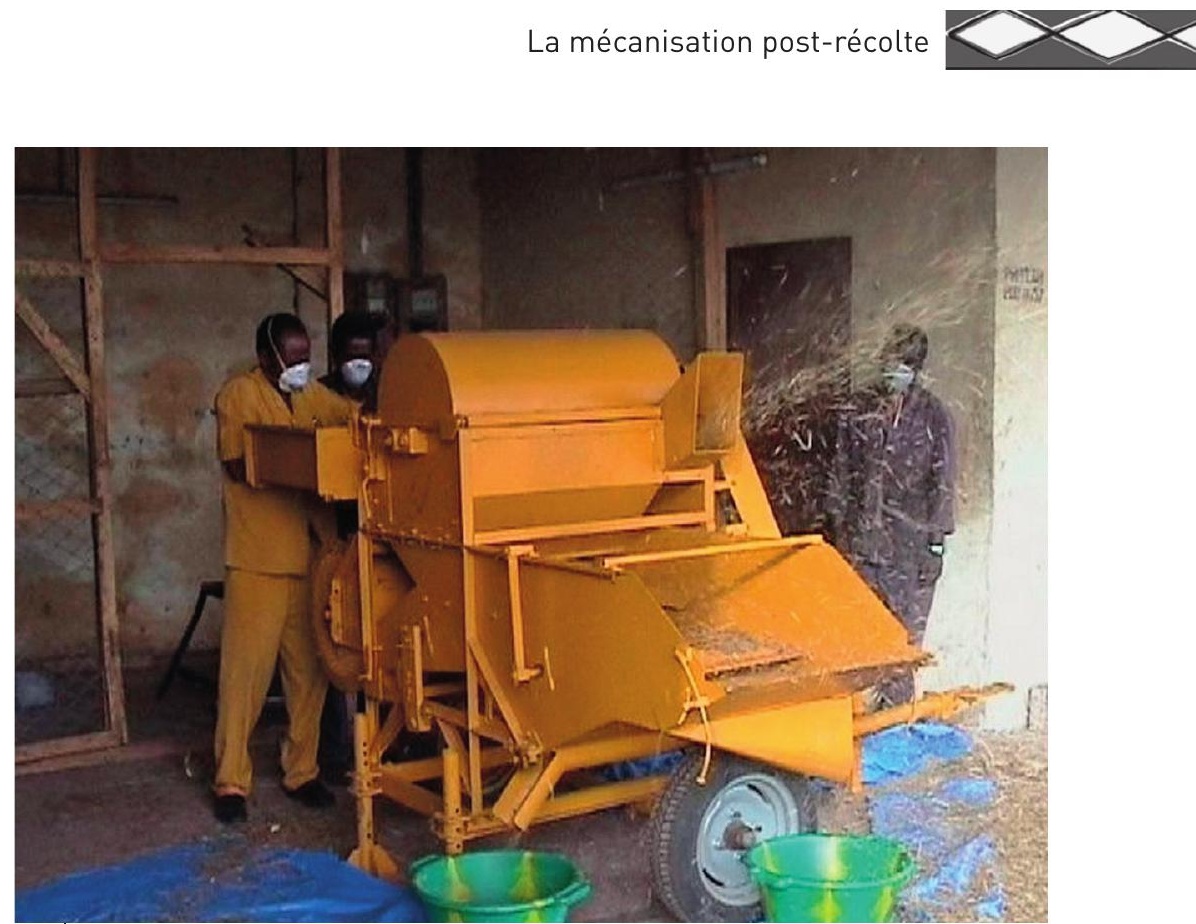

Batteuse Assi modifiée pour le battage mécanique du fonio (৫ J.-F. Cruz).

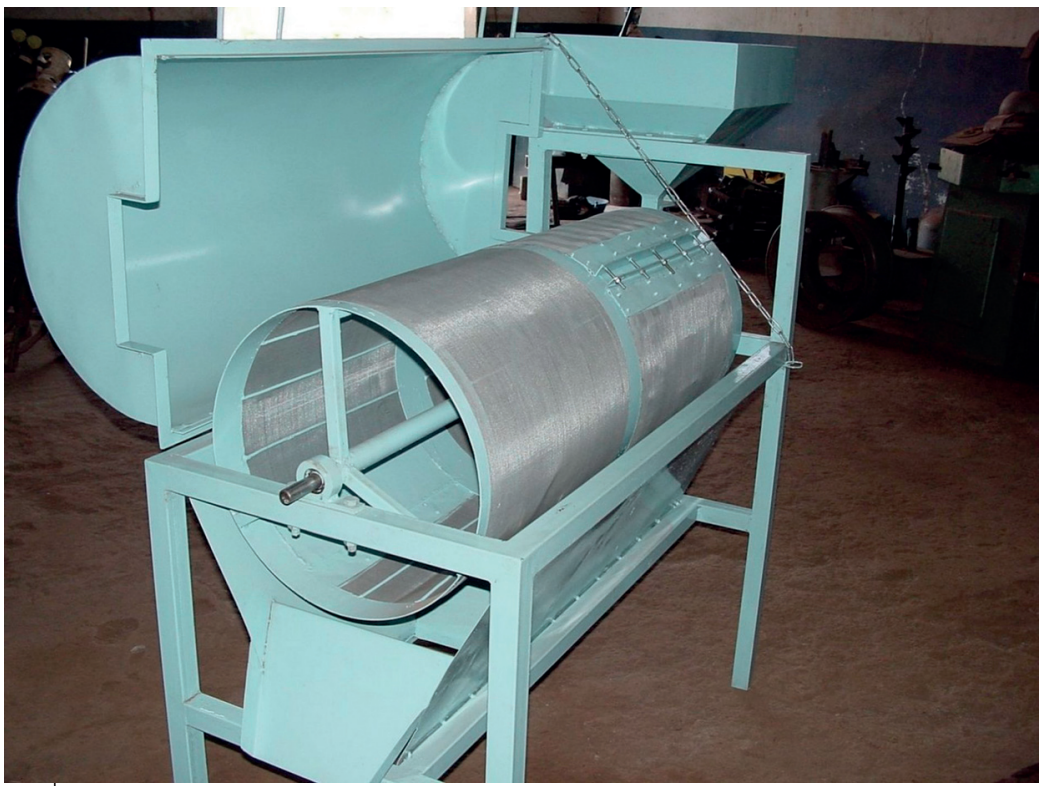

Crible rotatif conçu pour le nettoyage du fonio (৫ M. Rivier). 


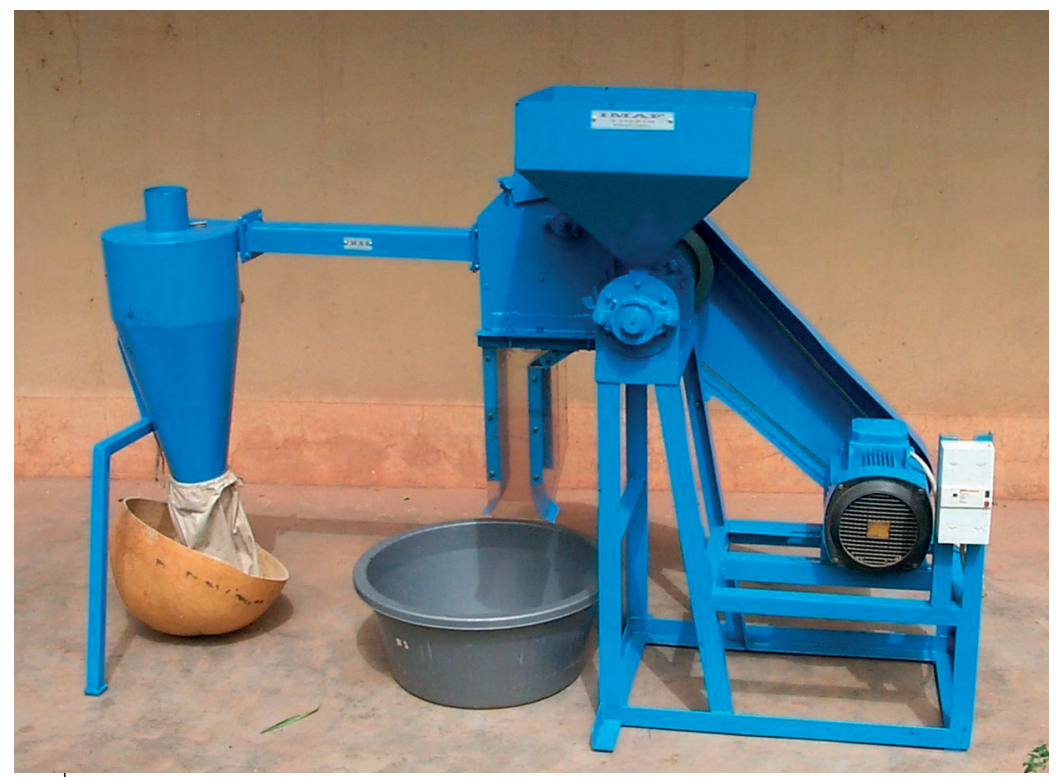

Décortiqueur à fonio GMBF avec moteur électrique (๑ D. Dramé).

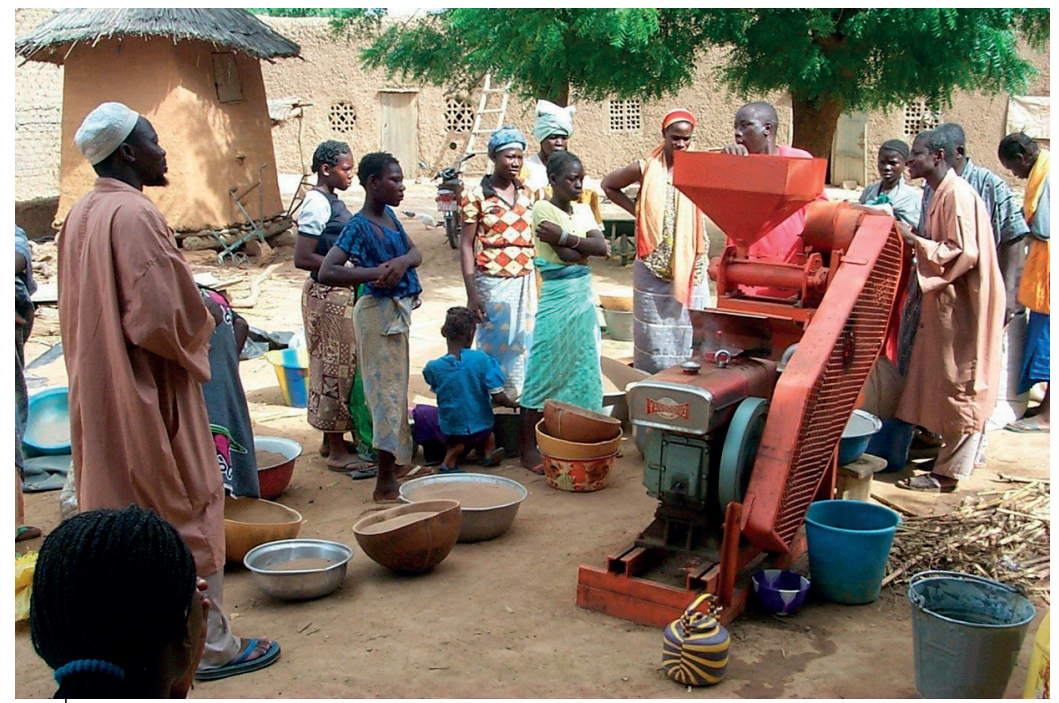

Démonstration du décortiqueur à fonio GMBF dans un village du Mali (@ D. Dramé). 

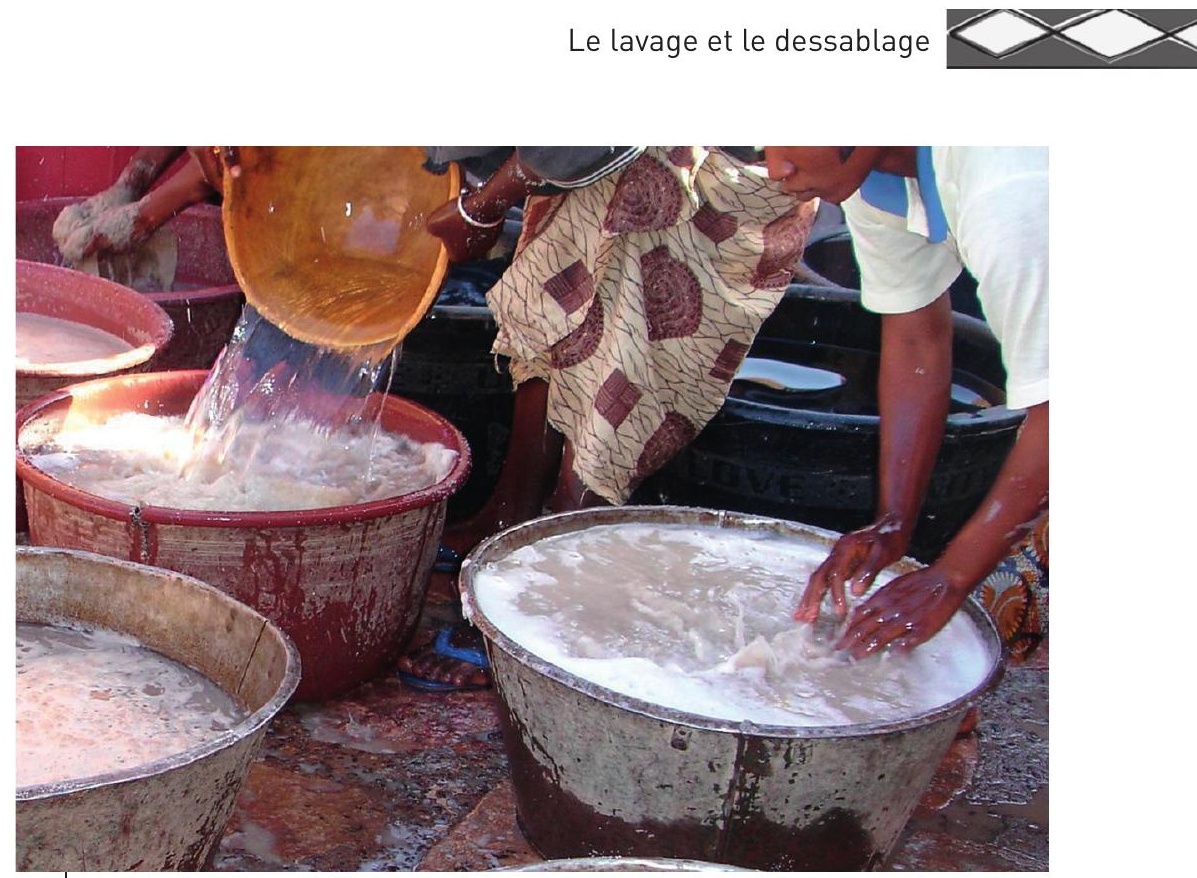

Lavage des grains de fonio après décorticage et blanchiment (৫ J.-F. Cruz).

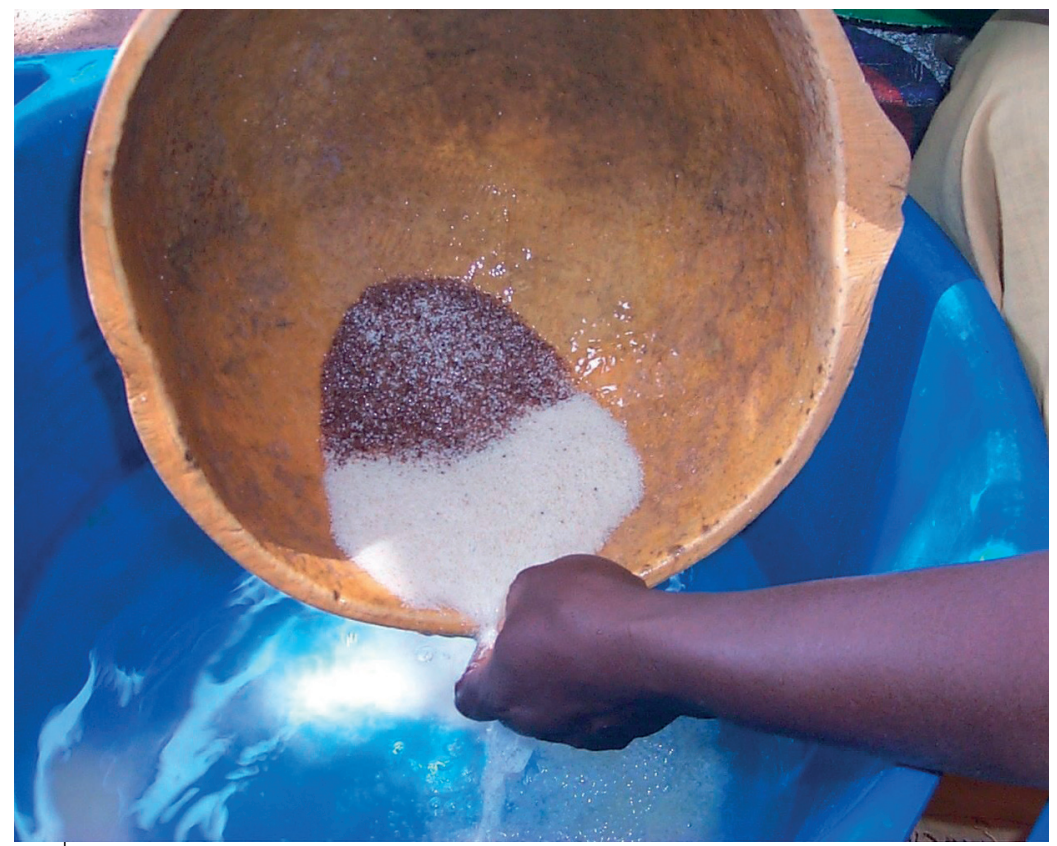

Dessablage ou séparation des sables du fonio blanchi (@ P. Thaunay). 


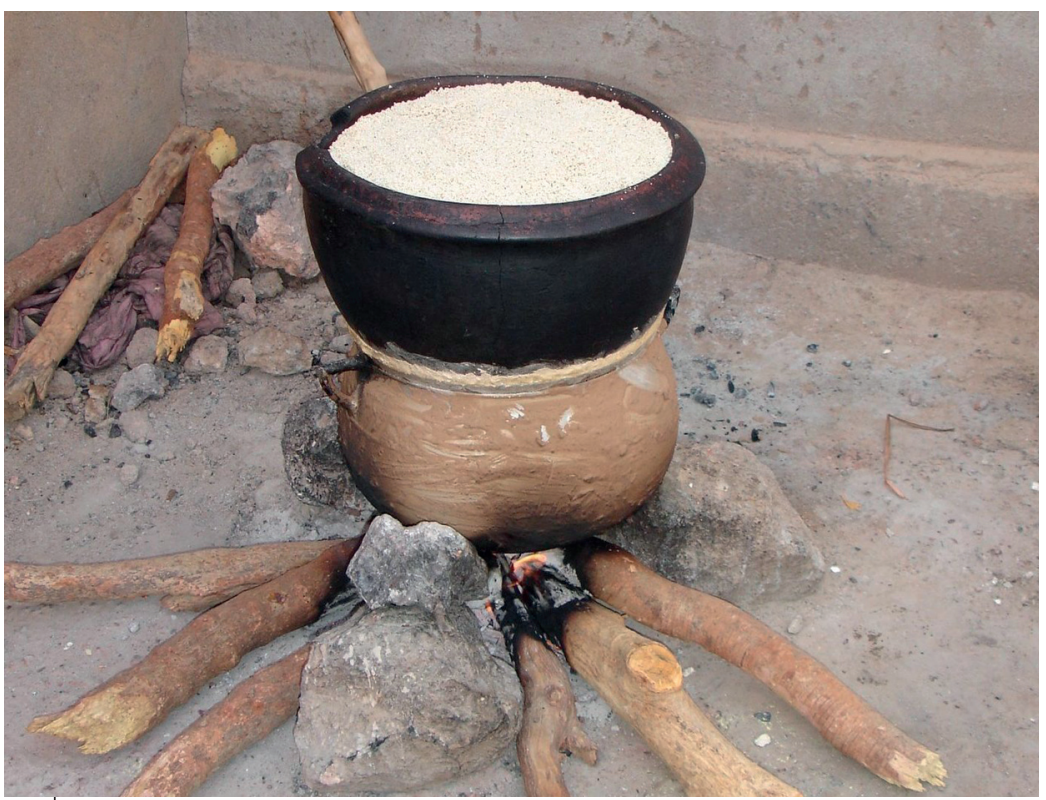

Précuisson traditionnelle du fonio (@ J.-F. Cruz).

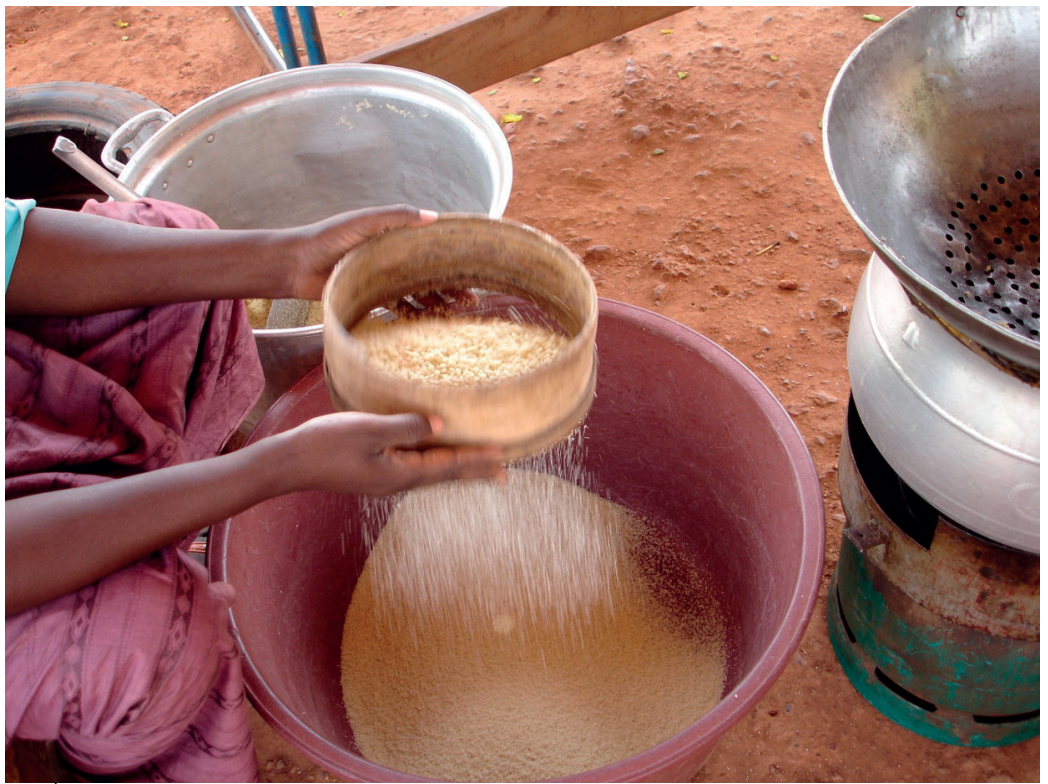

Émottage et tamisage après la précuisson du fonio (৫ J.-F. Cruz). 


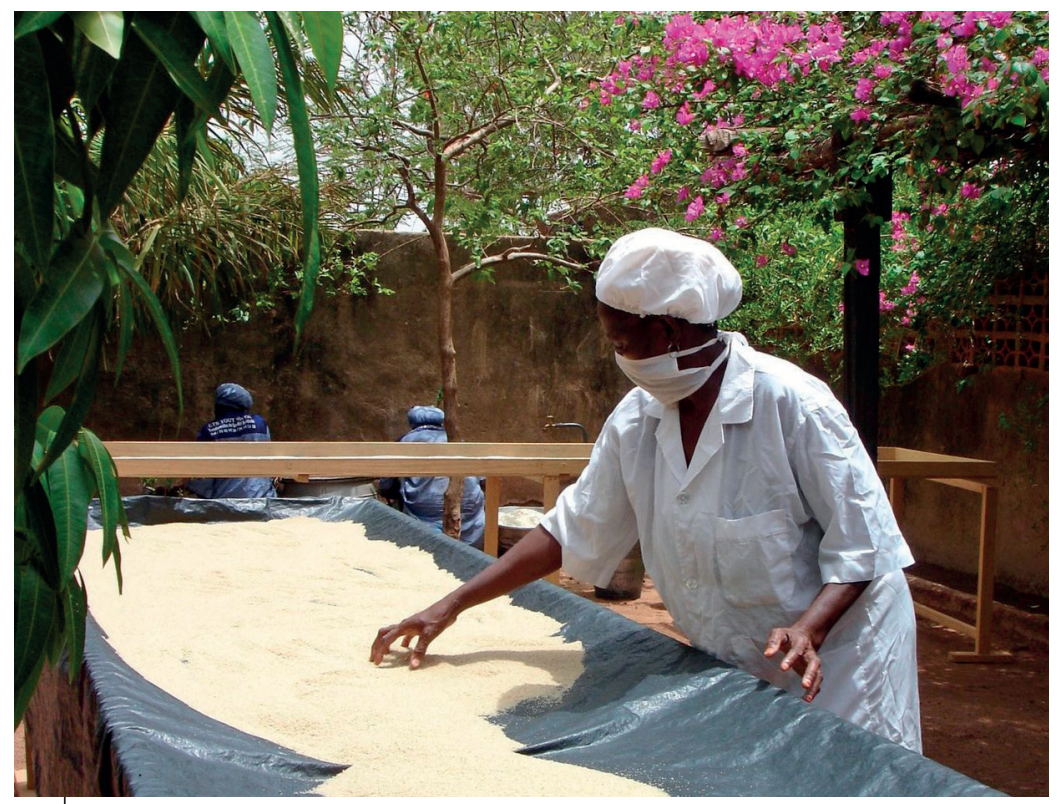

Séchage naturel du fonio précuit sur table (৫ J.-F. Cruz).

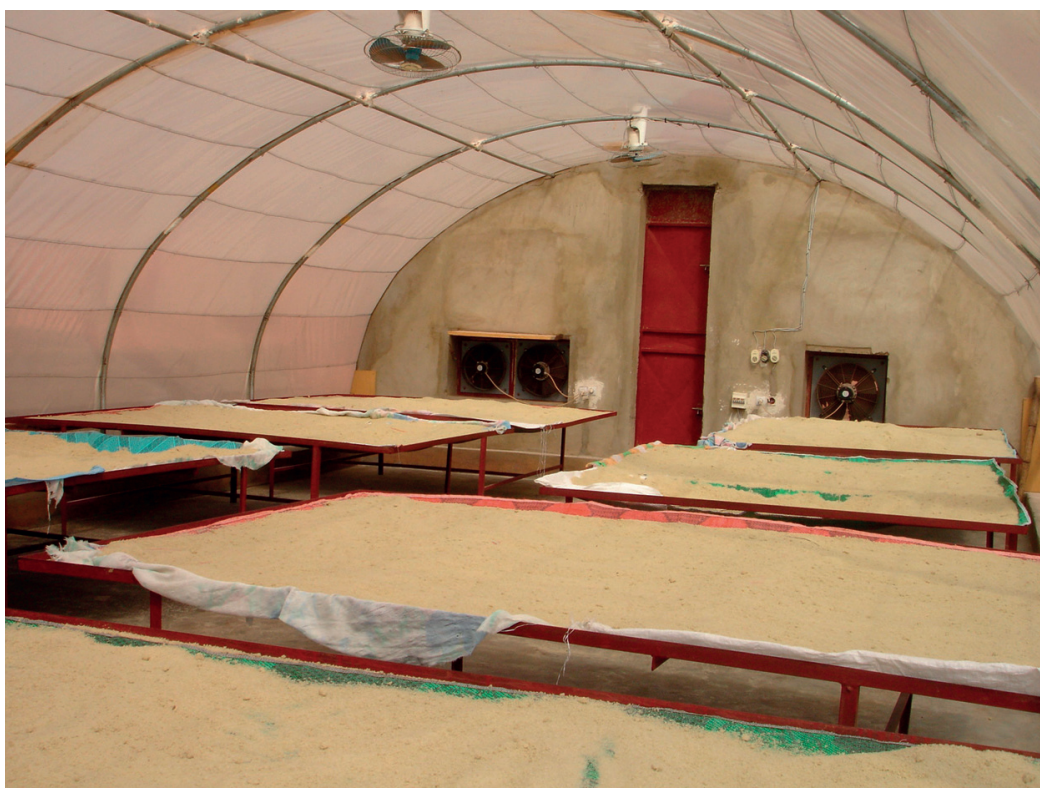

Séchoir serre CSec-S pour le séchage solaire du fonio précuit (๑ J.-F. Cruz). 


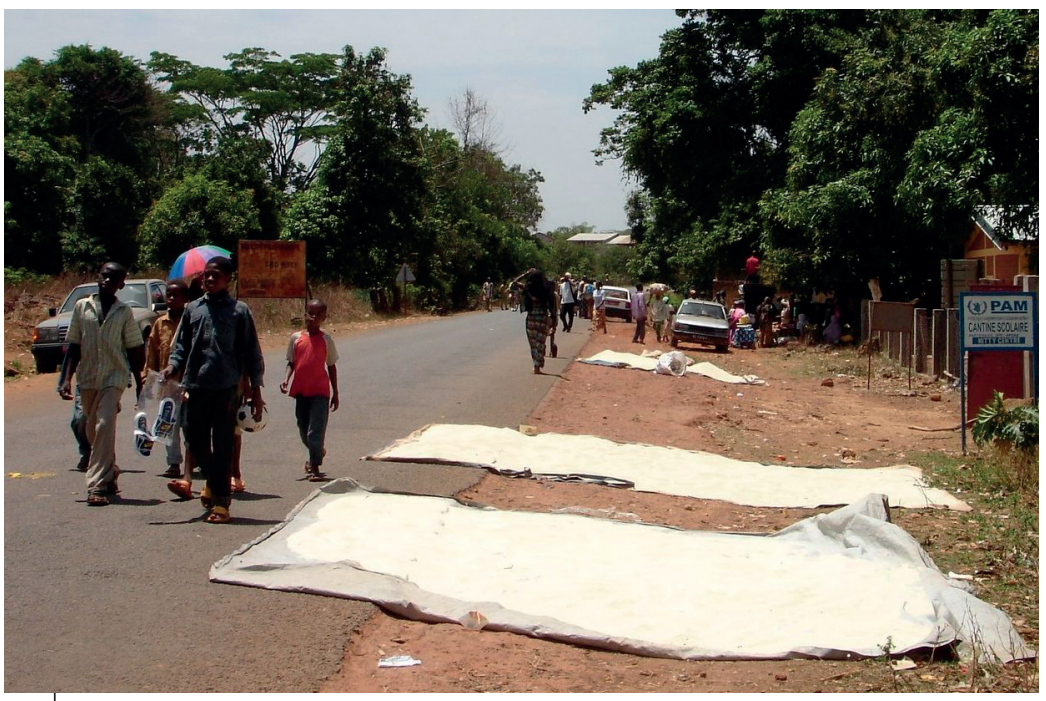

Fonio blanchi au marché de Miti en Guinée (৫ J.-F. Cruz).

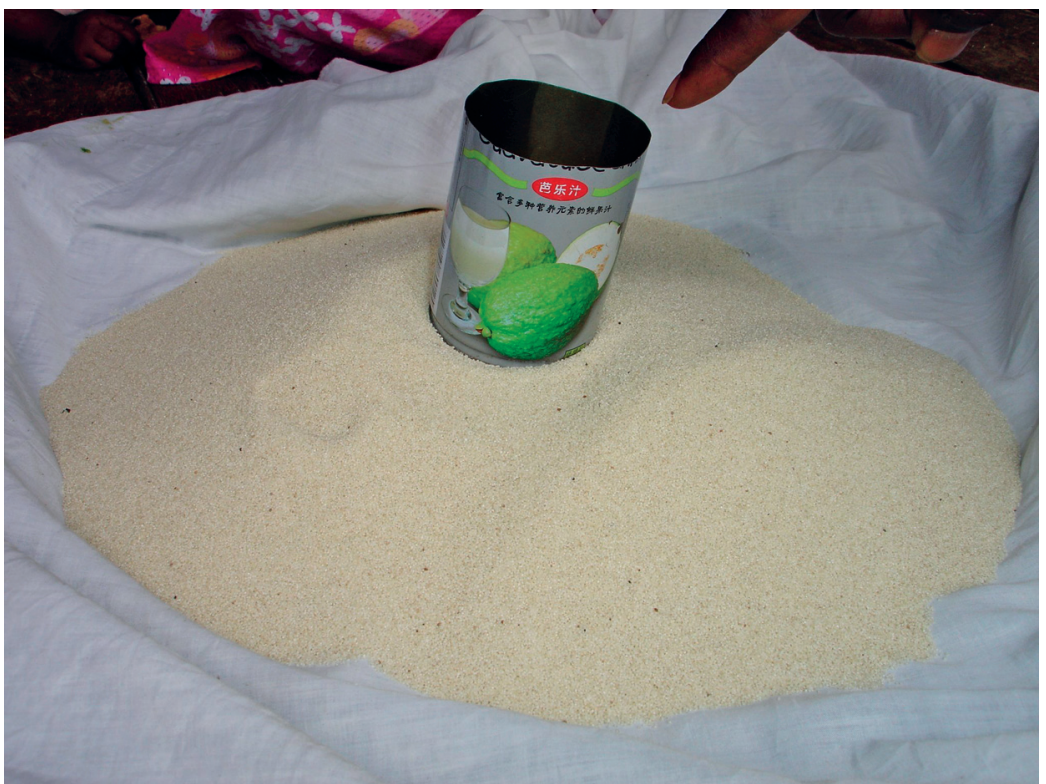

Fonio blanchi vendu au détail au marché de Labé en Guinée (๔ J.-F. Cruz). 

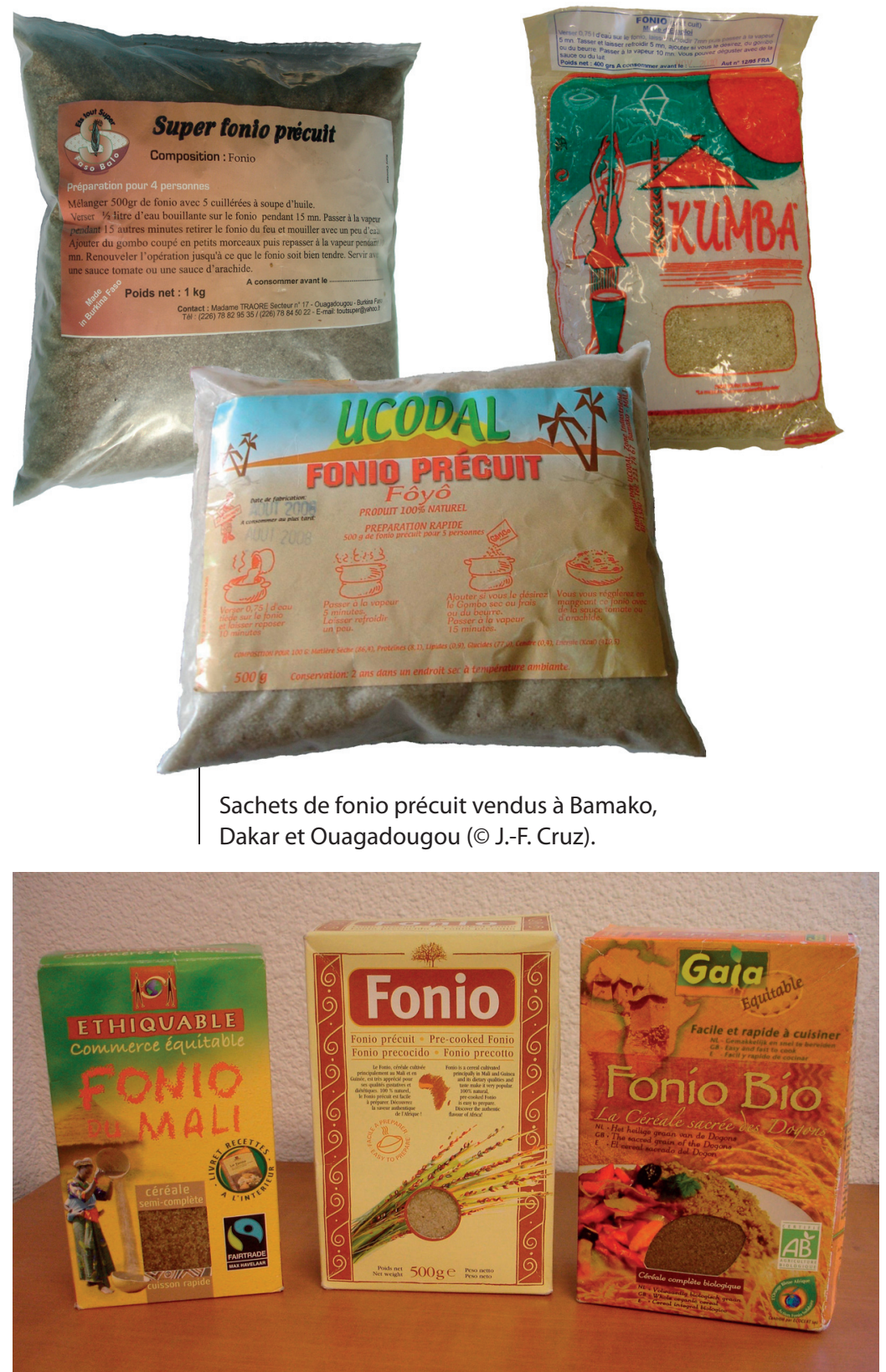

Paquets de fonio précuit ou étuvé vendus en France (@ J.-F. Cruz). 

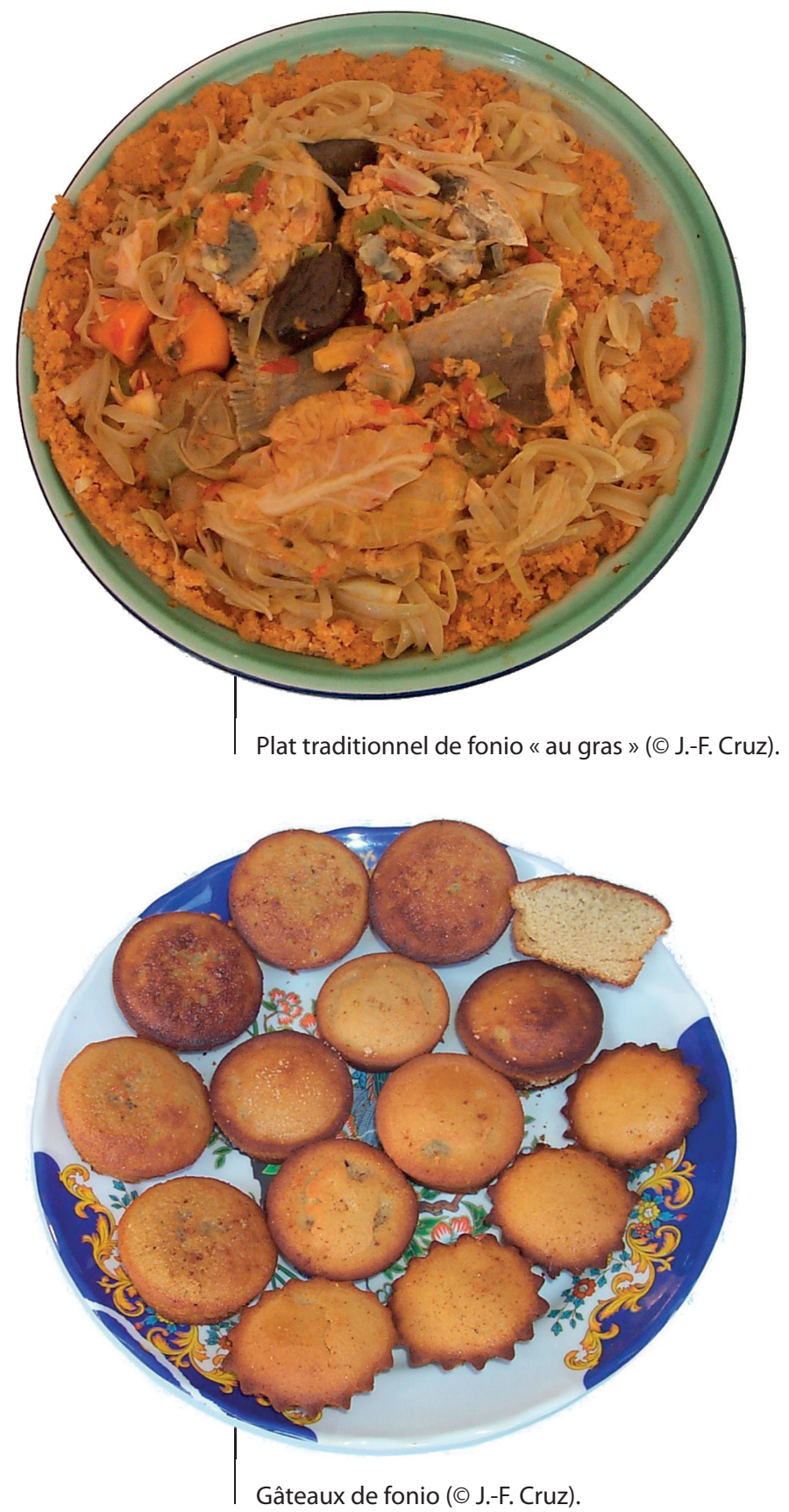


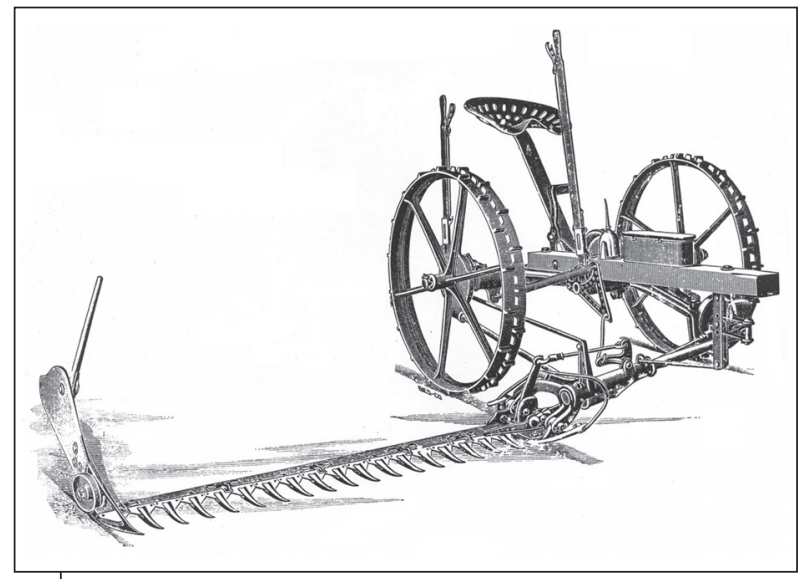

Figure 4.3.

Faucheuse à traction animale (Osborne).

zones tempérées ne peut pas être utilisée pour la coupe des graminées naturelles ou des légumineuses en zone tropicale. La masse végétale est bien souvent trop importante (Lhoste et al., 2010). Dans les années 1980, Jean Nolle, paysan inventeur français, avait proposé d'adjoindre à son célèbre porte-outils «tropicultor » une barre de coupe entraînée directement par un petit moteur auxiliaire de $4 \mathrm{ch}$ afin de soulager l'attelage et de faciliter la coupe (Nolle, 1986). Cette faucheuse à fourrage, qui permet aussi la récolte du riz ou d'autres céréales, aurait été testée de manière concluante en France, en Afrique, en Asie et en Amérique centrale, mais sans connaître un véritable développement.

Aujourd'hui, sur les terrains de plaine bien travaillés et correctement dessouchés, il pourrait être possible de tester de petites motofaucheuses motorisées (figure 4.4.), telles que celles qui sont utilisées

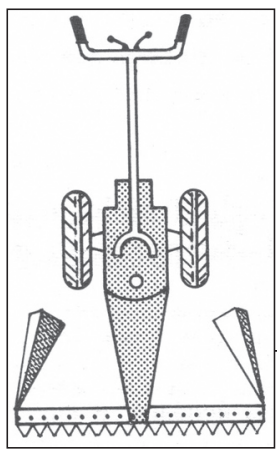

en Europe pour la fauche des pelouses ou des prairies de montagne. Mais la principale difficulté restera la verse du fonio à maturité. L'entretien du matériel (affutage des lames, réglage des guides, etc.) et sa maintenance sont essentiels au bon fonctionnement de l'équipement et représentent des contraintes importantes pour les utilisateurs.

Figure 4.4.

Motofaucheuse à barre frontale (Cneema, 1976). 


\section{Stockage et séchage des gerbes}

Les gerbes récoltées en fin d'hivernage sont généralement stockées en meules cylindriques près des habitations ou directement au champ. Ces meules sont érigées sur des plates-formes en rondins de bois surélevées d'une cinquantaine de centimètres du sol pour favoriser l'aération et faciliter le séchage naturel au soleil (figure 4.5.). Les meules sont réalisées en empilant les gerbes en cercles concentriques sur 1,5 à $2 \mathrm{~m}$ de hauteur, les épis dirigés vers l'intérieur de la meule pour éviter l'attaque des oiseaux. Une meule peut contenir jusqu'à un millier de gerbes correspondant à plus de $300 \mathrm{~kg}$ de grains.

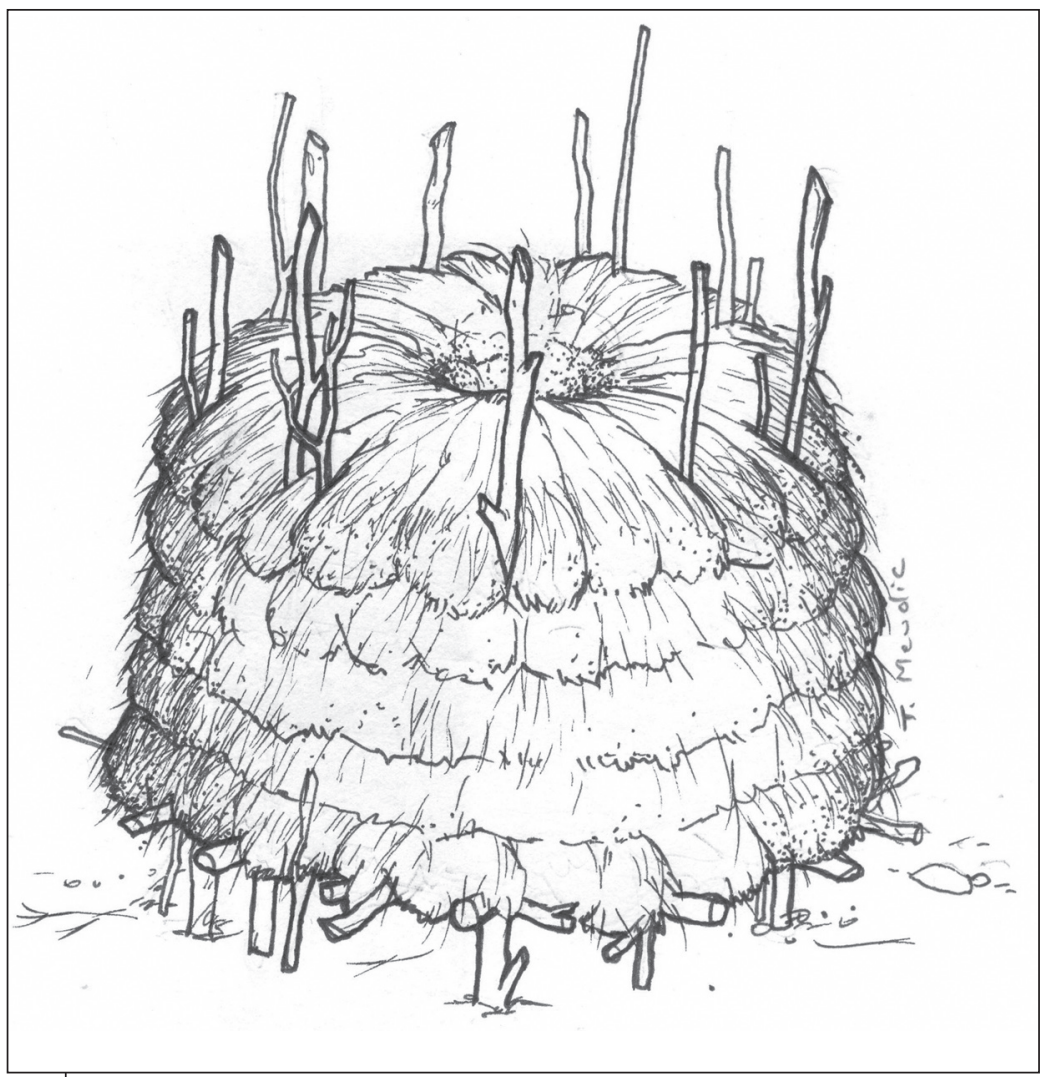

Figure 4.5.

Meule de gerbes de fonio (T. Meudic). 
Dans le Fouta-Djalon, la coutume veut qu'après avoir disposé neuf gerbes, la dixième soit jetée, en vrac, à l'intérieur de la meule. Cette pratique est appelée «la dîme du champ» et les grains obtenus après battage de cette dixième gerbe étaient traditionnellement offerts aux nécessiteux.

L. Renoux et P. Dumas ont décrit le mode de séchage et de stockage des gerbes de fonio récoltées en saison humide : «Les bottes, portées sous l'abri, sont disposées en meules cylindriques, les épis au centre. Ces meules doivent être petites, de 1 à $1,50 \mathrm{~m}$ au plus de hauteur, pour éviter qu'elles ne s'échauffent trop. Quand la récolte est abondante, on peut l'entasser en rectangles plus ou moins allongés mais toujours sur une faible hauteur. Malgré tout, la température ne tarde pas à s'élever dans les meules. Il faut la surveiller de près; empêcher qu'elle ne devienne trop intense et ne rende le grain stérile. On la ramène, si besoin est, en démolissant les meules. Il faut aussi veiller aux moisissures. On soulève les premières bottes pour voir si l'intérieur n'est pas envahi par le blanc, pour sentir le degré d'odeur et sa nature. Il faut porter les bottes moisies au soleil et même défaire les plus atteintes. Les grains imprégnés d'odeur de moisi n'ont plus de valeur marchande.»

Ils parlent également du stockage des gerbes de fonios tardifs récoltées en fin de saison des pluies : "La récolte des derniers fonios se faisant à la fin de l'hivernage, alors que les ondées deviennent rares, ne demande plus autant de précautions. On la laisse dans le champ en la disposant de la façon suivante : deux gros piquets sont enfoncés verticalement en terre avec une émergence de 3 mètres. Ils servent de support à des barres transversales échelonnées à 50 centimètres les unes des autres. Sur ces traverses, les bottes de fonio, attachées par leur base deux à deux, sont placées à cheval, superposées en autant de rangs que le permettent les intervalles. Les épis pendent au dehors. En recouvrant le rang le plus élevé, on abrite le tout. Cette disposition est très avantageuse pour prévenir toute altération. Le foulage n'a plus rien de pressé.»

Cette description du séchage et du stockage au champ des gerbes de fonio sur des perches horizontales date de 1905. Elle est tout à fait comparable à celle qu'en fait l'explorateur René Caillé, en juillet 1827, lorsqu'il aborde la région du Ouassoulo (ou Ouassoulou) en Haute Guinée aux confins du Mali et de la Côte d'Ivoire actuels. Il conte ainsi le travail des paysans locaux : «[...] En traversant une belle plaine bien cultivée, je voyais beaucoup d'ouvriers répandus dans la campagne, 
qui piochaient la terre et la remuaient aussi bien que nos vignerons en France; $[. .$.$] ce sont de vrais laboureurs qui travaillent pour avoir une$ belle et abondante récolte. Ils en sont bien récompensés, car leur riz, et tout ce qu'ils cultivent, croît plus vite et produit davantage que dans le Kankan. Je les ai vus récolter le foigné : ils se servent d'une faucille pour le couper, et ont l'habitude, dans bien des endroits, de le laisser dans la campagne, exposé à la pluie; ils mettent en terre des piquets sur deux rangs, et placent artistement entre eux leurs graminées; ainsi arrangées, elles ressemblent à une palissade; le dessus est couvert de paille, qui empêche la pluie de pénétrer; à mesure qu'ils ont besoin de foigné, ils viennent en prendre, et jamais personne ne se permet de voler ces espèces de magasins. »

Cette technique traditionnelle de séchage, qui ressemble aux séchoirs de type «palissade» ou «perroquet» utilisés autrefois en Europe pour le séchage du foin au champ, a été illustrée (figure 4.6.) par H. Jacques-Félix (1963).

Figure 4.6.

Champ de fonio, moissonneurs et séchage des gerbes sur "perroquet» (Jacques-Félix, 1963

(c) Publications scientifiques du MNHN, Paris).

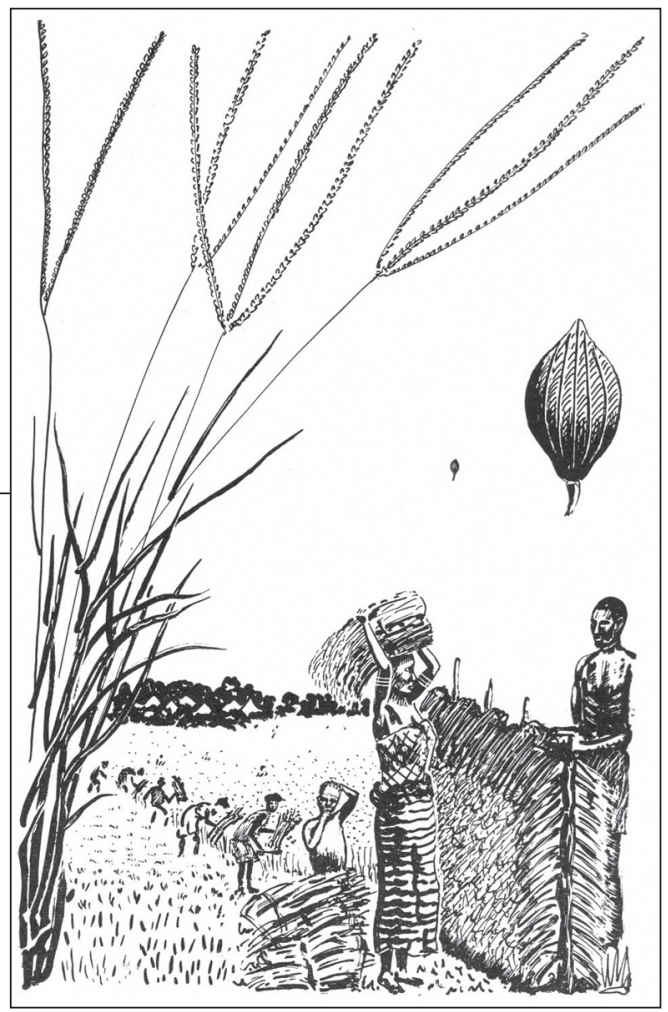




\section{Battage et vannage}

Après quelque temps de stockage sous abri près des habitations ou au champ, les gerbes de fonio ont partiellement séché. Le battage, qui consiste à séparer les grains des tiges, peut alors être réalisé. Pour les fonios hâtifs qui servent d'aliment de soudure aux paysans, impatients de consommer le fruit de leur première moisson, le battage est lancé très rapidement après la récolte. Mais, en général, la durée de stockage et de séchage des gerbes avant battage est d'une semaine à quinze jours ou plus. Dans les zones semi-arides du Burkina Faso ou du Mali, où la grande récolte a lieu vers la fin septembre, le fonio qui a été transporté près des habitations est battu durant la première décade du mois d'octobre. Dans les zones subhumides, le battage des meules de fonio laissées aux champs est généralement réalisé à partir de la mi-octobre, alors qu'en Moyenne Guinée le battage des fonios tardifs récoltés en novembre est souvent repoussé jusqu'à la fin du mois de décembre ou même après.

Les aires de battage, qu'elles soient au champ ou proches des habitations, sont toujours préparées avec soin pour éviter autant que possible de polluer les grains par diverses impuretés du sol (sables, cailloux). Ces aires sont généralement réalisées en terre battue et enduites avec de la bouse de vache mélangée à de l'argile et elles ne sont que très rarement bétonnées. À proximité des habitations, elles sont parfois recouvertes de nattes ou de bâches plastiques.

Le battage manuel est communément réalisé à l'aide de bâtons rigides ou parfois de baguettes plus souples. Il est en général effectué par des groupes d'entraide villageoise qui travaillent tour à tour pour les propriétaires des champs, qui ont alors la charge de les nourrir durant les journées entières que peut durer l'opération. Cette activité laborieuse est pratiquée par les hommes ou par les jeunes gens qui peuvent à cette occasion montrer leur résistance à l'effort. Dans certaines régions, le battage revêt encore un caractère festif où des chants, accompagnés par des tambours et des balafons, permettent de rythmer l'effort (figure 4.7.). Dans la région d'Orodara dans le sud-ouest du Burkina Faso, les grands chantiers de battage peuvent mobiliser plus d'une cinquantaine de personnes. Le battage manuel reste productif et nécessite environ 15 à 20 hommes-jour par hectare. C'est, après le fauchage, l'opération agricole qui requiert le plus de main-d'œuvre (Vall et al., 2007).

En 1940, Denise Paulme a décrit le battage du fonio au pays dogon : «Quatre ou cinq jours après la moisson, sur l'ordre du plus âgé d'entre 


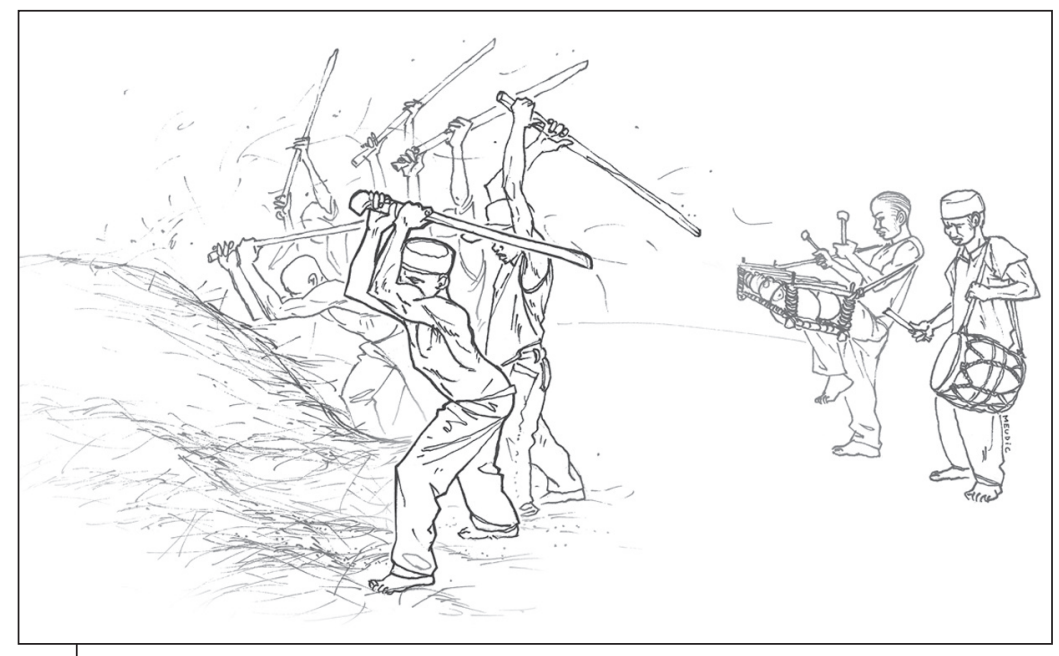

\section{Figure 4.7.}

Battage traditionnel du fonio au bâton au Burkina Faso (T. Meudic).

eux, tous les jeunes gens du quartier, filles et garçons qui n'ont pas encore eu d'enfant, viennent la nuit battre le fonio que les femmes ont disposé en tas dans le champ. Le travail est obligatoire et nul ne peut s'y soustraire sans devoir payer au plus âgé des travailleurs une amende de cinq cents cauris, qui permettra d'acheter de la bière de mil au marché suivant. Tandis qu'à l'aide de bâtons coudés qui font office de fléau, ses camarades battent les tiges sur une aire durcie, un jeune homme joue de la trompe. Les jeunes filles sont chargées du vannage et jettent contre le vent le mélange de balle et de grain. Le fonio battu est ensuite mis dans des sacs en peau de chèvre, que l'on va remettre au propriétaire du champ. Celui-ci remercie les travailleurs; dans le courant de la saison sèche, il offrira du mil à ceux qui ont battu son grain, à raison d'une mesure par sac de grains battus. Les jeunes filles transformeront le mil en bière, que les jeunes gens partageront : c'est le po bunu konyo, la bière pour le fonio battu.»

Dans d'autres zones, afin de limiter les dépenses, le battage est réalisé par les membres de la famille. Le suivi d'une opération de battage «au bâton», dans le village de Darsalam proche de Labé en Guinée, a permis de vérifier quelques données sur ce type de battage familial. Une aire de 20 à $25 \mathrm{~m}^{2}$, recouverte de bâches en plastique, est utilisée par un groupe de cinq personnes constitué de quatre femmes et d'un homme. On libère habituellement une douzaine de gerbes par 
personne avec des gerbes pesant en moyenne $600 \mathrm{~g}$. Un monticule d'une soixantaine de gerbes est ainsi édifié au centre de l'aire de battage. Puis, munis d'un bâton souple d'un mètre dans chaque main, les cinq opérateurs tournent, en rythme, autour du tas en frappant les gerbes qu'ils retournent périodiquement avec leurs pieds. Les mesures réalisées au cours de l'opération ont montré que les grains représentaient $40 \%$ du poids des gerbes (les $60 \%$ restant étant les pailles) et que le débit du battage manuel était de 7 à $10 \mathrm{~kg}$ de grains par heure et par personne (ce débit peut atteindre $15 \mathrm{~kg} / \mathrm{h}$ si le battage est réalisé par de jeunes hommes). Mais ce travail, très harassant, nécessite de fréquentes périodes de repos au cours du battage.

Le battage traditionnel peut également être réalisé par piétinement ou foulage au pied. En prenant appui sur une barre horizontale ou sur des bâtons, les femmes ou les enfants frottent alors les gerbes, une à une, entre leurs pieds pour séparer les grains de la tige. Là aussi, le travail peut être rythmé par des chants et les «batteuses» dansent sur le fonio (voir cahier de photos couleur).

Une fois battues, les grandes pailles sont récupérées manuellement et servent le plus souvent à l'alimentation du bétail. Le mélange de grains et de menues pailles qui reste sur l'aire de battage est ensuite placé dans des paniers tressés sommairement qui jouent le rôle de tamis et permettent de retenir les impuretés grossières, tout en laissant le bon grain et les impuretés fines tomber dans une bassine de récupération. Enfin, à l'aide de vans ou de tamis, les femmes ou les personnes âgées finissent par séparer les impuretés fines du bon grain.

Cette pratique de battage est encore aujourd'hui en tout point identique à celle décrite en 1905 par L. Renoux et P. Dumas : "On peut fouler le fonio deux jours après la récolte. Le grain a fini de recevoir de la tige tout ce qu'elle peut lui donner; la maturité est complète. Il ne faut pas prolonger beaucoup le délai pour les premiers fonios. Si l'on attend plus de huit jours quand ils sont en meule, on trouve le grain envahi par le mycélium, quelques précautions qu'on ait prises. Le foulage se pratique sur une aire recouverte de nattes ou de peaux de bœuf. Louvrier, debout, les mains appuyées sur une barre, froisse entre les pieds les bottes une à une, sans les délier d'abord. Quand les graines se sont plus ou moins détachées, il délie, piétine encore, secoue et passe à une autre botte. Ce travail peut être fait par les enfants. Dans les écoles, les élèves doivent au karamoko (maître d'école) le foulage de son fonio. À cause des glumes qui lui restent adhérentes, le grain du fonio conserve l'humidité. On l'étend au soleil en couches 
minces, qu'on laisse bien sécher. Lindigène achève le nettoyage de son produit en lui imprimant des mouvements de va-et-vient sur une peau ou dans un van. Ses corps étrangers se rassemblent à la surface. En somme, c'est un véritable vannage. Nous remarquerons que le foulage du fonio par la méthode indigène est une opération longue. Nous l'avons vu pratiquer très rapidement au moyen d'une petite batteuse, munie de secoueurs qui supprimaient en même temps le vannage. Quand le grain est bien sec, ce qui se reconnaît à la facilité avec laquelle il glisse dans les doigts, on l'enferme dans des sacs en jonc ou dans des corbeilles en bambous.»

En raison de sa pénibilité, le battage est l'opération pour laquelle les hommes souhaiteraient pouvoir bénéficier de services adaptés. Dans quelques très rares cas, le battage des gerbes est réalisé par dépiquage à l'aide d'un tracteur. Mais cette technique, relativement coûteuse (10 $000 \mathrm{FCFA} / \mathrm{ha}$, soit 15,2 €/ha), peut être à l'origine de pertes par enfouissement de grains dans le sol. Même si dès 1905 L. Renoux et P. Dumas faisaient déjà référence au battage mécanique du fonio, ce n'est que très récemment que la recherche a mis au point des batteuses à fonio qui peuvent être construites localement et qui pourraient connaître une plus large diffusion (voir chapitre 6).

\section{La valorisation des pailles de fonio}

Les pailles de fonio sont souvent utilisées comme fourrage pour nourrir les bovins mais aussi les chèvres, les moutons, etc., comme c'est le cas notamment dans les zones les plus arides, où les sources d'alimentation animale sont rares. Dans beaucoup de régions, les pailles de fonio sont aussi utilisées pour la confection de matelas. Certaines productrices ont parfois l'habitude de brûler cette paille pour obtenir de la «potasse».

Les pailles de fonio peuvent encore être mélangées à de la terre pour servir d'armatures dans la fabrication du banco, terre argileuse mêlée d'eau, longuement foulée au pied, utilisée pour la construction villageoise.

Quelles que soient les régions, une part importante des pailles de fonio est souvent abandonnée, alors que celles-ci pourraient être correctement valorisées en fumure organique ou en fourrage notamment par adjonction d'urée. La production de fumure organique à partir de pailles de fonio transformées dans des fosses compostières a été testée dans le cadre du projet récent sur le fonio (Vall et al., 2008b). 


\section{Séchage des grains}

Le séchage des grains est nécessaire pour éviter les risques d'altération par les moisissures au cours du stockage. Pour assurer une bonne conservation, leur activité en eau ou $\mathrm{a}_{\mathrm{w}}$ (activity of water) doit en général être inférieure à 0,6 ; seuil au-dessous duquel les micro-organismes ne peuvent pas se développer et où l'activité enzymatique est bloquée (Cruz et al., 1988). Les grains de fonio doivent ainsi être séchés jusqu'à une humidité de sauvegarde inférieure ou égale à $11 \%$, comme le montre l'isotherme de sorption du fonio représentée sur la figure 4.8. Il est intéressant de noter que cette valeur est inférieure à celle qui est habituellement recommandée pour les autres céréales, dans les mêmes conditions de température, et qui est souvent de $13 \%$.

\section{Isotherme de sorption du fonio}

La courbe d'équilibre air-fonio a été réalisée au laboratoire Cirad de Montpellier. Les teneurs en eau d'équilibre en base humide ( $\mathrm{H} \% \mathrm{wb})$ ont été mesurées à $30^{\circ} \mathrm{C}$ et ont permis de tracer l'isotherme caractéristique $\mathrm{du}$ fonio paddy à cette température. La valeur en abscisse est l'a $\mathrm{a}_{\mathrm{w}}$ (activity of water). Les données expérimentales ont été lissées par le modèle GAB (Guggenheim, Anderson, Boer).

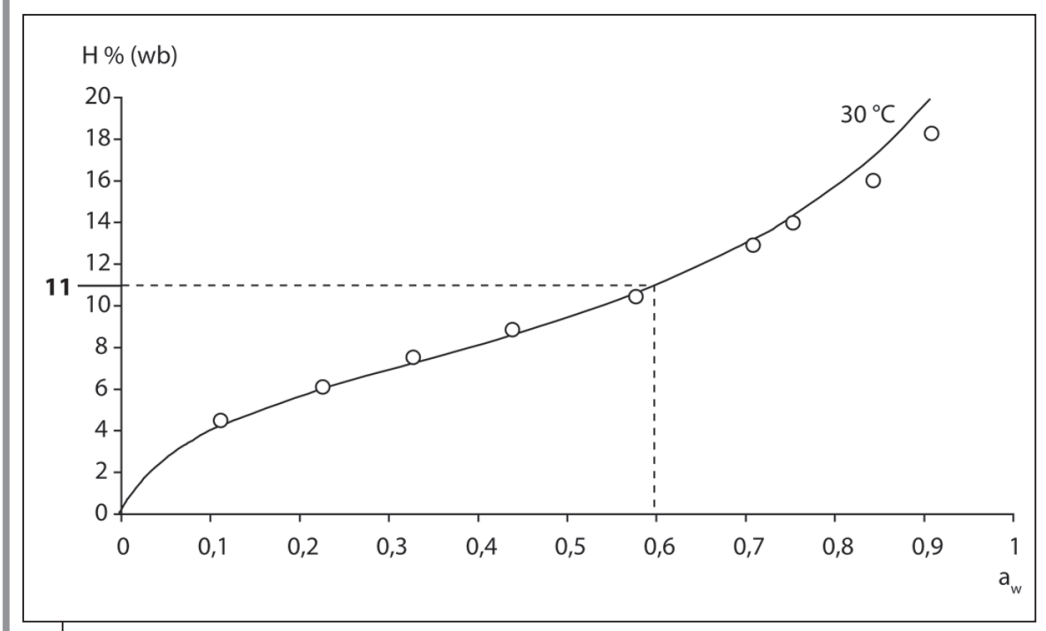

Figure 4.8.

Isotherme de sorption du fonio paddy à $30^{\circ} \mathrm{C}$ (Cruz et al., 2009). 
Le séchage au soleil est couramment effectué en étalant les grains sur des aires de séchage durant quelques jours. Les aires de battage ou les terrasses des habitations sont souvent employées à cet effet. Selon les zones, des nattes, des bâches plastiques ou des peaux sont également utilisées.

En saison des pluies, le séchage naturel ne permet pas toujours de bien sécher les grains des premières récoltes. Dans certaines régions de Guinée, la tradition consiste alors à les «griller» dans un récipient métallique placé sur un foyer ou sur une plaque de tôle chauffée avant de les décortiquer pour la consommation. Ce grillage permet une finition de séchage par contact qui facilite le décorticage.

\section{Stockage des grains}

Comme le riz, le fonio est habituellement conservé sous la forme «paddy» ou «grains vêtus». À l'instar des autres céréales, il est généralement stocké en vrac (photo 4.1.) dans des greniers traditionnels en terre ou «banco» (photo 4.2.). Le poids spécifique du fonio paddy est de 650 à $660 \mathrm{~g} / \mathrm{l}$. Dans certains cas il est conditionné en sacs, notamment lorsqu'il est destiné à être commercialisé sous la forme de fonio paddy ou de fonio décortiqué. Pour la conservation des grains décortiqués, certains producteurs commencent à utiliser des fûts métalliques ou des bidons en plastique.

Sans doute en raison de sa très petite taille, le fonio est en général l'objet de peu d'attaques de déprédateurs au cours du stockage. S'il est correctement séché à une humidité inférieure à 10 ou $11 \%$, il peut alors se conserver durant de longs mois, voire plusieurs années, même dans les structures de stockage traditionnelles.

$\mathrm{Au}$ fur et à mesure des besoins de consommation, le fonio est ensuite prélevé dans les greniers pour être décortiqué et blanchi avant d'être cuisiné. On quitte alors le domaine de l'après-récolte pour aborder celui de la transformation des grains. 

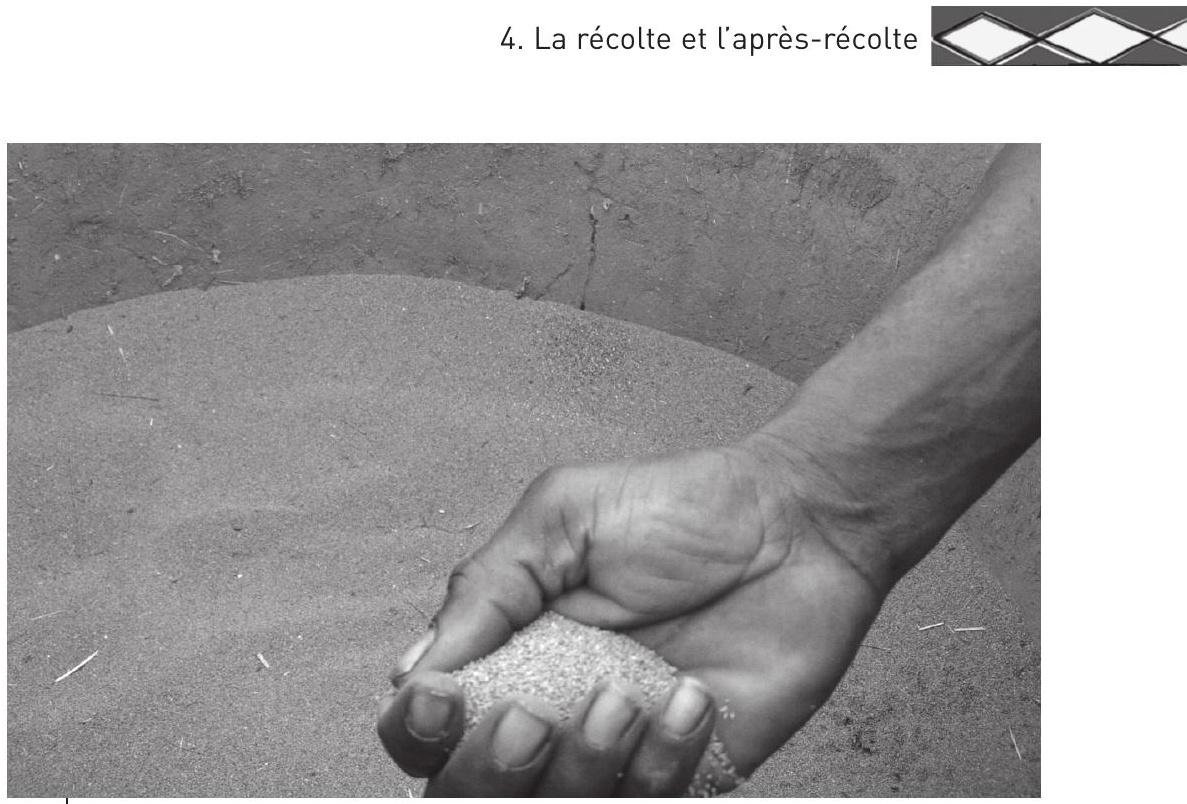

Photo 4.1.

Fonio stocké en vrac dans un grenier traditionnel (৫) É. Vall).

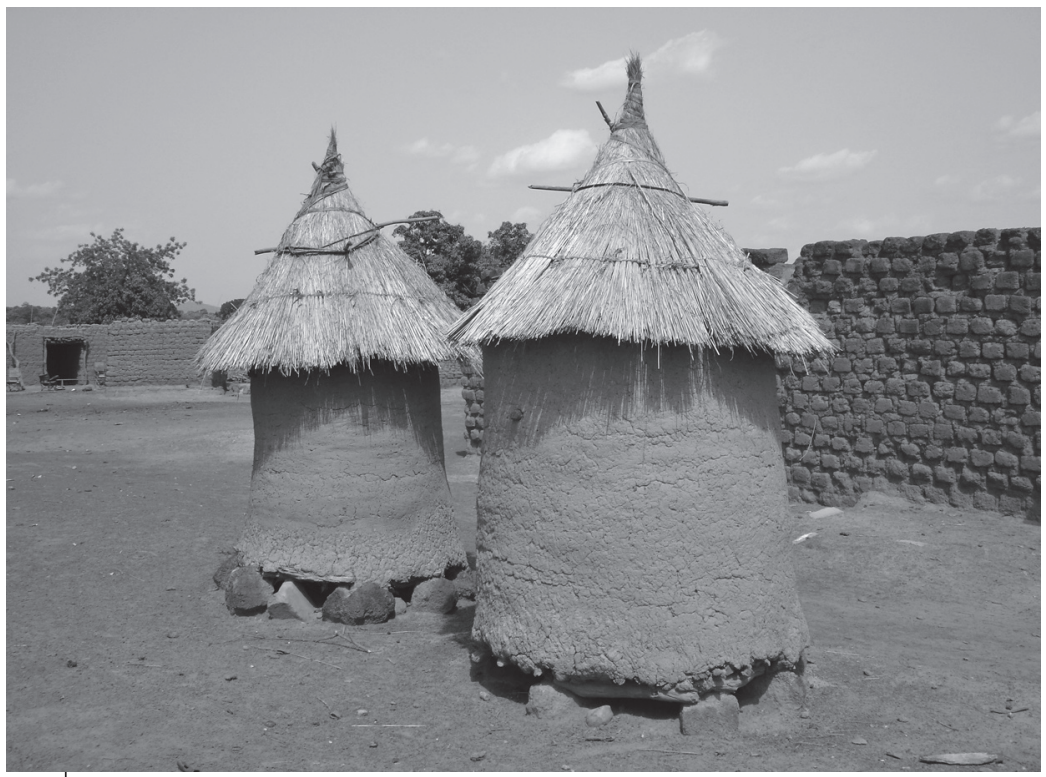

Photo 4.2.

Greniers traditionnels en banco pour le stockage des céréales (๔ J.-F. Cruz). 



\section{$\checkmark$ 5. La transformation et la qualité des grains}

Comme le riz, le fonio ne se consomme que décortiqué et le plus souvent blanchi. Mais, lorsqu'en juillet 1827 René Caillé décrit le Ouassoulo en Haute Guinée, il laisse entendre que les habitants consomment le fonio à l'état brut : «Le pays est arrosé par la rivière du Sarano, et plusieurs gros ruisseaux qui fertilisent la terre; elle produit en abondance tout ce qui est nécessaire à la vie de l'homme sobre. Les habitants sont doux, humains, et très hospitaliers [...]. Leur nourriture est très simple : ils mangent, comme dans le Kankan, du riz, du tau et du foigné sans être pilé; ils ajoutent à ces mets une sauce faite avec des feuilles d'herbe ou des pistaches grillées; rarement ils emploient du sel, qui est un objet de luxe, ils ne mangent de la viande que les jours de réjouissance; ils mettent dans leurs sauces, ainsi que le gombo, la feuille du baobab séchée et pilée» (Caillé, 1830).

Comme l'explorateur était un observateur assez attentif, on peut simplement supposer que le fonio dont il parle n'était pas totalement blanchi, mais on peut penser qu'il était quand même décortiqué.

\section{Structure physique et composition du grain de fonio}

\section{II) Structure du grain de fonio}

\section{Le fonio paddy}

Il a déjà été précisé que le fonio est une céréale vêtue dont les grains, après battage, sont entourés de «balles» (figure 5.1.). Ce «fonio paddy» n'est pas comestible tel quel en raison de la présence de ces balles (glumes et glumelles) riches en cellulose. Les grains de fonio paddy ont une forme ovoïde, légèrement aplatie sur le dos. Ils sont de très petite taille (leur longueur est d'environ $1,8 \mathrm{~mm}$ et leur largeur de $0,9 \mathrm{~mm})$. 

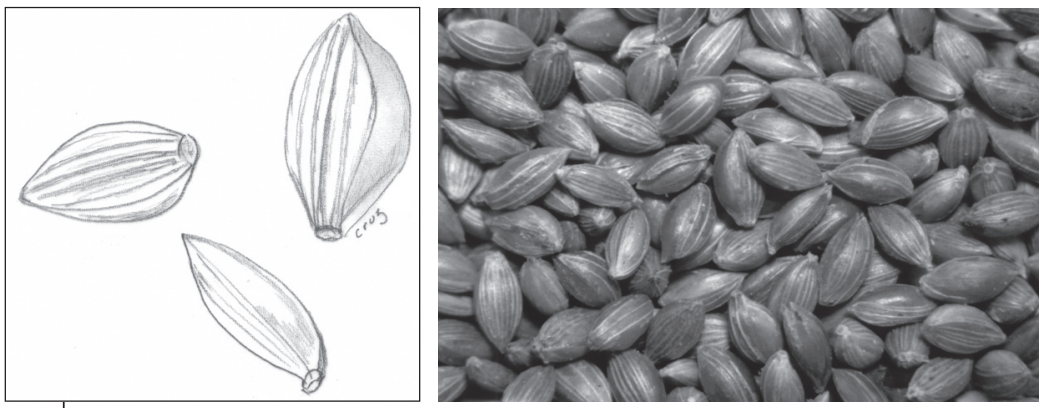

Figure 5.1.

Grains de fonio paddy

(৫ J.-F. Cruz).

\section{Le fonio décortiqué ou «fonio complet»}

Après élimination des balles, le grain nu obtenu est un caryopse. Anatomiquement, ces grains de fonio décortiqué correspondent aux grains de blé, de maïs ou de mil qui sont des céréales à grains nus. Le grain de fonio décortiqué, également appelé «fonio complet», a un péricarpe brillant de couleur blanche à jaune jusqu'à violette selon les variétés (voir cahier de photos couleur). Il ne mesure que 1,4 à $1,5 \mathrm{~mm}$ de long, 0,8 à $0,9 \mathrm{~mm}$ de large et $0,6 \mathrm{~mm}$ d'épaisseur. Sur une face, on repère le hile (photo 5.1.) et sur l'autre, le germe relativement gros qui contient les réserves lipidiques.

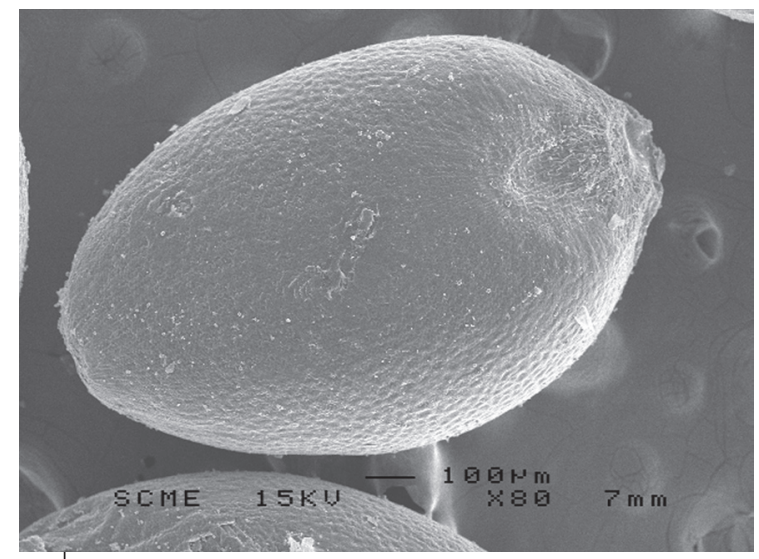

Photo 5.1.

Grain de fonio décortiqué

(৫ G. Fliedel). 
Le grain nu est formé de trois parties : le tégument, le germe et l'albumen (figure 5.2.).

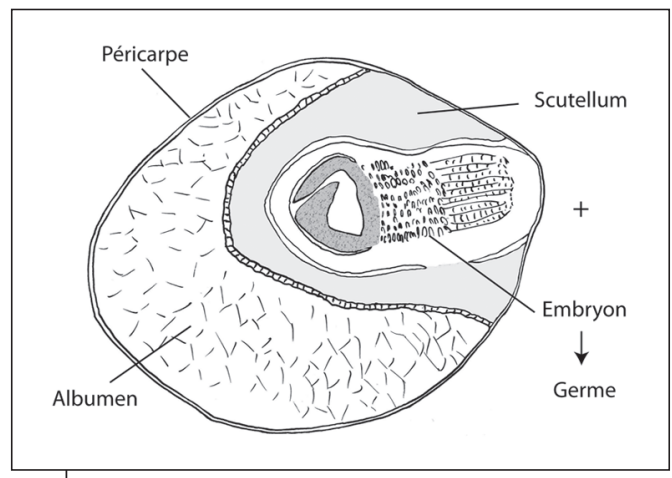

Figure 5.2.

Coupe schématique du caryopse de fonio

(Cruz et al., 2009).

Le tégument (figure 5.3.) comprend :

- le péricarpe qui correspond aux téguments du «fruit» dérivé de la paroi de l'ovaire.

- une assise protéique ou couche à aleurone qui représente la première assise constitutive de l'albumen.

Une fois éliminé, le tégument constituera une partie du son, riche en cellulose et en protéines.

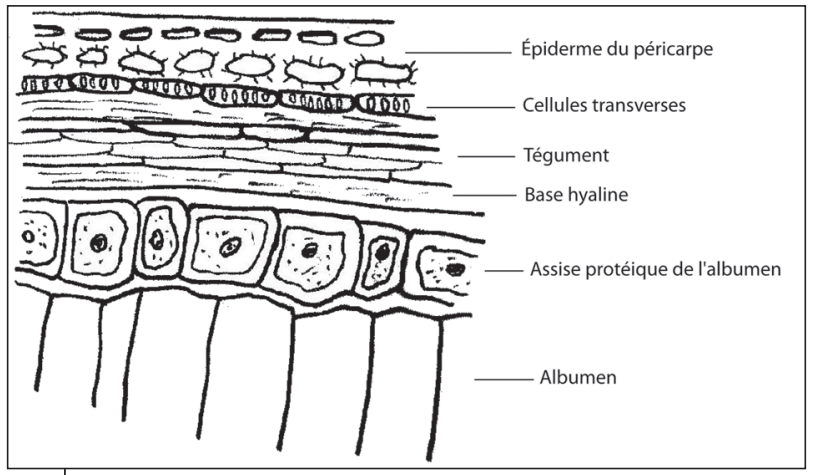

Figure 5.3.

Structure du péricarpe du fonio

(d'après Heim de Balsac, 1931). 
F. Heim de Balsac en 1931 décrit ainsi le caryopse : «La coupe transversale du caryopse présente, extérieurement, une rangée de cellules aplaties représentant l'épiderme du péricarpe (longueur $30 \mu$, largeur 6-8 $\mu$ ). Ces cellules examinées de face montrent des parois très fortement plissées, épaisses, comme cela s'observe dans presque tous les caryopses des graminées équatoriales ».

Le germe est formé de l'embryon et d'un cotylédon (ou scutellum). Il constitue un organe de réserve, riche en protéines et en lipides pour la jeune plantule. Une fois éliminé, le germe constituera une autre partie du son, riche en lipides.

Lalbumen représente l'amande du grain et correspond au fonio blanchi.

Selon F. Heim de Balsac, les caractères saillants du caryopse de fonio sont :

- absence de cellules tabulaires;

- zone protéíque irrégulière à une seule rangée de cellules;

- tégument très développé à plusieurs couches de cellules;

- grains d'amidon rappelant ceux du riz, mais s'en différenciant par leur hile arrondi, élargi et non en étoile ou en Y.

Plus récemment, la microstructure du fonio a été étudiée en microscopie électronique à balayage (Irving et Jideani, 1997). La description est succincte, mais elle confirme les caractéristiques suivantes : le caryopse comprend les couches du péricarpe et la testa, entourant l'endosperme et les tissus embryonnaires. L'endosperme est composé d'une seule couche de cellules à aleurone et de l'albumen amylacé. La couche à aleurone est fine sur tout l'endosperme et plus épaisse à la jonction de l'embryon et de l'endosperme. Les cellules à aleurone contiennent des gouttelettes de lipide et des corps protéiques. Le contenu des cellules de l'endosperme est constitué de granules d'amidon simples et polyédriques d'environ $10 \mu \mathrm{m}$ de diamètre. Comme pour le riz ou le maïs, les corpuscules protéiques sont plus abondants en périphérie de l'endosperme et diminuent vers le centre du grain contrairement au blé où la répartition est davantage continue.

\section{Le fonio blanchi}

Lélimination du son (péricarpe et germe) du caryopse permet d'obtenir le fonio blanchi, forme sous laquelle le fonio est le plus souvent consommé (photo 5.2.). En moyenne, le grain de fonio blanchi ne mesure que $1,2 \mathrm{~mm}$ de long, $0,7 \mathrm{~mm}$ de large et $0,5 \mathrm{~mm}$ d'épaisseur. Le poids spécifique des grains blanchis est de 860 à $870 \mathrm{~g} / \mathrm{l}$. 


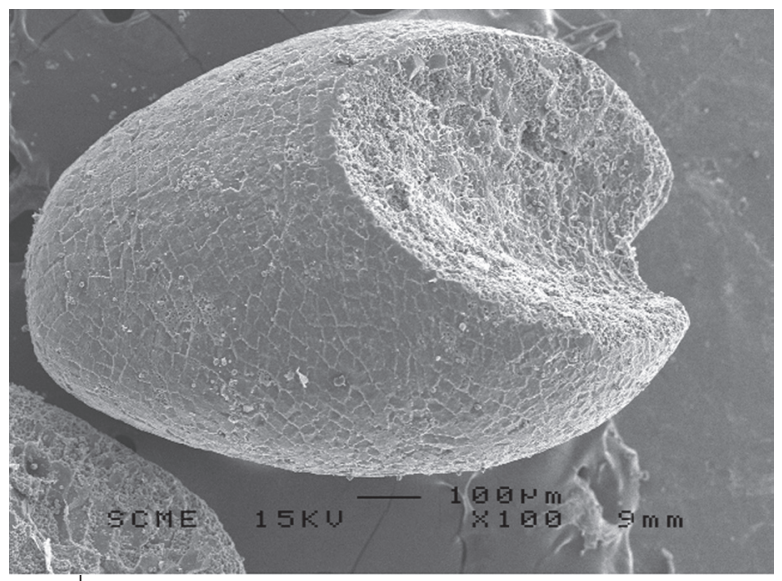

\section{Photo 5.2.}

Grain de fonio blanchi (๑ G. Fliedel).

Le fonio blanchi correspond donc à l'amande du grain constituée de cellules remplies de grains d'amidon (photo 5.3.) et d'un faible réseau protéique. Laspect microscopique des grains d'amidon est différent pour chaque espèce de céréales. Pour le fonio, les grains d'amidon sont polyédriques avec un diamètre d'une dizaine de micromètres : de 4 à $12 \mu \mathrm{m}$ (Heim de Balsac et al., 1931), de 2 à $13 \mu \mathrm{m}$ (Jideani et al., 1996) ou encore $8 \mu \mathrm{m}$ (Carcea et Acquistucci, 1997).

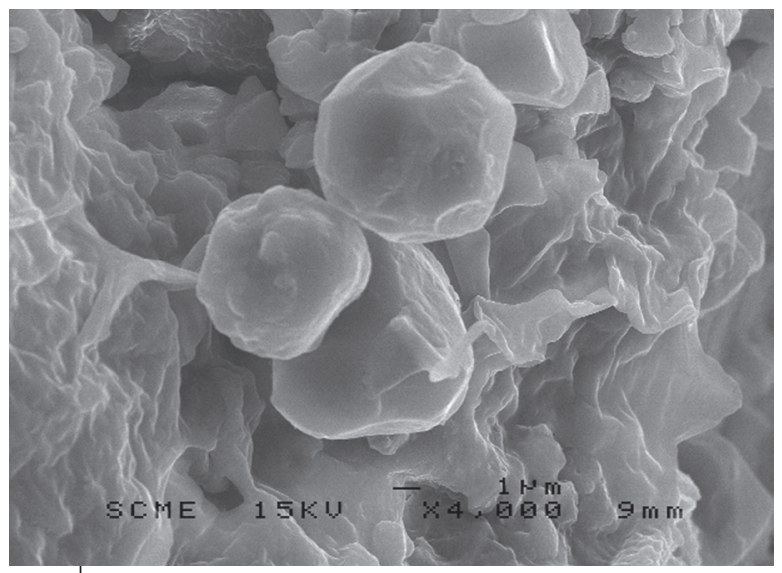

Photo 5.3.

Grains d'amidon de fonio (๔ G. Fliedel). 


\section{Composition biochimique du grain de fonio}

La composition biochimique du fonio décortiqué et du fonio blanchi a été étudiée par le Cirad (Fliedel et al., 2004).

\section{Composition biochimique du grain de fonio décortiqué ou fonio complet}

En ce qui concerne ses principales composantes, le fonio décortiqué a une composition comparable à celle des autres céréales nues (tableau 5.1.) : $85 \%$ de glucides, $3,5 \%$ de lipides, $10 \%$ de protides et $1 \%$ de matières minérales.

Tableau 5.1. Composition biochimique du fonio complet (comparée à d'autres céréales).

\begin{tabular}{lcccc}
\hline Céréale & $\begin{array}{c}\text { Glucides } \\
(\boldsymbol{\%} \text { matière sèche })\end{array}$ & $\begin{array}{c}\text { Lipides } \\
(\boldsymbol{\%} \text { m.s. })\end{array}$ & $\begin{array}{c}\text { Protides } \\
(\boldsymbol{\%} \text { m.s. })\end{array}$ & $\begin{array}{c}\text { Matières } \\
\text { minérales } \\
(\boldsymbol{\%} \text { m.s. })\end{array}$ \\
\hline Fonio décortiqué & $84-86$ & $3,3-3,8$ & $9-11$ & $1-1,1$ \\
\hline Sorgho & 84 & 3,5 & 11 & 1,2 \\
\hline Mil & 83 & 4,0 & 12 & 1,2 \\
\hline Maïs & 83 & 4,5 & 11 & 1,3 \\
\hline Riz cargo & 86 & 2,5 & 10 & 1,4 \\
\hline
\end{tabular}

Source : Cirad (Fliedel et al., 2004).

Plus en détail, en matière de glucides, le fonio décortiqué semble légèrement plus riche en amidon (68\% de matière sèche) que le sorgho et le mil (61 à $65 \%$ m.s.), mais les teneurs peuvent varier de 60 à $75 \%$ m.s. selon les variétés. La teneur en amylose est voisine de $24 \%$ m.s. La teneur en fibres totales (cellulose, hémicellulose et lignine), proche de 7 à $8 \%$ m.s., est équivalente à celle des mils et sorghos. Les teneurs respectives en hemicellulose et cellulose sont semblables et proches de 3 à $4 \%$ m.s., tandis que la teneur en lignine reste faible à $0,5 \%$ m.s. La teneur en sucres libres est voisine de $1 \%$ m.s. Les sucres présents sont principalement le saccharose $(0,7$ à $0,8 \%$ m.s.), puis le glucose et le fructose.

La teneur en lipides (3,3 à 3,8\% m.s.) est comparable à celle du sorgho $(3,5 \%$ m.s $)$ et légèrement inférieure à celle du mil ou du maïs (4 à 4,5 \% m.s.), mais supérieure à celle du riz cargo (2,5\% m.s.). Cela est cohérent avec la comparaison des tailles relatives des germes dans 
les différents grains. Plus de $75 \%$ des acides gras présents sont des acides gras insaturés, surtout représentés par l'acide linoléique C18:2 (45\%) et l'acide oléique C18:1 (31\%), alors que le principal acide gras saturé est l'acide palmitique C16:0 (17\%).

Le fonio décortiqué contient légèrement moins de protéines (9 à $11 \%$ m.s.) que le mil, le sorgho ou le maïs (11 à $12 \%$ m.s.), mais reste équivalent au riz cargo (10 \% m.s.).

\section{Fonio et gluten}

Le fonio contient bien les quatre fractions protéiques courantes des céréales : albumines, globulines, prolamines et glutélines. Dans l'intolérance au gluten, seules certaines prolamines ont une toxicité démontrée comme l' $\alpha$-gliadine du blé, l'hordéine de l'orge et la sécaline du seigle. D'autres prolamines comme celle du sorgho (kafirine) ou celle du riz (orzénine) n'entraînent pas d'intolérances particulières. Le fonio, plus proche du mil, du maïs ou du sorgho que du blé (Mugnier, 2001), ne produit pas de troubles spécifiques car il ne doit pas avoir la séquence particulière d'acides aminés qui semble responsable de l'intolérance au gluten dans la maladie coeliaque (voir chapitre 9). Cette supposition mériterait d'être vérifiée par des recherches spécifiques.

La composition en acides aminés (tableau 5.2.) est équilibrée même si la teneur en lysine est faible comme dans toutes les céréales.

Tableau 5.2. Composition du fonio complet en acides aminés.

\begin{tabular}{|c|c|c|c|c|c|}
\hline Acide aminé & $\begin{array}{l}\text { Teneur } \\
\text { (\% m.s.) }\end{array}$ & Acide aminé & $\begin{array}{l}\text { Teneur } \\
\text { (\% m.s.) }\end{array}$ & Acide aminé & $\begin{array}{l}\text { Teneur } \\
(\% \text { m.s. })\end{array}$ \\
\hline $\begin{array}{l}\text { Acide aspartique } \\
+ \text { asparagine }\end{array}$ & 0,68 & Histidine & 0,17 & Proline & 0,51 \\
\hline $\begin{array}{l}\text { Acide glutamique } \\
+ \text { glutamine }\end{array}$ & 2,16 & Isoleucine & 0,28 & Sérine & 0,49 \\
\hline Alanine & 1,24 & Leucine & 0,91 & Thréonine & 0,34 \\
\hline Arginine & 0,93 & Lysine & 0,19 & Tryptophane & 0,16 \\
\hline Cystéine & 0,07 & Méthionine & 0,34 & Tyrosine & 0,23 \\
\hline Glycine & 0,08 & Phénylalanine & 0,47 & Valine & 0,52 \\
\hline
\end{tabular}

Source : Cirad (Fliedel et al., 2004).

La valeur énergétique du fonio décortiqué est de $1470 \mathrm{~kJ}$ (environ $350 \mathrm{kcal})$ par $100 \mathrm{~g}$. 
Les éléments minéraux majoritaires du fonio décortiqué sont le phosphore et le potassium comme pour les autres céréales, et le fonio complet reste la céréale la plus riche en soufre. Le tableau 5.3. donne la composition en éléments minéraux du fonio complet comparée à celle d'autres céréales.

Tableau 5.3. Composition en éléments minéraux du fonio complet.

\begin{tabular}{lclll}
\hline Éléments minéraux & $\begin{array}{c}\text { Fonio } \\
\text { décortiqué }\end{array}$ & Maïs & Mil sanio & Sorgho \\
\hline
\end{tabular}

\begin{tabular}{lllll}
\hline Matières minérales (\% m.s.) & 1,02 & 1,28 & 1,16 & 1,13 \\
\hline
\end{tabular}

Macroéléments (\% m.s.)

\begin{tabular}{lrrrr}
\hline Calcium (Ca) & 0,022 & 0,012 & 0,017 & 0,014 \\
\hline Magnésium (Mg) & 0,13 & 0,12 & 0,11 & 0,13 \\
\hline Phosphore (P) & 0,25 & 0,34 & 0,23 & 0,25 \\
\hline Potassium (K) & 0,17 & 0,33 & 0,34 & 0,25 \\
\hline Soufre (S) & 0,16 & 0,12 & 0,12 & 0,13 \\
\hline
\end{tabular}

Microéléments (ppm)

\begin{tabular}{lrrrr}
\hline Cuivre $(\mathrm{Cu})$ & 6,8 & 2,2 & 4,9 & 6,2 \\
\hline Fer $(\mathrm{Fe})$ & 38,8 & 33,4 & 82,5 & 94,6 \\
\hline Manganèse $(\mathrm{Mn})$ & 21,6 & 9,4 & 13,0 & 20,9 \\
\hline Sodium $(\mathrm{Na})$ & 72,3 & 67,0 & 102,6 & 58,7 \\
\hline Zinc $(\mathrm{Zn})$ & 33,4 & 28,7 & 33,1 & 32,6 \\
\hline
\end{tabular}

Source : Cirad (Fliedel et al., 2004).

Les éléments minéraux sont, pour la plupart, concentrés dans les couches périphériques du grain, et sont donc, en grande partie, éliminés lors du blanchiment.

Le grain de fonio décortiqué contient surtout de la vitamine B1 (0,48 mg pour $100 \mathrm{~g} \mathrm{m.s.})$, mais ce taux chute considérablement $(0,06 \mathrm{mg}$ pour $100 \mathrm{~g}$ m.s.) après blanchiment.

\section{Composition biochimique du grain de fonio blanchi}

Au niveau de ses principales composantes, le fonio blanchi reste comparable aux autres céréales transformées. Comme le blanchiment a éliminé le son (péricarpe et germe) pour ne conserver que l'amande, le grain blanchi apparaît logiquement plus riche en glucides (89 à 
$91 \%$ m.s.) et plus pauvre en protides (7 à $9 \%$ m.s.), lipides ( 0,8 à $1 \%$ m.s.) et matières minérales $(0,3$ à $0,6 \%$ m.s.) que le fonio décortiqué (tableau 5.4.).

Tableau 5.4. Composition biochimique du fonio blanchi (comparée à celle d'autres céréales transformées).

\begin{tabular}{lcccc}
\hline Céréale & $\begin{array}{c}\text { Glucides } \\
(\boldsymbol{\%} \text { matière sèche })\end{array}$ & $\begin{array}{c}\text { Lipides } \\
(\boldsymbol{\%} \text { m.s. })\end{array}$ & $\begin{array}{c}\text { Protides } \\
(\boldsymbol{\%} \text { m.s. })\end{array}$ & $\begin{array}{c}\text { Matières } \\
\text { minérales } \\
(\% \text { m.s. })\end{array}$ \\
\hline Fonio blanchi & $89-91$ & $0,8-1,0$ & $7-9$ & $0,3-0,6$ \\
\hline Sorgho décortiqué & 88 & 1,2 & 10 & 0,5 \\
\hline Mil décortiqué & 87 & 1,2 & 11 & 0,8 \\
\hline Maïs décortiqué & 88 & 1,0 & 10 & 1,0 \\
\hline Riz blanc & 90 & 0,9 & 8 & 0,5 \\
\hline
\end{tabular}

Source : Cirad (Fliedel et al., 2004).

Au niveau des glucides, le fonio blanchi reste légèrement plus riche en amidon (80\% m.s.) que le sorgho et le mil (66 à $70 \%$ m.s.), mais les teneurs peuvent varier de 70 à $90 \%$ m.s. selon les variétés. La teneur en amylose est voisine de $28 \%$ m.s. La teneur en fibres totales (cellulose, hémicellulose et lignine) est logiquement réduite et proche de 4 à $5 \%$ m.s., avec des teneurs respectives en hemicellulose et cellulose de 2 et $3 \%$ m.s. Après blanchiment du grain, la teneur en sucres simples (glucose) chute à moins de $0,1 \%$ m.s.

Comme le blanchiment supprime l'essentiel du germe du grain, le fonio blanchi a une teneur en lipides très faible $(0,8$ à $1 \%$ m.s. $)$, voisine de celle du riz blanc et inférieure à celle des mils, sorghos ou maïs décortiqués (1 à 1,2\% m.s.). Les principaux acides gras présents restent les acides gras insaturés surtout représentés par l'acide linoléique C18:2 (43\%) et l'acide oléique C18:1 (31\%), alors que le principal acide gras saturé est l'acide palmitique C16:0 (19\%).

Le fonio blanchi contient légèrement moins de protéines (7 à $9 \%$ m.s.) que le mil, le sorgho ou le maïs (10 à $11 \%$ m.s.), mais reste équivalent au riz blanc (8\% m.s.). La composition en acides aminés est équilibrée (tableau 5.5.). Le fonio reste le plus riche en acides aminés soufrés. Sa richesse en méthionine $(0,42 \%$ m.s. $)$ est pratiquement le double de celle du mil ou du maïs $(0,22$ à $0,23 \%$ m.s. $)$ et le triple de celle du riz $(0,15 \%$ m.s. $)$. 
Tableau 5.5. Composition en acides aminés du fonio blanchi (comparée celle à d'autres céréales transformées).

\begin{tabular}{|c|c|c|c|c|c|}
\hline Acide aminé & $\begin{array}{c}\text { Fonio } \\
\text { blanchi }\end{array}$ & $\begin{array}{c}\text { Riz } \\
\text { blanchi }\end{array}$ & $\begin{array}{c}\text { Mil } \\
\text { décortiqué }\end{array}$ & $\begin{array}{c}\text { Sorgho } \\
\text { décortiqué }\end{array}$ & $\begin{array}{c}\text { Maïs } \\
\text { décortiqué }\end{array}$ \\
\hline $\begin{array}{l}\text { Acide aspartique } \\
+ \text { asparagine }\end{array}$ & 0,58 & 0,74 & 0,73 & 1,02 & 0,62 \\
\hline $\begin{array}{l}\text { Acide glutamique } \\
+ \text { glutamine }\end{array}$ & 2,33 & 1,35 & 1,27 & 3,48 & 2,25 \\
\hline Alanine & 0,94 & 1,32 & 1,15 & 1,48 & 1,29 \\
\hline Arginine & 1,00 & 0,44 & 0,63 & 1,50 & 0,80 \\
\hline Cystéine & 0,08 & 0,05 & 0,04 & 0,08 & 0,09 \\
\hline Glycine & 0,05 & 0,11 & 0,12 & 0,07 & 0,07 \\
\hline Histidine & 0,16 & 0,15 & 0,18 & 0,28 & 0,26 \\
\hline Isoleucine & 0,29 & 0,23 & 0,28 & 0,45 & 0,27 \\
\hline Leucine & 1,00 & 0,56 & 0,76 & 1,98 & 1,34 \\
\hline Lysine & 0,12 & 0,21 & 0,16 & 0,14 & 0,15 \\
\hline Méthionine & 0,42 & 0,15 & 0,23 & 0,24 & 0,22 \\
\hline Phénylalanine & 0,52 & 0,35 & 0,39 & 0,68 & 0,47 \\
\hline Proline & 0,56 & 0,27 & 0,59 & 1,12 & 0,88 \\
\hline Sérine & 0,48 & 0,35 & 0,37 & 0,59 & 0,47 \\
\hline Thréonine & 0,33 & 0,23 & 0,11 & 0,41 & 0,33 \\
\hline Tryptophane & 0,13 & 0,11 & 0,11 & 0,15 & 0,04 \\
\hline Tyrosine & 0,27 & 0,21 & 0,19 & 0,38 & 0,27 \\
\hline Valine & 0,52 & 0,43 & 0,49 & 0,68 & 0,48 \\
\hline
\end{tabular}

Source : Cirad (Fliedel et al., 2004).

La valeur énergétique du fonio blanchi est de $1430 \mathrm{~kJ}$ (environ $340 \mathrm{kcal})$ par $100 \mathrm{~g}$.

Beaucoup d'éléments minéraux, souvent concentrés en périphérie du grain, sont en grande partie éliminés lors du blanchiment. Dans le fonio blanchi, les teneurs en éléments minéraux sont donc nettement plus faibles que dans le fonio complet, sauf pour le soufre, qui semble présent plus en profondeur dans le grain. Le fonio blanchi reste ainsi plus riche en soufre $(0,16 \%$ m.s.) que les autres céréales transformées (tableau 5.6.). Contrairement à ce qui est parfois affirmé, le fonio n'est pas plus riche en fer que d'autres céréales comme les mils ou les sorghos. 
Tableau 5.6. Composition en éléments minéraux du fonio blanchi (comparée à celle d'autres céréales).

\begin{tabular}{lccccc}
\hline Éléments minéraux & $\begin{array}{c}\text { Fonio } \\
\text { blanchi }\end{array}$ & $\begin{array}{c}\text { Riz } \\
\text { blanchi }\end{array}$ & $\begin{array}{c}\text { Mil sanio } \\
\text { décortiqué }\end{array}$ & $\begin{array}{c}\text { Sorgho } \\
\text { décortiqué }\end{array}$ & $\begin{array}{c}\text { Maïs } \\
\text { décortiqué }\end{array}$ \\
\hline $\begin{array}{l}\text { Matières minérales } \\
\text { (\% m.s.) }\end{array}$ & 0,3 & 0,5 & 0,8 & 0,8 & 1,0 \\
\hline Macroéléments (\% m.s.) & & & & & \\
\hline Calcium (Ca) & 0,01 & 0,01 & 0,01 & 0,01 & 0,01 \\
\hline Magnésium(Mg) & 0,03 & 0,01 & 0,08 & 0,06 & 0,03 \\
\hline Phosphore (P) & 0,06 & 0,06 & 0,16 & 0,12 & 0,09 \\
\hline Potassium (K) & 0,02 & 0,03 & 0,20 & 0,10 & 0,08 \\
\hline Soufre (S) & 0,16 & 0,08 & 0,10 & 0,11 & 0,12 \\
\hline Microéléments (ppm) & & & & & 1,10 \\
\hline Cuivre (Cu) & 3,0 & 1,8 & 3,8 & 2,1 & 1,5 \\
\hline Fer (Fe) & 27,3 & 23,4 & 59,8 & 65,0 & 18,9 \\
\hline Manganèse (Mn) & 4,9 & 12,2 & 8,2 & 8,5 & 2,5 \\
\hline Sodium (Na) & 58,5 & 59,1 & 82,0 & 53,5 & 32,7 \\
\hline Zinc (Zn) & 21,8 & 18,6 & 28,5 & 13,2 & 7,4 \\
\hline
\end{tabular}

Source : Cirad (Fliedel et al., 2004).

En conclusion, le fonio blanchi est donc essentiellement un aliment glucidique dont la composition biochimique est comparable à celle du riz blanc, mais avec une richesse particulière en acides aminés soufrés comme la méthionine. Comme le riz blanc, il n'entraîne pas d'intolérances particulières au gluten.

\section{Décorticage et blanchiment}

Il a déjà été précisé que les grains bruts de fonio paddy obtenus après battage des épis n'étaient pas consommables en l'état et qu'ils devaient nécessairement être transformés avant d'être cuisinés.

\section{ID Diagramme de transformation}

À l'instar de l'usinage du riz, la transformation du fonio nécessite la succession de deux opérations unitaires (figure 5.4.) : le décorticage, 
qui permet d'enlever les balles du fonio paddy (grain vêtu) pour obtenir le fonio décortiqué ou fonio complet (grain nu); le blanchiment, qui a pour objet d'éliminer le son (péricarpe et germe) du fonio complet pour obtenir le fonio blanc.

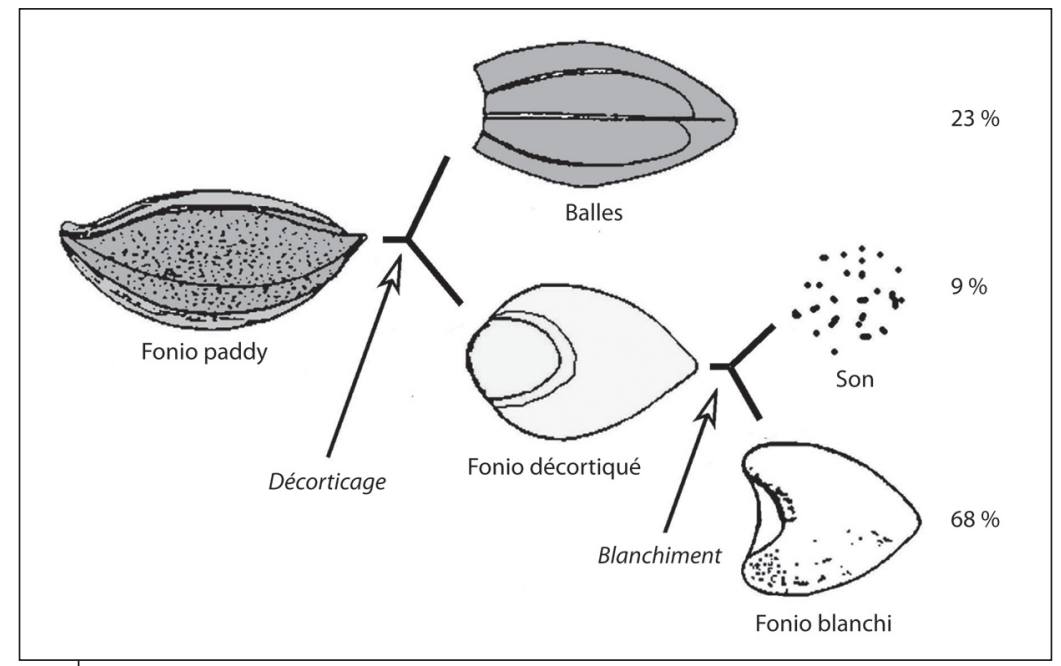

Figure 5.4.

Diagramme de transformation du fonio (Cruz, 2011).

Si l'on souhaite consommer du fonio complet, on ne procède alors qu'au décorticage.

Des mesures réalisées en 1999 au laboratoire Cirad à Montpellier sur cinq variétés de fonio de Guinée ont montré que les balles et le son représentaient respectivement $23 \%$ et $9 \%$ du grain paddy (Cruz, 2001).

Les rendements de transformation du fonio sont donnés par les formules suivantes :

Rendement de décorticage :

$\mathrm{Rd}=\frac{\text { Quantité de fonio décortiqué }}{\text { Quantité de fonio paddy }} \times 100$

Rendement de blanchiment :

$\mathrm{Rb}=\frac{\text { Quantité de fonio blanchi }}{\text { Quantité de fonio décortiqué }} \times 100$ 
Rendement de transformation :

$\mathrm{Rt}=\mathrm{Rd} \times \mathrm{Rb}=\frac{\text { Quantité de fonio blanchi }}{\text { Quantité de fonio paddy }} \times 100$

À partir du fonio paddy, les rendements potentiels en fonio complet et en fonio blanchi sont donc respectivement de : $\mathrm{Rd}=77 \%$ et $\mathrm{Rt}=68 \%$.

\section{ID Le décorticage traditionnel}

Le décorticage et le blanchiment du fonio sont des opérations traditionnellement réalisées par les femmes au moyen de mortiers et de pilons en bois (figure 5.5.). Pour obtenir un fonio décortiqué destiné à la vente, les femmes effectuent trois à quatre pilages successifs entrecoupés de vannages. Un dernier pilage permet ensuite d'obtenir le fonio blanchi.

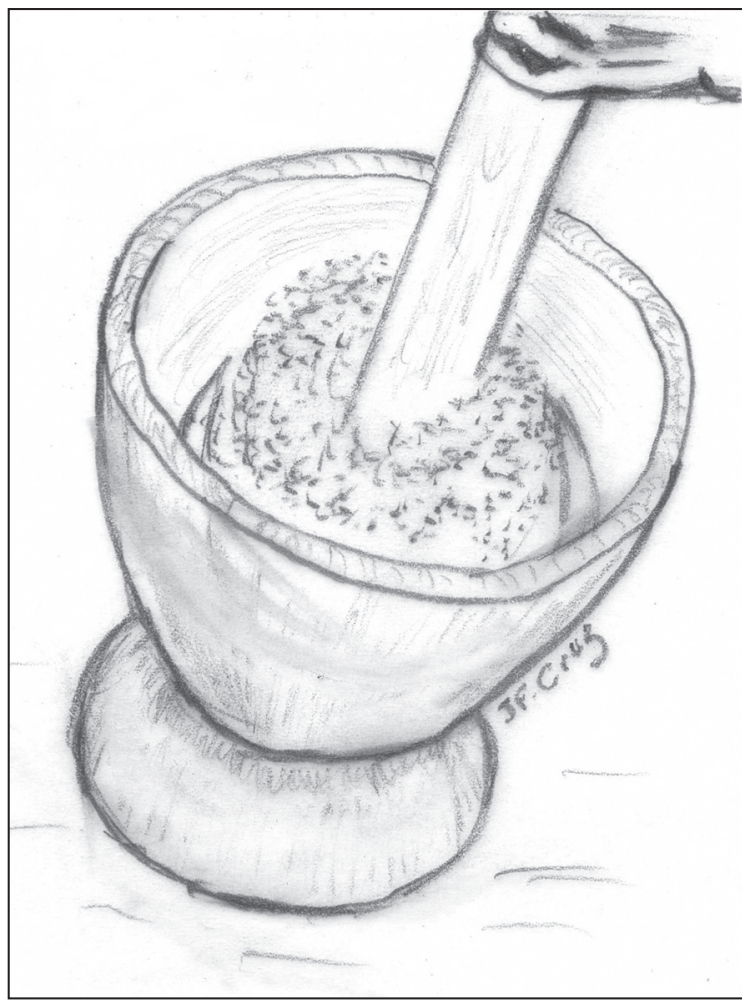

Figure 5.5.

Décorticage traditionnel du fonio au pilon et au mortier (J.-F. Cruz). 
L'observation d'un décorticage traditionnel dans le village de Kondia, près de Ségou au Mali, a permis de caractériser les différentes étapes de pilage du fonio (Cruz, 2001). La famille visitée, constituée de cinq ménages, produit du fonio sur un champ d'environ 2 ha et cultive habituellement deux variétés appelées «Souroukou Fini» et «Fini». En septembre 1999, le producteur a pu récolter près de $2600 \mathrm{~kg}$ de grains qui ont été stockés en vrac dans un grand grenier en banco. Malgré le bon rendement obtenu de $1300 \mathrm{~kg} / \mathrm{ha}$, cette famille ne souhaite pas cultiver davantage de fonio en raison des difficultés de transformation. Ce sont cinq femmes de la famille qui ont réalisé le décorticage du fonio en utilisant des grains de la variété Fini.

\section{Nettoyage des grains bruts}

La première phase du processus consiste à nettoyer le lot de grains puisé dans le grenier. Le contenu d'une calebasse, environ $6 \mathrm{~kg}$, est tamisé une première fois par les femmes pour éliminer les grosses impuretés (pailles, tiges, cailloux) à l'aide d'un tamis à maille de $2 \mathrm{~mm}$ appelé «bassi témé». Pour séparer les impuretés fines (terre, sable, poussières), un second nettoyage est ensuite réalisé à l'aide d'un tamis à maille fine de $1 \mathrm{~mm}$ appelé «mougou témé». Dans le cas présent, le fonio stocké dans le grenier était relativement sale puisque le taux d'impuretés atteignait $11,7 \%$.

\section{Décorticage et vannage des grains}

Après le nettoyage, les cinq femmes se relaient pour effectuer les différentes opérations de décorticage. Un premier décorticage d'une durée de cinq minutes est réalisé par deux femmes sur un même pilon. Il est suivi d'un premier vannage. Les femmes effectuent ensuite trois autres décorticages entrecoupés de vannages. Le fonio obtenu après le quatrième décorticage-vannage est souvent appelé «fonio prédécortiqué » et il est vendu comme tel sur les marchés locaux à un prix voisin de $300 \mathrm{FCFA} / \mathrm{kg}(0,46 € / \mathrm{kg})$ en période normale et de 375 à $400 \mathrm{FCFA} / \mathrm{kg}(0,57$ à $0,61 € / \mathrm{kg})$ en période de soudure.

Les rendements des différentes opérations sont donnés dans le tableau 5.7.

Le fonio dit "prédécortiqué» obtenu après le quatrième décorticagevannage devrait correspondre à du fonio complet, mais le rendement du décorticage traditionnel obtenu $(69,8 \%)$ se révèle être relativement faible par rapport au rendement potentiel qui devrait être voisin de $77 \%$ (figure 5.4.). En réalité, le quatrième décorticage réalisé ici 
Tableau 5.7. Mesure des rendements au cours de différents décorticages traditionnels.

\begin{tabular}{lccc}
\hline Opération & $\begin{array}{c}\text { Durée } \\
(\mathbf{m i n})\end{array}$ & $\begin{array}{c}\text { Quantité de produit } \\
\text { récupéré }(\mathbf{g})\end{array}$ & $\begin{array}{c}\text { Rendement } \\
(\boldsymbol{\%})\end{array}$ \\
\hline Prise de fonio dans le grenier & \multicolumn{6}{c}{6000} & \\
\hline Nettoyage & 10 & 5300 & 88,7 \\
\hline $1^{\text {er }}$ décorticage et vannage & 5 & 4700 & 80,0 \\
\hline $2^{\mathrm{e}}$ décorticage et vannage & 6 & 4250 & 73,6 \\
\hline $3^{\mathrm{e}}$ décorticage et vannage & 10 & 3900 & 69,8 \\
\hline $4^{\mathrm{e}}$ décorticage et vannage & 8 & 3700 & 68,0 \\
\hline $5^{\mathrm{e}}$ décorticage (blanchiment) & 4 & 3600 & \\
\hline
\end{tabular}

semble déjà correspondre à un premier blanchiment et il serait alors plus judicieux de qualifier le grain obtenu de «fonio préblanchi » plutôt que de «fonio prédécortiqué». À l'issue du cinquième décorticage, qui correspond au véritable blanchiment, le rendement observé de $68 \%$ est bien égal au rendement de transformation potentiel.

La durée totale de l'opération réalisée par les cinq femmes a été d'environ une heure. Le débit unitaire du décorticage traditionnel reste très faible puisqu'il dépasse à peine $1 \mathrm{~kg} / \mathrm{h}$. Le décorticage manuel au pilon et au mortier est toujours considéré comme très pénible par les femmes, qui sont disposées à payer $15 \mathrm{FCFA} / \mathrm{kg}$ pour faire réaliser cette opération par d'autres.

En Guinée, le décorticage manuel est également réalisé par les femmes au pilon et au mortier. Lorsque le fonio est destiné à la consommation familiale, la succession des opérations est menée avec soin jusqu'au blanchiment des grains, ce qui limite le débit moyen assuré par les ménagères de 1 à $1,5 \mathrm{~kg}$ par heure. Les femmes expérimentées qui pratiquent le décorticage à titre professionnel sont généralement plus performantes car elles peuvent transformer 2 à $3 \mathrm{~kg}$ à l'heure, mais elles arrêtent souvent l'opération avant que les grains ne soient réellement blanchis. Le coût de la prestation en 2002 était de 150 FG (franc guinéen) par mesure de $1,3 \mathrm{~kg}$, soit à l'époque environ $40 \mathrm{FCFA} / \mathrm{kg}$ $(0,06 € / \mathrm{kg})$.

Au Burkina Faso, le décorticage du fonio est effectué traditionnellement au mortier et au pilon par des groupes de femmes. Il consiste, là également, en une succession de trois à quatre pilages séparés par 
des nettoyages qui se limitent en général à de simples vannages. Le décorticage peut être l'objet d'un travail à façon dont le coût varie de 15 à $30 \mathrm{FCFA} / \mathrm{kg}$. Le produit décortiqué destiné à la vente au marché est parfois mélangé à de la cendre pour améliorer le stockage. Il est rarement nettoyé par les producteurs eux-mêmes qui considèrent que ce travail incombe aux transformatrices finales.

Partout, le décorticage traditionnel au pilon et au mortier est considéré par les femmes comme un travail long et harassant. Il nécessite des efforts importants en regard des faibles quantités obtenues et il génère de nombreuses poussières (balles, etc.) qui occasionnent de fortes démangeaisons oculaires. Dans ces conditions, les demandes des opérateurs de la filière fonio, et principalement des femmes, concernent prioritairement la mécanisation du décorticage.

\section{Lavage et dessablage avant cuisson}

Après transformation et vannage, des particules de son et de poussières restent souvent collées à la surface des grains de fonio. Les ménagères procèdent alors à plusieurs lavages du fonio blanchi. Les grains sont versés dans une grande calebasse remplie d'eau claire, puis brassés à la main pour bien décoller les impuretés. Les grains de fonio tombent au fond de la calebasse alors que les particules fines surnagent et sont éliminées en versant l'eau de surface dans un autre récipient. L'eau sale, chargée des sons et des diverses impuretés, est ensuite éliminée ou parfois donnée à boire aux animaux. Cette opération de lavage peut être répétée plusieurs fois selon la propreté des grains.

Puis les femmes procèdent à l'élimination minutieuse des grains de sable présents dans le fonio. Au cours des différentes opérations postrécolte et notamment lors du battage des gerbes sur le sol, des impuretés constituées le plus souvent par des grains de sable ou de latérite peuvent être mélangées aux grains de fonio. Les opérations ultérieures de vannage et de tamisage permettent d'éliminer, en partie, ces impuretés fines mais pas les grains de sable qui ont les mêmes dimensions que les grains de fonio. À l'instar des cailloux dans les lentilles, la présence de sable constitue un des principaux problèmes de qualité du fonio.

De l'eau claire est apportée au fonio préalablement lavé, puis le mélange est lentement versé dans un récipient plus grand (calebasse 


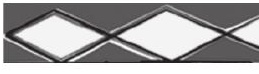

ou bassine). Les grains de fonio, plus légers, sont entraînés avec l'eau ainsi transvasée, alors que les sables, plus lourds, restent au fond de la première calebasse (photo 5.4.). Cette opération traditionnelle de dessablage ressemble beaucoup à l'opération d'orpaillage à l'aide d'une batée. La qualité de la séparation dépend essentiellement du savoir-faire de l'opératrice qui renouvelle l'opération plusieurs fois jusqu'à ce qu'elle considère qu'il n'y a plus de sable mélangé aux grains. Souvent quatre dessablages sont nécessaires pour obtenir un fonio exempt de sable. Les grains lavés sont ensuite placés par petites quantités dans un tamis fin ou dans un torchon et essorés d'un geste vif de balancier du bras. Le fonio blanchi ainsi lavé et essoré est prêt à être cuit, le plus souvent à la vapeur, et préparé selon différentes recettes.

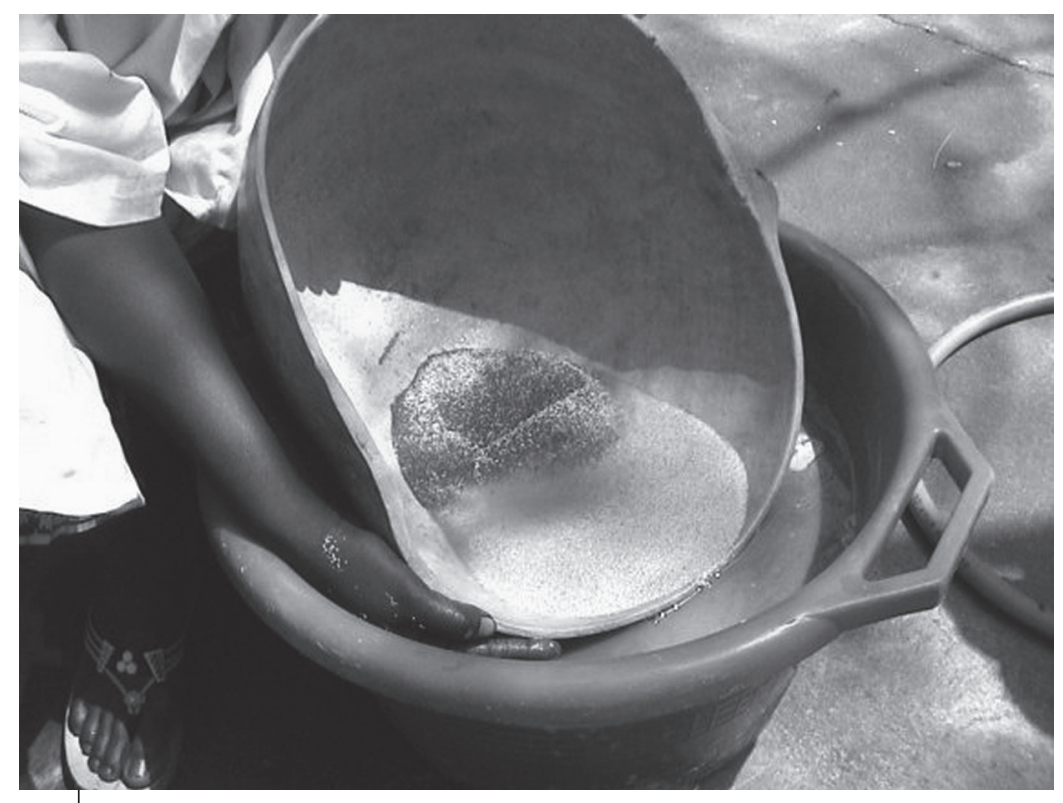

Photo 5.4.

Séparation des sables présents dans le fonio (৫) J.-F. Cruz).

Les transformatrices ont l'habitude de dire que le lavage et le dessablage sont des opérations difficiles qui nécessitent «beaucoup de patience et beaucoup d'eau». Certaines d'entre elles considèrent qu'il faut près de $10 \mathrm{l}$ d'eau pour laver et dessabler $1 \mathrm{~kg}$ de fonio et elles 
qualifient alors le fonio de céréale «la plus coquette» (Leplaideur et al., 1994). Cette forte consommation en eau est une réelle contrainte dans les régions où les ressources sont rares. Par ailleurs, l'absence de recyclage ou de traitement des effluents chargés en matières organiques pose également une question environnementale qui devient préoccupante, notamment à l'échelle des petites unités de transformation qui produisent annuellement plusieurs dizaines de tonnes de fonio. C'est aujourd'hui l'un des problèmes majeurs de la filière. 


\section{$\sqrt{6}$ 6. L'amélioration des technologies post-récolte}

La description des différentes pratiques traditionnelles après la récolte du fonio montre combien elles sont souvent harassantes pour les paysans et leur famille. Beaucoup de producteurs sont alors tentés d'abandonner cette céréale au profit d'autres cultures vivrières jugées moins contraignantes, comme c'est le cas dans le nord du Bénin, où le fonio est 71 progressivement remplacé par le maïs. Lamélioration des
technologies post-récolte du fonio est donc essentielle pour éviter que cette filière ne disparaisse et pour maintenir, partout où c'est possible, une diversité de la production agricole pour s'adapter au mieux aux changements climatiques.

La volonté de mécaniser les opérations post-récolte du fonio n'est pas nouvelle car déjà en 1905, L. Renoux et P. Dumas évoquaient le battage mécanique du fonio : «Nous remarquerons que le foulage du fonio par la méthode indigène est une opération longue. Nous l'avons vu pratiquer très rapidement au moyen d'une petite batteuse, munie de secoueurs qui supprimaient en même temps le vannage.»

Plus tard, en 1929, Émile Perrot, chimiste et botaniste français, écrit dans son rapport de mission en Guinée que le chef du canton de Dalaba «récolte des légumes superbes, du riz, du mil, du fonio». Il précise concernant le fonio : "Cette petite graine est en telle abondance, que le village en peut exporter 60 à 80 tonnes et que ce chef intelligent, riche, voulut me remettre 20000 francs pour lui envoyer une machine à décortiquer : les femmes ne pouvant plus trouver, comme autrefois, le temps nécessaire à cette opération de pilonnage à la main. Naturellement, je déclinai l'offre, aucune machine n'ayant encore été étudiée pour cet objet, mais je lui promis toutefois de m'occuper de la question.»

Puis, dans une note, il précise encore qu'il a finalement tenu parole et envoyé au gouverneur «deux machines à bras pour décortiquer le fonio».

Quelles étaient ces différentes machines ? Aucune description précise n'en a jamais été faite et aucune référence à d'éventuelles copies 
reproduites et diffusées par des artisans locaux n'existe, car ce sont partout les techniques manuelles qui prévalent encore aujourd'hui.

D'autres tentatives éparses ont pu exister çà ou là mais le tout premier projet international d'amélioration des technologies post-récolte du fonio n'a vu le jour qu'en 1999. Placé sous l'égide du Groupe intergouvernemental sur les grains de la FAO et financé par le CFC (Common Fund for Commodities), organisme des Nations unies, ce premier projet régional sur le fonio a été coordonné par le Cirad et réalisé en collaboration avec les instituts de recherche nationaux du Mali (Institut d'économie rurale), de la Guinée (Institut de recherche agronomique de Guinée) et du Burkina Faso (Institut de recherche en sciences appliquées et technologie). Le projet a regroupé des scientifiques de divers horizons - mécanisation, ingénierie de procédés, technologie alimentaire, agronomie, sciences sociales, etc. - et a favorisé la participation du secteur privé, et notamment les artisans locaux (manufacturiers) et les petites entreprises de transformation.

C'est dans ce cadre que diverses études techniques ont été réalisées pour mécaniser les principales opérations post-récolte (Cruz et Dramé, 2005).

\section{Battage}

Le battage manuel a été décrit comme une activité très pénible qui exige beaucoup de travail et de personnel. Avec le fauchage, c'est l'opération agricole qui requiert le plus de main-d'œuvre, soit environ 15 à 20 hommes-jour par hectare (Daho et al., 2007). Le délai entre la récolte et le battage, qui est parfois relativement long à cause du manque de temps et de main-d'œuvre, peut engendrer des pertes après récolte et affecter la qualité du grain selon les conditions de stockage des gerbes. En raison de sa pénibilité, le battage est l'opération pour laquelle les hommes souhaitent pouvoir bénéficier de machines adaptées à leurs besoins. C'est cette demande qui a justifié que la mécanisation du battage soit considérée comme une priorité dans le cadre du projet Amélioration des technologies post-récolte du fonio.

\section{ID Principes de battage mécanique}

Pour les céréales, le rôle essentiel des organes de battage est de séparer les grains des épis ou des panicules. Dans un batteur mécanique, ce 
résultat est obtenu par deux actions simultanées de choc du batteur et de frottement des tiges, sous faible épaisseur, entre le batteur et le contre-batteur. Habituellement, on distingue les batteurs à battes, de petit diamètre, utilisés pour le battage des épis compacts (maïs, mil) et les batteurs à dents, à doigts (figure 6.1.) ou à boucles, de plus grand diamètre, pour le battage des céréales à paille (riz, blé). Le fonio est une céréale à paille et le choix a donc porté sur l'adaptation d'une batteuse à riz au battage du fonio.

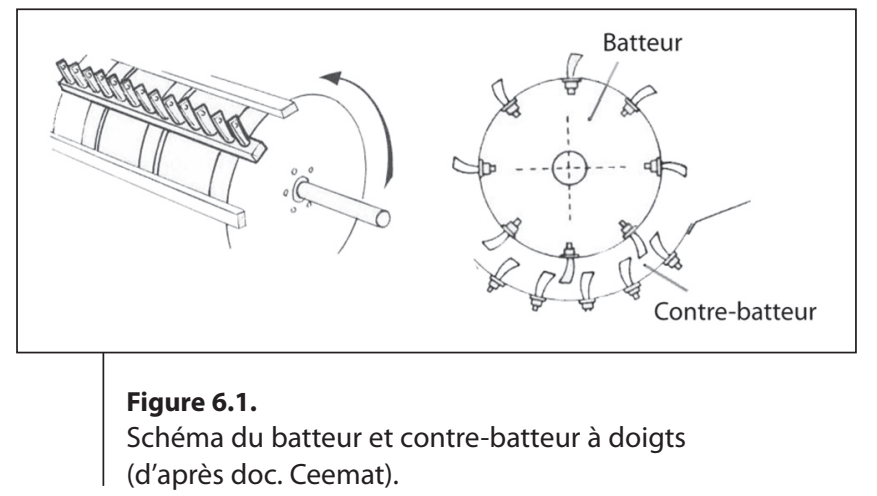

\section{II) Adaptation d'une batteuse Irri au battage du fonio}

La batteuse Irri, mise au point dans les années 1970 par l'International Rice Research Institute aux Philippines, est une batteuse à flux axial parmi les plus diffusées en Asie pour le battage du riz. Au début des années 1990, elle a été adaptée en Afrique pour devenir la batteuse Assi, développée au Sénégal par l'association du même nom, réunissant les partenaires suivants : Adrao (Association pour le développement de l'agriculture en Afrique de l'Ouest), Saed (Société nationale d'aménagement et d'exploitation des terres du delta du fleuve Sénégal), Sismar, société industrielle sénégalaise de matériel agricole, et Isra (Institut sénégalais de recherche agricole). Les batteuses de type Irri sont présentées avec ou sans système de nettoyage. Labsence de dispositif de nettoyage simplifie fortement la machine et réduit le coût de fabrication, mais nécessite un nettoyage manuel des grains.

La batteuse Assi utilisée pour le fonio a été fabriquée par la Sismar au Sénégal, puis adaptée au fonio en Guinée. Il s'agit d'une batteuse à poste fixe, entraînée par un moteur diesel de $14 \mathrm{ch}(10,3 \mathrm{~kW})$ et 
constituée d'un batteur à doigts à flux axial et d'une table de nettoyage ventilée (figure 6.2.). L'ensemble est monté sur un châssis à roues tractable par engins motorisés. Les dimensions principales de la machine, sans timon d'attelage, sont : 2 × 2,6 x 1,5 m (L x 1 x h).

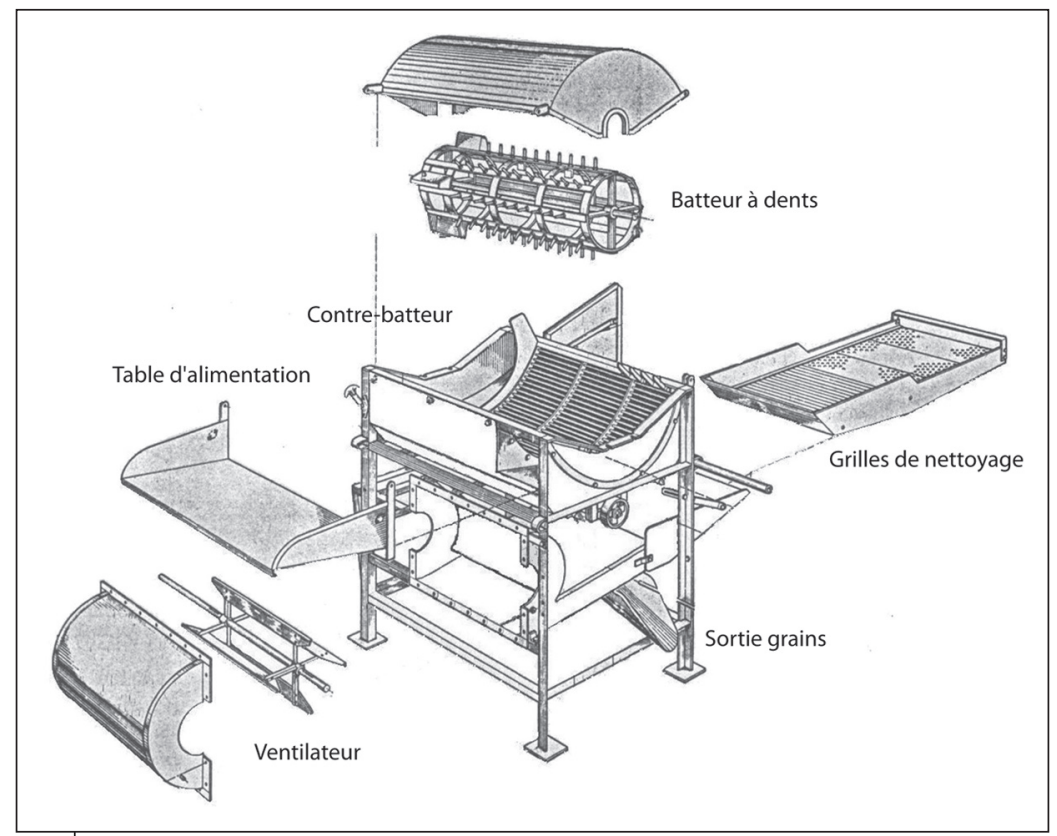

Figure 6.2.

«Écorché» d'une batteuse à riz (d'après doc. Irri).

Pour adapter cette batteuse à riz au battage du fonio, il n'y a pas eu de rectifications fondamentales de la structure de la machine, mais uniquement les modifications suivantes :

- Changement de la poulie du ventilateur pour réduire la vitesse du ventilateur : remplacement d'une poulie de $100 \mathrm{~mm}$ par une poulie de $125 \mathrm{~mm}$, avec montage d'un tendeur pour assurer la tension de la courroie.

- Mise au point des vitesses de rotation des pièces en mouvement et réglages :

- Vitesse de rotation du batteur : 710 à $785 \mathrm{tr} / \mathrm{min}$.

- Vitesse de rotation du ventilateur : 520 à $560 \mathrm{tr} / \mathrm{min}$.

- Vitesse de rotation de la vis sans fin : 415 à $480 \mathrm{tr} / \mathrm{min}$.

- Ouverture du volet de ventilation : 1,5 à 3,5. 
- Réglage de la distance entre l'extrémité des doigts et le contrebatteur diminuée de 10 à $8 \mathrm{~mm}$.

- Réduction de la longueur de la bielle du sasseur.

- Adaptation de la barre de traction pour permettre le remorquage de la batteuse par un véhicule.

- Modifications du système de nettoyage :

- Grille supérieure : tôle perforée de diamètre $3 \mathrm{~mm}$, grille rallongée de $450 \mathrm{~mm}$.

- Grille inférieure : montage sous le déflecteur inférieur d'un treillis de $1 \mathrm{~mm}$.

\section{II) Fonctionnement et performances de la batteuse Irri adaptée au fonio}

Les gerbes de fonio sont introduites manuellement dans la cage de battage au niveau de la table d'alimentation. Les grains battus et les menues pailles traversent le contre-batteur et tombent sur les grilles de nettoyage, tandis que les grandes pailles sont éjectées par le batteur à l'avant de la machine. Les grilles de nettoyage sont constituées d'une tôle supérieure avec des perforations de $3 \mathrm{~mm}$ et d'une grille inférieure à mailles de $1 \mathrm{~mm}$. Sous l'effet de la double action de secouage et de ventilation, le grain est séparé des menues pailles au niveau des grilles de nettoyage. Le grain propre est récupéré en sortie principale sur le côté de la machine, alors que les refus sont récupérés à une sortie secondaire et les impuretés à l'arrière de la machine.

Des essais de fonctionnement ont été réalisés de 2002 à 2004 au FoutaDjalon en Guinée dans le village de Seghen, puis dans différents villages des sous-préfectures de Garambé et de Hafia près de Labé. Pour une bonne efficacité de la machine, il est indispensable de bien sécher les gerbes entre la coupe et le battage pour réduire l'humidité des pailles. Les meilleurs débits obtenus correspondent à un séchage en meule pendant 3 à 8 jours. Avec la batteuse Assi modifiée, les débits de battage obtenus sont importants et varient de $250 \mathrm{~kg} / \mathrm{h}$ à $300 \mathrm{~kg} / \mathrm{h}$. La qualité du battage est jugée satisfaisante car il y a peu d'imbattus et le fonio obtenu est bien propre. Les producteurs de fonio qui ont participé aux essais ont fortement apprécié les performances de la machine.

Une estimation du coût du battage motorisé avec une batteuse Assi a été faite en avril 2004 en prenant l'hypothèse d'un tonnage d'environ $100 \mathrm{t}$ de fonio battu par an en 120 jours de fonctionnement (environ $400 \mathrm{~h}$ de travail par an à un débit moyen de $250 \mathrm{~kg} / \mathrm{h}$ ). 
En considérant un investissement de 13,6 millions de FG (environ 3,8 millions de FCFA à l'époque), amorti sur une durée de vie de la machine de huit ans, cette simulation conduit à un coût de battage voisin de 54 FG (ou 15 FCFA) par kilo de fonio battu; ce qui, dans les conditions locales, est équivalent au coût du battage manuel. Dans les dépenses, la part de l'amortissement de la machine représente $32 \%$, les réparations $25 \%$, la main-d'œuvre (trois opérateurs) $23 \%$ et les carburants et lubrifiants $19 \%$.

Les batteuses sont des équipements relativement coûteux à l'investissement et elles doivent normalement pouvoir être acquises par des associations villageoises ou des entrepreneurs privés, qui peuvent les rentabiliser en assurant des travaux en prestation de service. La machine a une capacité journalière qui correspond à la production moyenne de deux à trois producteurs. Elle doit donc être placée dans des lieux où elle est susceptible de fournir des prestations au groupe le plus large possible de producteurs, afin de limiter le temps et les coûts nécessaires à son déplacement dans un autre lieu de production.

En raison de son gabarit, la batteuse Assi convient très bien aux zones de plaine faciles d'accès, alors qu'en zones de montagne les déplacements sont plus difficiles. Il faut alors s'orienter vers l'utilisation de batteuses plus légères. C'est le cas dans l'ouest du Mali, dans la région accidentée de Kéniéba au sud de Kayes, où des batteuses à riz «ricefan» de type Votex (figure 6.3.), fabriquées par Socafon (Société coopérative artisanale des forgerons de l'Office du Niger), ont été testées dans certains villages par l'organisation de producteurs Benkouto, appuyée par l'ONG Le Damier.

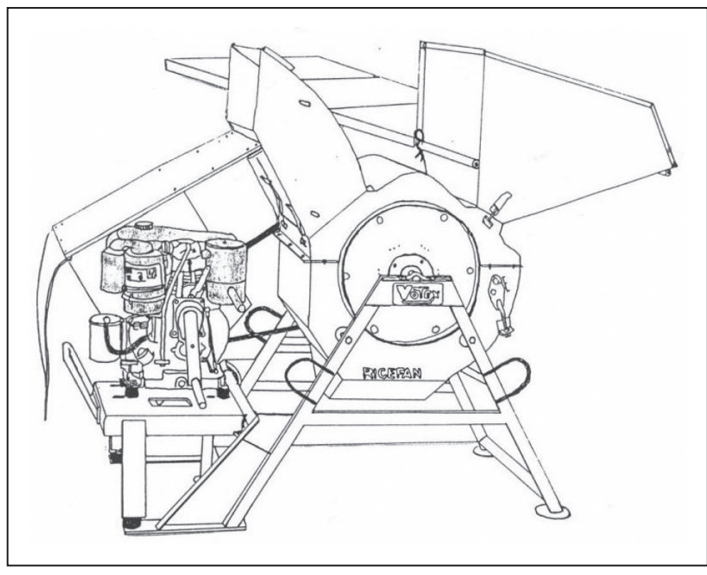

Figure 6.3.

Batteuse type «Votex» (d'après doc. FAO). 


\section{Nettoyage et triage}

Au cours des différentes séquences post-récolte et dès l'opération de battage, les bons grains peuvent être pollués par diverses matières étrangères. Ces impuretés mélangées à la matière première sont de nature minérale (cailloux, sables, métaux), végétale (pailles, graines étrangères, balles, sons, etc.) ou animale (insectes, fèces, etc.) et doivent être éliminées pour obtenir un produit transformé de qualité. Par ailleurs, les matières minérales, généralement plus dures, entraînent une usure prématurée des machines de transformation. Le nettoyage des grains est souvent réalisé par simple vannage pour éliminer les particules légères comme les pailles, puis par tamisage avec des tamis de différentes mailles pour séparer les impuretés grossières ou très fines comme les sables. Le nettoyage du fonio pose couramment plus de problèmes que celui d'autres céréales en raison de la petitesse de ses grains. Le lavage est alors souvent indispensable pour nettoyer la matière première mais, aussi et surtout, pour séparer les sables des produits transformés. Des avancées techniques ont été proposées dans le cadre du projet Amélioration des technologies post-récolte $\mathrm{du}$ fonio.

\section{II) Utilisation de tarares ou de cribles rotatifs}

Les matériels utilisés pour le nettoyage des céréales sont habituellement les tarares et les cribles rotatifs à entraînement manuel ou motorisés. Le tarare est un simple nettoyeur constitué de deux grilles superposées, animées d'un mouvement alternatif et traversées par un courant d'air généré par un ventilateur. La grille supérieure retient les grosses impuretés alors que la grille inférieure laisse passer les particules très fines; les bons grains sont toujours retenus entre les deux grilles alors que la ventilation permet d'éliminer les impuretés légères (figure 6.4.). Le tarare est polyvalent et a l'avantage de fonctionner même avec des produits chargés en pailles. Son principe de fonctionnement, consistant en un mouvement alternatif des grilles, le rend cependant fragile d'utilisation et on lui préfère alors souvent les nettoyeurs rotatifs plus robustes.

Le crible rotatif est un matériel très simple, constitué d'une trémie d'alimentation et d'un trommel cylindrique comportant deux grilles successives. La première grille à petites perforations laisse passer les impuretés très fines (poussières, sable), alors que la deuxième grille 


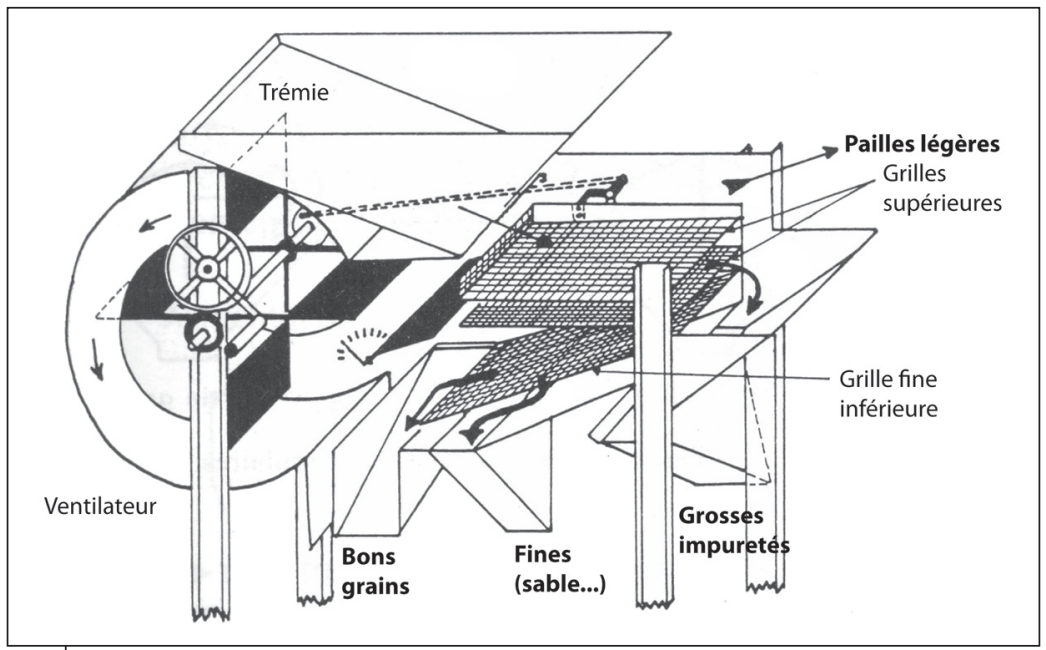

Figure 6.4.

Tarare

(Cruz et al., 1988).

laisse passer les bons grains et retient les corps étrangers grossiers, qui sont éliminés à l'extrémité de la machine (figure 6.5.). Léquipement a un axe légèrement incliné pour permettre une progression naturelle du produit lors du fonctionnement. Il est entraîné en rotation par une manivelle ou un petit moteur. Les bons grains et les diverses impuretés sont récupérés dans des récipients posés au sol sous la machine.

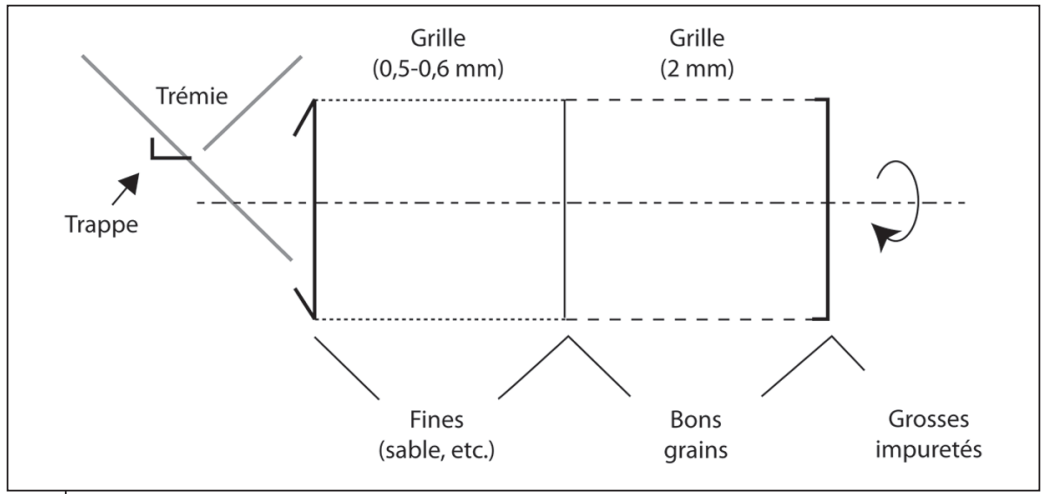

Figure 6.5.

Schéma du crible rotatif

(d'après Marouzé et al., 2005a). 
Dans le cadre du projet Amélioration des technologies post-récolte du fonio, différents modèles de cribles rotatifs de longueur plus ou moins importante ont été fabriqués au Mali et au Burkina Faso, et testés chez des partenaires privés. Les essais ont montré que les cribles rotatifs manuels permettent un bon nettoyage du fonio paddy ou du fonio décortiqué à des débits de 150 à $300 \mathrm{~kg} / \mathrm{h}$. Les transformatrices locales sont satisfaites de cet équipement qu'elles jugent très efficace pour le tamisage du fonio. Plusieurs évolutions du matériel sont possibles : polyvalence, motorisation électrique, etc. (Marouzé et al., 2005a). Avec un coût d'achat de 500000 FCFA, un amortissement sur cinq ans et pour le nettoyage de 50 à $100 \mathrm{t}$ par an, le coût d'utilisation du crible manuel varierait de 2 à 4 FCFA $/ \mathrm{kg}$ en fonction du type de machine.

\section{Mise au point d'un canal de vannage}

Le canal de vannage, conçu au Cirad en collaboration avec l'IER du Mali (Marouzé et al., 2005b), est constitué d'une tuyère verticale avec flux d'air ascendant dans laquelle le produit sale à nettoyer est introduit à mi-hauteur. Les particules légères sont aspirées par le flux d'air et récupérées au niveau d'un cyclone. Les grains et les particules plus lourdes tombent en partie inférieure du canal (figure 6.6.). Le canal de vannage est un équipement polyvalent qui peut être utilisé pour le vannage de différents grains (céréales, légumineuses, graines oléagineuses). Des essais réalisés chez une transformatrice au Mali ont permis d'obtenir un débit de $130 \mathrm{~kg} / \mathrm{h}$ avec du fonio décortiqué et d'atteindre 300 à $600 \mathrm{~kg} / \mathrm{h}$ avec du mil, du maïs ou du niébé décortiqué. Le canal de vannage peut aussi être placé en sortie du décortiqueur GMBF (voir plus loin). Pour un investissement de 400000 FCFA et un amortissement du matériel sur huit ans, le coût du

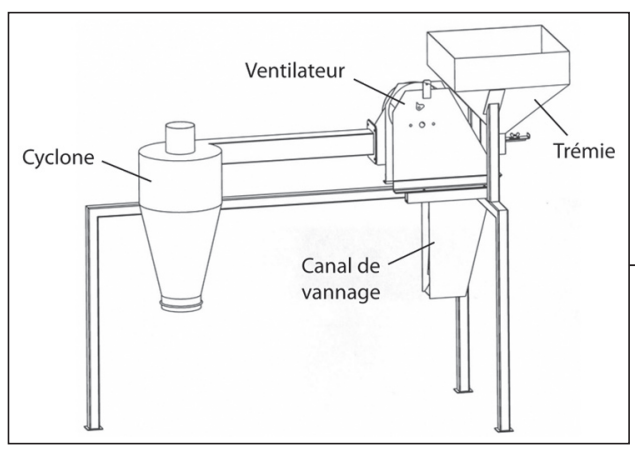

vannage mécanisé serait voisin de 3 FCFA $/ \mathrm{kg}$ (pour $65 \mathrm{t}$ de produits vannés en 200 jours de fonctionnement).

\section{Figure 6.6.}

Représentation du canal de vannage

(P. Thaunay). 


\section{IID Autres opérations de nettoyage : lavage et dessablage}

Après le décorticage du fonio, de nombreuses impuretés (sons, sables) restent mélangées aux grains. Lutilisation de nettoyeurs classiques n'est pas toujours efficace car, d'une part, les particules de son, souvent grasses, restent collées à la surface des grains et sont difficiles à séparer par simple vannage ou tamisage et, d'autre part, les sables, qui ont la même taille que les grains de fonio, ne peuvent être éliminés par simple criblage. Des opérations de lavage et de dessablage sont souvent indispensables pour éliminer ces diverses impuretés et obtenir un fonio blanchi de qualité.

\section{Conception d'un laveur à hélice}

Un dispositif de lavage a été conçu au Cirad pour être testé en laboratoire, en France et au Mali. La séparation des sons est réalisée dans un laveur constitué d'un cylindre à hélice incliné (figures 6.7. et 6.8.). Le cylindre est alimenté en grains à laver dans la partie basse et en eau de lavage dans la partie haute. La rotation du cylindre à hélice permet le brassage et la remontée des grains en partie haute. L'eau introduite, qui se charge progressivement en impuretés, est évacuée en partie basse. Sur le premier prototype (tube $\varnothing 30 \mathrm{~cm}$ ), des débits de 30 à $50 \mathrm{~kg} / \mathrm{h}$ ont été obtenus.

\section{Conception d'un dessableur «hydrolift»}

Un dispositif de dessablage appelé «hydrolift» a été conçu au Cirad pour être testé en laboratoire, en France et au Mali. Le prototype de dessableur hydrolift est constitué d'un tube vertical alimenté en eau en partie basse par une pompe (figure 6.9.). Le fonio blanchi contenant des impuretés (sables) est introduit à mi-hauteur par un tube central, avec un filet d'eau qui facilite la descente du grain. Le débit principal d'eau est réglé de façon que les graines de fonio soient entraînées par le flux d'eau. Après débordement en partie haute, les graines sont séparées de l'eau et récupérées par un tamis. Les sables, plus lourds, tombent malgré le flux d'eau et sont arrêtés par une grille inclinée et dirigés vers un cylindre adjacent, où ils sont récupérés en fin d'opération. Les dimensions de l'équipement sont les suivantes :

- Diamètre intérieur de la colonne : $100 \mathrm{~mm}$.

- Hauteur de la colonne : $670 \mathrm{~mm}$.

- Hauteur utile : $600 \mathrm{~mm}$.

- Diamètre extérieur du tube central : $25 \mathrm{~mm}$.

- Longueur du tube plongeur d'alimentation : $300 \mathrm{~mm}$. 


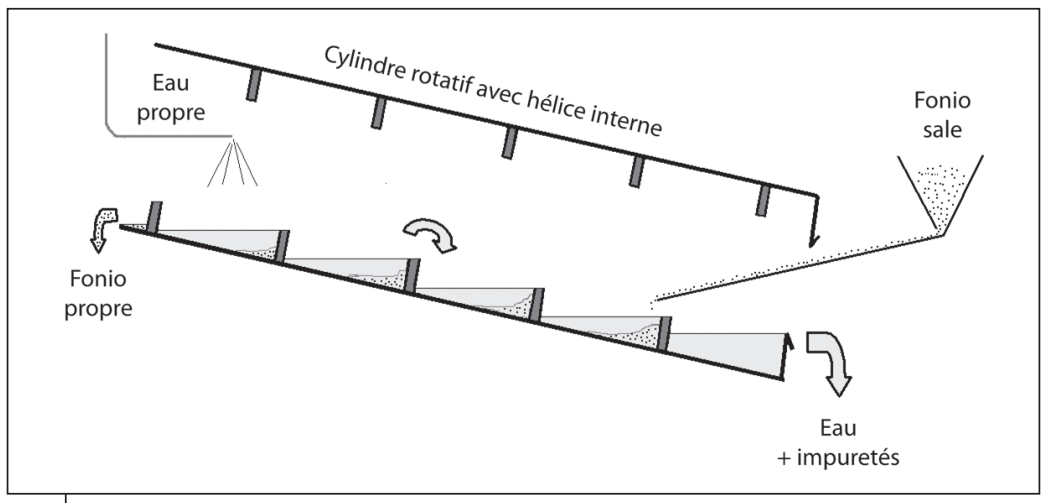

Figure 6.7.

Schéma de principe du laveur

(d'après C. Marouzé).

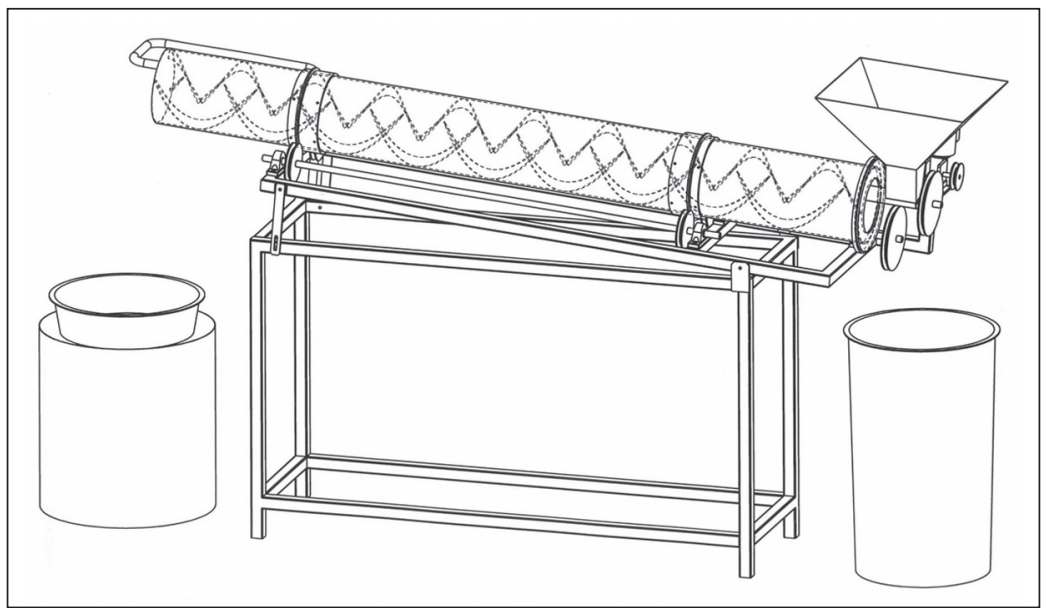

\section{Figure 6.8.}

Prototype de laveur à fonio

(P. Thaunay).

Un premier prototype a été testé au Mali. Il permet d'éliminer jusqu'à $90 \%$ des sables, mais cela reste insuffisant car un fonio de qualité doit être totalement exempt de sable. Son utilisation pourrait cependant être intéressante car elle devrait permettre de réduire le nombre de lavages manuels réalisés par les transformatrices, mais aussi d'économiser l'eau grâce à un fonctionnement en circuit fermé. 


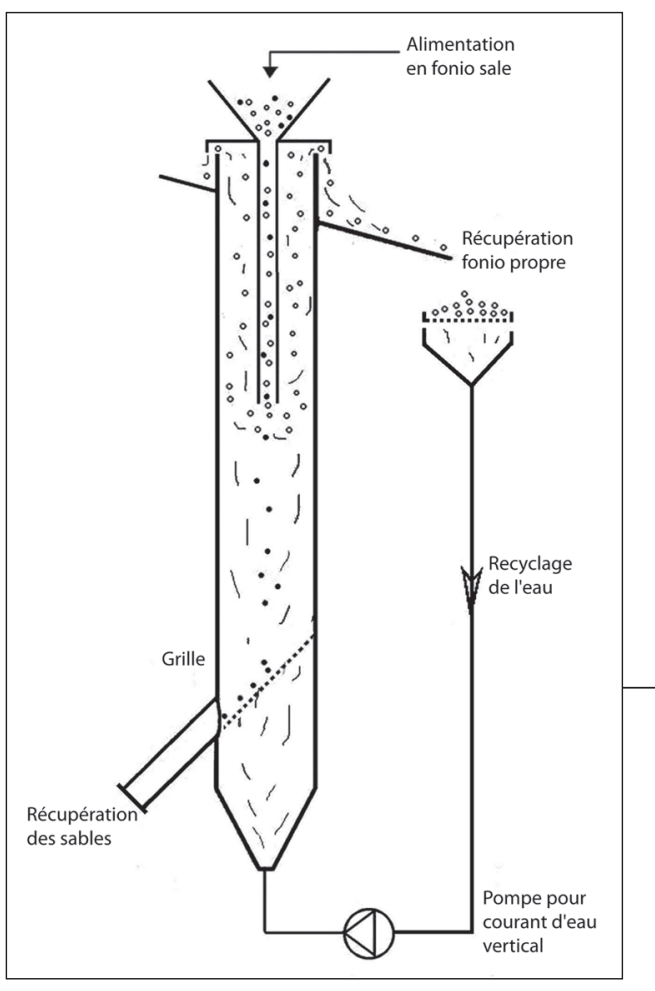

\section{Figure 6.9.}

Schéma de l'hydrolift (d'après C. Marouzé).

\section{Mécanisation du décorticage}

Le décorticage traditionnel réalisé au pilon et au mortier est un travail très pénible qui ne produit que 1 à $3 \mathrm{~kg}$ par heure selon l'habileté des opératrices. La mécanisation du décorticage du fonio est une demande souvent considérée comme prioritaire par les femmes. Dans le passé, quelques tentatives ont été faites par des projets ou des ateliers privés, notamment en Guinée, pour développer des machines adaptées aux besoins des ménagères et des transformatrices mais sans résultats probants.

\section{ID Le décortiqueur «Sanoussi»}

L'un des premiers matériels commercialisés a été le décortiqueur «Sanoussi», conçu et fabriqué au Sénégal au début des années 1990. La documentation montre que la machine est constituée d'une chambre 


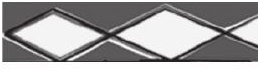

métallique tronconique dans laquelle tournent deux palettes. Le fond de la chambre, incliné pour permettre la vidange, est recouvert d'une surface granuleuse qui facilite la friction des grains et l'élimination des couches périphériques. Laxe vertical qui porte les palettes tourne à une vitesse voisine de $1300 \mathrm{tr} / \mathrm{min}$. Il est relié par un système pouliescourroies à un moteur électrique de $1,5 \mathrm{~kW}$ (1500 tr/min). Le matériel fonctionne en discontinu par lot de 2,5 à $3 \mathrm{~kg}$ de produit à traiter.

Au début des années 2000, des essais de fonctionnement du décortiqueur Sanoussi ont été réalisés en laboratoire par l'Institut national de recherche agricole du Bénin (Inrab) et par l'Institut d'économie rurale (IER) au Mali (photo 6.1.). Les résultats ont montré que les performances de la machine étaient parfois inférieures à celles qui sont annoncées puisque les débits obtenus n'ont été que 10 à $20 \mathrm{~kg} / \mathrm{h}$ au lieu des $35 \mathrm{~kg} / \mathrm{h}$ supposés. Le rendement de transformation atteint seulement $60 \%$ et la qualité du travail est souvent considérée comme insuffisante par les opérateurs car de nombreux grains ne sont pas correctement décortiqués. Cette machine a surtout le mérite d'avoir été pionnière, mais de nombreuses transformatrices l'ont aujourd'hui abandonnée car elles la considèrent comme dépassée en raison de ses modestes performances techniques.

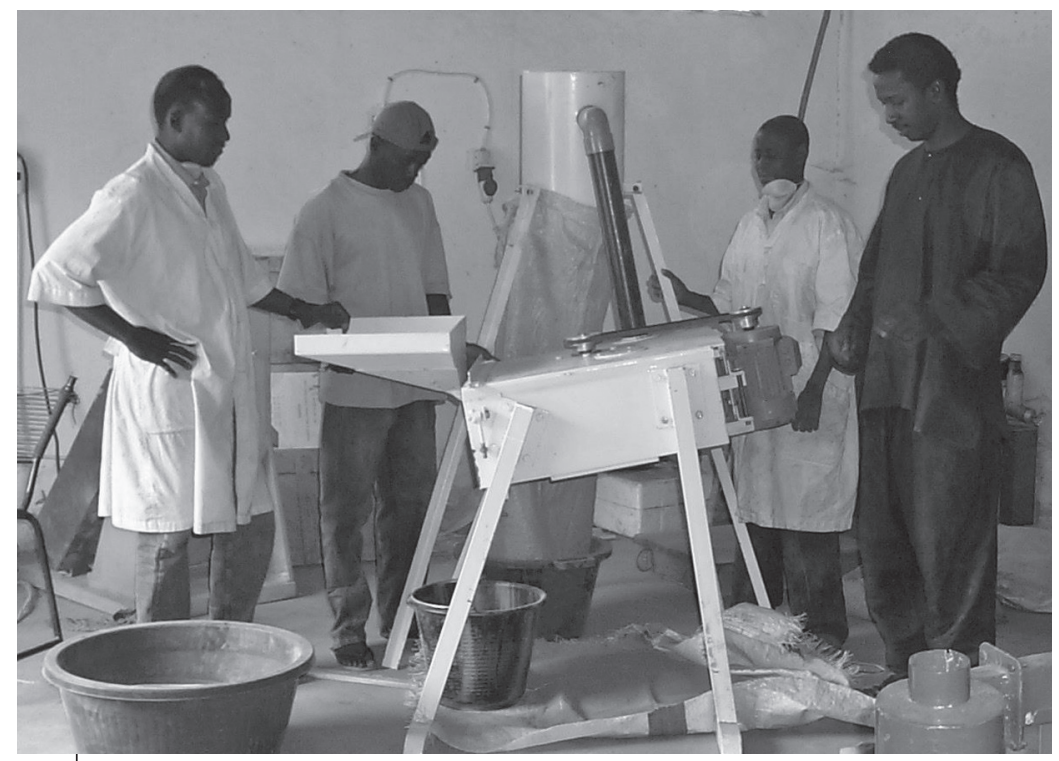

Photo 6.1.

Essais du décortiqueur Sanoussi à I'IER au Mali (৫ J.-F. Cruz). 


\section{|D Le décortiqueur «GMBF»}

En s'inspirant du décortiqueur à riz de type «Engelberg», un décortiqueur spécifique a été conçu pour permettre la transformation du fonio. Au début des années 2000, un premier prototype a été réalisé et testé au Cirad à Montpellier pour valider le principe de décorticage et réaliser les plans, en vue d'une fabrication locale en Afrique (Marouzé et al., 2008). Ce matériel a été nommé GMBF pour "Guinée, Mali, Burkina, France» afin de rappeler la collaboration des différents instituts de recherche qui ont participé à sa création.

\section{Description du décortiqueur GMBF}

Ce décortiqueur artisanal se compose essentiellement d'un cylindre métallique nervuré tournant dans un tube métallique constituant la coque de la machine (figure 6.10.). La chambre de décorticage est équipée d'une barre métallique réglable à l'intérieur de la coque qui joue le rôle de frein et, en sortie, d'une trappe de réglage du débit (Marouzé et al., 2005c). La trémie d'alimentation a une capacité de $35 \mathrm{~kg}$. Le décorticage-blanchiment du fonio est obtenu par friction des grains entre eux. Le réglage plus ou moins important du frein permet d'accroître le phénomène de friction (figure 6.11.). La sortie du mélange des grains décortiqués et blanchis et des sous-produits (balles et sons) est rendue possible par l'ouverture plus ou moins prononcée de la trappe de sortie. Son réglage permet de moduler l'intensité du décorticage ou du blanchiment.

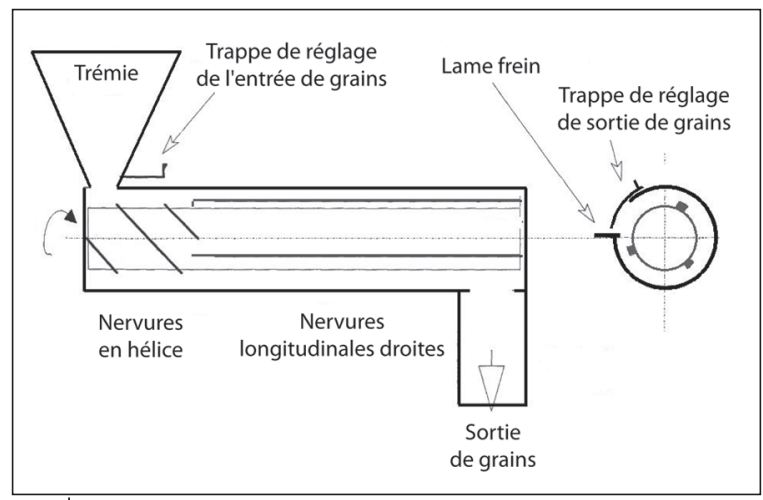

Figure 6.10.

Schéma de principe du décortiqueur GMBF

(d'après Marouzé et al., 2005c). 


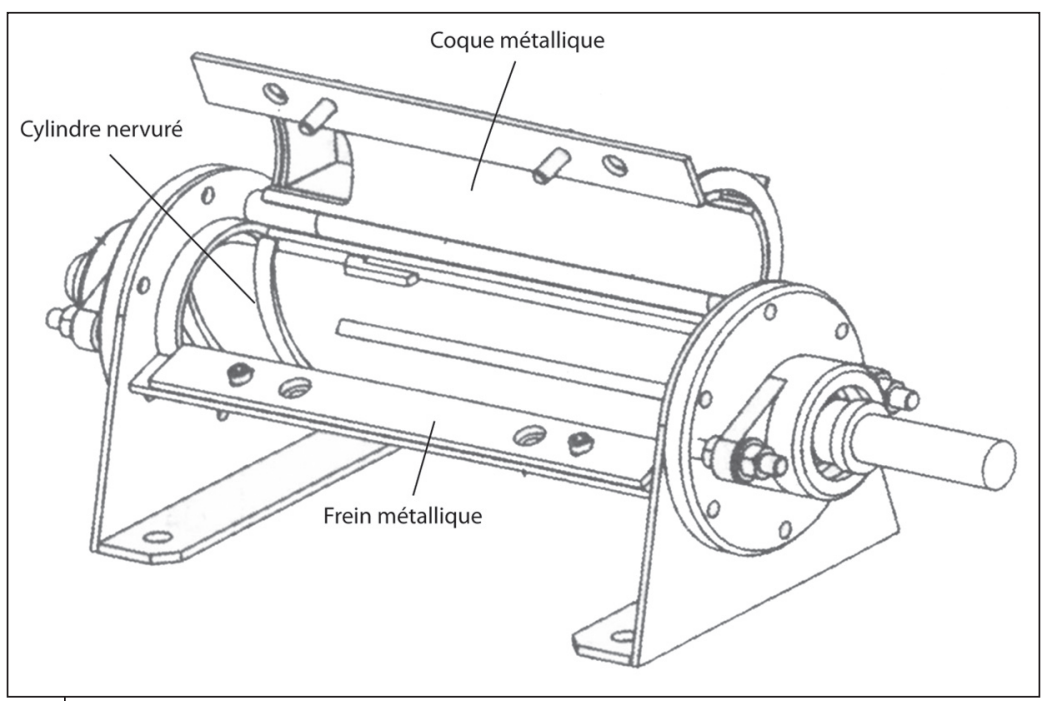

Figure 6.11.

Décortiqueur GMBF avec chambre de décorticage ouverte (P. Thaunay).

Le matériel peut être utilisé soit comme simple décortiqueur pour obtenir du fonio décortiqué à partir de fonio paddy, soit comme simple blanchisseur pour obtenir du fonio blanchi à partir de fonio décortiqué, soit, enfin, comme décortiqueur-blanchisseur pour obtenir du fonio blanchi à partir de fonio paddy. Dans ce dernier cas, la transformation peut être réalisée en un seul passage ou en deux passages successifs si l'on souhaite récupérer séparément les sous-produits (balles et sons).

Pour obtenir un produit propre, on peut placer un canal de vannage en sortie de la machine (figure 6.12.). Le mélange des grains décortiqués et blanchis et des sous-produits (balles et sons) tombent dans le canal de vannage. Les impuretés fines sont aspirées par le flux d'air et sont récupérées au niveau d'un cyclone alors que les grains tombent par gravité dans un récipient placé sous le canal de vannage.

Le décortiqueur GMBF peut être entraîné par un moteur électrique de 5,5 à 7,5 kW pour une utilisation en zone urbaine ou par un moteur Diesel de 8 à $10 \mathrm{~kW}$ pour une utilisation en zone rurale non électrifiée. Les caractéristiques générales des matériels sont les suivantes :

- Lencombrement ( $\mathrm{L}$ x l x h) est de 1,25 x 0,75 x 1,40 m (figure 6.13.).

- Pour la version électrique avec cyclone, la longueur atteint 2,10 m. 


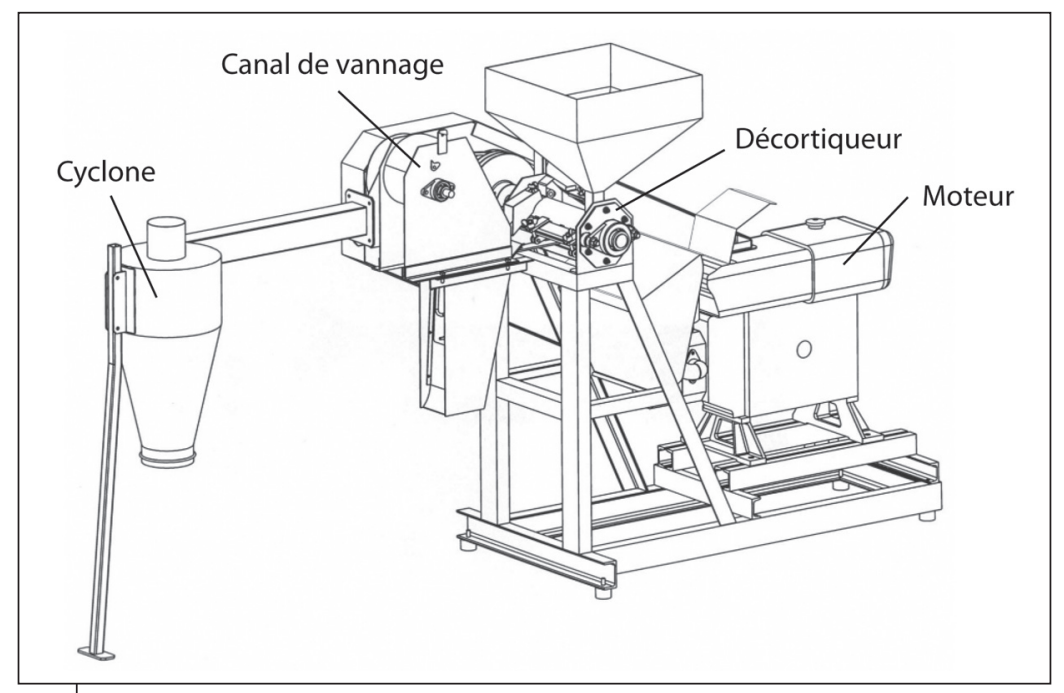

Figure 6.12.

Décortiqueur GMBF avec canal de vannage et moteur thermique (P. Thaunay).

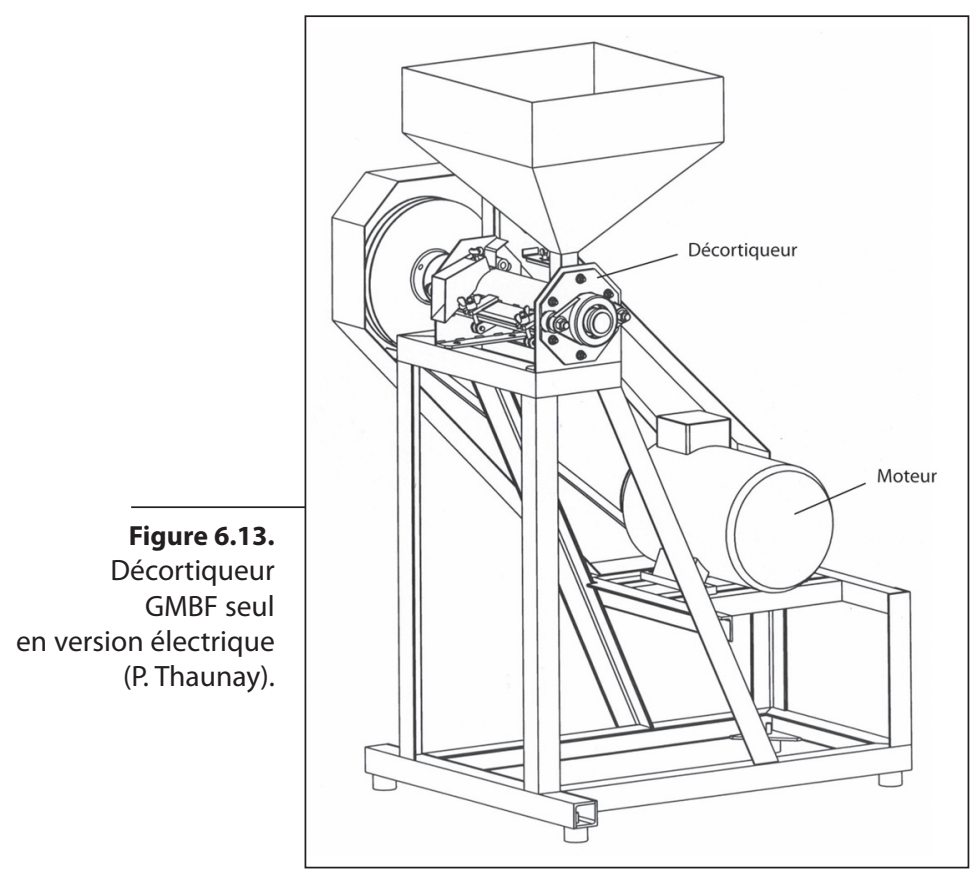


- Pour la version Diesel, la longueur est de 1,8 m sans le cyclone et 2,70 $\mathrm{m}$ avec le cyclone.

- Le poids de l'ensemble est d'environ $200 \mathrm{~kg}$ pour la version électrique et de $320 \mathrm{~kg}$ pour la version thermique.

\section{Performances du décortiqueur GMBF}

En 2002, trois premières machines ont été construites par un équipementier à Bamako et envoyées dans chacun des pays partenaires du projet Amélioration des technologies post-récolte du fonio pour être testées chez des opérateurs privés. Ces équipements ont ainsi été installés en zone rurale et en zone urbaine dans des petites entreprises à Bamako au Mali, à Bobo Dioulasso au Burkina Faso et à Labé en Guinée. Ils ont permis de transformer plusieurs dizaines de tonnes de fonio avec les performances suivantes :

Débits du décortiqueur :

- 50 à $100 \mathrm{~kg} / \mathrm{h}$ pour le décorticage-blanchiment en deux passages avec un rendement global de transformation voisin de $65 \%$.

- 100 à $120 \mathrm{~kg} / \mathrm{h}$ pour le simple décorticage avec un rendement de décorticage d'environ $75 \%$.

- 100 à $150 \mathrm{~kg} / \mathrm{h}$ pour le blanchiment avec un rendement de blanchiment proche de $90 \%$.

Le débit du décortiqueur peut décroître rapidement en fonction de l'usure des pièces travaillantes. La lame frein apparaît usée après la transformation de 10 à $12 \mathrm{t}$ de produit, tandis que les nervures du rotor sont émoussées après $40 \mathrm{t}$. Il faut rapidement changer ou réhabiliter ces pièces d'usure avant leur dégradation complète, car une usure excessive entraîne d'autres détériorations et augmente les coûts d'opération. Pour accroître la résistance de la machine et allonger sa durée de vie, il a été prévu d'équiper la chambre du dernier prototype d'une «coquille» amovible jouant le rôle de pièce d'usure. Limportance de bien nettoyer la matière première apparaît ici évidente, car l'usure des matériels est d'autant plus rapide que cette matière première est chargée en sables.

Tous les essais réalisés sur les différents prototypes ont donné satisfaction. La qualité des produits transformés a été jugée très bonne par les opérateurs locaux, et notamment par les femmes (Cruz, 2004). Après avoir vu fonctionner la machine, beaucoup de transformatrices ne veulent plus revenir à la transformation manuelle et certaines déclarent : «Nous avons jeté le pilon, nous ne voulons plus jamais reprendre le pilon.» Sur le plan culinaire, les analyses de la qualité 
du fonio décortiqué et blanchi avec le décortiqueur GMBF ont donné des résultats particulièrement convenables avec des caractéristiques équivalentes à celles du fonio blanchi traditionnellement : le grain est bien dégermé, il gonfle bien et sa consistance est moelleuse comme l'apprécient les consommateurs (Fliedel et al., 2004).

Du point de vue économique, le coût du blanchiment avec un décortiqueur GMBF en version électrique, avec canal de vannage, a été évalué en 2004 avec les hypothèses suivantes :

- Investissement : décortiqueur + canal de vannage $=1500000$ FCFA (environ $2300 €$ ).

- Durée de vie de l'équipement : cinq ans.

- Amortissement sur la durée de vie.

- Utilisation effective : $1000 \mathrm{~h} / \mathrm{an}$.

- Débit réel en continu : $100 \mathrm{~kg} / \mathrm{h}$.

- Quantité de fonio transformé : $100 \mathrm{t}$.

- Personnel nécessaire : 1 meunier (1 500 FCFA/jour).

- Coût de l'électricité : 150 FCFA/kWh.

Le coût d'utilisation de la machine testée au Mali a été évalué à 17 FCFA/kg de fonio. La consommation d'énergie représente $36 \%$, la maintenance et les pièces détachées $31 \%$, l'amortissement $18 \%$ et le personnel $12 \%$.

Ce coût s'élève à $24 \mathrm{FCFA} / \mathrm{kg}$ si l'on se limite à $40 \mathrm{t}$ par an. À titre de comparaison, le coût du blanchiment manuel traditionnel, réalisé par les femmes à Bamako, est de 20 à 25 FCFA $/ \mathrm{kg}$.

Les décortiqueurs à fonio GMBF sont aujourd'hui fabriqués, notamment au Mali, par différents petits constructeurs locaux d'équipements. Ces constructeurs doivent disposer de machines-outils performantes (tours, etc.) qui permettent de réaliser un usinage très précis des pièces constitutives du décortiqueur. Du fait de la très petite taille du grain de fonio, il est en effet nécessaire que la chambre de décorticage soit parfaitement ajustée afin d'éviter d'éventuelles fuites de produit au cours du décorticage et du blanchiment. Pour la réalisation des machines, ces constructeurs doivent choisir des matériaux résistants à l'usure et doivent rechercher une bonne qualité de fabrication pour que les matériels soient conformes aux plans de fabrication.

Les dossiers de fabrication des différents matériels (décortiqueurs, canal de vannage et cribles rotatifs) ont été publiés et peuvent être librement utilisés par tous les constructeurs d'équipements intéressés (Marouzé et al., 2005a, 2005b, 2005c). 


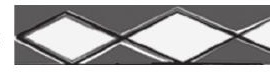

\section{IID Le décortiqueur à rouleaux}

Aujourd'hui, du fonio décortiqué parfois appelé «prédécortiqué» est vendu sur les marchés et certaines unités de transformation produisent du fonio décortiqué destiné à l'exportation. Pour réaliser un simple décorticage de fonio paddy, il peut alors être envisagé d'utiliser un décortiqueur à rouleaux en caoutchouc comme pour le riz.

Un tel décortiqueur est constitué de deux rouleaux en caoutchouc tangents, tournant en sens inverse à des vitesses différentes (figure 6.14.). Le décorticage des grains s'effectue par «cisaillement» lors du passage des grains entre les deux rouleaux. Le mélange des grains décortiqués et des balles tombe dans le canal de séparation où les balles sont aspirées par un ventilateur, alors que le fonio décortiqué est récupéré par gravité sur le côté de la machine.

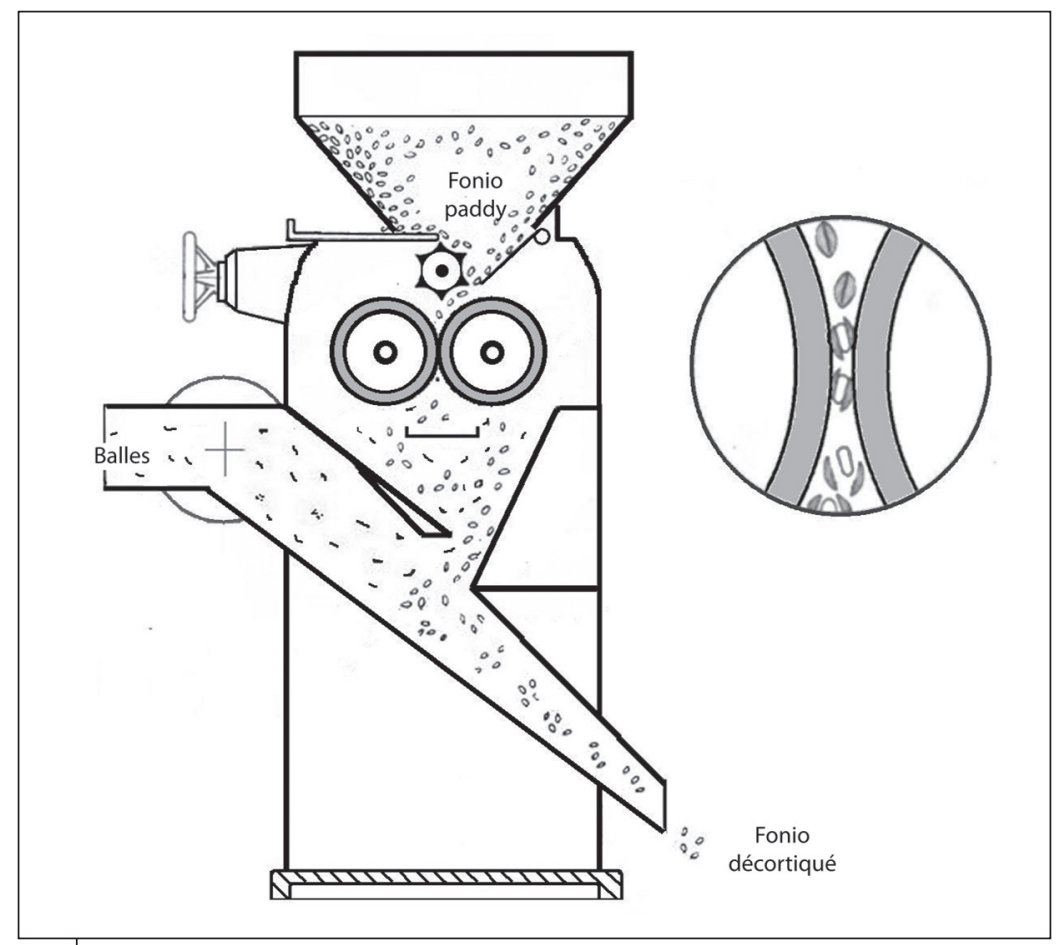

Figure 6.14.

Schéma de principe du décortiqueur à rouleaux

(Cruz et al., 2009). 
Ces machines, qui sont commercialisées pour le riz, pourraient être adaptées au fonio, en améliorant le système d'alimentation pour l'ajuster à la petite taille des grains de fonio et en réglant correctement le flux d'aspiration des balles, comme pour le canal de vannage décrit précédemment.

Avec de tels matériels, on devrait pouvoir obtenir des débits importants avec un bon rendement de décorticage voisin de $80 \%$. Si le taux de grains décortiqués n'est pas suffisant, il est toujours possible de réaliser plusieurs passages successifs. Les décortiqueurs à rouleaux ont l'avantage de permettre un décorticage «doux» de la céréale en produisant peu de brisures. Le problème principal est celui de l'usure des rouleaux en caoutchouc, car le fonio brut est un produit très abrasif. Dans tous les cas, le nettoyage préalable de la matière première devra être très poussé pour éliminer les impuretés et notamment les sables, qui sont toujours à l'origine d'une usure prématurée des machines. 


\section{L'élaboration de produits nouveaux}

Le fonio transformé artisanalement et vendu en vrac sur les marchés urbains est le plus souvent du fonio décortiqué ou du fonio blanchi que les ménagères vont ensuite finir de préparer pour en faire un plat de base.

Mais, aujourd'hui, de nombreuses petites entreprises ou des = groupements féminins commercialisent du fonio déjà transformé et conditionné en sachets plastiques de $500 \mathrm{~g}$ ou $1 \mathrm{~kg}$. Parmi les nouveaux produits du fonio, on peut distinguer la gamme de produits suivants :

- fonio précuit (le plus courant, vendu au Mali, au Burkina Faso, au Sénégal);

- fonio blanchi (assez rare, vendu au Mali, au Burkina Faso, au Sénégal et en Guinée);

- fonio grillé (assez rare, essentiellement vendu en Guinée);

- fonio «djouka» (fonio à l'arachide, essentiellement vendu au Mali);

- farine de fonio (assez rare);

- couscous «moni» et «dégué» (produits roulés à base de farine de fonio, assez rares);

- fonio étuvé (produit nouveau, encore rare, souvent réservé à l'exportation).

Ces produits sont principalement vendus dans les boutiques de quartier ou les supermarchés des grandes villes d'Afrique de l'Ouest. Le fonio précuit est le produit le plus fabriqué et le plus exporté en Europe et aux États-Unis, où il est vendu sur des marchés de niche.

En 2006, la Commission européenne a financé un projet Fonio portant sur l'amélioration de la qualité et de la compétitivité du fonio en Afrique de l'Ouest. Ce projet international a été coordonné par le Cirad et réalisé en collaboration avec des instituts de recherche nationaux au Mali (Institut d'économie rurale) et en Guinée (Institut de recherche agronomique de Guinée), un centre international au Burkina Faso (Cirdes), une ONG internationale au Sénégal (Enda), un centre de recherche agronomique en Belgique (CRA-W) et une université aux Pays-Bas (université de Wageningen). En privilégiant 
une démarche interdisciplinaire, le projet a regroupé des scientifiques de divers horizons - technologie alimentaire, nutrition, ingénierie de procédés, mécanisation, sciences sociales, agronomie, etc. — et les actions de recherche-développement réalisées ont favorisé les approches participatives impliquant des producteurs, des transformateurs, des groupements de femmes et des petites entreprises. Outre l'étude des systèmes de culture et de production (voir chapitre 3 ), ce projet a permis d'analyser les qualités technologiques et nutritionnelles du fonio (voir chapitre 5) et de mieux caractériser les nouveaux produits que sont le fonio précuit et le fonio étuvé. C'est dans ce cadre que diverses études techniques ont été réalisées concernant notamment la précuisson, l'étuvage et le séchage du fonio, et que les connaissances sur les modes de commercialisation et de consommation ont pu être approfondies. Les résultats ont été publiés dans un CD-Rom (Cruz, 2011b).

\section{Fonio précuit}

Le fonio précuit est un fonio blanchi passé à la vapeur, puis séché avant d'être conditionné. Le fonio précuit a l'avantage de mieux se conserver que du simple fonio blanchi et de bien répondre, localement, aux demandes des jeunes ménagères urbaines, qui souhaitent de plus en plus pouvoir disposer de produits alimentaires prêts à l'emploi.

\section{ID La fabrication du fonio précuit}

Les différentes étapes de fabrication du fonio précuit ont été observées dans des petites entreprises à Ségou, à Bamako et à Ouagadougou.

Les ustensiles utilisés à ce niveau sont relativement rudimentaires. Les couscoussiers sont classiquement constitués de deux récipients en terre cuite ou en aluminium. La marmite inférieure, qui contient de l'eau, est surmontée d'une marmite ou d'une bassine à fond perforé qui sera remplie de fonio blanchi (figure 7.1.). Les récipients sont assemblés par un joint d'étanchéité réalisé avec de l'argile humide ou avec une pâte à base de farine de graines de néré. L'ensemble du dispositif est placé sur un foyer à bois, à charbon de bois ou à gaz selon le cas. Les foyers peuvent aller du simple foyer « 3 pierres» au brûleur à gaz plus sophistiqué.

Lorsque l'eau de la marmite inférieure bout, il y a apparition de vapeur au niveau du récipient supérieur. Les grains de fonio blanchis, qui ont 


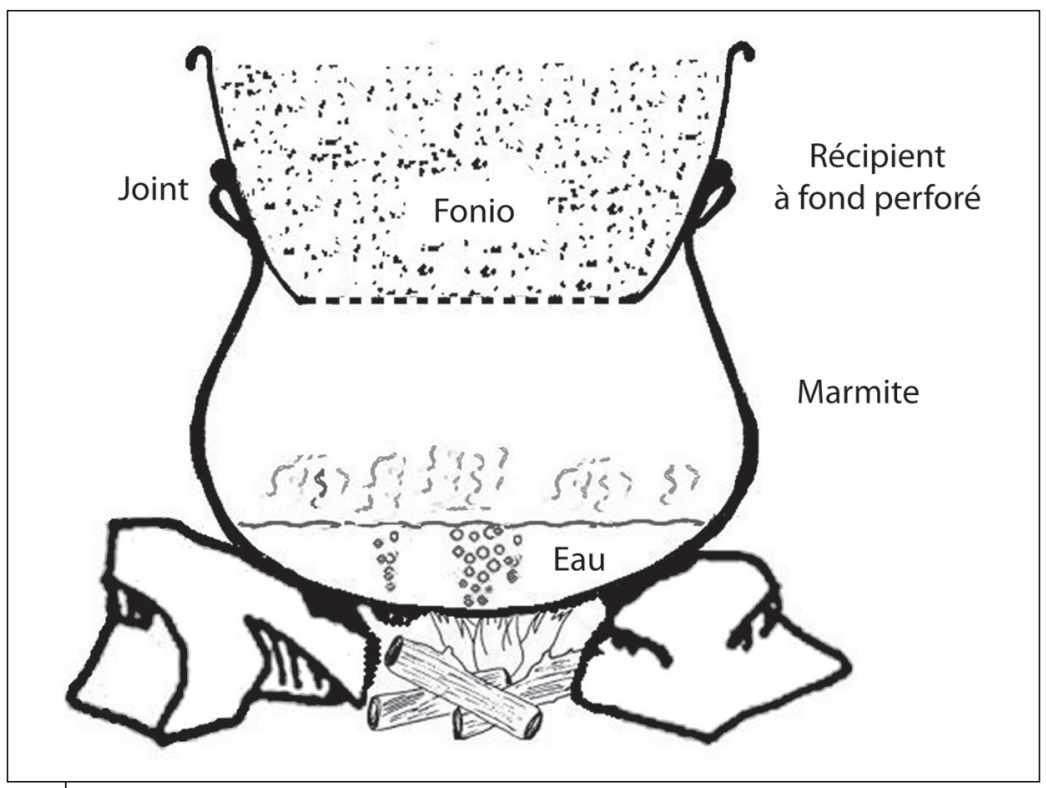

Figure 7.1.

Schéma d'un couscoussier traditionnel sur foyer « 3 pierres » (Cruz et al., 2009).

été lavés et séparés des impuretés comme les sables, sont alors versés directement dans la bassine supérieure. Si cette bassine est percée de grosses perforations, un linge propre de type popeline est disposé sur le fond pour éviter des fuites de grains. Le tout est ensuite recouvert d'un tissu fin puis d'un couvercle métallique. Selon la taille des ustensiles utilisés, les quantités de fonio humide placées dans la marmite supérieure peuvent varier de 10 à $45 \mathrm{~kg}$. Après trente à quarante minutes de passage à la vapeur, les opératrices considèrent que la précuisson du fonio est terminée. Certaines d'entres elles repèrent la fin de la précuisson par une modification de teinte de la masse des grains et l'apparition de vapeur en surface.

Le foyer est alors arrêté et le fonio précuit est vidé dans des bassines à l'aide de grandes écumoires ou de grandes cuillères, puis il est légèrement pilé pour casser les mottes et enfin forcé au travers d'un tamis pour briser les derniers agglomérats.

Le fonio précuit humide est ensuite étalé en couche mince sur des tables de séchage pour être séché à l'air libre ou dans un séchoir de type «serre» ou encore sur des claies d'un séchoir à gaz. Après 
séchage, le fonio précuit est conditionné en petits sachets plastiques soudés (de $500 \mathrm{~g}$ et $1 \mathrm{~kg}$ ) pour être commercialisé.

\section{Le diagramme de précuisson du fonio}

Lors des essais réalisés au Mali, le diagramme de précuisson du fonio a été établi (figure 7.2.).

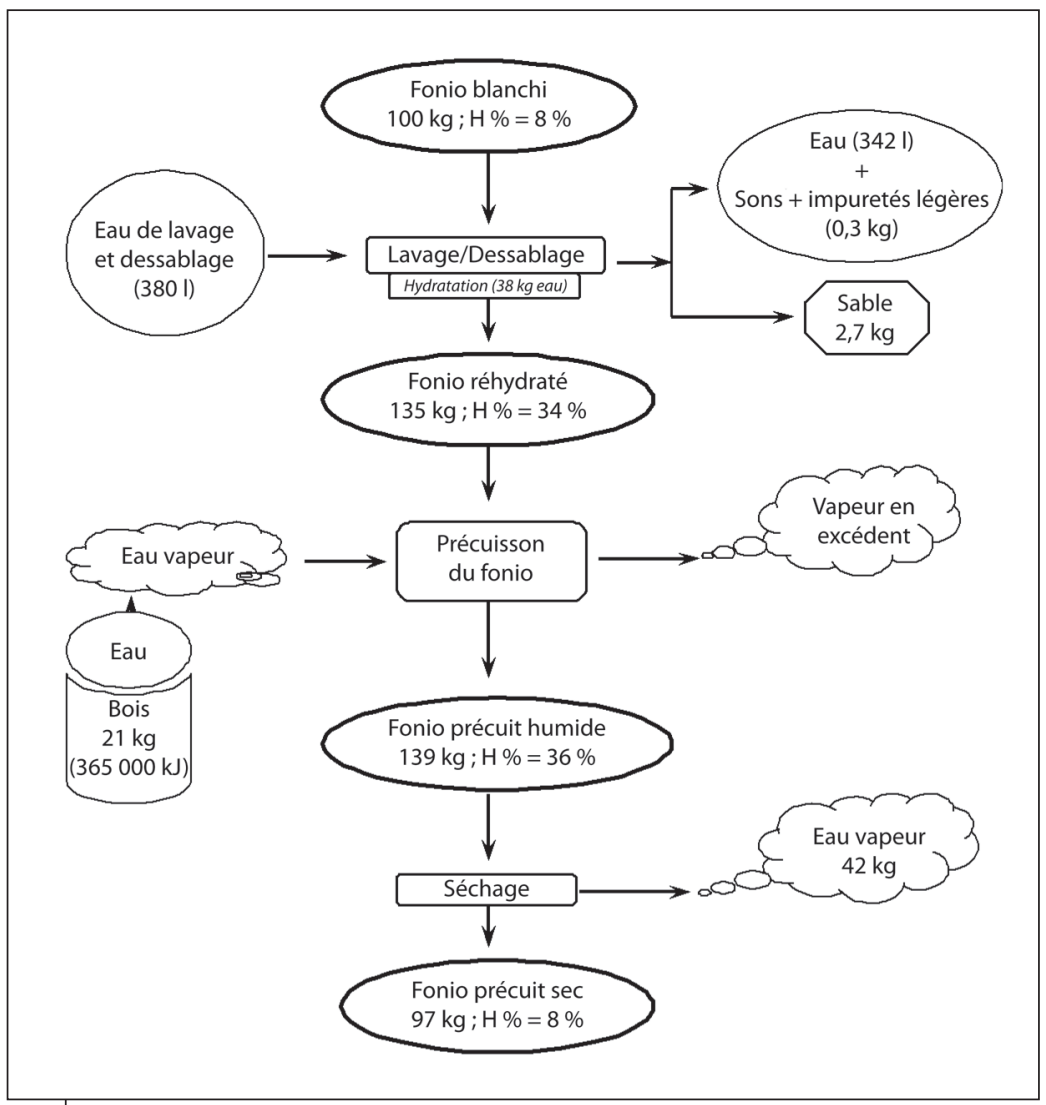

Figure 7.2.

Diagramme de précuisson du fonio sur foyer à bois (Rivier et Cruz, 2007).

On note que le lavage et le dessablage consomment près de 41 d'eau par $\mathrm{kg}$ de fonio et que $10 \%$ de cette eau sont absorbés par le produit qui 
se réhydrate lors de ces opérations. Sur un foyer sommaire, la consommation en bois est importante : plus de $20 \mathrm{~kg}$ de bois pour précuire $100 \mathrm{~kg}$ de fonio, soit une quantité d'énergie de près de $3600 \mathrm{~kJ}$ par $\mathrm{kg}$ de fonio. Avec un foyer à gaz, généralement plus performant, la quantité d'énergie utilisée est quatre à cinq fois moindre, soit environ $800 \mathrm{~kJ}$ par $\mathrm{kg}$ de fonio.

\section{Fonio étuvé}

Létuvage est un procédé très ancien généralement appliqué au riz et qui consiste en un traitement hydrothermique des grains paddy, suivi d'un séchage. Cette technologie a pour avantage d'améliorer les caractéristiques technologiques, nutritionnelles et culinaires du riz.

Lidée est donc d'appliquer le même procédé au fonio paddy afin de bénéficier des mêmes avantages technologiques et nutritionnels. Létuvage a néanmoins pour conséquence de colorer les grains. Or, l'aspect peu coloré et bien blanchi des grains constitue un des principaux critères de qualité du fonio définis par les consommateurs africains habituels. Ainsi, dans un premier temps, le fonio étuvé devrait être davantage apprécié, en tant que nouveau produit, par les consommateurs néophytes, qu'ils soient africains, européens ou américains. Grâce au développement des équipements post-récolte et notamment du décortiqueur GMBF, certaines entreprises se sont lancées dans la production de fonio transformé et proposent déjà sur le marché européen du fonio complet étuvé.

À l'origine, les connaissances restaient très empiriques et le diagramme d'étuvage était inexistant. À l'occasion du projet Fonio, le Cirad a consacré une partie de ses recherches à l'étude de l'étuvage du fonio et à l'élaboration du diagramme d'étuvage.

D'un point de vue technique, l'étuvage est un procédé qui consiste en une précuisson du fonio paddy préalablement réhydraté. Cette précuisson permet une gélatinisation de l'amidon qui perd sa structure cristalline. Après refroidissement et séchage, l'amande du grain a une texture homogène et vitreuse. Leétuvage améliore donc la qualité technologique du fonio en ressoudant les grains clivés et en diminuant ainsi le taux de brisures lors du décorticage. Il accroît les qualités organoleptiques et nutritionnelles, en enrichissant l'amande en éléments hydrosolubles (minéraux, vitamines, protéines) initialement concentrés dans les couches périphériques du grain. 
Les études ont montré que la teneur en eau du fonio après trempage devait être de 32 à $34 \%$ wb (humidité base humide), pour qu'il y ait une gélatinisation suffisante de l'amidon pendant le traitement ultérieur à la vapeur. En laboratoire, cette teneur en eau a pu être obtenue par trempage de grains secs $\left(9 \%\right.$ wb) dans de l'eau maintenue à $40^{\circ} \mathrm{C}$ pendant environ deux heures. Sur site, des essais réalisés au Mali ont permis d'atteindre cette teneur en eau par trempage du fonio paddy durant trois heures dans une eau portée à $65^{\circ} \mathrm{C}$, puis refroidie naturellement, ou par trempage durant quinze heures dans une eau à $25^{\circ} \mathrm{C}$. Ce dernier trempage, durant toute une nuit, est plus pratique à mettre en ouvre par les petites entreprises, mais il peut affecter significativement la couleur des grains, qui seront moins blancs.

Lorsque le fonio a été réhydraté par trempage jusqu'à $32 \%$ d'humidité, il peut alors être transféré dans une étuveuse pour être passé à la vapeur pendant environ trente minutes. Les étuveuses peuvent être les mêmes ustensiles que ceux utilisés pour la précuisson ou encore des fûts métalliques classiquement employés pour l'étuvage du riz (figure 7.3.).

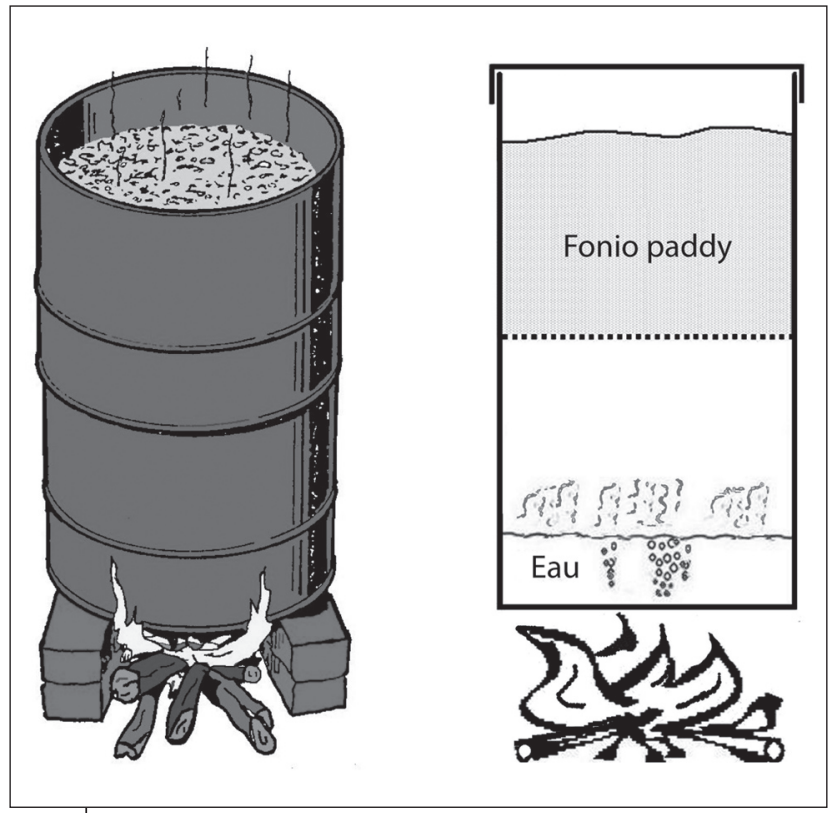

Figure 7.3.

Principe de l'étuvage du fonio paddy en fût (Cruz et al., 2009). 
Des essais d'étuvage de fonio paddy (figure 7.4.) ont été réalisés au Mali dans les conditions suivantes :

- Matière première : $30 \mathrm{~kg}$ de fonio de la variété «Tama».

- Trempage du fonio paddy : trois heures dans une eau chauffée à $65^{\circ} \mathrm{C}$, puis refroidissement naturel (en fin de trempage la température de l'eau n'est plus que de $46^{\circ} \mathrm{C}$ ).

- Égouttage du fonio puis remplissage de l'étuveuse.

- Mise en chauffe de l'étuveuse : la vapeur apparaît en surface du produit après une heure et dix minutes d'étuvage. Létuvage a ensuite été maintenu durant vingt minutes.

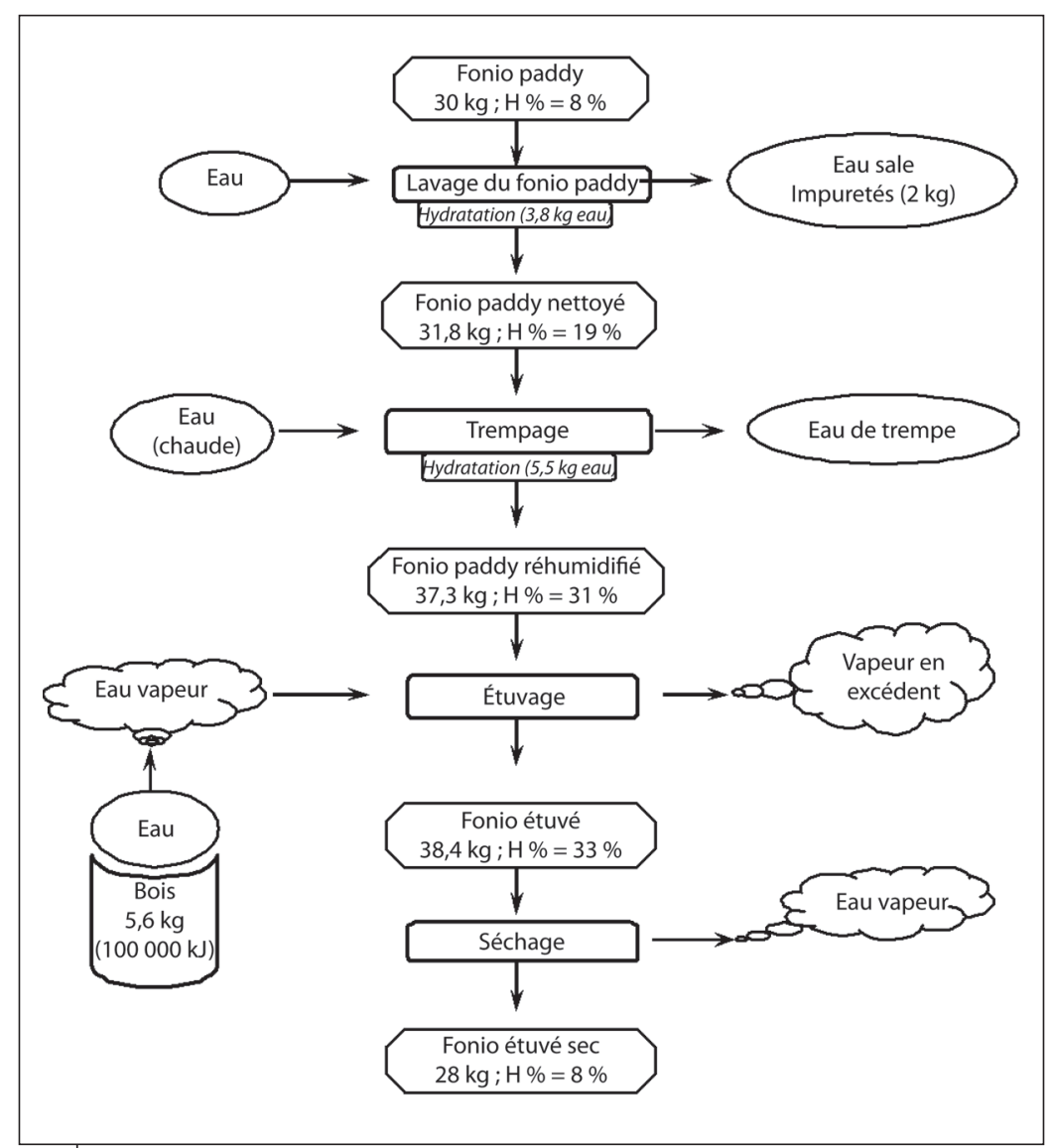

Figure 7.4.

Diagramme de l'opération d'étuvage du fonio

(Cruz et al., 2009). 
Les analyses des échantillons de fonio prélevés avant et après confirment que l'étuvage améliore la qualité technologique et diminue le taux de brisures (tableau 7.1.).

Tableau 7.1. Amélioration de la qualité technologique du fonio par l'étuvage.

\begin{tabular}{lcccc}
\hline Produit & $\begin{array}{c}\text { Rendement } \\
\text { décorticage } \\
(\boldsymbol{\%})\end{array}$ & $\begin{array}{c}\text { Rendement } \\
\text { blanchiment } \\
(\boldsymbol{\%})\end{array}$ & $\begin{array}{c}\text { Rendement } \\
\text { transformation } \\
(\boldsymbol{\%})\end{array}$ & $\begin{array}{c}\text { Taux } \\
\text { de brisures } \\
(\boldsymbol{\%})\end{array}$ \\
\hline Fonio paddy & 82,0 & 91,0 & 74,6 & 0,64 \\
\hline Fonio paddy étuvé & 83,0 & 93,0 & 77,2 & 0,03 \\
\hline
\end{tabular}

Source : Cirad.

Un trempage trop long peut affecter la couleur du grain. Après étuvage, l'amande du grain de fonio étuvé est d'une couleur dorée à brune, d'autant plus prononcée que l'étuvage est prolongé. Néanmoins, à la cuisson, le grain de fonio aura tendance à s'éclaircir progressivement, même s'il ne retrouve pas tout à fait sa couleur blanche d'origine. Les grains de fonio étuvés sont moins collants et gonflent souvent mieux à la cuisson.

Des recherches doivent être poursuivies pour parfaire la connaissance de l'étuvage du fonio et mettre au point des équipements d'étuvage adaptés aux besoins des petites entreprises et des groupements de femmes, et prenant mieux en compte les contraintes énergétiques et environnementales. 


\section{L'amélioration
des techniques de séchage du fonio transformé}

Les grains de fonio doivent être séchés jusqu'à une humidité de sauvegarde proche de $11 \%$ et même de $10 \%$ pour le produit transformé afin d'assurer une bonne conservation. Le séchage traditionnel du fonio transformé (fonio blanchi lavé, fonio précuit, fonio étuvé, etc.) est souvent réalisé par une simple exposition directe au soleil, en étalant les grains sur des nattes ou des plateformes recouvertes d'un tissu ou d'un plastique. Au cours du séchage, les grains risquent alors d'être "pollués » par diverses impuretés (poussières, fientes d'oiseaux) qui déprécient considérablement le produit.

\section{Quelques initiatives pour améliorer le séchage}

\section{ID Le séchoir «coquillage»}

Ce séchoir, conçu par le Groupe énergies renouvelables et environnement (Geres) de Marseille et le Groupe de recherche et d'échanges technologiques (Gret) à Paris, est diffusé au Burkina Faso depuis les années 1980 pour le séchage des fruits, des légumes et des produits céréaliers (Rozis, 1995). Il est constitué d'une chambre circulaire à fond tronconique reposant sur trois pieds (figure 8.1.). La chambre, dont le diamètre peut atteindre $110 \mathrm{~cm}$ pour les grands modèles, est équipée de claies circulaires et percée d'aérations pour permettre une circulation de l'air par convection naturelle. Le corps du séchoir est recouvert d'un toit conique qui peut être refermé en cas de pluie. L'ensemble du séchoir ressemble à un coquillage bivalve, d'où son nom.

Des essais de séchage ont été réalisés au cours de l'année 2000 sur des échantillons de $5 \mathrm{~kg}$ de fonio blanchi lavé ou de fonio précuit chargés sur une seule claie. En saison sèche, il a fallu près de $24 \mathrm{~h}$ pour obtenir un bon niveau de séchage du produit $(<10 \%)$. En saison humide, le degré de séchage du fonio (fonio blanchi lavé ou fonio précuit) est resté nettement insuffisant même après $72 \mathrm{~h}$ de séchage. Des phénomènes 


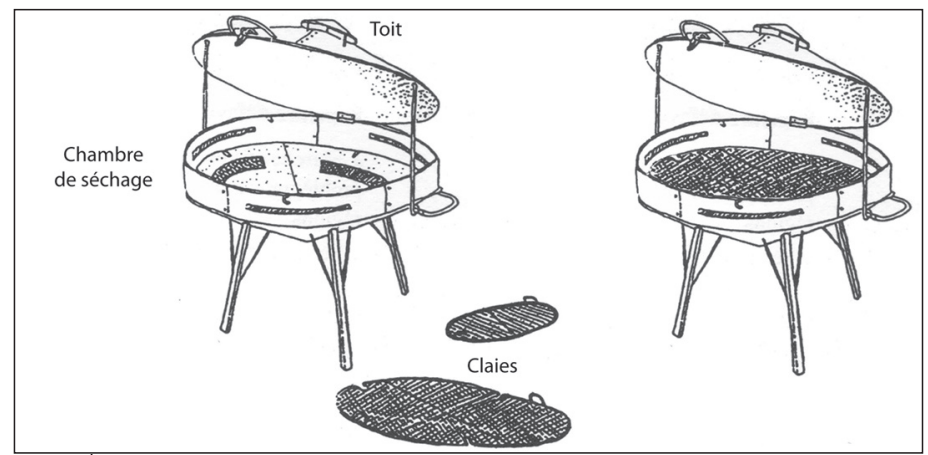

Figure 8.1.

Séchoir coquillage (d'après Rozis, 1995).

de condensation sur la coupole supérieure du séchoir sont apparus lors des refroidissements nocturnes, entraînant la chute de gouttelettes d'eau sur le produit et des débuts d'altération. Par temps couvert et très humide, le séchoir coquillage ne permet pas d'obtenir un séchage suffisamment rapide du produit. Il est souvent limité à un usage domestique, car sa trop faible capacité le rend mal approprié à une exploitation commerciale pour des quantités importantes de fonio.

\section{Le séchoir «Ceas-Atesta»}

Le séchoir "Ceas-Atesta» a été conçu au début des années 1990 au Burkina Faso par le Centre écologique Albert Schweitzer (Ceas) et fabriqué par l'Atelier énergie solaire et technologies appropriées (Atesta) à Ouagadougou. Il s'agit d'un séchoir à gaz à convection naturelle destiné d'abord au séchage des fruits (mangues, etc.) et des légumes (oignons, gombos, etc.), mais qui est parfois utilisé par les transformatrices de céréales (fonio, produits roulés de type «couscous», etc.).

Le séchoir Ceas-Atesta est constitué d'une base en briques ou maçonnerie qui supporte deux cellules adjacentes métalliques, équipées de claies de séchage (figure 8.2.). L'ensemble est recouvert d'un toit percé d'une cheminée d'évacuation de l'air usé.

Sous chacune des cellules, la base comprend un compartiment équipé d'une rampe à gaz. Une ouverture à l'arrière permet l'entrée d'air comburant et une trappe à l'avant permet l'allumage et le contrôle des brûleurs. Chacune des cellules de séchage peut recevoir dix claies superposées, de $0,7 \mathrm{~m}^{2}$, posées sur des glissières. Le chargement du 


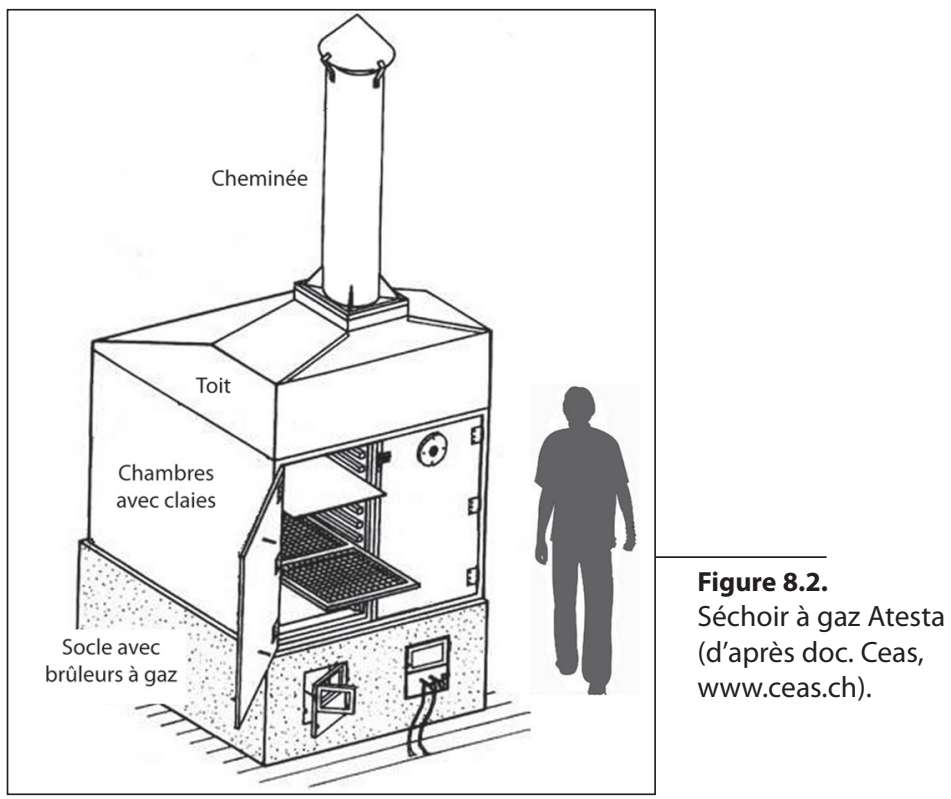

séchoir est frontal et se fait en discontinu. Le séchoir Atesta peut être fabriqué localement et son coût est voisin de 1 million de francs CFA (environ $1500 €$ ).

Des essais de séchage de fonio ont été réalisés au Mali durant l'hivernage en chargeant chaque claie de 2,5 à $3 \mathrm{~kg}$ de produit humide. Les résultats ont montré qu'il était possible d'abaisser la teneur en eau du fonio précuit de $30 \%$ d'humidité à moins de $10 \%$ d'humidité en trois heures environ. Toutes les heures, une permutation des claies est cependant nécessaire pour assurer une meilleure homogénéité de séchage.

La convection naturelle ne permet pas une utilisation optimale du pouvoir séchant de l'air chaud. Le rendement du séchoir est relativement médiocre et conduit à une consommation en gaz importante qui engendre un coût de séchage de 50 à 55 FCFA $(0,07$ à $0,08 €)$ par kilo de fonio sec. Le coût de l'énergie représente une dépense trop importante pour certaines transformatrices, qui ont abandonné ce séchoir ou qui ne l'utilisent qu'en finition de séchage.

Pour supprimer la contrainte que représente la manutention fréquente des claies, une variante a été proposée au Mali sous l'appellation «séchoir Fac 2000 ». Lair chaud, distribué à plusieurs niveaux dans la chambre de séchage, aurait l'avantage de permettre un séchage rapide et homogène 
du produit sans avoir à permuter les claies. Mais ce principe n'assure pas une bonne saturation de l'air usé et conduit alors à une consommation énergétique excessive en raison d'un mauvais rendement thermique.

\section{Séchoirs mis au point dans le cadre du projet Fonio}

\section{|| Le séchoir «à flux traversant»}

Le séchoir «à flux traversant»a été développé par le Cirad sous le nom de «séchoir CSec-T» pour le séchage de produits granuleux (fonio, couscous) ou de fruits transformés (joues de mangue, tranches d'ananas). Il est constitué de trois cellules, contenant chacune quatre claies superposées, et équipé d'un générateur d'air chaud avec brûleur à gaz et d'un ventilateur entraîné par un moteur électrique (figure 8.3.).

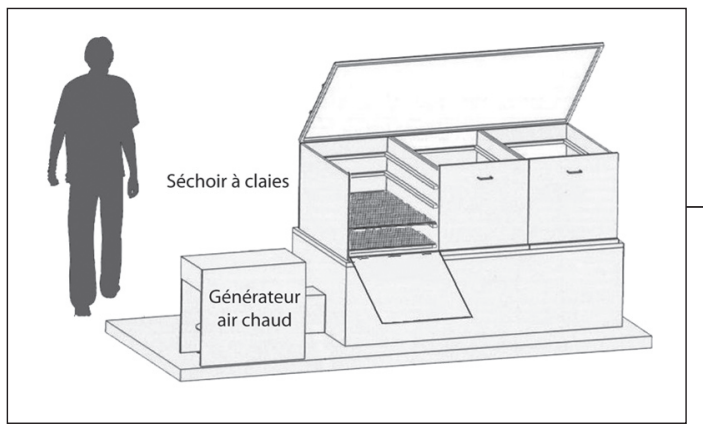

Figure 8.3.

Dessin du séchoir à flux traversant $\mathrm{CSec}-\mathrm{T}$ (d'après J. Brouat, Cirad).

La structure est réalisée en bois contreplaqué. Au niveau de chaque claie, le fonio humide est étalé sur un tissu de type voilage qui permet de contenir le produit et de le récupérer une fois sec. L'air chaud parcourt les trois cellules dans une gaine métallique placée sous les claies, puis il traverse les différentes claies de bas en haut, permettant ainsi le séchage des grains (figure 8.4.).

Les vitesses d'air à l'attaque des claies doivent être limitées de 0,2 à $0,3 \mathrm{~m} / \mathrm{s}$ pour éviter l'entraînement des grains. Lorsque le produit de la claie inférieure est sec, elle est alors retirée, puis les claies supérieures sont descendues d'un niveau; la claie supérieure étant alors rechargée en produit humide. Cette pratique permet de bien saturer l'air de séchage et d'améliorer ainsi le rendement thermique du séchoir. 


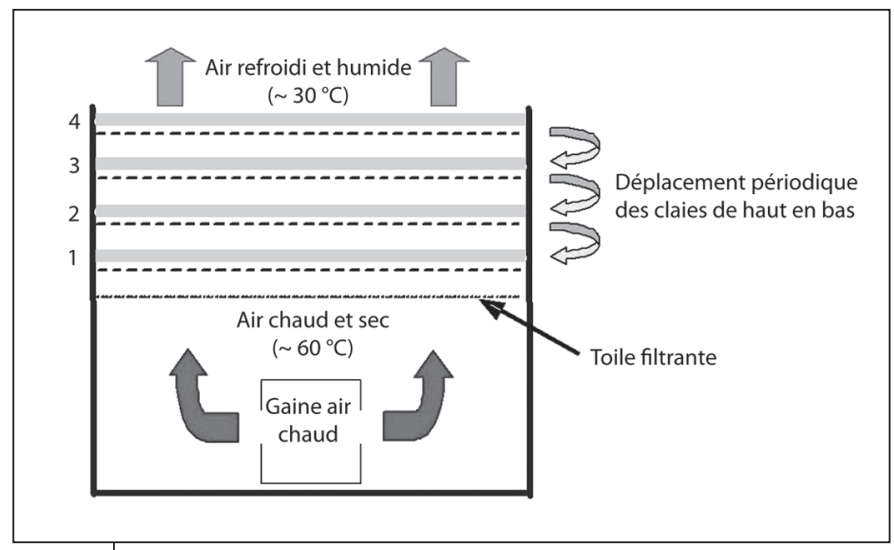

Figure 8.4.

Principe du séchoir à claies à flux traversant

(Cruz et al., 2008).

Le séchoir à flux traversant a été installé dans plusieurs petites entreprises au Burkina Faso et au Mali, et testé en collaboration avec les personnels des entreprises et les équipes locales de recherche. Au Mali, des essais de séchage ont été réalisés sur du fonio précuit en saison sèche et en saison humide. Les principaux résultats obtenus pendant la période humide d'hivernage (juillet et août) sont donnés dans le tableau 8.1.

Tableau 8.1. Performances du séchoir à flux traversant (CSec-T).

\begin{tabular}{lc}
\hline Masse de fonio précuit humide & $98 \mathrm{~kg}$ \\
\hline Humidité initiale du fonio précuit (wb) & $31,1 \%$ \\
\hline Masse de fonio précuit sec & $72,8 \mathrm{~kg}$ \\
\hline Humidité du fonio précuit séché & $7,3 \%$ \\
\hline Durée totale du séchage & $4 \mathrm{~h}$ \\
\hline
\end{tabular}

Source : Cirad.

Selon les responsables des PME qui l'ont utilisé, ce séchoir présente deux avantages :

- bonne capacité de séchage. Un cycle de séchage permet de sécher une centaine de kilos en quatre heures, soit 200 à $300 \mathrm{~kg}$ de fonio précuit par jour en effectuant plusieurs cycles;

- consommation en gaz inférieure à celle d'autres séchoirs à gaz (Atesta, Fac 2000, etc.). 
Cette économie en consommation d'énergie est due au fait que l'air de séchage exploite au mieux sa capacité évaporatoire en traversant les quatre claies et en ressortant quasiment saturé en eau.

Comme pour beaucoup de séchoirs à claies, la principale difficulté du séchoir à flux traversant réside dans la nécessité de déplacer fréquemment les claies de séchage, par des permutations toutes les trente minutes, pour obtenir un séchage efficace.

Le séchoir peut aisément être réalisé par des entreprises locales, car les matériaux nécessaires à sa fabrication sont le bois pour les cellules de séchage et la tôle métallique pour le circuit d'air chaud. Le coût de fabrication d'un séchoir CSec-T avoisine 1 million de FCFA (environ $1500 €)$ et son coût d'utilisation est évalué à 35 FCFA $(0,05 €)$ par kilo de produit séché (Cruz et al., 2008).

À l'avenir, il pourrait être envisagé d'adjoindre, à l'amont du dispositif, un capteur solaire comme générateur d'air chaud, tout en conservant le brûleur à gaz comme appoint thermique pour les périodes de faible ensoleillement ou pour relayer le séchage en fin de journée.

Avec un capteur d'un débit spécifique de $40 \mathrm{~m} 3 / \mathrm{h} . \mathrm{m}^{2}$, il faut une surface de capteur de $30 \mathrm{~m}^{2}$ pour assurer le débit d'alimentation du séchoir, estimé à $1200 \mathrm{~m}^{3} / \mathrm{h}$. Une telle surface est souvent disponible dans les ateliers de transformation. Avec un capteur plan, il est néanmoins difficile d'obtenir un accroissement de la température de l'air ambiant de plus de $20^{\circ} \mathrm{C}$ et d'atteindre une température d'air chaud supérieure à $60^{\circ} \mathrm{C}$, ce qui réduit d'autant les performances du séchoir.

\section{|| Le séchoir «serre solaire»}

Le séchoir «serre solaire» développé par le Cirad sous le nom de «séchoir CSec-S» est une alternative au séchage solaire direct.

Le séchoir serre se compose d'une structure en tubes galvanisés supportant un film plastique. La structure repose sur une dalle et des pignons en maçonnerie. Le pignon avant est percé d'une porte et de deux fenêtres équipées d'une toile moustiquaire, renforcée d'un tissu arrêtant les poussières tout en permettant les entrées d'air (figure 8.5.).

Le pignon arrière du séchoir est équipé de deux ventilateurs axiaux, qui peuvent fonctionner en continu pour renouveler l'air du séchoir, et d'un autre ventilateur à plus grand débit, qui doit être mis en marche 


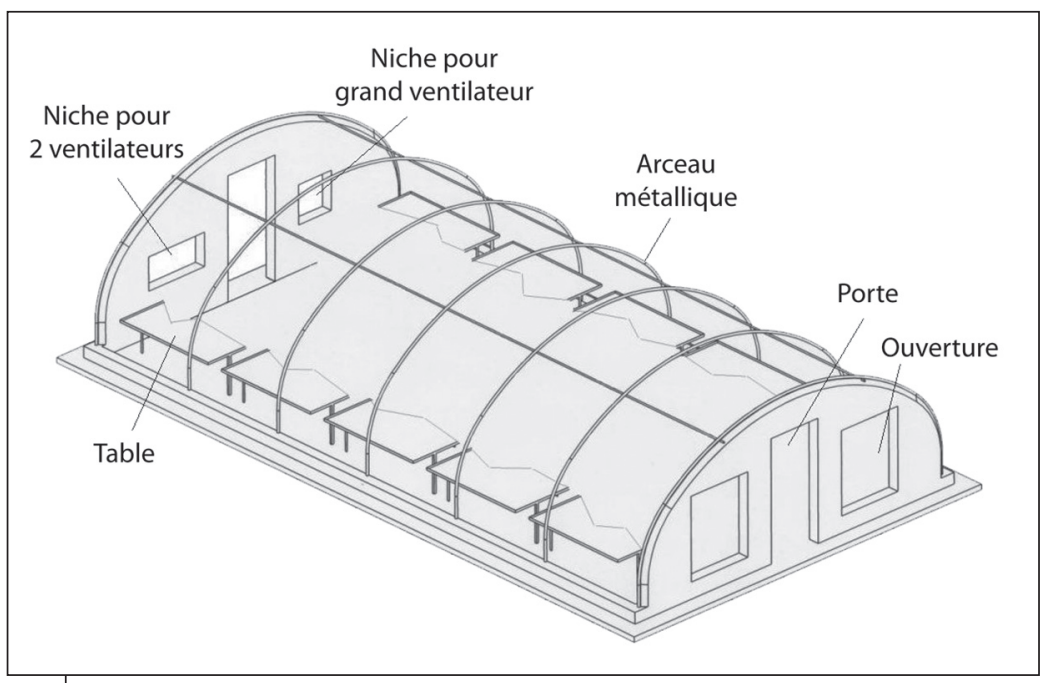

Figure 8.5.

Structure du séchoir serre (d'après J. Brouat, Cirad).

pour permettre aux opératrices d'intervenir dans le séchoir au cours de la journée pour brasser le produit. À l'intérieur du séchoir, trois ventilateurs de plafond brassent l'air intérieur de la serre et assurent un renouvellement de l'air autour du produit.

Le séchoir serre est équipé de tables métalliques recouvertes de nattes et de tissus sur lesquels le fonio humide est étalé en couche mince. Il est possible de sécher 300 à $400 \mathrm{~kg}$ de fonio précuit avec ce modèle de séchoir.

Un premier modèle de séchoir serre solaire a été installé à Bamako, au Mali, dans une entreprise qui produit du fonio précuit. Les principales caractéristiques du séchoir expérimental sont données dans le tableau 8.2.

Tableau 8.2. Principales caractéristiques du séchoir serre solaire (CSec-S).

\begin{tabular}{ll}
\hline Longueur & $12 \mathrm{~m}$ \\
\hline Largeur & $6,5 \mathrm{~m}$ \\
\hline Surface totale des claies & $45 \mathrm{~m}^{2}$ \\
\hline Charge par $\mathrm{m}^{2}$ & 9 à $10 \mathrm{~kg} / \mathrm{m}^{2}$ \\
\hline
\end{tabular}

Source : Cirad. 
Les tests du séchoir serre solaire ( $\mathrm{CSec}-\mathrm{S})$ ont été réalisés en collaboration avec le personnel de l'entreprise et les équipes locales de recherche. Les principaux résultats de séchage de fonio précuit effectué pendant la période humide d'hivernage (juillet et août) sont donnés dans le tableau 8.3.

Tableau 8.3. Performances du séchoir serre solaire (CSec-S).

\begin{tabular}{lc}
\hline Masse de fonio précuit humide & $400 \mathrm{~kg}$ \\
\hline Humidité initiale du fonio $(\mathrm{wb})$ & $32,5 \%$ \\
\hline Masse de fonio précuit sec & $294,7 \mathrm{~kg}$ \\
\hline Humidité du fonio séché $(\mathrm{wb})$ & $8,4 \%$ \\
\hline Durée totale du séchage & $24 \mathrm{~h}$ \\
\hline
\end{tabular}

Source : Cirad.

Selon les utilisateurs, les principaux avantages du séchoir serre solaire sont les suivants :

- le produit est protégé des intempéries et le séchage est de bonne qualité quelle que soit la saison (sèche, humide);

- le produit est protégé des déprédations (oiseaux, rongeurs) et des pollutions extérieures (poussières, sables);

- la manutention est réduite : le fonio peut rester dans le séchoir pendant toute la nuit même lorsqu'il pleut;

- le séchage est relativement rapide (moins de $24 \mathrm{~h}$ ) et le cycle de séchage s'adapte bien à l'organisation du travail dans l'entreprise;

- la consommation énergétique est faible et correspond uniquement au fonctionnement des ventilateurs.

Le montant de l'investissement pour la réalisation d'un séchoir serre solaire est relativement élevé et peut atteindre 3,5 à 4 millions de FCFA (environ 5300 à $6000 €$ ), mais son coût d'utilisation est inférieur aux autres séchoirs mécanisés, soit environ 25 FCFA $(0,04 €)$ par kilo de fonio sec.

Les séchoirs à flux traversant et serre solaire ont donné satisfaction aux utilisatrices tant pour leur capacité journalière que pour leur qualité de séchage. Le fait de pouvoir produire du fonio de qualité tout au long de l'année représente pour elles un très grand avantage (Cruz et al., 2008). Par ailleurs, ces équipements sont polyvalents et peuvent être utilisés sur d'autres produits alimentaires granuleux (couscous et autres produits roulés, grits, etc.). 


\section{La commercialisation}

Pendant de très nombreuses années, la production de fonio était essentiellement destinée à l'autoconsommation pour satisfaire les besoins des producteurs durant la période de soudure. Une faible part était commercialisée en vrac sur les marchés locaux. Mais les difficultés de transformation conduisaient de nombreux producteurs à abandonner cette culture. Puis, des groupements de femmes et des entreprises privées ont commencé à commercialiser du fonio transformé et notamment du fonio précuit, conditionné en sachets, dans les petites boutiques ou les supermarchés des grandes agglomérations. Ce nouveau débouché a positivement changé l'image du fonio, qui n'est plus considéré comme la «céréale du pauvre», mais comme une denrée très appréciée des consommateurs urbains. Avec le développement récent de la mécanisation du décorticage et l'amélioration du séchage, la fabrication de fonio précuit peut dorénavant être répartie tout au long de l'année et les volumes commercialisés dans les commerces locaux et à l'exportation sont en progression.

\section{Commercialisation du fonio en Guinée}

\section{II) Le fonio, principale céréale commercialisée après le riz}

La commercialisation du fonio en Guinée a notamment été étudiée par l'Irag dans le cadre du projet Amélioration des technologies postrécolte du fonio. Il est rappelé que si le fonio est cultivé partout dans le pays, il est surtout produit dans les régions naturelles de la Moyenne Guinée (Fouta-Djalon) et de la Haute Guinée (de Faranah à Kankan et Siguiri). Dans ces régions, il est la seconde céréale commercialisée après le riz, comme le montrent des relevés réalisés sur les marchés de Labé, Faranah ou Kankan (tableau 9.1.).

Il existe aussi certains marchés spécifiquement organisés autour du fonio comme celui de Miti, petite bourgade située sur la route de Labé entre Dalaba et Pita.

Sur les différents marchés hebdomadaires, le fonio est essentiellement vendu sous la forme de fonio décortiqué. La vente sous forme de fonio paddy est plus rare et le fonio blanchi n'est vendu qu'occasionnellement. 
Tableau 9.1. Part relative (\%) des céréales commercialisées sur certains marchés de Guinée.

\begin{tabular}{lccc}
\hline Produit & $\begin{array}{c}\text { Marché } \\
\text { de Labé }\end{array}$ & $\begin{array}{c}\text { Marché } \\
\text { de Faranah }\end{array}$ & $\begin{array}{c}\text { Marché } \\
\text { de Kankan }\end{array}$ \\
\hline Riz & 58 & 71 & 55 \\
\hline Fonio & 31 & 25 & 23 \\
\hline Mil et sorgho & 5 & 4 & 12 \\
\hline Maïs & 6 & & 10 \\
\hline
\end{tabular}

Source : Irag.

\section{ID Les opérateurs de la filière}

Les principaux opérateurs de la filière sont répertoriés dans la figure 9.1.

\section{Les transformatrices rurales}

Les transformatrices rurales sont souvent les femmes des producteurs de fonio, qui réalisent elles-mêmes le décorticage par pilage manuel pour éliminer les balles, sans aller jusqu'au blanchiment parfait. Le fonio ainsi transformé, et parfois qualifié de "fonio prédécortiqué», est alors vendu sur les marchés locaux ou à des collecteurs.

\section{Les collecteurs}

Les collecteurs - qui sont souvent des collectrices — reçoivent de l'argent de la part des grandes collectrices ou semi-grossistes pour acheter sur les différents marchés villageois du fonio prédécortiqué et parfois du fonio déjà blanchi. La plupart d'entre eux collectent, par la même occasion, d'autres denrées comme du riz, du sorgho, des arachides, etc. Beaucoup de ces collecteurs sont aujourd'hui équipés de téléphones portables pour être informés en temps réel des prix du marché. Les transactions se font rarement au poids, mais généralement sur la base de mesures locales comme la saria en Moyenne Guinée et le moussa traoré en Haute Guinée.

\section{Les grandes collectrices}

C'est souvent sur les marchés hebdomadaires que les grandes collectrices récupèrent les produits réunis par les collectrices rurales après en avoir vérifié la qualité. Le fonio ainsi collecté (fonio prédécortiqué, 


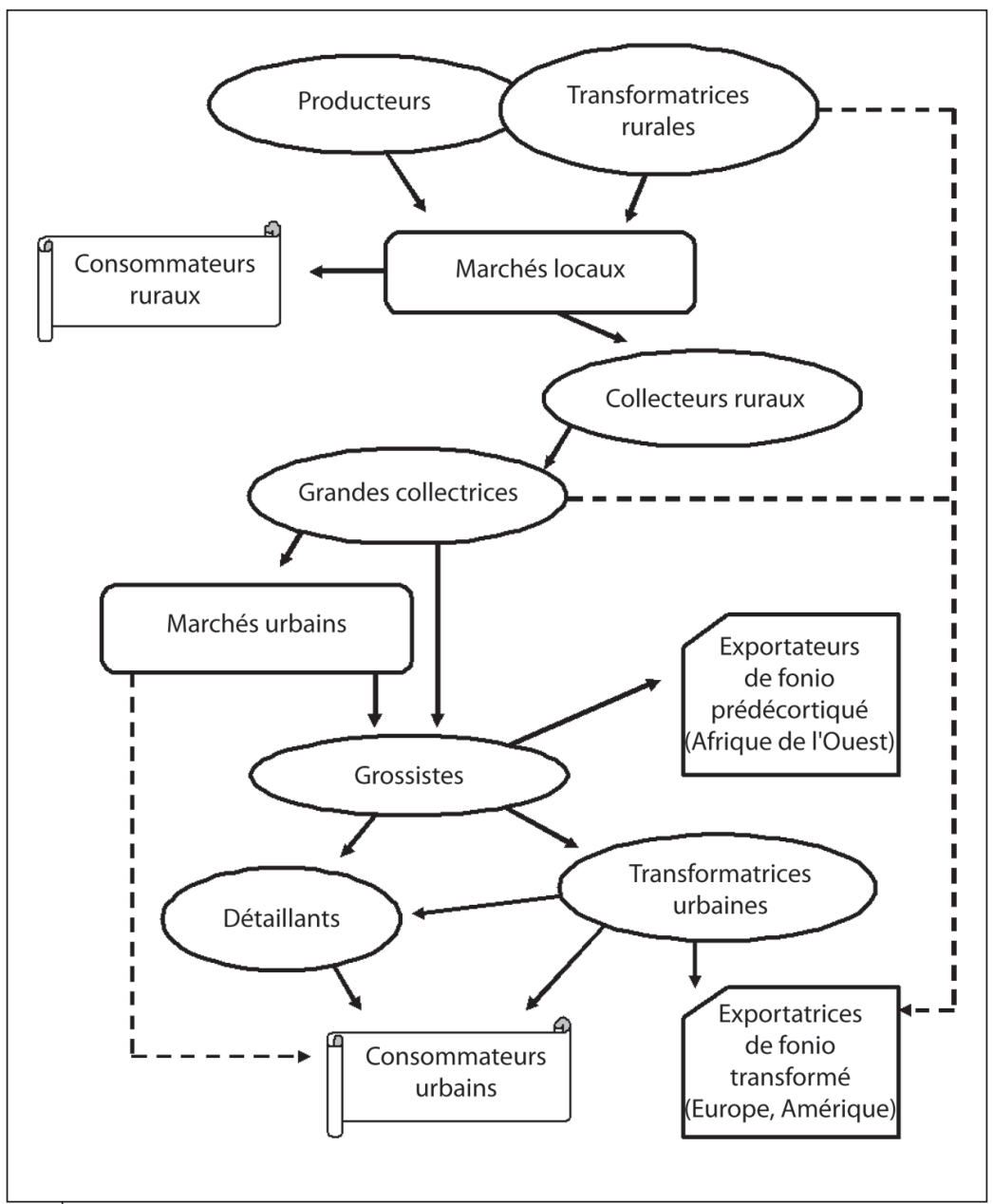

Figure 9.1.

Schéma simplifié de la filière fonio en Guinée.

fonio blanchi, etc.) est ensuite conditionné en sacs de 50 à $100 \mathrm{~kg}$ pour être revendu aux grossistes des grandes agglomérations.

\section{Les grossistes}

Les grossistes récupèrent différentes collectes qu'ils stockent pour approvisionner les marchés urbains et la capitale Conakry. Les villes de Labé, Mamou, Faranah, Kissidougou et Kindia sont les principaux 
marchés où va être regroupé le fonio avant l'approvisionnement des centres urbains de Conakry, Kankan et Guéckédou. Organisés en associations, les grossistes exportent également leurs denrées vers les pays voisins. Une partie du fonio de Moyenne et de Haute Guinée est ainsi exporté au nord vers le Sénégal et la Gambie, et à l'est vers le Mali ou la Côte d'Ivoire. Au Sénégal, c'est sur le grand marché hebdomadaire de Diaobé, situé en Haute Casamance, entre Velingara et Kolda, qu'une part importante du fonio guinéen vendu au Sénégal est commercialisé sous la forme de fonio prédécortiqué.

\section{Les transformatrices urbaines}

Ces transformatrices urbaines sont parfois des femmes qui ont créé leur PME ou se sont regroupées en association pour acheter du fonio prédécortiqué en vrac sur les marchés ou auprès de grossistes. Elles vont le transformer pour en faire un produit fini (fonio blanchi, fonio grillé), souvent conditionné en sachets plastiques et vendu aux détaillants, aux exportatrices ou directement aux consommateurs eux-mêmes.

\section{Les détaillants}

Derniers maillons de la filière locale, les détaillants sont les garants de la bonne commercialisation du fonio auprès des consommateurs urbains. Les détaillants vont parfois reconditionner eux-mêmes le fonio transformé qu'ils ont pu acheter en vrac auprès des transformatrices. Ils sont très sensibles à la qualité pour mieux fidéliser leur clientèle.

\section{Les exportatrices}

Depuis quelques années, un marché à l'exportation de fonio transformé s'est développé vers l'Europe et le continent américain (États-Unis, Canada). Ce nouveau marché, qui peut avoir un effet d'entraînement sur la filière, nécessite néanmoins de satisfaire à des exigences de qualité relativement strictes (grains bien décortiqués, absence de sable, etc.). Les exportatrices actuelles s'approvisionnent généralement auprès des transformatrices urbaines, mais des volumes plus importants de commandes à l'exportation pourraient conduire les exportatrices à s'approvisionner directement auprès de transformatrices villageoises, qui réaliseraient alors la transformation complète du fonio en milieu rural. 


\section{ID L'évolution des prix}

Les prix connaissent d'importantes variations saisonnières entre la grande période de récolte (septembre et octobre) et la période de soudure (juin, juillet et août).

Les coûts de transformation et de transport sont deux dépenses qui pèsent lourdement sur le prix du fonio.

En 2003, alors que le coût de production moyen se situait autour de 130 à $140 \mathrm{FG} / \mathrm{kg}$ (environ $40 \mathrm{FCFA} / \mathrm{kg}$, soit $0,06 € / \mathrm{kg}$ ), les prix des différentes formes de fonio commercialisées en Guinée étaient les suivants :

- Fonio paddy : 250 à $410 \mathrm{FG} / \mathrm{kg}$ (soit 71 à 117 FCFA/kg ou 0,11 à $0,18 € / \mathrm{kg})$.

- Fonio décortiqué : 700 à $1200 \mathrm{FG} / \mathrm{kg}$ (soit 200 à $345 \mathrm{FCFA} / \mathrm{kg}$ ou $0,30$ à $0,42 € / \mathrm{kg})$.

- Fonio blanchi : 800 à $1500 \mathrm{FG} / \mathrm{kg}$ (soit 230 à $430 \mathrm{FCFA} / \mathrm{kg}$ ou 0,35 à $0,65 € / \mathrm{kg})$.

- Fonio blanchi (grillé ou non), conditionné en sachet : $2500 \mathrm{FG} / \mathrm{kg}$ (soit $715 \mathrm{FCFA} / \mathrm{kg}$ ou $1,1 € / \mathrm{kg}$ ).

Jusqu'à présent, le fonio guinéen est encore commercialisé sous une forme assez peu élaborée et sans très grande valeur ajoutée. Alors qu'il approvisionne beaucoup de marchés sous-régionaux, il est mal valorisé à l'échelon international, où l'essentiel des produits vendus sur les marchés «biologiques et équitables» des pays développés provient des pays voisins comme le Mali, le Sénégal ou, plus loin, le Burkina Faso. Le potentiel nouveau que représente la mécanisation récente des opérations post-récolte devrait permettre, à l'avenir, de diversifier l'offre en produits du fonio de qualité.

\section{Commercialisation du fonio précuit}

Le fonio précuit fait partie des «nouveaux produits du fonio », le plus commercialisé en Afrique de l'Ouest et à l'exportation.

\section{II) Quelques petites entreprises pionnières}

Au début des années 1990, quelques petites entreprises, très souvent familiales, et des groupements de femmes ont commencé à produire 
du fonio précuit au Mali, puis au Burkina Faso et au Sénégal. Parmi les entreprises pionnières se trouvaient notamment Ucodal à Bamako, l'association de femmes Wend Benedo à Ouagadougou, qui commercialisait du fonio sous la marque Tomé, et le GIE Koba Club à Kédougou. Beaucoup d'entre elles n'étaient pas spécialisées dans le fonio, mais proposaient une gamme diversifiée de produits à base de céréales ou de condiments locaux. Les opérations de préparation et de conditionnement restaient essentiellement manuelles et, malgré la pénibilité du travail, ces entreprises pionnières ont perduré et ont joué un rôle important pour la relance de la filière fonio.

\section{ID Développement du secteur grâce à la mécanisation des opérations post-récolte}

Progressivement, certaines de ces petites entreprises se sont spécialisées dans la production de fonio précuit, conditionné en sachets pour approvisionner les boutiques de quartier et les supermarchés locaux, et elles ont commencé à créer de petites filières d'exportation. Les cibles visées étaient alors la clientèle relativement aisée des zones urbaines et la diaspora ouest-africaine de certains États européens ou nord-américains.

Le succès du fonio précuit a été important et la demande s'est accrue fortement, tant au niveau local qu'à l'exportation. Pour répondre à ce nouveau besoin, les entreprises, rapidement confrontées aux limites imposées par le travail manuel, ont sollicité la recherche pour disposer d'équipements spécifiques et performants tant en termes de productivité que de qualité du travail réalisé. La mise au point d'équipements de décorticage, de nettoyage et de séchage a permis aux entreprises existantes de mieux répondre à la demande croissante et a favorisé l'émergence de nouvelles petites entreprises. Alors qu'on ne comptait que quelques unités au cours des années 1990, on peut considérer aujourd'hui que le nombre de petites entreprises qui produisent du fonio précuit en Afrique de l'Ouest avoisine la cinquantaine. Beaucoup ne sont pas encore équipées de machines et s'adressent alors, pour le décorticage, à des prestataires de service récemment installés pour répondre à cette nouvelle demande. La plupart des entreprises sont établies dans les capitales, où se situe l'essentiel du marché et, dans une moindre mesure, dans les villes principales des zones de production. Au Mali, les petites entreprises sont ainsi implantées à près de $80 \%$ à Bamako et le reste à Ségou et à Kayes. Au 
Burkina Faso, les entreprises sont surtout installées à Ouagadougou et à Bobo Dioulasso, tandis qu'au Sénégal elles sont présentes à Dakar, Kédougou et Kolda.

Au Mali, certaines transformatrices de Bamako achètent leur matière première directement auprès des producteurs ou sur les grands marchés des zones de production (Bougouni, San), mais la plupart d'entre elles s'approvisionnent au «marché de Guinée» à Bamako, où des grossistes revendent du fonio importé du Fouta-Djalon ou de Haute Guinée. La qualité du fonio de Guinée reste très appréciée. Les quantités disponibles sont toujours importantes et peuvent représenter plusieurs dizaines de tonnes de fonio de différentes qualités et à différents prix en fonction du niveau de décorticage et de propreté des lots.

\section{ID Le commerce local du fonio précuit}

Le marché du fonio précuit s'est fortement développé depuis le début des années 1990 et l'on recense aujourd'hui plus d'une vingtaine de marques différentes, tant à Ouagadougou qu'à Bamako ou à Dakar. Le fonio précuit est habituellement conditionné en sachets de polyéthylène thermosoudé de $1 \mathrm{~kg}$ et parfois de $500 \mathrm{~g}$ (photo 9.1.). Grâce aux campagnes de promotion, mais surtout grâce au dynamisme des transformatrices locales, il est maintenant disponible dans la plupart des boutiques ou des supermarchés de Bamako, Ouagadougou ou Dakar, et il est connu par la majorité des clients, même si tous n'en achètent pas. Un relevé fait dans un grand supermarché de Bamako en 2007 montrait qu'une centaine de kilogrammes de fonio précuit étaient proposés à la clientèle, répartis en 80 sachets de $1 \mathrm{~kg}$ de deux marques différentes et en 40 sachets de $500 \mathrm{~g}$ d'une même marque.

Les prix du fonio précuit ainsi conditionné sont relativement stables tout au long de l'année et varient, à Bamako, entre 850 FCFA $(1,30 €)$ et 1200 FCFA $(1,83 €)$, même si le prix le plus fréquemment observé est de 1000 FCFA $(1,52 €)$ pour le sachet de $1 \mathrm{~kg}$ et de 500 FCFA $(0,76 €)$ pour le sachet de 500 g. Ces mêmes prix sont également observés à Ouagadougou. Ils peuvent varier légèrement, mais essentiellement en fonction des marques et des lieux de vente. Dans le prix payé par l'acheteur de fonio précuit, on peut considérer que globalement $30 \%$ vont aux producteurs, $20 \%$ aux commerçants et $50 \%$ aux transformatrices, qui ont la plus lourde charge de travail et les frais les plus élevés. 


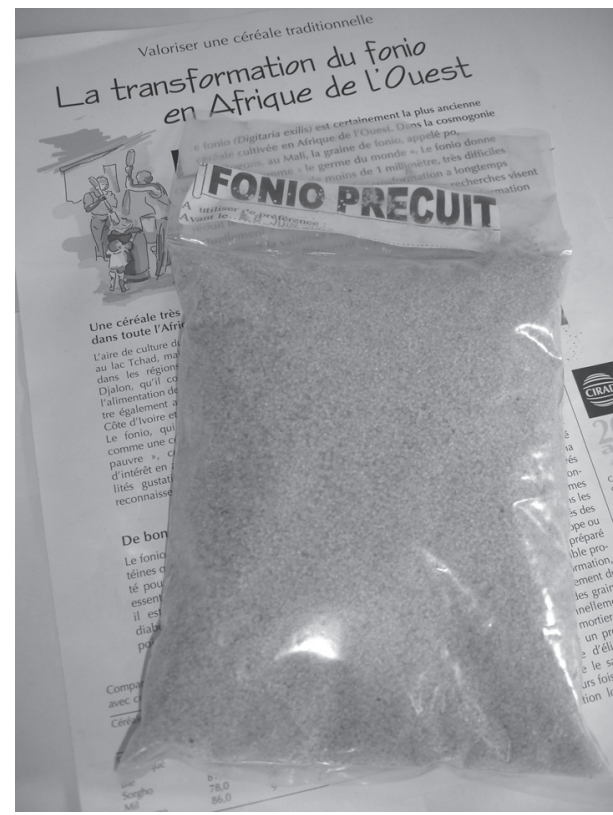

\section{Photo 9.1.}

Sachet de fonio précuit

(৫ J.-F. Cruz).

Les clients sont souvent très satisfaits de la qualité du fonio précuit ainsi conditionné, même si, dans de rares cas, certains se plaignent de la présence de sable ou d'une mauvaise odeur. Les principales critiques portent le plus souvent sur la mauvaise qualité de l'emballage, qui ne serait pas assez solide ou pas assez étanche.

Les acheteurs de fonio précuit sont en général des urbains parmi les plus aisés, qui ont un niveau d'éducation plus élevé que celui des acheteurs de produits traditionnels (fonio décortiqué et fonio blanchi vendus en vrac sur les marchés). Les achats unitaires portent sur des quantités relativement faibles, à savoir 1 à $2 \mathrm{~kg}$, mais lorsque les besoins sont plus importants, notamment à l'occasion de fêtes ou de cérémonies, de nombreux clients retournent alors vers les produits traditionnels vendus à moindre coût. Le fonio précuit ne se substitue donc que très partiellement aux produits traditionnels.

\section{ID La vente du fonio précuit à l'export}

Pendant longtemps, la vente de fonio à l'export est restée informelle et son importance difficile à apprécier. Parfois, elle pouvait se résumer à quelques sacs de fonio blanchi, placés dans un conteneur rempli de 
divers produits africains destinés à l'étranger. Au cours des années 1990, seules deux marques, dont Ucodal du Mali, proposaient en France du fonio précuit conditionné en sachets plastiques. La clientèle cible était alors essentiellement constituée de consommateurs originaires de pays sahéliens comme le Mali, mais aussi le Burkina Faso ou le Sénégal. Le volume global pouvait varier de quelques tonnes à quelques dizaines de tonnes.

Progressivement, la demande s'est accrue, mais l'offre des transformatrices locales restait limitée en raison des faibles moyens de production dont elles disposaient. La mise au point par les différents «projets fonio» de machines de décorticage et de séchoirs performants a permis d'éliminer quelques-uns des principaux goulets d'étranglement de la filière. Au début des années 2000, les entreprises déjà existantes ont pu commencer à s'équiper en machines pour mieux satisfaire la demande. De même, la mécanisation du décorticage a favorisé l'émergence de nouvelles entreprises de production de fonio précuit dont certaines sont devenues exportatrices. En 2007, la production de nouveaux produits du fonio au Mali, essentiellement du fonio précuit, était évaluée à plus de $250 \mathrm{t}$, dont au moins deux tiers étaient destinés à l'exportation. Il était prévu que cette production augmente, voire double en 2009. Ces quantités ne représentent cependant que 5 à $10 \%$ du fonio commercialisé localement et à peine 1 à $2 \%$ de la production nationale malienne estimée à près de $30000 \mathrm{t}$ de fonio paddy.

En France, la société Racines, installée à Montpellier, commercialise de nombreux produits alimentaires d'origine tropicale. Au début des années 2000, grâce à une collaboration étroite avec des laboratoires de recherche comme le Cirad par exemple, elle a été une des premières sociétés à importer du fonio précuit du Mali, pour le reconditionner et le distribuer dans ses nombreux points de vente sur tout le territoire français. Aujourd'hui, cette société commercialise à elle seule plusieurs dizaines de tonnes de fonio précuit par an.

Plus tard, en 2004, l'association Le Damier a participé à la création d'une organisation de producteurs de fonio dans le cercle de Kéniéba au sud de la région de Kayes, dans l'ouest du Mali. En 2006, cette organisation appelée «Benkouto», qui signifie « concorde» en langue malinké, regroupait plusieurs centaines de producteurs répartis sur neuf villages et avait pour objectif de développer une filière de fonio biologique et équitable. Grâce à l'appui financier des régions françaises Nord-Pas-de-Calais et Île-de-France, et à l'engagement de l'entreprise coopérative française Éthiquable, très réputée dans le domaine du 
commerce équitable, une production locale de fonio précuit a pu être lancée. Ainsi, le fonio paddy est battu, puis décortiqué dans les villages qui, à cet effet, ont été équipés de batteuses et de décortiqueurs GMBF. Le fonio décortiqué est ensuite transporté dans la capitale régionale, Kayes, où il est blanchi, précuit et reconditionné en boîtes en carton par une petite entreprise, Le grenier du paysan, dont les producteurs sont aussi actionnaires. La production porte sur quelques dizaines de tonnes dont la moitié est exportée et commercialisée en France par la marque Éthiquable, sous l'appellation «Fonio du Mali» avec le label Fairtrade Max Havelaar.

À la même époque, la société Gaia, une entreprise installée dans le département du Tarn au sud de la France, spécialisée dans le commerce de produits alimentaires biologiques (galettes, biscuits), a créé une filiale africaine appelée «Gaia Bio Solidaire» pour mieux valoriser le fonio. Après une première expérience non aboutie dans la région de Koussanar au Sénégal, l'entreprise Gaia Bio Solidaire s'est associée à des producteurs du nord-ouest du Burkina Faso. Elle a construit une unité de transformation à Nouna, capitale de la province de Kossi, pour produire du fonio complet ou semi-complet étuvé qu'elle commercialise en France comme produit certifié «Agriculture Biologique». La couleur très sombre du fonio complet étuvé le destine davantage à une clientèle européenne. Des enquêtes réalisées à Montpellier ont montré que les consommateurs européens choisissent aussi bien du fonio complet étuvé de couleur foncée que du fonio précuit de couleur claire, alors que les consommateurs africains considèrent généralement que la couleur bien blanche du fonio constitue l'un des premiers critères de qualité de cette céréale.

Racines, Éthiquable et Gaia sont en 2010 les principales marques qui distribuent du fonio en France (voir cahier de photos couleur). Certaines autres marques en proposent également, mais il s'agit soit de fonio complet ou semi-complet étuvé, produit par Gaia Bio Solidaire et reconditionné par les marques Celnat, Moulin des moines, France Aglut, soit de fonio précuit produit par des groupements de femmes et commercialisé par des ONG à l'occasion d'opérations ponctuelles de commerce équitable. C'est le cas, par exemple, du fonio précuit commercialisé en 2010 par Artisans du monde de la région française Rhône-Alpes, en opération conjointe avec l'ONG Afrique Verte Burkina. 


\section{La consommation}

\section{Pratiques de consommation}

Le fonio est consommé depuis des siècles en Afrique de l'Ouest. $\mathrm{Au} \mathrm{XIV}^{\mathrm{e}}$ siècle, Ibn Battûta rapporte que, dans ces contrées, le couscous est préparé avec du fonio. En 1830, l'explorateur René Caillé précise que le fonio constitue une le préparent en bouillie assaisonnée d'herbes et de gombo ou sous la forme de tô. Le fonio est toujours très apprécié par les populations locales et les Européens qui vivent dans ces régions. En 1909, le botaniste Auguste Chevalier rappelle que le fonio constitue tout au long de l'année l'alimentation presque exclusive des habitants des hauts plateaux du Fouta-Djalon. Certains voyageurs parlent souvent du fonio avec enthousiasme. En 1929, Émile Perrot, botaniste à la faculté de pharmacie de Paris, en mission en Guinée, dit que le goût du fonio est exquis. Mais certains avis sont parfois contraires. En 1937, Henri Labouret rapporte le propos d'un notable de Mamou disant: «Le fonyo est agréable à manger au printemps et pendant les pluies. Mais, quand les vents blancs de novembre sont arrivés, c'est le riz. Alors maïs, mil, fonyo sont délaissés pour le riz; une poignée de ce dernier vaut mieux qu'une grande calebasse de fonyo, que l'on met à ce moment en "retraite de continence"."

En 1955, l'agronome R. Portères rappelle que «partout, les Européens emploient le fonio depuis le potage jusqu'à la pâtisserie, comme plat principal, ils le consomment en couscous avec des crustacés (crevettes, écrevisses, langoustines), parfois du poisson» et que «le couscous au beurre ou au lait est très apprécié des Européens pour l'alimentation des enfants. On le recommande aux convalescents et malades ainsi qu'aux personnes à estomac et intestins fatigués ». Il note qu'en dessous du $12^{\mathrm{e}}$ parallèle — situé entre 60 et $70 \mathrm{~km}$ sous une ligne Ouagadougou (Burkina Faso), Bamako (Mali), Koundara (Guinée) 一, on peut considérer le fonio comme «une céréale alimentaire de fond autant qu'une autre». Au nord du $12^{\mathrm{e}}$ parallèle, il ne subsiste plus que des «variétés précoces et très précoces jouant seulement le rôle de briseurs de famine et de disette». 
La Guinée est presque entièrement située au sud du $12^{\mathrm{e}}$ parallèle et, dans l'importante zone de production qu'est le Fouta-Djalon, le fonio est consommé pratiquement chaque jour comme plat principal par la majorité de la population rurale. Il constitue réellement l'aliment de base des familles, souvent nombreuses, qui se nourrissent de leurs propres récoltes comme dans la plupart des villages à travers le monde. Bien souvent, les producteurs de fonio destinent plus de $80 \%$ de leurs réserves à l'autoconsommation, en conservent $15 \%$ pour les semences et en commercialisent moins de $5 \%$. Seules les mauvaises récoltes ou les difficultés inhérentes à sa préparation (décorticage) en limitent parfois la consommation.

En ville, la consommation est moindre, mais certains ménages en consomment encore au moins une fois par semaine et notamment les familles originaires de régions productrices comme la Moyenne ou la Haute Guinée. Le fonio est alors souvent considéré comme un plat ordinaire consommé sous la forme courante du fonio foyo (ou couscous de fonio).

\section{ID Le fonio : une céréale de gourmet, savoureuse et digeste}

Si le fonio est considéré comme un plat ordinaire, il n'en demeure pas moins qu'en ville les difficultés de sa préparation ou son coût, lorsqu'il s'agit d'un fonio précuit emballé et commercialisé, limitent souvent son utilisation aux grandes occasions. De nombreuses Bamakoises considèrent le fonio comme un produit de luxe (Fogny-Fanou et al., 2009). À Bamako, à Ouagadougou, à Dakar ou même à Conakry, la grande majorité des consommateurs n'en prépare qu'occasionnellement, notamment durant le Ramadan ou à l'époque des récoltes lorsqu'on en reçoit de la part de parents restés au village (KonkoboYaméogo et al., 2004). Réputée comme la céréale la plus savoureuse, sa finesse et ses qualités gustatives en font un mets de choix, toujours servi lors de fêtes, de cérémonies importantes ou pour la réception d'hôtes de marque. Un proverbe populaire dit que « le fonio ne fait jamais honte à la cuisinière ». En dehors des repas habituels servis le midi ou le soir, il peut aussi être proposé comme "petit plat», ou plat de gourmet, à des hôtes privilégiés. Très digeste, il est traditionnellement recommandé pour l'alimentation des enfants, des femmes enceintes ou allaitantes, des personnes âgées et pour les personnes souffrant de surpoids. 


\section{La consommation du fonio hors domicile}

La consommation hors domicile, trop souvent occultée, est aujourd'hui importante dans de nombreuses villes d'Afrique de l'Ouest. Elle participe à la diversification de l'alimentation, qui est une tendance forte de l'évolution des pratiques alimentaires. Par manque de temps (journée continue) et de moyens de transport adéquats, beaucoup de salariés, fonctionnaires, commerçants, étudiants, écoliers, etc. ne prennent plus leur repas de midi à leur domicile, souvent très éloigné de leur lieu d'activité, mais dans les nombreuses cantines, gargotes, petits restaurants ou simples tables qui se sont installés dans la plupart des grandes villes. Quel que soit le milieu social, la consommation hors foyer peut aussi être un moyen d'échapper aux contraintes des repas en famille et de s'offrir, peut-être égoïstement mais toujours agréablement, un plat «nouveau » rarement disponible à la maison, en raison de possibles pressions sociales, culturelles ou financières. Mais l'alimentation à l'extérieur, souvent diversifiée, a surtout le mérite de compléter les apports nutritionnels généralement peu variés au domicile, notamment pour les enfants des familles modestes.

Dans les petits restaurants de Ouagadougou ou de Bamako, les plats à base de céréales sont les plus consommés et c'est généralement le riz sauce qui est le plus commandé. Mais, à Bamako, le riz est immédiatement suivi par le fonio, préparé en foyo sauce tomate ou en djouka, alors que les mils et sorghos, aliments de base traditionnels que l'on a l'habitude de consommer à la maison, y sont moins appréciés. En 1998, le nutritionniste malien Mohamed Ag Bendesh précisait que «l'alimentation hors domicile se spécialise dans les produits rarement consommés à domicile tels que le fonio, le haricot, les boissons, les produits de friture, les fruits et les légumes», en rappelant que «le fonio n'est pas une céréale qui entre dans l'alimentation habituelle du domicile, mais [qu']il est très souvent choisi hors domicile dans les plats achetés de type "base et sauce" et notamment sous la forme de djouka ou couscous de fonio à l'arachide pilée». Des enquêtes réalisées à Bamako dans le cadre du projet Amélioration des technologies post-récolte du fonio, au début des années 2000, ont montré que les plats à base de fonio étaient bien connus des consommateurs et que le djouka était plutôt consommé le matin ou en milieu de matinée à l'occasion d'une pause précédant le repas de midi. À midi, ce sont davantage le foyo et le fonio sauce tomate qui sont commandés, alors que la bouillie de fonio est plutôt réservée au repas du soir. 
En Guinée, dans les petites villes de l'intérieur comme à Mamou, les restaurants préparent rarement du fonio, car c'est un plat que l'on consomme fréquemment à domicile. Seules quelques vendeuses ambulantes proposent parfois du fonio aux voyageurs qui transitent par les gares routières. Mais à Conakry, de très nombreux clients, et notamment de jeunes hommes célibataires, fréquentent les restaurants et les gargotes pour consommer du fonio, surtout comme repas de midi. Il arrive parfois que des consommateurs commandent du fonio non pas uniquement pour se nourrir, mais simplement pour satisfaire une «envie de fonio».

Dans les grandes villes d'Afrique de l'Ouest, certains restaurants proposent des plats plus élaborés et plus chers avec du fonio accompagné de poisson ou de viande, et offrent ainsi aux clients plus aisés la satisfaction de consommer un plat typiquement africain à haute qualité gustative et symbolique. Les restaurateurs sont néanmoins confrontés à certaines difficultés dans la vente de plats à base de fonio en raison des contraintes liées à sa préparation. La disponibilité de fonio précuit commercialisé en sachet permet de résoudre ce problème, mais c'est alors le coût qui devient une contrainte majeure, sauf pour les plus grands restaurants où les plats peuvent être vendus plus cher. Le fonio, aliment de base de nombreuses populations rurales, devient alors une denrée de luxe, qui doit être de qualité irréprochable et totalement exempt de sable et d'impuretés.

\section{II) Critères de qualité du fonio}

Que ce soit pour l'achat de fonio blanchi ou précuit, en vrac ou en sachet, ou pour le choix de plats à base de fonio, la propreté du lieu de vente et du produit reste le critère de qualité considéré comme essentiel par les consommateurs. Pour le lieu de vente, ils tiennent compte de l'hygiène de l'endroit et de la présentation du vendeur ou de la vendeuse, car ils sont conscients que l'absence de contrôle officiel de la vente d'aliments préparés hors domicile peut présenter un risque pour leur santé. La propreté du produit est d'abord caractérisée par l'absence perceptible d'impuretés (graines étrangères, débris végétaux) ou de grains mal décortiqués. Mais la seule observation visuelle ne permet pas de savoir précisément si le produit est pollué par des sables qui ont la même taille que les grains de fonio. Les ménagères ou les clients se fient alors à la réputation du commerçant ou du restaurateur, ou prennent en compte la région d'origine du 
produit lorsqu'elle peut être déterminée (Dury et al., 2007). Au Mali, on préfère parfois le fonio de Bougouni et en Guinée, au FoutaDjalon, on apprécie davantage le fonio de montagne, cultivé sur des sols gravillonnaires parce qu'il ne contient pas de sable contrairement au fonio de plaine. Il est par ailleurs bien blanc, facile à préparer et convient tout à fait au goût des consommateurs.

Le second critère important est la couleur. La couleur des grains, évidemment étroitement liée au degré de décorticage-blanchiment, a une incidence directe sur les prix d'achat par les consommateurs (Dury et Meuriot, 2011). Comme pour le riz, les consommateurs africains recherchent le plus souvent un fonio bien blanc. En Guinée, où il existe une très grande diversité d'écotypes, les consommateurs apprécient, par exemple, les variétés Siragué et Konso qui, après décorticage et blanchiment, donnent des grains d'une belle blancheur. Ailleurs aussi le fonio est naturellement associé à la notion de blanc : en pays dogon au Mali, la période de fin septembre est désignée par l'expression : «Qu'est-ce qui est plus blanc, le fonio ou la lune ?». Le fonio précuit, commercialisé en sachet plastique, est plutôt de couleur beige du fait de son traitement à la vapeur. Les consommateurs urbains s'y sont habitués et ils sont alors davantage sensibles à la présence ou non de grains noirs (graines étrangères) dans le paquet. Pour les nouveaux consommateurs français qui découvrent le fonio, la blancheur ne semble pas être le premier critère de qualité. D'après des enquêtes réalisées à Montpellier, certains sont même davantage attirés par le fonio complet de couleur très brune, qui leur paraît plus naturel.

La taille des grains est assez rarement évoquée pour être retenue comme véritable critère de qualité et il serait prétentieux de vouloir l'augmenter. Un proverbe bambara dit : «Seul le grain de fonio reste minuscule.»

Dans tous les cas, pour les consommateurs africains comme pour les consommateurs européens ou les autres, le tout premier critère de qualité d'un plat de fonio est l'absence totale de sable. Pour chacun, il n'y a rien de plus désagréable qu'un grain de sable qui crisse sous la dent lors d'un repas. Les fournisseurs de fonio en sachet, destiné aux marchés urbains ou à l'export, doivent impérativement commercialiser un fonio exempt de sable s'ils ne veulent pas que, dans l'esprit des consommateurs, le terme fonio soit pour longtemps synonyme de sable (comme, à une certaine époque, on associait lentilles et cailloux). 


\section{Mode de préparation et recettes}

La cuisine africaine est parfois considérée comme différente des autres cuisines par les ingrédients utilisés (céréales, racines ou tubercules, viandes et poissons, épices, etc.) et la manière particulière dont ils sont cuisinés. Mais à l'instar de nombreuses autres cuisines du monde, les plats ordinaires sont souvent constitués d'un aliment de base et d'un accompagnement (ou sauce). En Guinée, au Mali, au Burkina Faso, au Sénégal ou ailleurs en Afrique de l'Ouest, le fonio constitue la base de nombreuses recettes très appréciées au plan culinaire et diététique. Il est habituellement consommé sous forme de couscous (foyo) ou de bouillies légères ou épaisses (dégu, moni, tô), mais de nombreuses autres préparations culinaires sont possibles (fonio au gras, salades, gâteaux, beignets, etc.).

En 1929, dans son rapport de mission en Guinée, Émile Perrot précise : «Cette céréale se présente sous trois aspects : en graines brutes; en graines décortiquées, en les mouillant légèrement; en graines blanchies, par lavages à l'eau, puis séchage. On la consomme cuite à l'eau, avec ou sans légère torréfaction préalable et son goût est exquis ». En réalité, il ne décrivait là qu'un des modes de cuisson du fonio, spécifique à la Guinée, alors qu'ailleurs la cuisson du fonio est surtout une cuisson à la vapeur.

\section{ID Cuisson du fonio à la vapeur}

Ce mode de cuisson du fonio, le plus répandu dans toute l'Afrique de l'Ouest, est le plus prisé notamment pour la préparation de plats de fête. Il est réalisé avec un couscoussier constitué d'une marmite inférieure qui contient de l'eau et d'une bassine supérieure, à fond perforé, que l'on remplit de fonio blanchi encore humide après lavage. Les deux récipients, en terre cuite ou en aluminium, sont reliés par un joint étanche pour empêcher la fuite de vapeur. La première cuisson peut durer de dix à quinze minutes. Le fonio est ensuite vidé du couscoussier dans un autre récipient pour y être émotté, remué et arrosé d'eau modérément. On peut également ajouter du beurre ou un constituant végétal (gombo, feuilles de baobab pilées) qui fournira un liant gluant et facilitera sa déglutition lors de la consommation. Le fonio est ensuite replacé dans le couscoussier pour y subir une seconde, puis une troisième cuisson, afin d'obtenir un fonio moelleux et cuit à point. 


\section{Cuisson du fonio à l'eau}

Ce mode de cuisson du fonio semble spécifique à la Guinée et se pratique avec du fonio blanchi ayant préalablement été grillé à sec dans une casserole. Ce grillage ou torréfaction, qui permet l'action d'une chaleur sèche sur l'amidon, doit lui conférer davantage de solubilité et de digestibilité et donne également une saveur très agréable aux préparations. Pour préparer le niri fonye, célèbre en Guinée, on grille les grains de fonio blanc jusqu'à ce qu'ils prennent une couleur jaune. Puis, on les jette dans une casserole d'eau portée à ébullition. On retire une partie de l'eau que l'on rajoute progressivement ensuite, puis on laisse cuire à petit feu. Le plat est accompagné de sauce gombo et de sauce arachide, additionnées de viande ou de poisson préalablement émietté.

En Guinée, les avis sont très partagés sur les avantages supposés de la cuisson à l'eau par rapport à la cuisson à la vapeur : «rapidité de cuisson », «meilleur gonflement à la cuisson», pour les uns; «plus difficile à réussir», "gonflant moins que le fonio cuit à la vapeur», pour les autres. Des essais de dégustation de plats réalisés en Guinée avec les deux modes de cuisson ont montré que la cuisson à la vapeur était généralement très appréciée. Le plat a un bel aspect avec des grains bien isolés d'une couleur très blanche et d'une fermeté agréable. Avec la cuisson à l'eau, les plats sont moins blancs et parfois moins appétissants, mais ils ont un arôme et une saveur de "grillé» très agréables qui satisfont beaucoup de consommateurs. Pour la plupart, la cuisson à l'eau reste néanmoins plus difficile que la cuisson à la vapeur, car une mauvaise maîtrise des quantités d'eau et des temps de cuisson peut se traduire rapidement par un plat mal cuit, pâteux et peu présentable.

La préparation du fonio dit «au gras », courante en Afrique de l'Ouest, est aussi une cuisson à l'eau car elle est faite dans un bouillon de viande, de volaille ou de poisson.

\section{ID Quelques recettes à base de fonio}

\section{Plats à cuisson vapeur}

Le plat à cuisson vapeur le plus souvent préparé, notamment à l'occasion de fêtes, est le fameux couscous de fonio ou foyo. Il est fréquent en Guinée, au Mali et au Burkina Faso. 


\section{Foyo}

Temps de préparation et cuisson :

$1 \mathrm{~h}$ à $1 \mathrm{~h} 30 \mathrm{~min}$

Ingrédients (pour 5 personnes) :

Fonio : $1 \mathrm{~kg}$ - Eau : $750 \mathrm{ml}$ à 11 - Viande : $2 \mathrm{~kg}$

Tomate fraîche : 250 à $300 \mathrm{~g}$ - Tomate concentrée : $100 \mathrm{~g}$ - Oignons : $1 \mathrm{~kg}$

Ail : à volonté - Piments frais : 2 à 3 unités

Légumes : carottes, choux, aubergines, poivrons, navets, courgettes

Arômes : 1 à 2 bouillon-cubes - Huile : $250 \mathrm{ml}$ - Sel - Épices (poivre)

Préparation :

- Mettre le fonio dans un récipient et l'arroser d'eau (approximativement 0,51 d'eau pour $1 \mathrm{~kg}$ ).

- Faire cuire à la vapeur une première fois pendant 10 min.

- Ajouter, après cette première cuisson, un peu d'eau sur le fonio tout en le malaxant doucement.

- Faire cuire à la vapeur une deuxième fois pendant $5 \mathrm{~min}$.

- Mettre ensuite dans le couscoussier le fonio et les morceaux de gombo frais coupés en fines lamelles, placés au-dessous du fonio.

- Faire cuire à la vapeur une troisième fois pendant $15 \mathrm{~min}$.

- Mélanger en fin de cuisson le fonio et le gombo.

Cette préparation peut être accompagnée de différentes sauces : sauce tomate viande, sauce tomate poisson, sauce arachide, sauce feuille.

Au Mali, le djouka ou couscous à l'arachide pilée est un plat très populaire.

\section{Djouka}

Temps de préparation et cuisson :

$1 \mathrm{~h}$ à $1 \mathrm{~h} 30 \mathrm{~min}$

Ingrédients (pour 5 personnes) :

Fonio : $1 \mathrm{~kg}$ - Arachides : $2 \mathrm{~kg}$ - Eau : 11 - Huile : 1/4 1 - Oignons : $1 \mathrm{~kg}$

Potasse : $45 \mathrm{~g}$ - Gombo frais : $500 \mathrm{~g}$ - Aubergines : 4 à 5 unités

Piment : 2 à 3 unités - Ail - Sel - Vinaigre

Épices (poivre, bouillon-cube, etc.)

Préparation :

- Vanner, trier, laver, puis sécher les arachides.

- Faire cuire les graines non dépelliculées à la vapeur 5 min.

- Piler et tamiser pour enlever la pellicule.

- Mélanger l'arachide pilée avec la potasse (40 g) et le sel.

- Mettre le fonio dans un récipient et l'arroser d'eau

(environ 0,5 1 d'eau pour $1 \mathrm{~kg}$ ). 
- Faire cuire à la vapeur une première fois pendant $10 \mathrm{~min}$.

- Ajouter après cette première cuisson un peu d'eau (300 à 400 ml) sur le fonio tout en le malaxant doucement.

- Faire cuire à la vapeur une deuxième fois pendant $5 \mathrm{~min}$.

- Ajouter sur le fonio la poudre d'arachide et les épices (poivre, piment, etc.).

- Faire une troisième cuisson à la vapeur pendant 5 à 10 min.

- Faire cuire dans un peu d'eau pendant 15 à 20 min les morceaux de gombo frais coupés en fines lamelles; ajouter une pincée de potasse (environ $5 \mathrm{~g}$ ).

- Mélanger le fonio cuit trois fois avec la sauce gombo.

- Cuire dans l'eau bouillante les aubergines et les piments pendant 10 à $15 \mathrm{~min}$.

- Faire cuire dans l'huile les oignons finement émincés avec le sel, les cubes, le poivre et un filet de vinaigre.

- Garnir le fonio cuit avec la sauce à base d'oignons, le piment et les aubergines.

Les temps de cuisson sont indicatifs car la cuisson est bonne quand le grain devient assez moelleux. La sauce oignons peut être préparée avec des boulettes de viande ou de poisson.

\section{Plats à cuisson à l'eau ou au bouillon}

Le niri fonye ou founden bande est un plat typique de Guinée dans lequel le fonio est cuit à l'eau.

\section{Niri fonye}

Temps de préparation et cuisson :

$1 \mathrm{~h}$

Ingrédients :

Fonio blanchi (non précuit !)

Sauce d'arachide :

Pâte d'arachide - Viande ou poisson - Tomate fraîche et/ou purée

Oignon et/ou ail - Gombo (facultatif) - Sel - Piment - Bouillon-cube

Sauce Gombo :

Gombo frais - Huile de palme - Viande ou poisson - Oignon - Sel

Piment - Bouillon-cube

Préparation :

1. Fonio

- Griller le fonio jusqu'à ce qu'il prenne une couleur jaune.

- Faire bouillir de l'eau puis ajouter le fonio.

- Retirer une bonne partie de l'eau; à remettre progressivement.

- Faire cuire ensuite à petit feu. 
2. Sauce d'arachide

- Dissoudre la pâte d'arachide dans l'eau en ébullition.

- Ajouter la viande ou le poisson préalablement émietté puis les autres ingrédients.

- Laisser cuire pendant 35 à 40 min.

3. Sauce Gombo

- Hacher le gombo frais.

- Mettre le gombo haché dans la marmite d'eau.

- Mettre au feu et remuer de temps en temps pendant 15 min.

- Ajouter les ingrédients.

- Faire cuire 25 à $30 \mathrm{~min}$.

En Guinée, au Mali, au Burkina Faso, le fonio dit «au gras» (à l'instar du riz au gras) est un plat familial et copieux.

\section{Fonio au gras}

Temps de préparation et cuisson :

$45 \min$ à $1 \mathrm{~h}$

Ingrédients (pour 5 personnes) :

Fonio précuit : $500 \mathrm{~g}$ à $1 \mathrm{~kg}$ - Viande, poulet ou poisson : $500 \mathrm{~g}$ à $1 \mathrm{~kg}$

Oignons : 2 gros - Tomates : 6 grosses - Carottes : 6 moyennes

Navets : 2 moyens - Courgettes : 2 moyennes - Aubergines : 2 moyennes

Choux : 2 petites tranches - Poivron vert : 1 gros - Poivrons rouges : 2 petits

Gombo frais : 5 petits - Concentré de tomate : 2 cuillères à soupe

Huile : 1/4 1 - Sel iodé : à volonté - Épices, aromates : laurier, poivre,

bouillon-cube, ail, persil, etc. - Eau : 21

Préparation :

- Faire revenir dans l'huile, la viande (ou le poisson ou le poulet),

les oignons émincés, l'ail et le persil pilés, les tomates pelées, épépinées et coupées et le concentré de tomate.

- Ajouter du sel.

- Ajouter 21 d'eau, les épices et aromates, et laisser cuire pendant $1 \mathrm{~h}$ environ.

- À mi-cuisson, ajouter les légumes lavés et coupés régulièrement.

- Retirer les légumes au fur et à mesure qu'ils sont cuits et les mettre de côté dans un plat.

- Laisser cuire la viande à point et vérifier l'assaisonnement.

- Prélever une à deux louches de bouillon et retirer la viande (ou le poisson ou le poulet). Ajouter aux légumes et garder au chaud.

- Verser le fonio précuit en pluie dans le reste du bouillon tout en remuant; le bouillon doit recouvrir le fonio.

- Fermer la marmite et laisser cuire à feu réduit tout en remuant de temps en temps. Arroser, au besoin, avec le bouillon mis de côté.

Servir chaud le fonio garni des légumes et de la viande (ou du poisson ou du poulet), ou les présenter séparément. 
Récemment commercialisé en Europe ou aux États-Unis et utilisé par de nouveaux consommateurs qui le cuisinent à leur goût, le fonio fait l'objet de nombreuses nouvelles recettes imaginées ou calquées sur des recettes à base de riz ou de couscous de blé : taboulé ou salades, fonio au lait, pudding, gâteaux ou cakes, etc. La petite taille de ses grains permet de préparer des recettes originales et de diversifier les repas.

\section{Fonio et diététique}

«Que ton aliment soit ta seule médecine», disait Hippocrate il y plus de vingt-quatre siècles. Les habitants des régions productrices de fonio semblent prêter à cette céréale de très nombreuses vertus, parfois autres que simplement alimentaires. Outre le fait que le fonio paddy appliqué sur le corps aurait des effets thérapeutiques sur certaines infections ou maladies de peau, la croyance populaire considère souvent le fonio comme un aliment «pour diabétique». Il est nécessaire de modérer cette affirmation, quelquefois reprise et mise en exergue par certains organes de la presse non spécialisée qui veulent vanter l'intérêt de tel ou tel produit local ou exotique.

\section{ID Fonio et diabète}

Le diabète, notamment de type 2, est une maladie qui touche de plus en plus de personnes à travers le monde et singulièrement en Afrique urbaine en raison d'une alimentation déséquilibrée, souvent accompagnée d'un surpoids accentué par la sédentarisation. Le diabétique doit chercher à mieux équilibrer son alimentation en réduisant surtout son apport calorique. Or le fonio est essentiellement un aliment calorique au même titre que d'autres céréales. Des premières études réalisées par le Cirad, puis reprises ensuite par l'ONG internationale Santé Diabète, ont néanmoins montré que le fonio avait un index glycémique voisin de 57 (la référence pain blanc est de 100) et donc inférieur à celui des autres céréales (excepté le mil). Leévolution comparée de la glycémie (mmol/l) avec du fonio blanc et du pain blanc est illustrée par la figure 10.1.

Pour les diabétiques, le fonio peut sans doute être préféré à la plupart des autres céréales, mais il doit néanmoins être consommé avec modération en respectant les quantités prescrites par les médecins. Le fonio est un aliment très digeste qui procure une satiété relativement courte et il est souvent considéré par la population comme un 


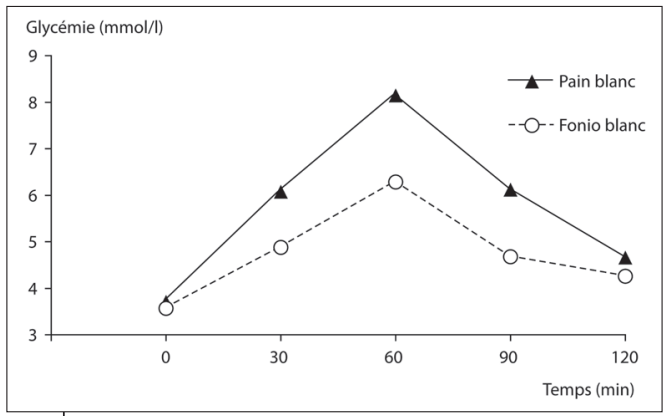

Figure 10.1.

Évolution comparée de la glycémie ( $\mathrm{mmol} / \mathrm{l})$ avec fonio blanc et pain blanc (d'après S. Besançon, Cirad).

aliment léger, peu nourrissant, qui ne contient pas de sucres. Certains diabétiques risquent alors une surconsommation de fonio pouvant générer de fortes hyperglycémies. Une bonne éducation nutritionnelle des malades est indispensable pour éviter de tels risques. Il faut par ailleurs prendre en compte le fait que les plats sont souvent accompagnés de sauces qui jouent également un rôle important dans l'apport glycémique du repas. Le diabétique doit ainsi éviter les sauces riches en lipides (arachide) et privilégier les sauces plus neutres (gombo, légumes, etc.). En se référant aux recettes précédemment décrites, il peut consommer du foyo sauce gombo, mais éviter le djouka, le niri fonyé ou le fonio au gras! Des recherches sont encore nécessaires pour parfaire les connaissances sur le fonio et sur son intérêt dans l'alimentation des diabétiques.

\section{ID Fonio et gluten}

Le milieu médical considère aujourd'hui que la maladie coliaque (ou intolérance au gluten) est une des maladies gastro-intestinales les plus fréquentes, touchant plus d'une personne sur mille dans la population générale. Elle se traduit par une réponse immunitaire, localisée au niveau de l'intestin grêle, à l'ingestion d'aliments contenant du gluten. Les réactions immunologiques et biochimiques impliquées dans l'intolérance au gluten ne sont pas encore clairement déterminées et de nombreuses recherches restent à réaliser pour connaître les mécanismes précis de la maladie cœliaque et identifier toutes les protéines et les peptides toxiques pour les malades. 
Le terme de gluten est ambigu car il a plusieurs significations selon les professionnels qui l'utilisent. Pour le meunier ou le boulanger, le gluten est ce qui confère à des farines de blé, d'épeautre, de triticale, d'orge ou de seigle, hydratées et pétries, des propriétés viscoélastiques qui les rendent panifiables. Le gluten est la matière visqueuse qui reste dans la main lorsqu'on lave la farine et que tout l'amidon est parti. Pour le biochimiste, le gluten est constitué des protéines de réserve du grain que sont les prolamines et les glutélines et qui, chez le blé, sont respectivement les gliadines et les gluténines, les autres protéines que sont les albumines et les globulines étant considérées comme des protéines de structure. Toutes les céréales contiennent ces quatre fractions protéiques dans des proportions variables.

Aujourd'hui, seules certaines prolamines ont une toxicité démontrée dans la maladie coliaque et notamment l' $\alpha$-gliadine du blé, l'hordéine de l'orge et la sécaline du seigle. Il semblerait que ce soient en réalité des séquences particulières d'acides aminés fréquemment retrouvées dans ces prolamines qui les rendent toxiques pour les intolérants au gluten. Ces séquences seraient moins fréquentes dans les prolamines de l'avoine (ou avénines), céréale qui est parfois tolérée en petite quantité, et elles seraient absentes dans les prolamines d'autres céréales parfaitement bien tolérées, comme la zéine du maïs, la kafirine du sorgho, l'orzénine du riz.

Le fonio contient bien les quatre fractions protéiques courantes des céréales, mais il serait plus riche en glutélines («digiténines») qu'en prolamines comme le montre le tableau 10.1., élaboré par des chercheurs de l'université de Leeds au Royaume-Uni (Jideani et al., 1994).

Tableau 10.1. Fractions protéiques comparées du fonio et du blé dur selon la méthode Osborne.

\begin{tabular}{lcc}
\hline Fraction protéique & Fonio & Blé dur \\
\hline Albumine & 3,5 & 11,0 \\
Globuline & 1,8 & 7,0 \\
Prolamine & 5,5 & 42,0 \\
Glutéline & 14,0 & 30,0 \\
Résidus & 55,2 & 7,8 \\
\hline
\end{tabular}

On peut considérer qu'à l'instar du sorgho et du maïs, le fonio est génétiquement plus proche du mil (sous-famille des panicoidées) que du blé ou de l'orge (sous-famille des pooidées) et que, comme eux, il ne présente pas de toxicité pour les intolérants au gluten. 


\section{ID Le fonio et le quinoa}

La comparaison entre le fonio et le quinoa est intéressante et mérite réflexion.

Le quinoa (Chenopodium quinoa) est une petite graine traditionnellement cultivée dans les vallées d'altitude de Bolivie et du Pérou, en raison de sa très bonne adaptation aux sols pauvres et arides des hauts plateaux andins. Le quinoa, qui n'est pas une graminée mais une chénopodiacée (famille des épinards, de la betterave), est souvent qualifié de «pseudo-céréale». Il a longtemps été négligé et considéré comme une «nourriture de pauvre» ou une «nourriture d'Indiens», jusqu'à ce que l'on redécouvre ses qualités nutritionnelles et diététiques, et notamment sa richesse en protéines «sans gluten».

Aujourd'hui, le quinoa connaît un grand succès sur les marchés américains ou européens, et l'émergence de filières équitables assure aux producteurs des débouchés stables et des revenus importants grâce à la valeur ajoutée de leur produit fini. Dans les pays du Nord, une médiatisation entretenue permet d'informer les consommateurs qui sont souvent séduits par cette «nouvelle» graine, originale, exotique et mythique car associée à la culture inca.

Mais de nombreuses voix se sont élevées récemment pour dénoncer les effets pervers de cette soudaine notoriété. Le quinoa serait progressivement passé d'une activité de subsistance à une culture d'exportation, entraînant une forte élévation de son coût et une érosion de la biodiversité pour ne conserver qu'une seule variété aux grains blancs et de grande taille qui correspondrait au choix des «consommateurs du Nord». Le quinoa, devenu trop cher, ne serait plus consommé par les producteurs eux-mêmes, qui préfèrent le vendre et s'alimenter avec des produits importés. Le succès du quinoa aiguiserait la convoitise de certaines entreprises et d'universitaires américains qui auraient même tenté d'en breveter, heureusement sans succès, une variété.

Certaines critiques sont peut-être abusives, mais tous ceux qui s'intéressent au fonio et à sa valorisation ont à tenir compte de cette expérience. Ils doivent rester vigilants pour que le développement de la filière fonio ne tombe pas dans ces travers, mais contribue, au contraire, à améliorer la rentabilité et la durabilité des systèmes de production. 


\section{Conclusion}

Dans cet ouvrage, parmi les premiers - sinon le premier consacrés exclusivement au fonio, nous avons voulu rassembler les quelques informations, dont certaines déjà très anciennes, disponibles sur cette petite céréale africaine très longtemps négligée. La réalisation récente de quelques projets internationaux associant des chercheurs africains et européens, et des transformatrices locales a permis de développer des innovations, notamment dans le domaine de l'après-récolte, qui laissent espérer un regain d'intérêt de la part des décideurs et surtout des producteurs et autres acteurs de la filière.

Limage du fonio est en train de changer. Longtemps relégué au rang de céréale rustique ou considéré comme une «nourriture du pauvre», souvent synonyme de disette, le fonio semble acquérir une nouvelle noblesse comme céréale appréciée des consommateurs urbains et même exportée. Cette nouvelle notoriété est parfois exagérée quand certains blogs ou sites Internet la qualifient de «céréale du XXI ${ }^{\mathrm{e}}$ siècle », mais ses qualités agronomiques de bonne résistance à la sécheresse en font une plante bien adaptée aux changements climatiques. Ses qualités nutritionnelles caractérisées par sa richesse en acides aminés soufrés et ses protéines «sans gluten» sont également très intéressantes, même si le fonio reste un aliment très proche du riz.

Aujourd'hui, grâce aux avancées technologiques réalisées par la recherche, le fonio est présent dans les supermarchés des grandes villes d'Afrique de l'Ouest et régulièrement exporté, en petites quantités, vers l'Europe ou les États-Unis, où sont en vogue les produits naturels et les saveurs nouvelles. Le développement progressif de filières bio et équitables peut, à terme, offrir de meilleurs revenus aux producteurs de fonio et potentiellement relancer sa culture dans les zones où il a progressivement été abandonné, mais ce développement doit être bien maîtrisé et réfléchi pour ne pas succomber au «syndrome quinoa».

Les pays du Nord disposent déjà de leurs propres céréales «rustiques » (épeautre, engrain, avoine, seigle, etc.) ou «sans gluten» (riz, maïs, sarrasin, etc.). Ainsi, la valorisation du fonio devrait être prioritairement orientée vers l'alimentation des villes du Sud et notamment des pays producteurs eux-mêmes. Les exigences des consommateurs des villes du Sud sont souvent comparables à celles des consommateurs 
du Nord et portent sur les qualités hygiéniques, nutritionnelles, culinaires, organoleptiques et sur la diversification des produits proposés. Des appuis doivent être apportés aux transformatrices locales qui ne disposent souvent que de moyens techniques et financiers précaires. Des recherches, en partenariat avec les acteurs privés, sont encore nécessaires dans les domaines des ressources génétiques (variétés), de l'agronomie (intensification écologique, systèmes de production durables), de l'après-récolte, de la technologie (procédés de lavage, dessablage, étuvage, emballages, etc.) et de la science des aliments (nouveaux produits) pour répondre pleinement à ces attentes et participer ainsi au renouveau de cette céréale africaine originale qu'est le fonio. 


\section{Glossaire}

Abattis-brûlis (slash and burn) : méthode de défrichement par essartage, selon laquelle on coupe les ligneux, en laissant les plus gros arbres, puis on brûle les branchages quand ils sont secs. C'est la méthode habituelle de défrichement de la forêt ou des vieilles friches.

Activité en eau (activity of water) : symbolisée par le terme $a_{w}$, elle représente la disponibilité de l'eau dans les produits. Elle est égale au rapport entre la pression de vapeur d'eau à la surface d'un produit et la pression de vapeur saturante à la même température. Leau pure a une $a_{w}$ égale à 1 .

Adventice (weed) : une plante adventice est une plante étrangère au semis et qui pousse spontanément dans une culture où elle est jugée indésirable. Les plantes adventices sont souvent qualifiées de «mauvaises herbes».

Agriculture biologique (organic farming) : agriculture qui n'utilise pas de produits chimiques de synthèse (fertilisants, pesticides) ou d'OGM (organismes génétiquement modifiés).

Agriculture durable (sustainable agriculture) : agriculture qui vise à préserver les ressources naturelles (sol, eau, air, biodiversité) sur le long terme.

Agriculture familiale (family agriculture, family farming) : agriculture reposant sur une main-d'œuvre familiale et souvent synonyme d'agriculture paysanne notamment dans les pays en développement.

Agriculture vivrière (food crop farming) : agriculture essentiellement destinée à l'autoconsommation et à la commercialisation des productions sur les marchés locaux. Lagriculture vivrière est surtout présente dans les pays en développement.

Allogamie (allogamy) : système de reproduction par fertilisation croisée. Le pollen qui féconde provient d'une autre plante. Par opposition à l'autogamie qui est une autofécondation de la plante.

Amendement organique (organic soil amendment) : matière fertilisante, principalement composée de matières organiques d'origine végétale et animale, apportée pour améliorer les propriétés physiques et biologiques des sols cultivés.

Amidon (starch) : glucide complexe formé de molécules de glucose. L'amidon constitue la réserve énergétique des grains de céréales.

Amylose (amylose) : constituant de l'amidon formé par des chaînes non ramifiées de molécules de glucose. Le principal constituant de l'amidon est l'amylopectine (chaînes ramifiées de glucose) et l'amylose est plus ou moins présent selon les céréales.

Assolement (cropping plan) : découpage des terres d'une exploitation agricole en parties distinctes ou soles.

Balles (hulls) : enveloppes externes (glumes et glumelles) des grains de céréales vêtues (riz, fonio, orge, avoine, épeautre, etc.). Les balles représentent 20 à $25 \%$ du poids brut.

Banco (banco) : terre crue argileuse, enrichie de pailles de céréales, utilisée comme matériau de construction pour la réalisation de différentes structures (habitations, greniers).

Bas-fonds (stream inland valleys) : fonds plats ou concaves des vallons et 
des petites vallées où convergent les eaux de surface. Le fonio n'est jamais cultivé dans ces bas-fonds submergés pendant une partie de l'année où l'on cultive davantage le riz.

Battage (threshing) : en agriculture, le battage est une opération post-récolte qui consiste à séparer les grains de l'épi ou de la tige.

Binage (hoeing) : le binage consiste à casser la croûte superficielle du sol pour l'ameublir et l'aérer. Le binage est souvent associé au sarclage.

Biodiversité (biodiversity) : variété des espèces vivantes qui peuplent la biosphère.

Blanchiment (whitening) : opération de transformation qui consiste à éliminer le péricarpe et le germe des grains pour ne conserver que l'albumen. Cette opération suit le décorticage.

Campagne (campaign) : la campagne agricole est une période ou un cycle de production saisonnier.

Caryopse (caryopsis) : fruit sec simple de graminées obtenu après fécondation de la fleur. Le caryopse est plus prosaïquement appelé «grain».

Champs de case (homestead fields) : champs situés à proximité des habitations et cultivés en permanence. Dans ces champs, enrichis par des cendres, du fumier ou d'autres déchets, on plante des arbres fruitiers et on produit des légumes, des cultures précoces ou exigeantes.

Commerce équitable (fairtrade) : le commerce équitable est un commerce social fondé sur le dialogue, la transparence et le respect, et qui vise à une plus grande équité dans les échanges entre producteurs, transformateurs et consommateurs.
Cuirasse latéritique (hard lateritic crust) : carapace ou croûte formée par le durcissement d'un sol rouge ferrallitique dans les pays tropicaux. On parle alors de sols cuirassés.

Cultivar (cultivar) : variété obtenue par sélection au cours de cultures successives.

Culture attelée (draught cultivation) : la culture attelée consiste à utiliser des animaux (chevaux, ânes, mules, bœufs) pour tirer les outils ou les machines nécessaires à la réalisation de certaines opérations agricoles (travail du sol, semis et entretien, récolte).

Culture itinérante (shifting cultivation) : système de culture dans lequel on défriche un champ, on le cultive quelques années, puis on l'abandonne à la jachère. La culture itinérante est un système performant, mais qui exige de grandes surfaces de jachère non cultivée.

Cycle végétatif (growth cycle) : les différentes étapes de développement entre la germination de la graine et la maturité de la plante.

Cyclone (cyclone collector) : système de récupération des particules fines comme les sons ou les poussières.

Daba (daba) : houe traditionnelle d'Afrique généralement à manche court. La forme des dabas est très variable selon les régions, le travail à réaliser (travail du sol, binage, billonnage, buttage) ou le type de sol (sableux, argileux, etc.).

Décorticage (hulling) : opération postrécolte qui consiste à débarrasser les grains de leurs enveloppes externes.

Dépiquage (trampling) : technique de battage qui consiste à utiliser le piétinement de chevaux, de mulets ou 
de bœufs ou le passage d'un tracteur pour séparer les grains des gerbes de céréales.

Déprédateurs (pests) : on qualifie le plus souvent de déprédateurs ou de ravageurs, les insectes et les rongeurs qui s'attaquent aux réserves de grains et qui sont à l'origine de pertes importantes.

Désertification (desertification) : dégradation des terres et de la couverture végétale dans les zones sèches en raison des activités humaines et des changements climatiques.

Digitaires (crabgrasses) : plantes herbacées annuelles dont l'inflorescence est composée de plusieurs épis grêles disposés un peu comme les doigts d'une main.

Dogon (Dogon people) : les Dogon sont un peuple traditionnel du Mali vivant dans la région de Mopti et plus précisément de part et d'autre de la falaise de Bandiagara (plateau de Bandiagara et plaine du Séno).

Écotype (ecotype) : «variété paysanne» qui peut être hétérogène. Cette hétérogénéité est une source de diversité.

Édaphique (edaphic) : relatif aux rapports entre le sol et les plantes.

Élément nutritif (nutrient) : élément minéral dont une plante doit disposer pour pouvoir se développer et croître normalement.

Épillet (spikelet) : petit épi de quelques fleurs, deux dans le cas du fonio (une fleur fertile et une fleur stérile).

Étuveuses (parboilers) : ustensiles (marmites, fûts, machines, etc.) utilisés pour réaliser l'étuvage des grains et, par extension, femmes réalisant l'étuvage des grains.
Fauchage ou fauche (reaping) : opération de récolte qui consiste à couper les tiges à l'aide d'un couteau, d'une faucille ou d'une faux.

Ferrallitique (ferrallitic) : sols tropicaux de couleur rouge, riches en hydroxydes de fer et en aluminium et provenant de l'altération de roches de couverture.

Fertilisation (fertilization) : apport de fertilisants et d'amendements pour maintenir ou améliorer la fertilité d'un sol. Les principaux fertilisants sont l'azote $(\mathrm{N})$, le phosphore $(\mathrm{P})$ et le potassium $(\mathrm{K})$.

Fertilité (soil fertility) : aptitude d'une terre, d'un champ ou d'une région à produire des récoltes. Elle dépend du climat, du sol et des techniques appliquées.

Fesro : plat traditionnel du nord-ouest de la Côte d'Ivoire qui est une sorte de «fonio au gras » où la cuisson des grains de fonio est démarrée avec un peu de matière grasse (huile) comme pour la préparation du «riz au gras».

Friction (friction) : principe de transformation des céréales consistant à favoriser les frottements «grain sur grain» pour réaliser le blanchiment.

Fumure (fertiliser) : amendement apporté à une terre pour l'améliorer. Les fumures organiques sont les déchets végétaux ou animaux que l'on réintègre dans le sol. Elles sont souvent opposées aux engrais chimiques.

Glumacé (with lemmae) : muni de glumes.

Glumes (glumes) : bractées qui entourent la base des épillets chez les graminées. 
Glumelles (lemma and palea) : bractées qui forment l'enveloppe extérieure de chaque fleur, chez les graminées.

Gombo (gumbo) : plante tropicale dont le fruit est utilisé pour préparer une sauce très gluante qui entre dans la composition de nombreux plats africains. Fonio et gombo sont souvent associés.

Graminées ou Poacées (Graminae or Poaceae) : famille de plantes très courantes parmi lesquelles on trouve les céréales et de nombreuses herbes.

Grain vitreux (corneous grain) : grain dont l'albumen est naturellement dur et translucide avec une structure compacte par opposition aux grains farineux à structure friable et donnant une farine blanche.

Graine oléagineuse (oilseed) : graine (arachide, sésame, colza, tournesol, etc.) riche en huile.

Hersage (harrowing) : opération culturale qui consiste à casser les grosses mottes de terre après le labour pour obtenir un terrain ameubli apte à recevoir les semences. Le hersage est également pratiqué pour enfouir les graines semées à la volée.

Hile (hilum) : point d'attache du grain avec la plante mère dont il est issu. Le hile des céréales apparaît sous la forme d'une cicatrice à une extrémité des grains.

Hivernage (rainy season) : période qui correspond à la saison des pluies dans les pays tropicaux, soit de juin à octobre en Afrique de l'Ouest.

Humidité (moisture content) : l'humidité ou teneur en eau des grains est le rapport, exprimé en pourcentage, entre la masse d'eau contenue dans un échantillon de grains et la masse totale de l'échantillon. «En base humide» exprime bien que la mesure est effectuée par rapport à la matière humide (masse totale) plutôt que par rapport à la matière sèche.

Humidité de sauvegarde (safe moisture content) : humidité du produit au-dessous de laquelle les micro-organismes, et notamment les moisissures, ne peuvent pas se développer lors du stockage.

Hydromorphe (hydromorphic) : type de sol régulièrement saturé en eau ou qui présente des signes d'engorgement par l'eau.

Index glycémique (glycemic index) : index qui caractérise le pouvoir hyperglycémiant d'un aliment par rapport à un glucide de référence (index 100 pour glucose dans de l'eau ou pain blanc).

Intrant (input) : produit utilisé pour améliorer la production des cultures (engrais, produits phytosanitaires).

Isohyète (isohyet) : ligne imaginaire reliant les points d'une zone où les précipitations annuelles moyennes sont les mêmes.

Isotherme de sorption (sorption isotherm) : courbe représentant, à une température donnée, l'humidité du produit en fonction de la valeur de l'activité en eau (ou de l'humidité relative de l'air en équilibre).

Jachère (fallow) : terre cultivable laissée temporairement sans culture pour reconstituer un sol épuisé par une succession de cultures.

Labour (ploughing) : action de retourner la terre, avec une charrue, une bêche, etc., pour l'aérer et la préparer aux semis. 
Layot : petite bannette en paille qui joue le rôle de tamis. Terme utilisé à plusieurs reprises par René Caillé lorsqu'il évoque le nettoyage du fonio ou du fonio sauvage.

Légumineuses (legumes) : plantes dont le fruit est une gousse (haricot, pois, fève, niébé, soja, etc.) et qui sont plus riches en protéines que les céréales. Les légumineuses sont capables de fixer l'azote atmosphérique en association symbiotique avec des bactéries (voir «nodosités»).

Limon (silt) : fines particules du sol dont les tailles vont de 2 à $20 \mu \mathrm{m}$ pour les limons fins et de 20 à $50 \mu \mathrm{m}$ pour les limons grossiers.

Lougan : en Afrique, parcelle de terre ou champ cultivé en brousse (sur abattis-brûlis).

Mandingue (Mandingo) : groupe de peuples d'Afrique de l'Ouest originaires du Mali. Les Malinké, Bambara, Dialonké, Sarakolé (Soninké) font partie du groupe mandingue.

Marché de niche (niche market) : segment de marché très étroit correspondant à une clientèle précise et associé à un produit très spécialisé.

Mécanisation (mechanization) : développement ou utilisation de machines au niveau des exploitations agricoles ou des unités de transformation des produits agricoles.

Monocotylédone (monocot) : Plante dont les graines n'ont qu'un seul cotylédon (ex. : céréales) par opposition aux plantes à deux cotylédons (ex. : légumineuses).

Monoculture (monoculture) : pratique agricole consistant à ne planter qu'une seule espèce sur les exploitations. La monoculture peut être à l'origine de déséquilibres écologiques.

Mougou témé : les différents tamis utilisés par les opératrices pour tamiser les grains de fonio sont le mougou témé (1 mm), le klantié témé (1,5 mm), le bassi témé (2 $\mathrm{mm})$, le wara wara (2,5 $\mathrm{mm})$ pour l'émottage du fonio après cuisson à la vapeur par exemple et le nylon témé $(<1 \mathrm{~mm})$ pour le son ou la farine.

Natte (mat) : sorte de tapis en paille tressée souvent utilisé pour le séchage naturel des produits agricoles et alimentaires.

Nématodes (nematodes) : les nématodes (ou Némathelminthes) sont de très petits vers, souvent invisibles à l'œil nu, qui vivent dans le sol et dont certains parasitent les plantes.

Niébé (cowpea) : petit haricot ou dolique à œil noir (Vigna unguiculata), couramment cultivé en Afrique de l'Ouest.

Nodosités (nodules) : organes (renflements allongés ou ronds) observés sur les racines des légumineuses contenant des bactéries fixatrices d'azote atmosphérique.

Nutriments (nutrients) : divers éléments nutritifs indispensables à la physiologie des organismes. Les nutriments majeurs des plantes sont les phosphates, les nitrates, les sels minéraux et le potassium.

Oseille de Guinée (roselle or sorrel) : il s'agit de l'Hibiscus sabdariffa L., plante herbacée d'Afrique de l'Ouest, dont les fleurs rouges sont utilisées pour préparer une boisson appelée «bissap», «karkadé» ou «dah». Germaine Dieterlen (1952) rappelle que «les deux graines essentielles des 
clavicules des Kéita, fondateurs de l'empire du Mali, sont le fonio (fani) et l'Hibiscus $(d a) »$.

Pédicelle (pedicel) : petit pédoncule qui porte, à son sommet, une fleur (ou un épillet dans le cas du fonio).

Pegu : le «pegu», cité par l'anthropologue Denise Paulme, est Lannea acida de la famille des Anacardiacées. Les fruits de ce petit arbuste sont utilisés par les Dogon pour préparer une boisson très sucrée.

Péricarpe (pericarp) : le péricarpe est la paroi du fruit ou, pour les céréales, la «peau» du grain ou caryopse.

Pesticide (pesticide) : produit chimique destiné à éliminer les animaux déprédateurs et les plantes considérés comme nuisibles, mais qui représente un très grand facteur de pollution.

Peuhl ou Peul (Fula people) : ethnie d'éleveurs nomades et semi-nomades, aujourd'hui en partie sédentarisés dans de nombreux pays soudano-sahéliens où ils pratiquent aussi l'agriculture.

Piémont (piedmont plain) : plaine située au pied d'un massif montagneux.

Pistache : en Afrique, correspond souvent à l'arachide (pistache de terre) ou peut-être au pois bambara (voandzou). En Haïti aussi, l'arachide est nommée «pistache».

Polyculture (polyculture) : pratique agricole consistant à produire plusieurs cultures sur une même exploitation agricole. Contrairement à la monoculture, la polyculture permet d'équilibrer l'écosystème agricole en y augmentant la biodiversité.

Post-récolte (post-harvest) : opérations réalisées après la récolte et qui pour les céréales comprennent notamment les principales activités techniques que sont le battage, le nettoyage, le séchage, le stockage, la transformation.

Primo-domestication (primo-domestication) : début de domestication ou de contrôle du développement des plantes par les communautés humaines.

Racème (raceme) : inflorescence simple (d'épillets dans le cas du fonio).

Rendement (yield) : en agriculture, le rendement (ou rendement agricole) est la quantité de produit récolté sur une surface cultivée donnée. Il est exprimé en kilogrammes (kg) par hectare, en tonnes $(1 \mathrm{t}=1000 \mathrm{~kg})$ ou en quintaux ( $1 \mathrm{q}=100 \mathrm{~kg})$ par hectare.

Révolution verte (Green Revolution) : politique ou modèle de développement agricole du $\mathrm{xx}^{\mathrm{e}}$ siècle fondé sur l'intensification de la production agricole.

Riz pluvial (dry land rice) : riz produit sans submersion de la parcelle mais par l'arrosage naturel par les pluies.

Rotation agricole (crop rotation) : alternance, d'une année à l'autre, de différentes cultures pour régénérer la terre après chaque récolte. La rotation des cultures est souvent considérée comme le pivot d'une agriculture durable.

Sarclage (weeding) : action qui consiste à arracher les mauvaises herbes à la main ou avec un outil. Le sarclage est souvent associé au binage qui a pour but de briser la croûte du sol pour l'aérer.

Semi-aride (semi-arid) : caractère d'un climat dans lequel les précipitations d'été ne dépassent pas $800 \mathrm{~mm} / \mathrm{an}$.

Semis (sowing) : opération culturale qui consiste à semer les graines. Le 
semis du fonio est généralement réalisé à la volée.

Son (bran) : sous-produit ou coproduit de la transformation obtenu après blanchiment des grains. Les sons, constitués de fragments de péricarpe et de germe, sont riches en fibres, en matières grasses et en vitamines et sont souvent valorisés en alimentation animale.

Soudano-sahélien (soudano-sahelian) : zone climatique au sud du Sahel caractérisée par une longue saison sèche et une seule saison des pluies, très courte, avec des précipitations annuelles se situant entre 500 et $900 \mathrm{~mm}$.

Soudure (lean season) : période difficile (souvent de juin à août) qui sépare l'épuisement des réserves des greniers de la récolte suivante.

Soumbala (soumbala) : condiment traditionnel d'Afrique de l'Ouest, appelé «nététou» au Sénégal, réalisé à partir de graines de néré (cuites, décortiquées, fermentées, salées, séchées). Ce produit est souvent conditionné sous la forme de boulettes.

Taller (tillering) : capacité à produire de nombreuses tiges secondaires (ou talles) chez les graminées. Ces ramifications se forment à la base de la plante sur le plateau de tallage.

Tapade (tapade) : concession enclose au cour de l'exploitation agricole au Fouta-Djalon en Guinée. Le mot tapade est un terme franco-guinéen qui viendrait du portugais tapar : fermer.

Tô (tô) : plat traditionnel d'Afrique consommé quotidiennement dans cer- tains pays comme le Mali, le Burkina Faso, le nord de la Côte d'Ivoire et du Togo; c'est une pâte (ou bouillie épaisse) à base de farine de céréales (mil, sorgho, maïs ou fonio).

Toposéquence (toposequence) : succession de sols qui diffèrent surtout par leur topographie.

Transformation des grains (grain processing) : terme général utilisé pour parler de l'ensemble des opérations technologiques réalisées sur les grains comme le décorticage, le blanchiment, la mouture. Dans le cas du fonio, l'association des deux opérations de décorticage et de blanchiment devrait être qualifiée de «mondage».

Transformatrices (women processors) : femmes qui transforment les produits locaux pour les valoriser. En Afrique, ces transformatrices, très dynamiques, travaillent parfois en groupements de femmes ou créent et gèrent des petites entreprises de transformation.

Trémie d'alimentation (feeding hopper) : réservoir placé au-dessus d'une machine et permettant de l'alimenter en grains.

Van (winnowing basket) : sorte de panier plat en paille tressée utilisé pour nettoyer les grains par vannage.

Vannage (winnowing) : nettoyage des grains battus pour les séparer de leurs impuretés (balles, portions de tiges, poussières) au moyen d'un van et en utilisant l'effet d'un courant d'air.

Verse (lodging) : état des céréales ou des légumineuses dont les tiges sont couchées au sol généralement à cause du vent et de la pluie. 



\section{Bibliographie}

Aboua F., Nemlin J., Kossa A., Kamenan A., 1989. Transformation traditionnelle de quelques céréales cultivées en Côte d'Ivoire. In : Céréales en régions chaudes, Aupelf-Uref, John Libbey Eurotext, Paris, 223-229.

Adoukonou-Sagbadja H., Wagner C., Ordon F., Friedt W., 2010. Reproductive system and molecular phylogenetic relationships of fonio millets (Digitaria spp., Poaceae) with some polyploid wild relatives. Tropical Plant Biology, 3 (4), 240-251.

Adoukonou-Sagbadja H., Schubert V., Dansi A., Jovtchev G., Meister A., Pistrick K., Akpagana K., Friedt W., 2007. Flow cytometric analysis reveals different nuclear DNA contents in cultivated Fonio (Digitaria spp.) and some wild relatives from West-Africa. Plant Systematics Evolution, 267, 163-176.

Ag Bendesh M., Chauliac M., 1998. Alimentation de rue, mutations urbaines et différenciations sociales à Bamako (Mali). Cahiers Santé, 2 (16), 33-57.

André V., Pestaña G., 2002. Les visages du Fouta-Djalon. Les Cahiers d'OutreMer, 217, 63-88.

Aune J.B., 1991. Régénération des plaines à Panicum laetum dans le Gourma malien. Revue d'Élevage et de Médecine Vétérinaire des Pays Tropicaux, 44 (3), 363-372.

Balachowsky A.S., 1954. Le FoutaDjalon en Moyenne Guinée. La Nature, Revue des Sciences et de leurs Applications, janvier 1954, 3227, 83-88.

Baudet J.C., 1981. Les céréales mineures : bibliographie analytique,
Agence de Coopération Culturelle et Technique, Paris, 38-48.

Béavogui F., Cissé S., Friebl M., Pedelahore P., 1992. Suivi de culture : le fonio, document multigraphié, Irag, Cra, Kankan, Guinée, 18 p.

Bourdillat F., 1995. Les voies d'amélioration de la culture du fonio dans les plaines de Timbi, mémoire de fin d'études, document multigraphié, Istom, Irag, Guinée, 60 p.

Busson F., 1965. Étude chimique et biologique des végétaux alimentaires de l'Afrique noire de l'Ouest dans leurs rapports avec le milieu géographique et humain, thèse présentée à la faculté des Sciences de l'université d'Aix-Marseille, 568 p.

Caillé R., 1830. Voyage à Tombouctou, 2 tomes, réédition de 1989, La Découverte, Paris.

Carcea M., Acquistucci R., 1997. Isolation and physicochemical characterization of fonio (Digitaria exilis Stapf) starch. Starch/Stärke, 49 (4), 131-135.

Ceemat, 1975. Manuel de culture avec traction animale, collection Techniques rurales en Afrique, ministère de la Coopération, Paris, 336 p.

Chantereau J., Nicou R., 1991. Le Sorgho, Maisonneuve et Larose, Paris, 159 p.

Chevalier A., 1909. Les hauts plateaux du Fouta-Djalon. Annales de Géographie, 18 (99), 253-261.

Cruz J.-F., 2011a. Le fonio, céréale ancestrale d'Afrique occidentale. In : Dictionnaire des cultures et des modèles alimentaires, Presses universitaires de France (à paraître).

Cruz J.-F., 2011b. Amélioration de la qualité et de la compétitivité de la 
filière fonio en Afrique de l'Ouest. Projet Fonio [CD-Rom], Cirad, Montpellier, France.

Cruz J.-F., 2009. Le fonio, une céréale ancestrale remise au goût du jour. Travaux et Innovations (La revue des agents du développement agricole et rural), 163, 28-31.

Cruz J.-F., 2004. Fonio : a small grain with potential. Leisa (magazine on low external input and sustainable agriculture. Valuing crop diversity), 20 (1), 16-17.

Cruz J.-F., 2001. Le fonio, document multigraphié, Cirad, Montpellier, France, $24 \mathrm{p}$.

Cruz J.-F., Dramé D., 2005. Technologies post-récolte du fonio. Projet CFC - Amélioration des technologies post-récolte du fonio [CDRom], Cirad, Montpellier, France.

Cruz J.-F., Rivier M., Fliedel G., 2009. Étude de l'étuvage du fonio et essais expérimentaux. In :Amélioration de la qualité et de la compétitivité de la filière fonio en Afrique de l'Ouest (J.-F. Cruz, éd.) [CD-Rom], Cirad, Montpellier, $32 \mathrm{p}$.

Cruz J.-F., Marouzé C., Rivier M., Méot J.-M., Dramé D., Diarra M., Tangara K., Yalcouyé D., 2008. Amélioration de la qualité du fonio. Développement de séchoirs [Poster]. In : La filière fonio en Afrique de l'Ouest (J.-F. Cruz, éd.) [CD-Rom], Cirad, Montpellier, Conférence Fonio, 28 avril 2008, Bamako, Mali.

Cruz J.-F., Troude F., Griffon D., Hébert J.-P., 1988. Conservation des grains en régions chaudes, $2^{e}$ édition, ministère de la Coopération et du Développement, Paris, 545 p.
Daho B.,Vall É., Dembélé K., Béavogui F., Diallo T. A., Sogodogo D., 2007. Place du fonio dans le système de production, priorités pour renforcer la place du fonio dans l'économie des ménages, Projet Fonio. In : Amélioration de la qualité et de la compétitivité de la filière fonio en Afrique de l'Ouest (J.-F. Cruz, éd.) [CD-Rom], Cirad, Montpellier, 22 p.

Dalziel J.-M., 1937. The Useful Plants of West Tropical Africa, Crown agents for the colonies, London, 526.

De Wet J.M.J., 1995. Minor cereals. In : Evolution of Crop Plants (J. Smartt et N.W. Simmonds, éds), $2^{\mathrm{e}}$ édition, Longman, Londres, 202-208.

Diallo T. A., 2003. Connaissances endogènes sur le fonio en Guinée. In : Actes du premier atelier sur la diversité génétique du fonio (Digitaria exilis Stapf) en Afrique de l'Ouest (S.R. Vodouhè, A. Zannou et E. Achigan Dako, éds), 4-6 août 1998, Conakry, Guinée, IPGRI, Rome, 42-44.

Diallo T. A., Fliedel G., Stilmant D., Cruz J.-F., 2008. Catalogue de quelques écotypes de fonio de Guinée, du Mali et du Burkina Faso. Projet Fonio. In : Amélioration de la qualité et de la compétitivité de la filière fonio en Afrique de l'Ouest (J.-F. Cruz, éd.) [CD-Rom], Cirad, Montpellier, 48 p.

Dieterlen G., 1952. Classification des végétaux chez les Dogon. Journal de la Société des Africanistes, Paris, 22, 115-158.

Dramé D., Cruz J.-F., 2002. Amélioration des technologies postrécolte du fonio, rapport de mission au Bénin et au Sénégal, Coraf (Conseil Ouest et Centre africain pour 
la recherche et le développement agricoles), 24 p.

Dudgeon G.C., 1922. The Agricultural and Forest Products of British West Africa, $2^{\mathrm{e}}$ edition, collection Imperial Institute Handbooks, J. Murray, Londres, 176 p.

Dury S., Meuriot V., 2011. Do urban African dwellers pay a premium for food quality and, if so, How much ? An investigation of the Malian fonio grain market. Review of Agricultural and Environmental Studies, 91 (4), 417-433.

Dury S., Meuriot V., Fliedel G., Blancher S., Bore Guindo F., Dramé D., Bricas N., Diakite L., Cruz J.-F., 2007. The retail market prices of fonio reveal the demand for quality characteristics in Bamako, Mali. In : Pro-poor development in low income countries : food, agriculture, trade and environment, $106^{\text {th }}$ Seminar of the European Association of Agricultural Economists $(E A A E)$, octobre 2007, Montpellier, France, $15 \mathrm{p}$.

Fliedel G., Ouattara M., Grabulos J., Dramé D., Cruz J.-F., 2004. Effet du blanchiment mécanique sur la qualité technologique, culinaire et nutritionnelle du fonio, céréale d'Afrique de l'Ouest. In : Voies alimentaires d'amélioration des situations nutritionnelles en Afrique de l'Ouest : le rôle des technologues alimentaires et des nutritionnistes, actes $d u 2^{e}$ Atelier international (D. Brouwer Inge, S. Traoré Alfred., S. Trèche, éds), 23-28 novembre 2003, Ouagadougou, Presses universitaires de Ouagadougou, Burkina Faso, 599614.

Fogny-Fanou N., Koreissi Y., Dossa R.A.M., Brouwer I.D., 2009. Consumption of, and beliefs about fonio (Digitaria exilis) in urban area in Mali. African Journal of Food, Agriculture, Nutrition and Development, 9 (9), 1927-1944.

Gallais J., 1959. La riziculture de plaine en Haute Guinée. Annales de Géographie, 68 (367), 207-223.

Garreau J.-M., 1993. Étude des systèmes de production dans la région de Timbi-Madina en République de Guinée, document multigraphié, Cnearc/Eitarc, Montpellier, France, 94 p.

Gigou J., Stilmant D., Diallo T.A., Cissé N., Sanogo M.D., Vaksmann M., Dupuis B., 2009. Fonio millet (Digitaria exilis) response to N, $\mathrm{P}$ and $\mathrm{K}$ fertilizers under varying climatic conditions in West Africa. Experimental Agriculture, Cambridge University Press, 45, 401-415.

Gigou J., Giraudy F., Doucouré C.O.T., Healy S., Traoré K., Guindo O., 2004. Lâge des champs : un indicateur du passage de la culture itinérante à la culture permanente dans le bassin cotonnier du Mali. Évolution des pratiques et dynamique des territoires. Cahiers Agricultures, 13 (6), 467-472.

Guillaume, Portères, Guilloteau, Maistre, 1949. Le problème rizicole dans les territoires africains de l'Union française. L'Agronomie Tropicale, 4 (7-8), 339-378.

Haq N., Dania Ogbe F., 1995. Fonio (Digitaria exilis and D. iburua). In : Cereals and Pseudocereals (J.T. Williams, éd.), Chapman and Hall, Londres, 225-245.

Havinden M.A., 1970. The history of crop cultivation in West Africa : a bibliographical guide. Economic History Review, 23 (3), 532-555. 
Heim de Balsac F., Fernbach E., Husson M., Maheu J., 1931. Le grain de fonio, valeur alimentaire, essais de fermentation. Travaux du Service d'études des productions coloniales - Productions et cultures coloniales. Technologie, Biotechnie coloniales, Bulletin de l'Agence Générale des Colonies, Paris, 271, 1329-1340.

House L.R., 1995. Sorghum and millets : history, taxonomy, and distribution. In : Sorghum and Millets, Chemistry and Technology (D.A.V. Dendy, ed.), AACC, Minnesota, ÉtatsUnis, 1-10.

Ibn Battûta, 1982. Voyages III. Inde, Extrême-Orient, Espagne et Soudan, collection FM/La Découverte, Librairie François Maspero, Paris, 456 p.

Irving D.W., Jideani I.A., 1997. Microstructure and composition of Digitaria exilis Stapf (acha) : a potential crop. Cereal Chemistry, 74, 224-228.

Jacques-Félix H., 1963. Contribution de René Caillé à l'ethnobotanique africaine au cours de ses voyages en Mauritanie et à Tombouctou : 1819-1828, Orstom, Paris, $172 \mathrm{p}$.

Jideani I.A., Takeda Y., Hizukuri S., 1996. Structures and physicochemical properties of starches from acha $(D$. exilis), Iburu (D. iburua) and tamba (E. coracana). Carbohydrates, 73 (6), 677-685.

Jideani I.A., Owusu R.K., Muller H.G., 1994. Proteins of acha (Digitaria exilis Stapf) : Solubility fractionation, gel filtration, and electrophoresis of protein fractions. Food Chemistry, 51, 51-59.

Jumelle H., 1912. Les cultures coloniales. Plantes à fécule et céréales, Paris, 103-104.
Konkobo-Yaméogo C., Chaloub Y., Kergna A., Bricas N., Karimou R., Ndiaye J.L., 2004. La consommation urbaine d'une céréale traditionnelle en Afrique de l'Ouest : le fonio. Lalimentation des villes. Cahiers Agricultures, 13 (1), 125-128.

Labouret H., 1937. La géographie alimentaire en Afrique Occidentale. Annales de Géographie, 46 (264), 591610.

Leplaideur M.-A., Seck M., Ouattara S., 1994. Le Sahel contre-attaque. In : L'Afrique, côté cuisines (Syfia), Éditions Syros et Fondation pour le progrès de l'homme, Paris, 115-119.

Lhoste P., Havard M., Vall É., 2010. La traction animale, collection Agricultures tropicales en poche, Quæ, CTA, PAG, 224 p.

Marouzé C., Thaunay P., Fliedel G., Cruz J.-F., 2008. Designing a fonio mill, screening an operating principle and its validation. Agricultural Mechanization in Asia, Africa and Latin America, 39, 9-15.

Marouzé C., Dramé D., Brouat J., Coulibaly B., 2005a. Crible rotatif long (CRL), dossier de fabrication : version manuelle et version motorisée. Projet Fonio CFC/ICG - Projet Fonio CFC/ ICG - Amélioration des technologies post-récolte du fonio, Cirad, IER, Irag, Irsat, L'Harmattan, Paris, 26 p.

Marouzé C., Thaunay P., Dramé D., Diop A., 2005b. Canal de vannage pour grains et graines, dossier de fabrication. Projet Fonio CFC/ICG - Amélioration des technologies postrécolte du fonio, Cirad, IER, Irag, Irsat, L'Harmattan, Paris, 38 p.

Marouzé C., Thaunay P., Dramé D., Loua F., Son G., Diop A., 2005c. 
Décortiqueur à fonio GMBF, dossier de fabrication. Projet Fonio CFC/ICG - Amélioration des technologies postrécolte du fonio, Cirad, IER, Irag, Irsat, L'Harmattan, Paris, 44 p.

Mazoyer M., Roudart L., 1997. Histoire des agricultures du monde. Du néolithique à la crise contemporaine, Seuil, Paris, 534 p.

Morales-Payán J.-P., Ortiz J.R., Cicero J., Taveras F., 2002. Digitaria exilis as a crop in the Dominican Republic. In : Trends in New Crops and New Uses (J. Janick et A. Whipkey, éds), ASHS Press, Alexandrie, Virginie, ÉtatsUnis, S1-S3.

Mugnier J., 2001. La nouvelle classification des plantes à fleurs. De la graine à la plante. Pour la Science, Belin, Paris, 60-68.

Ndiaye M., Termorshuizen A. J., van Bruggen A.H.C., 2008. Effect of rotation of cowpea (Vigna unguiculata) with fonio (Digitaria exilis) and millet (Pennisetum glaucum) on Macrophomina phaseolina densities and cowpea yield. African Journal of Agricultural Research, 3 (1), 37-43.

Niangado O., Kebe D., 2002. Enjeux des droits de propriété intellectuelle pour la recherche agricole et la filière des semences en Afrique de l'Ouest et $d u$ Centre. Chapitre 7. Commerce, propriété intellectuelle et développement durable vus de l'Afrique, ICTSD, Enda, Solagral, 127-141.

Nolle J., 1986. Machines modernes à traction animale : itinéraire d'un inventeur au service des petits paysans, Paris, L'Harmattan, 478 p.

NRC (National Research Council), 1996. Lost crops of Africa, Vol.1 : Grains. Board on Science and Technology for
International Development, National Academy Press, Washington D.C., 59-75.

Paulme D., 1940. Organisation sociale des Dogon, Domat-Montchrestien, Paris, réédition 1988, éditions JeanMichel Place, Paris, 595 p.

Perrot É., 1929. Sur les productions végétales indigènes ou cultivées de l'Afrique Occidentale Française, rapport de mission, Office national des matières premières végétales, Paris, 468 p.

Portères R., 1976. African cereals : Eleusine, Fonio, Black Fonio, Teff, Brachiara, Paspalum, Pennisetum and African Rice. In: The origins of African Plant Domestication (J. Harlan, J.M.J. de Wet et A.B.L Stemler, éds), The Hague-Mouton, Pays-Bas, 409-451.

Portères R., 1955. Les céréales mineures du genre Digitaria en Afrique et en Europe. Journal d'Agriculture Tropicale et de Botanique Appliquée, 2, 349-386, 477-510, 620-675.

Portères R., 1951. Une céréale mineure cultivée dans l'Ouest-Africain (Brachiaria deflexa C.E. Hubbard). L'Agronomie Tropicale, 6 (1-2), 38-42.

Portères R., 1946. Laire culturale du Digitaria Iburua Stapf, céréale mineure de l'Ouest-Africain. L'Agronomie Tropicale, 1 (11-12), 589-592.

Purseglove J.W., 1985. Tropical Crops. Monocotyledons, Longman, Harlow, Royaume-Uni, 142-144.

Rançon A., 1894. Dans la Haute Gambie. Voyage d'exploration scientifique 1891-1892, Société d'éditions scientifiques, Paris, 592 p.

Renoux L., Dumas P., 1905. Culture du fonio dans la vallée du Sénégal et 
du Haut Niger. L'Agriculture pratique des pays chauds. Bulletin du Jardin Colonial de Nogent, novembre, 32, 357-367.

Richard-Molard J., 1944. Essai sur la vie paysanne au Fouta-Djalon. Le cadre physique - L'économie rurale L'habitat. Revue de Géographie Alpine, 32 (2), 135-239.

Rivier M., Cruz J.-F., 2007. Étude de la précuisson du fonio au sein de petites entreprises de transformation à Bamako (Mali) et à Ouagadougou (Burkina Faso). In : Amélioration de la qualité et de la compétitivité de la filière fonio en Afrique de l'Ouest (J.-F. Cruz, éd.) [CDRom], Cirad, Montpellier, 38 p.

Rozis J.-F., 1995. Sécher des produits alimentaires : techniques, procédés, équipements, Gret, ministère de la Coopération, Paris, 344 p.

Samaké O., 2003. Intergrated crop management strategies in Sahelian land use systems to improve agricultural productivity and sustainability : a case study in Mali, thèse $\mathrm{PhD}$, université de Wageningen, Pays-Bas, 132 p.

Sarr É., Prot J.-C., 1985. Pénétration et développement des juvéniles d'une souche de Meloidogyne javanica et d'une race B de $M$. incognita dans les racines du fonio (Digitaria exilis Stapf). Revue de Nématologie, 8, 59-65.

Stapf O., 1915. Iburu and Fundi, two cereals of Upper Guinea (Digitaria Iburua; D. exilis), Royal Botanic Gardens, Kew, Bulletin of miscellaneous information, 8, 381-386.

Stilmant D., Dupuis B., 2007. Réalisation d'expérimentations agronomiques sur le fonio. In: Amélioration de la qualité et de la compétitivité de la filière fonio en Afrique de l'Ouest
(J.-F. Cruz, éd.) [CD-Rom], Cirad, Montpellier, $13 \mathrm{p}$.

Sudres A. 1947. La dégradation des sols au Fouta-Djalon. L'Agronomie Tropicale, 11 (5-6), 227-246.

USAID, 2008. Chaîne de valeurs de la filière fonio au Sénégal, International Resources Group, Washington D.C., 90 p.

Vall É., Béavogui F., Sogodogo D., Daho B., Kanwé A., Diallo T.A., 2008a. Les facteurs de variation du rendement du fonio en milieu paysan (Guinée, Mali, Burkina) [Poster]. In : La filière fonio en Afrique de l'Ouest (J.-F. Cruz, éd.) [CD-Rom], Cirad, Montpellier.

Vall É., Dembélé K., Kanwé A., 2008b. Options pour le développement de la production de fonio. Projet Fonio. In : Amélioration de la qualité et de la compétitivité de la filière fonio en Afrique de l'Ouest (J.-F. Cruz, éd.) [CD-Rom], Cirad, Montpellier, 40 p.

Vall É., Daho B., Béavogui F., Sogodogo D., Kanwe A., Diallo T.A., Kollet Soumah M.A., Diallo S., 2007. Typologie des systèmes de production, base de données, identification des zones prioritaires d'intervention. Projet Fonio. In : Amélioration de la qualité et de la compétitivité de la filière fonio en Afrique de l'Ouest (J.-F. Cruz, éd.) [CDRom], Cirad, Montpellier, 38 p.

Vodouhè S.R., Achigan Dako E.G., 2006. Digitaria exilis (Kippist) Stapf. In : Prota 1-Cereals and pulses/Céréales et légumes secs (M. Brink et G. Belay, éds) [CD-Rom], Prota, Wageningen, Pays-Bas. 


\section{Sites Internet}

Note : une liste des sites Internet utiles est proposée (évidemment non exhaustive et à actualiser régulièrement avec les moteurs de recherche).

\section{Sites institutionnels}

- Site thématique sur le fonio : http://fonio.cirad.fr

- Projet européen Inco sur le fonio : http://inco-fonio.cirad.fr

- Site du Cirad (France) : http://www.cirad.fr

- Site de l'Institut de recherche agronomique de Guinée (Irag) : http://www.irag-guinee.org

- Site de l'Institut d'économie rurale du Mali (IER) : http://www.ier.gouv.ml

- Base de données statistiques de la FAO : http://faostat.fao.org

- Réseau FAO d'information sur les opérations après récolte : www.fao.org/inpho

- Espèces sous-utilisées : http://www.underutilized-species.org

- Biodiversité : http://www.fao.org/biodiversity/biodiversity-home/fr

- Fonio et diabète : www.santediabete.org/fr

\section{Sites du secteur privé}

- Produits agroalimentaires des régions chaudes - recettes culinaires : www.racines-sa.com

- Transformation et conditionnement des denrées alimentaires au Mali : www.ucodal.com

- Fonio et commerce équitable : http://www.ethiquable.com/fr/filieres-impacts/cereales/fonio/ producteurs/benkouto.php

- Fonio de la société Gaia : http://www.fonio-bio.org

- Transformatrices de céréales au Burkina Faso : http://rtcf.biz/index.php 


\section{Sigles et acronymes}

Assi : Association des partenaires Adrao (Association pour le développement de l'agriculture en Afrique de l'Ouest), Saed (Société nationale d'aménagement et d'exploitation des terres du delta du fleuve Sénégal), Sismar (Société industrielle sénégalaise de matériel agricole) et Isra (Institut sénégalais de recherche agricole).

Ceemat : Centre d'études et d'expérimentation du machinisme agricole tropical, Montpellier, France (ancien département du Cirad spécialisé en mécanisation des cultures tropicales).

CFC : Common Fund for Commodities (Fond commun pour les produits de base), organisme des Nations unies dont le siège est à Amsterdam aux Pays-Bas.

Cirad : Centre de coopération internationale de recherche agronomique pour le développement, Montpellier, France.

Cirdes : Centre international de recherche-développement sur l'élevage en zone subhumide, Bobo-Dioulasso, Burkina Faso.

CRA-W : Centre wallon de recherches agronomiques, Libramont, Belgique.

Enda : Environnement et développement du tiers monde, Dakar, Sénégal.

FAO : Food and Agriculture Organization of the United Nations, Rome, Italie.

Geres : Groupe énergies renouvelables et environnement, Marseille, France.
GMBF : Nom du décortiqueur à fonio. «GMBF» signifie «Guinée, Mali, Burkina, France».

Gret : Groupe de recherche et d'échanges technologiques, Paris, France.

IER : Institut d'économie rurale du Mali, Bamako, Mali.

Inrab : Institut national de recherche agricole du Bénin, Cotonou, Bénin.

Irag : Institut de recherche agronomique de Guinée, Conakry, Guinée.

IRD : Institut de recherche pour le développement (Ex-Orstom), Montpellier, France.

Irri : International Rice Research Institute, Los Baños, Philippines.

MNHN, Muséum national d'histoire naturelle, Paris, France

NRC : National Research Council, Washington D.C., États-Unis.

ONG : Organisation non gouvernementale.

Sismar : Société industrielle sahélienne de mécanique, de matériels agricoles et de représentations, Dakar, Sénégal.

Socafon : Société coopérative artisanale des forgerons de l'Office du Niger, Niono, Mali.

USAID : United States Agency for International Development, Washington D.C., États-Unis.

Votex : Société néerlandaise de fabrication de matériel agricole (batteuse, décortiqueur, etc.), Middelburg, Pays-Bas. 


\section{Index}

Acides aminés 83, 85, 86, 87, 153, 155

Activité en eau 73

Adventices 48, 49, 54, 57

Agronome 14, 15, 17, 19, 141

Aliment 13, 15, 17, 21, 22, 23, 36, 38, $69,87,142,144,146,151,152,155$

Alimentation 13, 16, 38, 42, 141, 142, $143,151,152,155$

Amidon 80, 81, 82, 85, 119, 120, 147, 153

Amylose 82, 85

Autoconsommation 39, 40, 131, 142

Balles 42, 77, 78, 88, 92, 101, 108, 109, $113,114,132$

Bambara 16, 32, 33, 145

Banco 72, 74, 90

Batteuse 72, 95, 97, 98, 99, 100

Binage 54

Biodiversité 19, 47, 154

Blanchiment 84, 85, 86, 87, 88, 89, 91, 111, 112, 132

Bouillie 15, 41, 62, 141, 143

Brachiaria deflexa 21, 28

Brisures 114, 119, 120

Brûlis 27, 30, 50

Caillé René 15, 41, 42, 44, 53, 67, 77, 141

Calcium 28

Céréales 17, 20, 31, 34, 131, 140, 141, $142,143,146,151,155,156$

céréale africaine 14, 155, 156

céréale de soudure 40,47 céréale secondaire, rustique 16 , 36,155

Champs 26, 27, 28, 35, 48, 49, 50, 52, $54,57,61,62,69$
Climat ou zone semi-aride 37, 38, 52, 63, 69

soudano-guinéen 24, 39 soudano-sahélien 32,38 subhumide 57

Commerce 30, 34, 137, 140

Commercialisation 13, 30, 40, 116, $131,134,135$

Compost 31

Conservation 73, 74, 123

Consommation 13, 74, 91, 116, 141, $142,143,146$

Cribles ou nettoyeurs 101, 102, 103, 104, 112

Cueillette 22, 30, 34

Cuisson 121, 146, 147, 148, 149, 150 cuisson vapeur 147

Cultivar 47

Culture

systèmes de culture $13,26,34$, 116 systèmes de production 13, 116, 154, 156

Culture attelée $38,47,51,55$

Cycle 19, 28, 31, 38, 39, 40, 47, 52, 59

Décortiqueur 103, 106, 107, 108, 109, 111, 112, 113, 119 décortiqueur GMBF 103, 108, 109, 111, 112, 119 décortiqueur Sanoussi 106, 107

Dessablage 92, 93, 104, 118, 156

Diabète 151

Diététique 146

Digitaria

digitaria cruciata 17

digitaria exilis 15, 16, 17, 22, 60

digitaria iburua 17,21

digitaria longiflora 16

digitaria sanguinalis 17 
Dogon 15, 32, 35, 145

Écotypes 19, 47, 145

Élevage 26, 30, 35, 37

Emballage 138

Engrais 31, 59

Environnement 13, 47, 123

Épillets 17, 19, 20, 59

Équipement 65, 102, 103, 104, 112

Équitable 139, 140

Érosion 154

Étuvage 116, 119, 120, 121, 122, 156

Exploitation 26, 30, 32, 39, 47, 49, 97, 124

Exportation 113, 115, 131, 134, 135, 136, 139, 154

Fauchage ou fauche $42,61,64,65$, 69, 96

Faucille 47, 61, 62, 64, 68

Fer 84,87

Ferrallitique 24, 25

Fertilité 26, 28, 31, 33, 48, 64

Fonio

fonio étuvé 116, 119, 121, 123

fonio paddy $20,52,73,74,77$, $87,88,89,103,109,113,120,131$, 140,151

fonio sauvage $22,42,44$

Fouta-Djalon 15, 16, 23, 24, 26, 28, 51, 63, 67, 131, 137, 141, 145

Foyo 142, 143, 146, 147, 152

Friches 48

Fumure 72

Gerbes 62, 63, 66, 67, 68, 69, 70, 71, 72, 92, 96, 99

Germe 78, 79, 80, 84, 85, 88

Germination 54, 55, 57, 58

Glucides 82, 84, 85

Gluten 83, 87, 152, 153, 154, 155
Gombo 26, 41, 77, 141, 146, 147, 148, 149, 150, 152

Graminées 17, 25, 44, 57, 65, 68, 80

Greniers 35, 38, 61, 74

Guinée

Haute Guinée 23, 29, 30, 31, 49, $53,67,77,131,132,137$

Moyenne Guinée 23, 48, 58, 69, 131, 132

Hersage 50, 54

Hivernage $24,25,53,55,61,62,63$, $66,67,125,127,130$

Humidité 54, 55, 61, 71, 73, 74, 99, $120,123,125$

Index glycémique 151

Insectes 58, 101

Intrant 58

Jachère 26, 27, 30, 33, 35, 49

Labour 37, 50, 52, 64

Légumineuses 30, 31, 33, 37, 38, 59, 65, 103

Lipides 80, 82, 85, 152

Maladie coeliaque 83,152

Mandingues 26

Marchés locaux 30, 34, 42, 90, 131, 132

Mécanisation 38, 54, 92, 96, 106, 116, $131,135,136,139$

Ménages 25, 37, 38, 39, 47, 90, 142

Minéraux 24, 84, 86, 87, 119

Moisissures 62, 67, 73

Monoculture 30, 31, 48

Nématodes 31

Néré 30, 34, 116

Niébé 26, 31, 32, 34, 37, 38, 40, 48, 50,103

Nourriture 15, 17, 41, 42, 77, 154, 155

Oseille de Guinée 26, 31, 49 
Paille 20, 30, 41, 42, 64, 71, 72

Paysans 30, 34, 35, 47, 49, 58, 64, 67, 69, 95

Péricarpe 20, 78, 79, 80, 84, 88

Pertes après récolte 96

Pesticides 59

Pluviométrie 23, 37, 38, 39

Portères Roland 15, 16, 17, 19, 21, 22, 28, 51, 53, 55, 59, 60, 141

Post-récolte 39, 40, 92, 95, 96, 101, 119, 135, 136

Potassium 28, 84

Projet fonio 72, 96, 101, 103, 111, 115, 116, 119, 126, 131, 143

Propreté 92, 137, 144

Protéines ou protides $33,79,80,82$, $83,85,119,152,153,154,155$

Qualité

qualité gustative 142, 144 qualité nutritionnelle 116, 119, 154, 155, 156 qualité organoleptique 119,156 qualité technologique 116, 119, 120, 155

Racèmes 17, 19, 20, 59

Recettes 93, 146, 147, 151, 152

Rendement de transformation 89, 91, 107, 111 rendement de blanchiment 88 , 111 rendement de décorticage 88,90 , 111,114
Rotation 27, 30, 31, 32, 34, 37, 48, 48,50

Sable 52, 53, 90, 92, 93, 101, 105, 134 , 138, 144, 145

Sachet 135, 137, 144, 145

Sarclage 27, 35, 57

Savanes 21, 29, 33, 37, 40

Sécheresse 13, 16, 18, 55, 155

Sécurité alimentaire 13

Semences 42, 49

Semis 27, 50, 52, 53, 54, 55, 57, 58, 59

Solaire 124, 128, 129, 130

Soudure 21, 23, 32, 37, 38, 69, 90, 131, 135

Soufre 84,86

Statistiques agricoles 28, 39

Stockage 66,74

Striga $30,49,57,58$

Tapades 26, 27, 28

Toposéquence 26,30

Tô 15, 41, 141, 146

Transformatrices 92, 93, 103, 105, 106, $107,111,124,125,132,134,137,139$

Trémie 101, 108

Valorisation 13, 72, 154, 155

Vannage 42, 69, 70, 72, 90, 92, 95, $101,103,104$

Verse 62, 64, 65

Vitamine 84, 119 
Photo de couverture : (c) Jean-François Cruz Épis de fonio

Édition : Corinne Thonnat

Maquette : Patricia Doucet

Mise en pages : Hélène Bonnet

Impression : Jouve

Dépôt légal : septembre 2011 
Le fonio est une céréale dite "mineure », par rapport aux céréales « majeures » que sont le riz, le blé et le maïs. Il est pourtant l'aliment de base de nombreuses familles rurales d'Afrique de l'Ouest. Aujourd'hui redécouvert par les consommateurs urbains des grandes métropoles africaines, il a aussi fait son apparition sur le marché européen, essentiellement dans le cadre du commerce équitable et de produits exotiques.

Bien adaptée aux conditions locales, cette petite céréale peut jouer un rôle important dans la sécurité alimentaire des pays du Sud, comme dans la préservation des sols en assurant une couverture végétale sur des terres écologiquement fragiles.

Premier ouvrage consacré au fonio, ce livre aborde tous les aspects de cette céréale, de la culture à la transformation, et fournit même quelques recettes culinaires. Destiné en priorité aux producteurs, techniciens et agents de développement, il intéressera également tous ceux qui souhaitent se documenter sur cette céréale - enseignants, étudiants, agronomes, technologues - mais aussi les consommateurs curieux d'en découvrir les qualités.

Jean-François Cruz est ingénieur de recherche au Centre de coopération en recherche agronomique pour le développement (Cirad), à Montpellier. Spécialiste des technologies post-récolte des céréales, il a coordonné plusieurs projets internationaux sur le fonio. II a déjà publié plusieurs ouvrages sur la conservation des grains en régions chaudes.

Famoï Béavogui, directeur général de l'Institut de recherche agronomique de Guinée (Irag), à Conakry, est ingénieur agronome, docteur en études rurales, spécialiste des systèmes de production agricoles et des dynamiques agraires.

Djibril Dramé est technologue alimentaire. Après avoir été chercheur au laboratoire de technologie alimentaire de l'Institut d'économie rurale (IER) à Bamako, il est aujourd'hui expert à la Division des infrastructures rurales et des agro-industries de la FAO, à Rome.

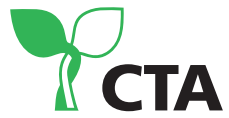

partageons les connaissances au profit des communautés rurales sharing knowledge, improving rural livelihoods

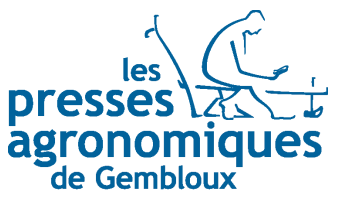

